\title{
Results of Copper Catalyzed Peroxide Oxidation (CCPO) of Tank 48H Simulants
}

\author{
T. B. Peters \\ J. M. Pareizs \\ J. D. Newell \\ F. F. Fondeur \\ C. A. Nash \\ T. L. White \\ S. D. Fink
}

August 2012

Savannah River National Laboratory

Savannah River Nuclear Solutions, LLC Aiken, SC 29808

Prepared for the U.S. Department of Energy under contract number DE-AC09-08SR22470. 
SRNL-STI-2012-00342

Revision 0

\section{DISCLAIMER}

This work was prepared under an agreement with and funded by the U.S. Government. Neither the U.S. Government or its employees, nor any of its contractors, subcontractors or their employees, makes any express or implied:

1. warranty or assumes any legal liability for the accuracy, completeness, or for the use or results of such use of any information, product, or process disclosed; or

2. representation that such use or results of such use would not infringe privately owned rights; or

3. endorsement or recommendation of any specifically identified commercial product, process, or service.

Any views and opinions of authors expressed in this work do not necessarily state or reflect those of the United States Government, or its contractors, or subcontractors.

\section{Printed in the United States of America \\ Prepared for \\ U.S. Department of Energy}




\title{
Results of Copper Catalyzed Peroxide Oxidation (CCPO) of Tank 48H Simulants
}

\author{
T. B. Peters \\ J. M. Pareizs \\ J. D. Newell \\ F. F. Fondeur \\ C. A. Nash \\ T. L. White \\ S. D. Fink
}

August 2012

Savannah River National Laboratory Savannah River Nuclear Solutions, LLC Aiken, SC 29808

Prepared for the U.S. Department of Energy under contract number DE-AC09-08SR22470. 


\section{REVIEWS AND APPROVALS}

\section{AUTHORS:}

T. B. Peters, Author, SRNL/SASP

Date

J. M. Pareizs, Co-author, SRNL/PTP

Date

J. D. Newell, Co-author, SRNL/PTP

Date

F. F. Fondeur, Co-author, SRNL/SASP

Date

C. A. Nash, Co-author, SRNL/ACP

Date

T. L. White, Co-author, SRNL/AD

Date

TECHNICAL REVIEW:

C. J. Martino, Technical Reviewer, SRNL/ACP

Date

APPROVAL:

S. D. Fink, SRNL/SASP, Manager

Date

S. L. Marra, SRNL/E\&CPT Research Programs, Manager

Date

K. H. Subramanian, Manager, SRR Chief Technology Officer

Date 


\section{EXECUTIVE SUMMARY}

Savannah River National Laboratory (SRNL) performed a series of laboratory-scale experiments that examined copper-catalyzed hydrogen peroxide $\left(\mathrm{H}_{2} \mathrm{O}_{2}\right)$ aided destruction of organic components, most notably tetraphenylborate (TPB), in Tank 48H simulant slurries. The experiments were designed with an expectation of conducting the process within existing vessels of Building 241-96H with minimal modifications to the existing equipment.

Results of the experiments indicate that TPB destruction levels exceeding $99.9 \%$ are achievable, dependent on the reaction conditions. The following observations were made with respect to the major processing variables investigated.

- A lower reaction $\mathrm{pH}$ provides faster reaction rates $(\mathrm{pH} 7>\mathrm{pH} 9>\mathrm{pH} 11)$; however, $\mathrm{pH} 9$ reactions provide the least quantity of organic residual compounds within the limits of species analyzed.

- Higher temperatures lead to faster reaction rates and smaller quantities of organic residual compounds.

- Higher concentrations of the copper catalyst provide faster reaction rates, but the highest copper concentration $(500 \mathrm{mg} / \mathrm{L})$ also resulted in the second highest quantity of organic residual compounds.

- Faster rates of $\mathrm{H}_{2} \mathrm{O}_{2}$ addition lead to faster reaction rates and lower quantities of organic residual compounds.

Testing with simulated slurries continues. Current testing is examining lower copper concentrations, refined peroxide addition rates, and alternate acidification methods. A revision of this report will provide updated findings with emphasis on defining recommended conditions for similar tests with actual waste samples. 


\section{Contents}

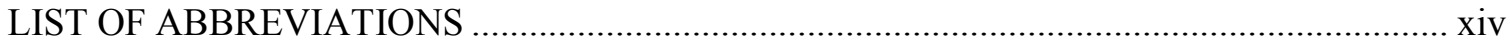

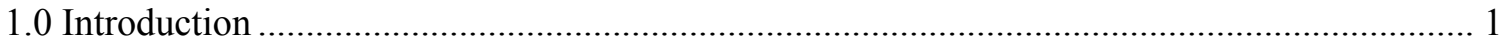

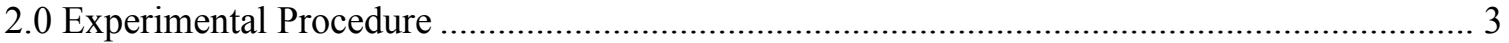

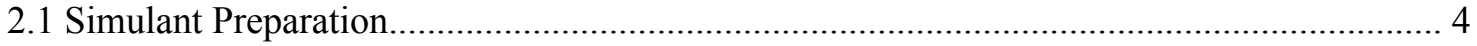

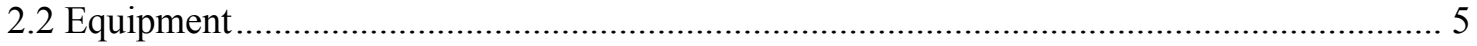

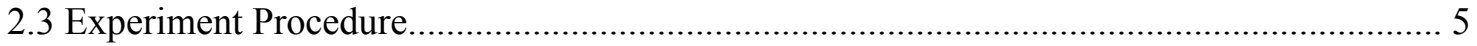

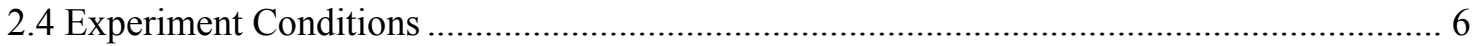

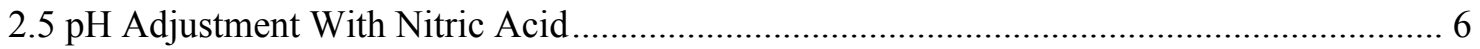

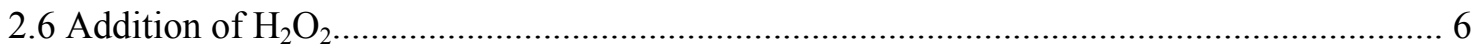

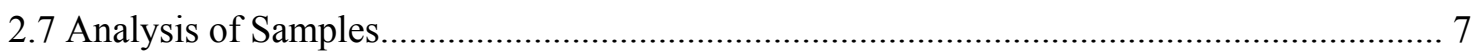

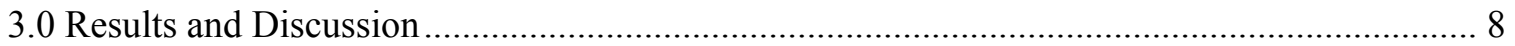

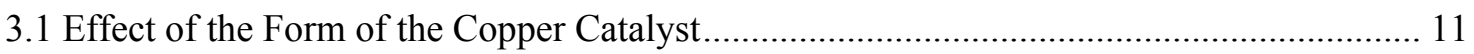

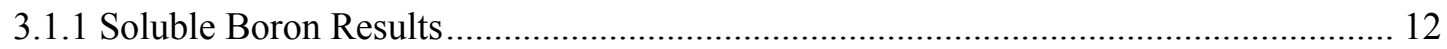

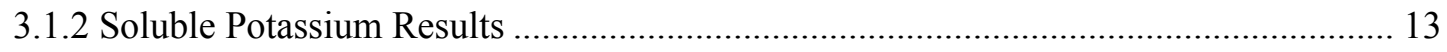

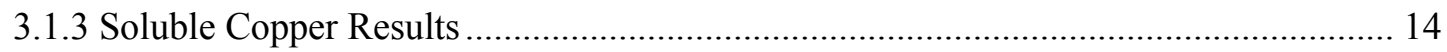

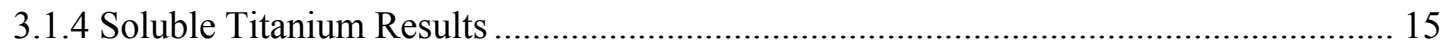

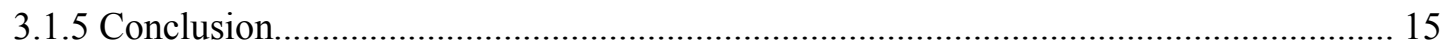

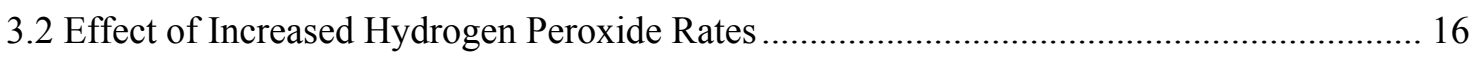

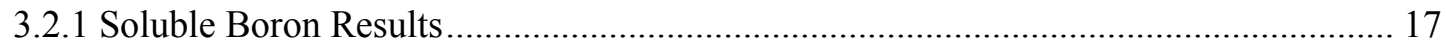

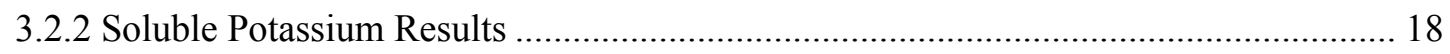

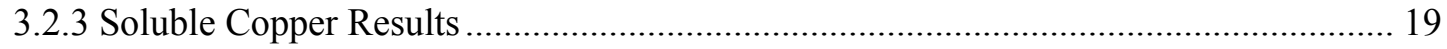

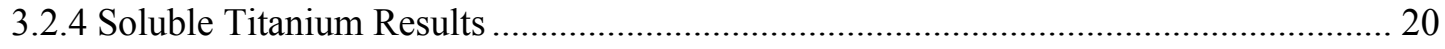

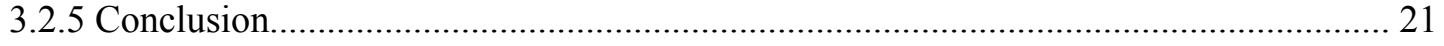

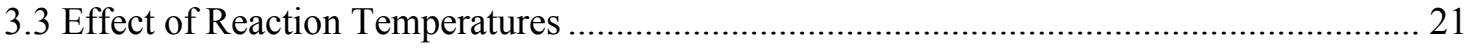

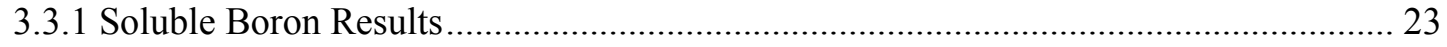

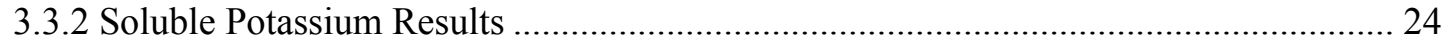

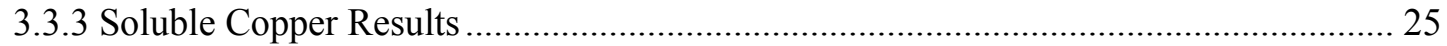

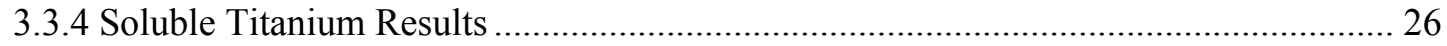

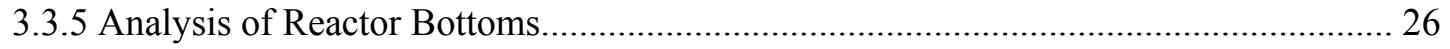

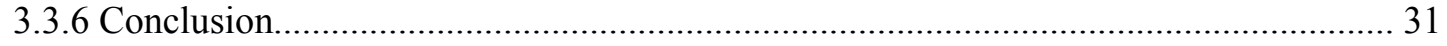

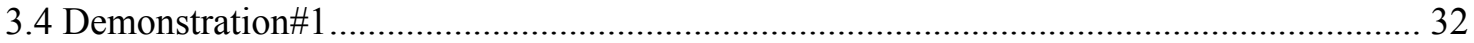




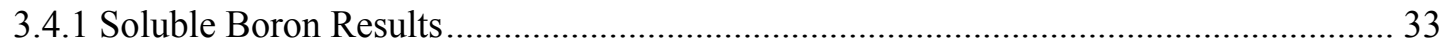

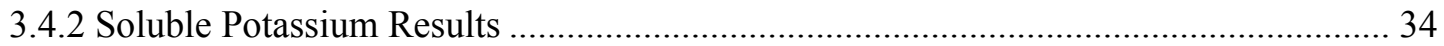

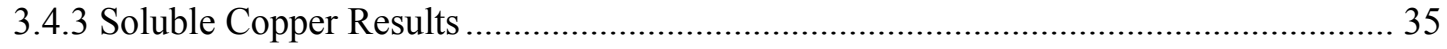

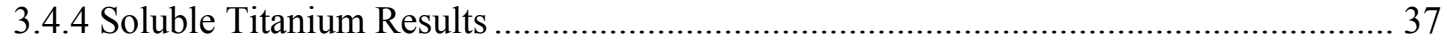

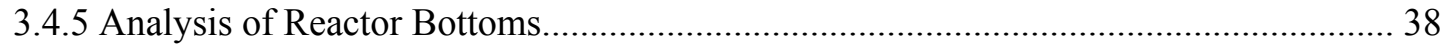

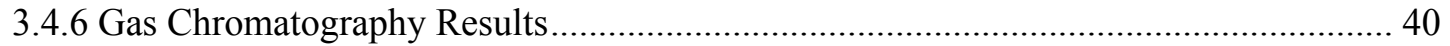

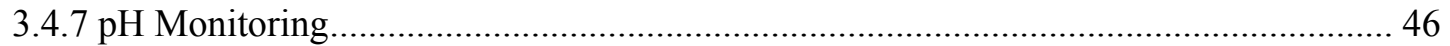

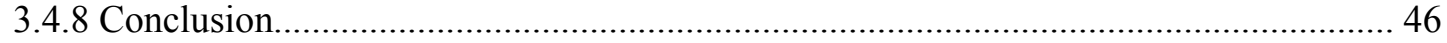

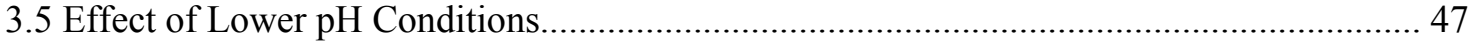

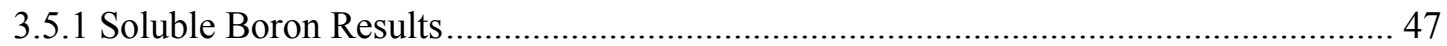

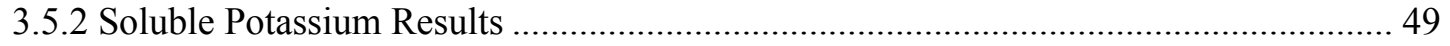

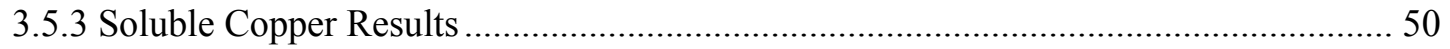

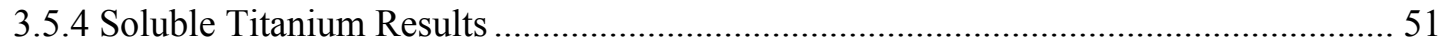

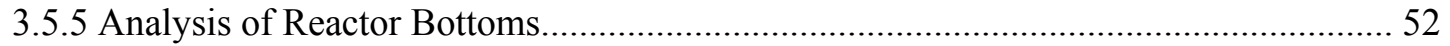

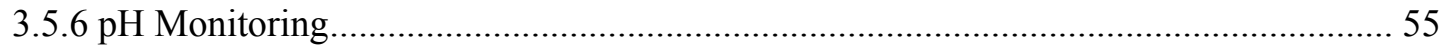

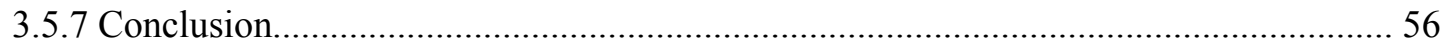

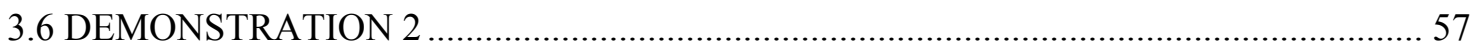

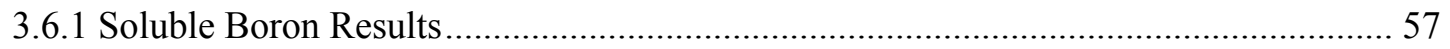

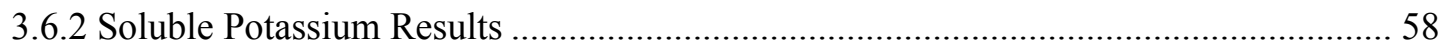

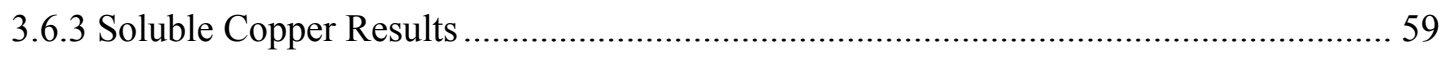

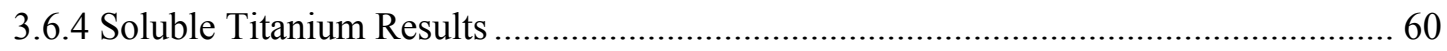

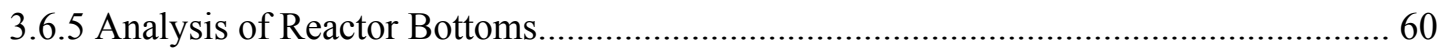

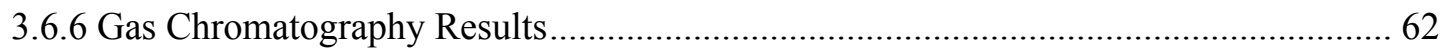

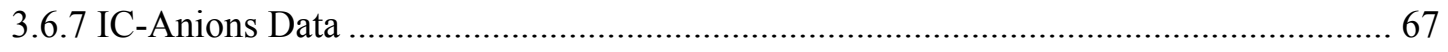

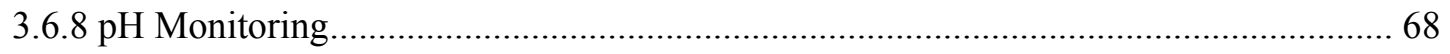

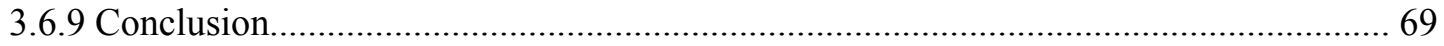

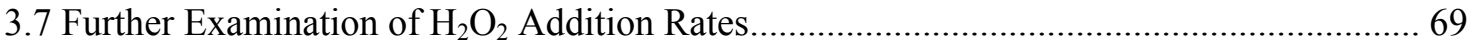

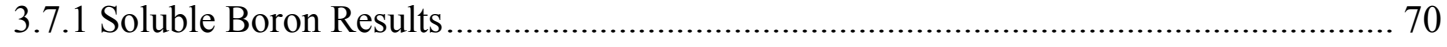

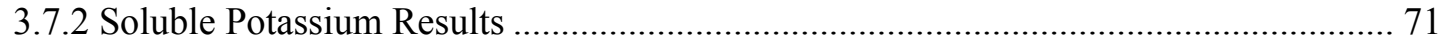

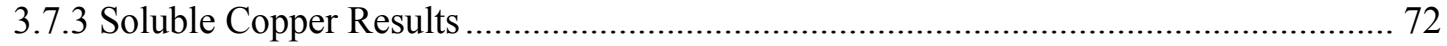

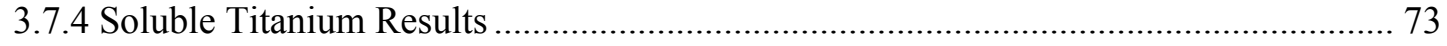

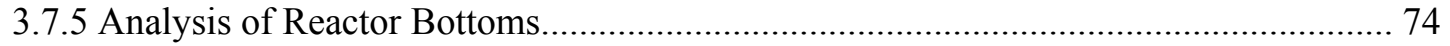

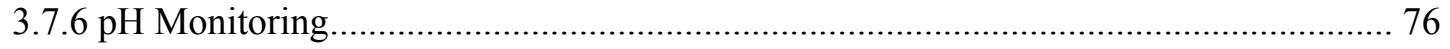

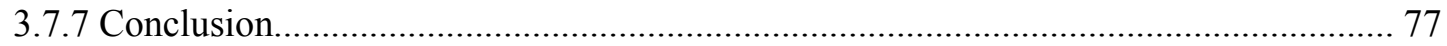


SRNL-STI-2012-00342

Revision 0

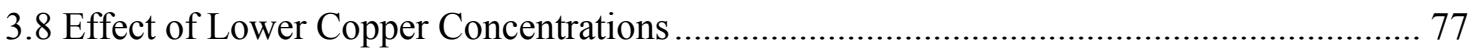

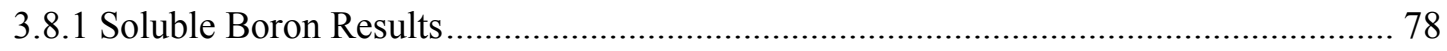

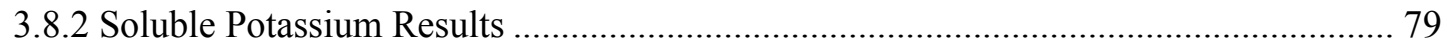

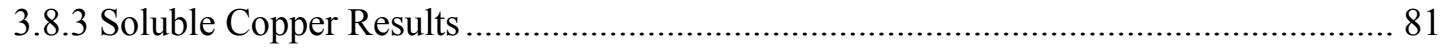

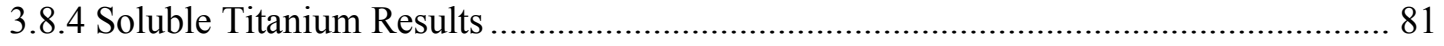

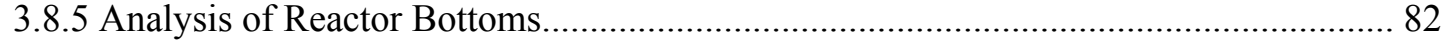

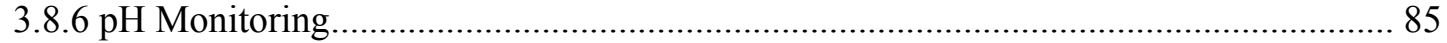

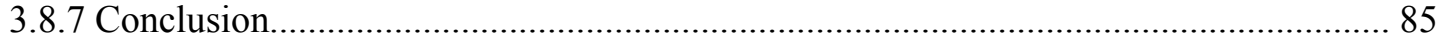

3.9 Comparison of Demonstration 1 and the 2004 Final Test ............................................... 86

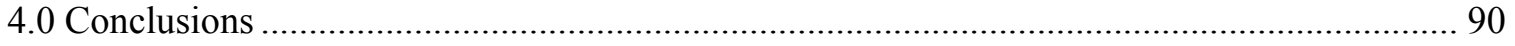

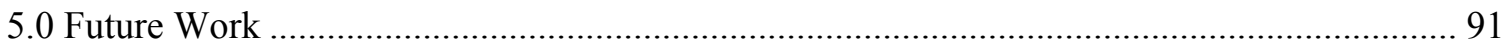

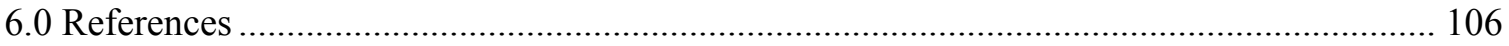




\section{List of Tables}

Table 1. Simulant Slurry Recipe (nominal $500 \mathrm{~mL}$ slurry) ...................................................... 4

Table 2. Total TPB Destruction from Final Boron Results for Varying Copper Compounds ..... 12

Table 3. Total TPB Destruction from Final Potassium Results for Varying Copper Compounds 13

Table 4. Total TPB Destruction from Final Boron Results at Varying Peroxide Addition Rates 17

Table 5. Total TPB Destruction from Final Potassium Results at Varying Peroxide Addition Rates.

Table 6. Total TPB Destruction from Final Boron Results at Varying Temperatures ................. 23

Table 7. Total TPB Destruction from Potassium Results at Varying Temperatures.................... 25

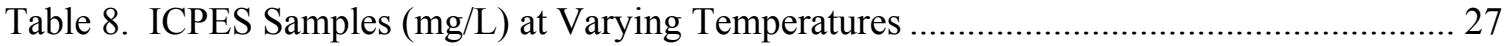

Table 9. HPLC Results from Reactor Bottoms Analyses (mg/L) at Varying Temperatures........ 28

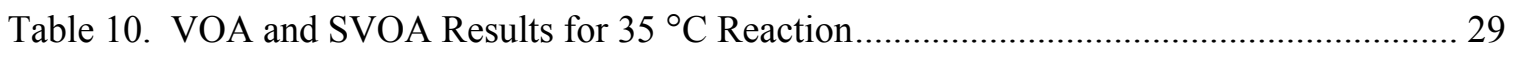

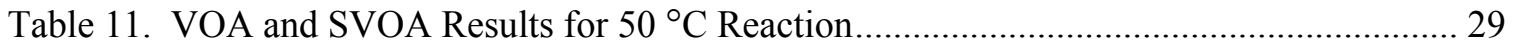

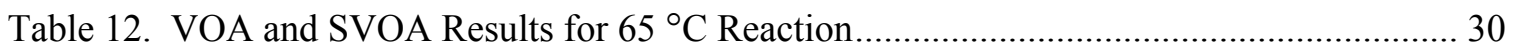

Table 13. Total TPB Destruction from Final Boron Results for Demonstration 1...................... 34

Table 14. Total TPB Destruction from Potassium Results for Demonstration 1 ......................... 34

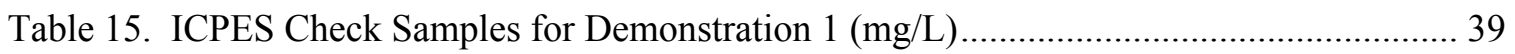

Table 16. HPLC Results from Reactor Bottoms Analysis (mg/L) for Demonstration 1 ............. 39

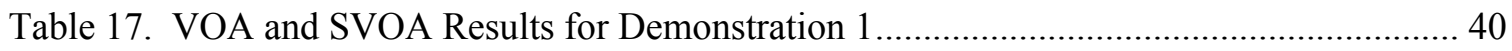

Table 18. Total TPB Destruction from Final Boron Results for Initial $\mathrm{pH}$ of 7 and $9 \ldots \ldots \ldots \ldots \ldots . . . . .48$

Table 19. Total TPB Destruction from Potassium Results for Initial $\mathrm{pH}$ of 7 and $9 \ldots \ldots \ldots \ldots \ldots . . . . . . . .49$

Table 20. ICPES Check Samples (mg/L) for Varying Initial pH Reactions ............................... 53

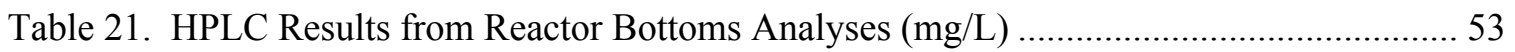

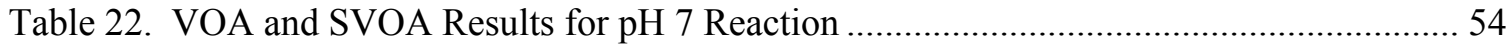

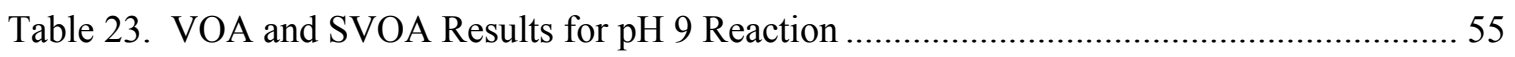

Table 24. Total TPB Destruction from Final Boron Results: Demonstration 2 ......................... 58

Table 25. Total TPB Destruction from Potassium Results: Demonstration 2 ............................ 59

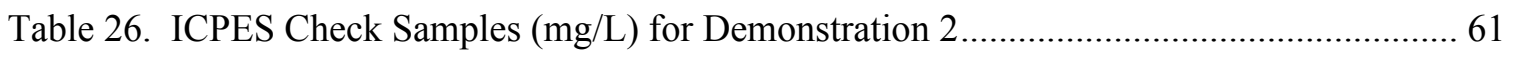

Table 27. HPLC Results from Reactor Bottoms Analyses (mg/L) for Demonstration 2 ............ 61 


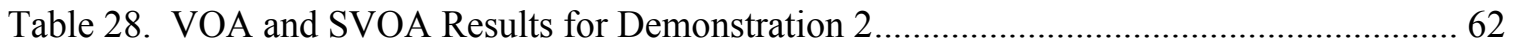

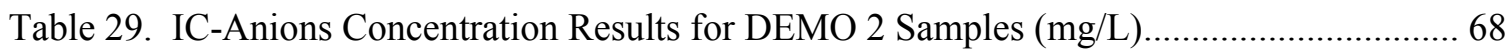

Table 30. Total TPB Destruction from Final Boron Results: 5× Peroxide Addition Rate........... 70

Table 31. Total TPB Destruction from Potassium Results at $5 \times$ Peroxide Addition Rate........... 72

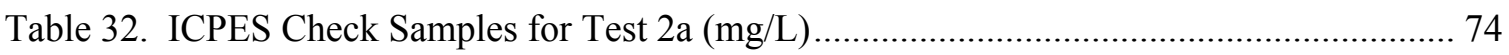

Table 33. HPLC Results from Reactor Bottoms Analyses for Test 2a (mg/L) ........................... 75

Table 34. HPLC Results from Time = 207, 304 Hour Slurry Samples for Test 2a (mg/L) ........ 75

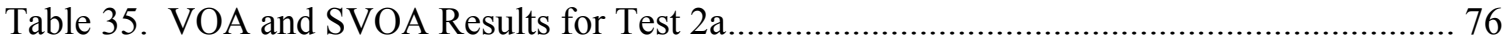

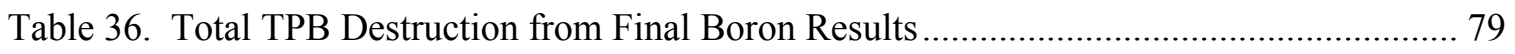

Table 37. Total TPB Destruction from Potassium Results............................................................. 80

Table 38. ICPES Check Samples (mg/L) for Varying Amounts of Added Copper ..................... 83

Table 39. HPLC Results from Reactor Bottoms Analyses (mg/L) for Lesser Amounts of Added

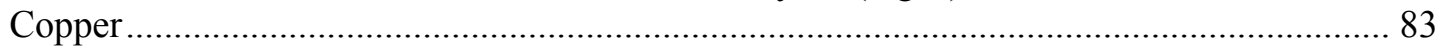

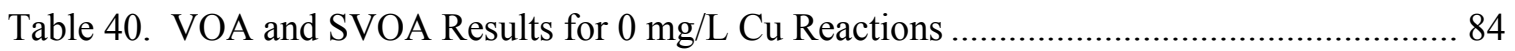

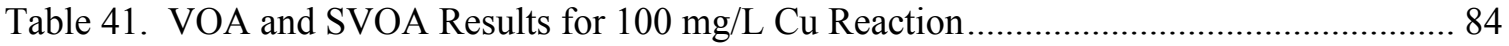

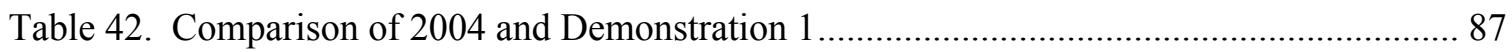

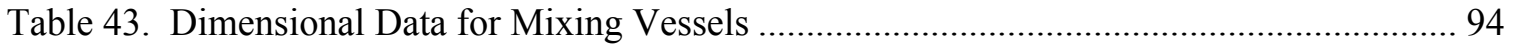

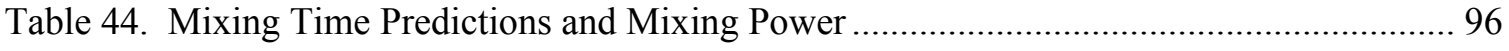

Table 45. Summary of Reversed-phase HPLC Methods for TPB and Degradation Products ... 100

Table 46. Summary of Reversed-phase Gradient HPLC Method for Degradation Products ..... 101

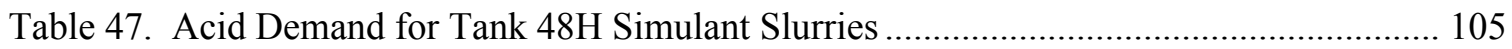




\section{List of Figures}

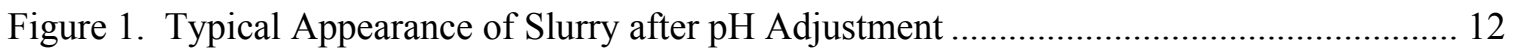

Figure 2. Boron Results Comparison for Varying Copper Compounds....................................... 13

Figure 3. Potassium Results Comparison for Varying Copper Compounds ................................ 14

Figure 4. Copper Concentration Comparison for Reactions with Varying Copper Compounds . 15

Figure 5. Titanium Concentration Comparison for Reactions with Varying Copper Compounds16

Figure 6. Boron Concentration Comparison at Varying Peroxide Addition Rates ...................... 17

Figure 7. Potassium Concentration Comparison at Varying Peroxide Addition Rates ................. 18

Figure 8. Copper Concentration Comparison at Varying Peroxide Addition Rates..................... 19

Figure 9. Titanium Concentration Comparison at Varying Peroxide Addition Rates.................. 20

Figure 10. Picture of One of the Designed Reactor Components.............................................. 22

Figure 11. Boron Concentration Comparison at Varying Temperatures..................................... 23

Figure 12. Potassium Concentration Comparison at Varying Temperatures .............................. 24

Figure 13. Copper Concentration Comparison at Varying Temperatures .................................... 25

Figure 14. Titanium Concentration Comparison at Varying Temperatures ................................ 26

Figure 15. Boron Concentration Results for Demonstration 1 .................................................. 33

Figure 16. Potassium Concentration Results for Demonstration 1............................................ 35

Figure 17. Copper Concentration Results for DEMO 1 ........................................................... 36

Figure 18. Boron and Copper Concentration Behavior Correlation for DEMO 1 ...................... 37

Figure 19. Titanium Concentration Results for Demonstration 1 ............................................. 38

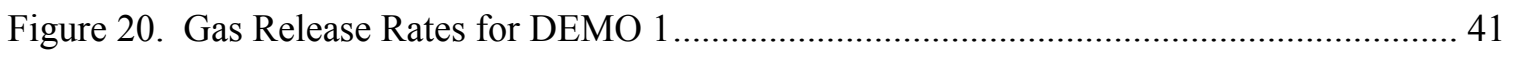

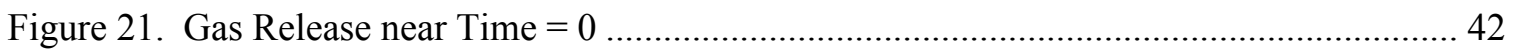

Figure 22. Cumulative Off-gas Release in Demonstration 1................................................. 44

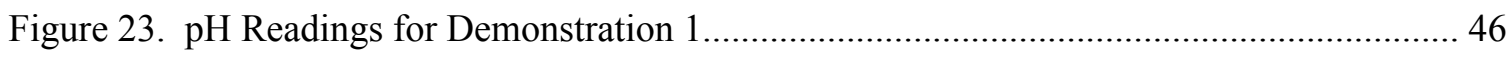

Figure 24. Boron Concentration Comparison Between pH 7 and 9 Reactions ............................ 48

Figure 25. Potassium Concentrations for the $\mathrm{pH} 7$ and 9 Reactions ......................................... 49

Figure 26. Copper Concentration Results for $\mathrm{pH} 7$ and 9 Reactions......................................... 51

Figure 27. Titanium Concentration Results for $\mathrm{pH} 7$ and 9 Experiments .................................. 52 


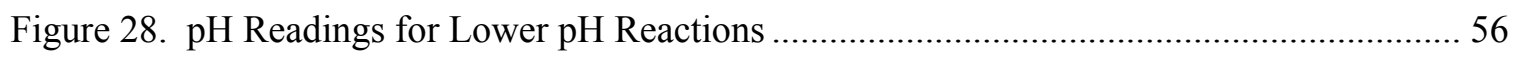

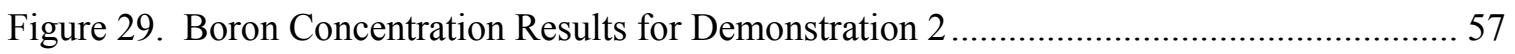

Figure 30. Potassium Concentration Results for Demonstration 2 ........................................... 58

Figure 31. Copper Concentration Results for Demonstration 2 ….......................................... 59

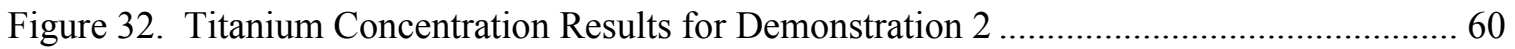

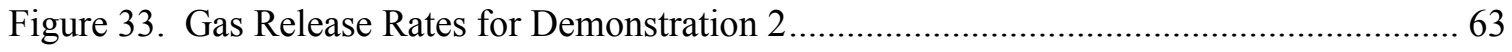

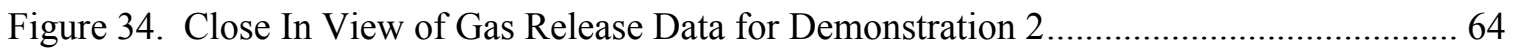

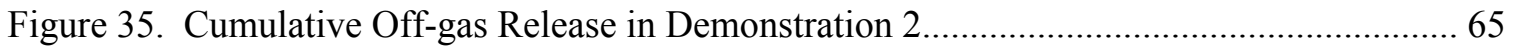

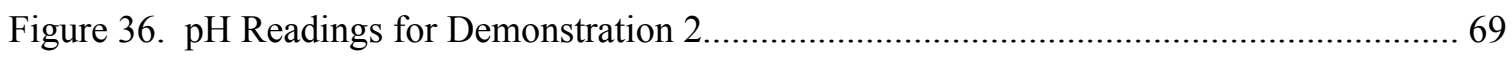

Figure 37. Boron Concentration Results Comparison at Varying Peroxide Addition Rates........ 71

Figure 38. Potassium Concentration Results Comparison at Varying Peroxide Addition Rates . 72

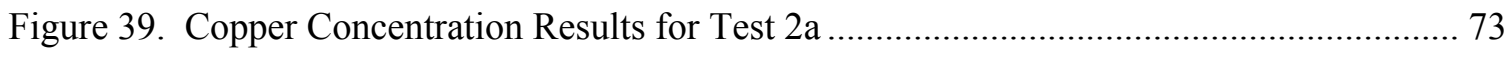

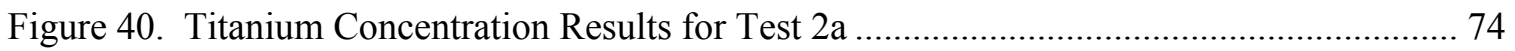

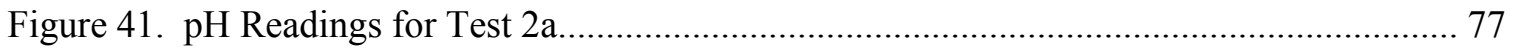

Figure 42. Boron Concentration Comparison From Low Copper Reactions ............................... 79

Figure 43. Potassium Concentration Comparison from Low Copper Reactions.......................... 80

Figure 44. Copper Concentration Results for Low Copper Reactions ...................................... 81

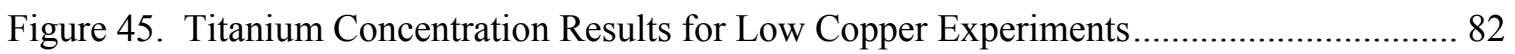

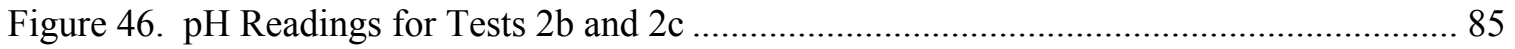

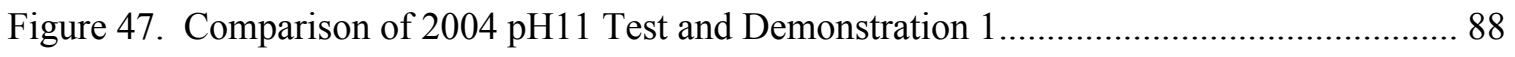

Figure 48. Comparison of the \%Destruction by Boron Results in the 2004 and Current Work .. 89

Figure 49. Comparison of the \%Destruction by Potassium Results in the 2004 and Current Work

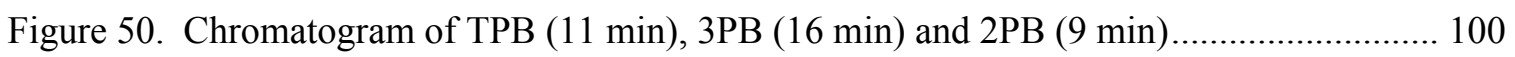

Figure 51. Chromatogram $100 \mathrm{mg} / \mathrm{L}$ Standard in Acentonitrile of PBA (10 min), Phenol (15 min), Nitrobenzene (28 $\mathrm{min})$, Nitrosobenzene (30 $\mathrm{min})$, 4-Phenylphenol (31 min), 2-Phenylphenol (33 min), Diphenylamine (37 min), Biphenyl (40 min), o-Terphenyl (43 min), $m$-Terphenyl

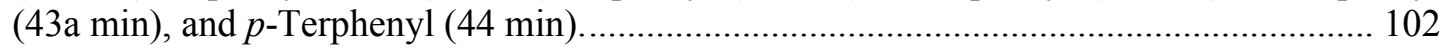

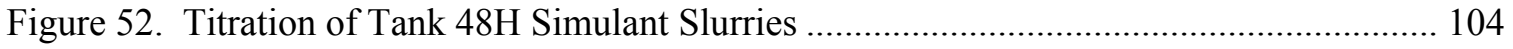




\section{List of Appendices}

Appendix A - Design of a Mixing Vessel for TPB/Peroxide Reactions

Appendix B - Analysis for Tetraphenylborate and Decomposition Products Sample

Preparation

Appendix C - List of Experiments and Conditions

Appendix D - Nitric Acid Titration of Tank 48H Simulant Slurries 


\section{LIST OF ABBREVIATIONS}

\begin{tabular}{ll} 
1PB & phenylborinic acid \\
2PB & diphenylboronic acid \\
3PB & triphenylborane \\
ARP & Actinide Removal Process \\
ASTM & American Society for Testing and Materials \\
B & boron \\
CCPO & Copper Catalyzed Peroxide Oxidation \\
CCV & Continuing Calibration Verification \\
DWPF & Defense Waste Processing Facility \\
FBSR & fluidized bed steam reformer \\
GC & gas chromatograph \\
GCMS & Gas Chromatographic Mass Spectroscopy \\
HPLC & high performance liquid chromatography \\
IC-Anions & Ion Chromatography Anions \\
ICPES & Inductively-Coupled Plasma Emission Spectroscopy \\
ICV & Initial Calibration Verification \\
ITP & In-Tank Precipitation \\
K & potassium \\
LIMS & Laboratory Information Management System \\
MCU & Modular Caustic-Side Solvent Extraction Unit \\
MST & monosodium titanate \\
PUREX & Plutonium Uranium Extraction \\
PVC & polyvinylchloride \\
SRNL & Savannah River National Laboratory \\
SRS & Savannah River Site \\
SS & stainless steel \\
SVOA & Semi-Volatile Organic Analysis \\
SWPF & Salt Waste Processing Facility \\
TIC/TOC & Total Inorganic Carbon/Total Organic Carbon \\
TPB & tetraphenylborate \\
TTQAP & Task Technical and Quality Assurance Plan \\
TTR & Task Technical Request \\
VOA & Volatile Organic Analysis \\
\% RSD & percent relative standard deviation \\
\hline
\end{tabular}




\subsection{Introduction}

Tank $48 \mathrm{H}$ currently holds legacy material containing organic tetraphenylborate (TPB) compounds from the operation of the In-Tank Precipitation (ITP) process. The TPB was added during the ITP process to remove soluble cesium $\left({ }^{137} \mathrm{Cs}\right)$, but excessive benzene generation curtailed this treatment method. The contents of Tank $48 \mathrm{H}$ are not compatible with the waste treatment facilities at SRS since the organic content and the associated flammability issues pose a challenge to the salt processing and sludge processing facilities within the liquid waste system. As such the contents of Tank $48 \mathrm{H}$ must be treated to destroy the organic compounds before the tank can be emptied. Tank $48 \mathrm{H}$ currently contains $\sim 240,000$ gallons of alkaline slurry with approximately $19,000 \mathrm{~kg}$ $(42,000 \mathrm{lb})$ of potassium and cesium tetraphenylborate (KTPB and CsTPB). In the last 10 years, the volume in the tank has remained fairly constant with evaporation balanced to some degree by caustic addition for corrosion control.

Recent efforts to use fluidized bed steam reformer (FBSR) technology to remediate the Tank $48 \mathrm{H}$ contents were put on hold. ${ }^{1}$ During this hold period, SRNL has been tasked with re-examining previous work performed from 2003 through 2005. This work consisted of a series of tests that examined the ability of a copper catalyst and hydrogen peroxide to destroy the TPB in Tank $48 \mathrm{H}$ simulant slurries. Former emphasis with respect to the Copper Catalyzed Peroxide Oxidation (CCPO) process was, however, placed on insitu treatment of the Tank $48 \mathrm{H}$ waste. However, Tank $48 \mathrm{H}$ is constructed from carbon steel which corrodes rapidly in low $\mathrm{pH}$. In alkaline solutions the formation of protective films greatly reduces the corrosion rate, and thus the successful application of the CCPO process at $\mathrm{pH} 11^{2}$ was considered compatible with processing in-situ in Tank $48 \mathrm{H}$. In contrast the current application of the CCPO process is intended to take place in two stainless steel (SS) tanks located in $241-96 \mathrm{H}$ with each tank having a liquid capacity of approximately 6200 gallons. These tanks were considered unavailable in previous treatment evaluations due to their use for the Actinide Removal Process (ARP), as monosodium titanate (MST) strike tanks. They will, however, become available once processing operations commence in Salt Waste Processing Facility (SWPF), and ARP operations are discontinued; the intent is to transfer batches of waste from Tank 48 to the 241-96H SS tanks for organic treatment via the CCPO process.

In a Technical Task Request (TTR) issued to SRNL, ${ }^{3}$ the work scope outlined a series of simulant and real waste tests. These tests were designed to examine individual reaction condition parameters. The overall goal was to examine and optimize the reaction so that the Tank $48 \mathrm{H}$ actual waste can be safely processed in Building 241-96H utilizing a minimum of time and reagents. In particular, the following process attributes were considered of significant importance: 
- Complete (or Near-Complete) Organic Destruction - the required level of organic destruction is dictated by the destination of the treated waste and the organic limits imposed on a particular transfer destination. A flow-sheet options report has been developed ${ }^{4}$ to assess various transfer options for the CCPO-processed waste and to determine whether the treated waste meets feed composition requirements with respect to allowable levels of chemical (including organic species) and radioactive constituents.

- Repeatable and Predictable Levels of Organic Destruction - it is necessary to develop a process with a sufficiently robust operating envelope that provides both repeatable and predictable levels of organic destruction.

- Enhanced Reaction Kinetics - improving the reaction kinetics (while maintaining safe operation) will enable completion of the Tank 48 clean up within the currently devised Liquid Waste System Plan. ${ }^{5}$

- Minimized Chemical Addition - the CCPO process postulates the addition of nitric acid, copper catalyst, hydrogen peroxide, and potentially both anti-foam and sodium hydroxide. It is desirable to limit the proportion of chemicals added to the waste to negate potential downstream impacts with respect to the composition. For example, there is a limit on the amount of copper that can be incorporated into vitrified glass, and thus the goal would be to minimize the proportion of catalyst required without significantly impacting the reaction kinetics or level of organic destruction.

- Minimized Processed Waste Volume - due to the addition of the aforementioned chemicals the volume of waste increases. The 2004 study indicated a volume increase of $183 \%{ }^{2}$ It is advantageous with respect to both processing life-cycle and cost to minimize the volume of waste that must subsequently be dispositioned as Saltstone grout or vitrified glass.

- Minimized Reaction Temperature - the 2004 study $^{2}$ ultimately utilized a temperature of $75^{\circ} \mathrm{C}$ to achieve a TPB destruction $>99.8 \%$. However, it is recognized that lower process temperatures yield benefits in terms of reducing system complexity, operation costs, and safety. Thus the goal is to promote the reaction at the lowest achievable temperature while maintaining the required reaction kinetics and level of organic destruction. The CCPO reaction vessels (MST strike tanks) do not have a dedicated heating capability and the current intent is to utilize the coiling coils for heating also. A thermal calculation will be required to determine the maximum achievable temperature in the reaction vessel by passing a heated medium through the currently installed cooling coils.

- Minimized Volatile Organic Compounds (VOCs) - VOCs, most notably benzene derived from degradation of the TPB, can volatilize to produce a flammable 
mixture in the vapor space of the reaction vessel. Minimizing the formation (and subsequent volatility) of the benzene will reduce risks associated with its flammability and the controls required to manage the vapor space.

- Minimized Hazardous Emissions - with respect to environmental emission compliance it is desirable to minimize the proportion of hazardous emissions, such as benzene and mercury. It may be possible to affect the off-gas composition by, for example, optimizing conditions for the peroxide oxidation reaction (at higher $\mathrm{pH}$ ) as opposed to the hydrolysis reaction (at lower $\mathrm{pH}$ ). It is believed that the latter results in higher benzene concentrations in the off-gas.

- Minimized MST Decomposition - a concern exists with the respect to degradation of the MST during CCPO-processing resulting in desorption and potential dissolution of the adsorbed actinides.

This work built off of previous work performed during the period of 2001-2005., 2,6,7 SRNL issued a Task Technical and Quality Assurance Plan (TTQAP) that encompasses the customer's scope. ${ }^{9}$

\subsection{Experimental Procedure}

The intent of this investigation was to essentially verify the organic destruction data from the 2004 experiment, and thereafter to optimize the CCPO process. Prior to verifying the 2004 data some preliminary studies were conducted to determine if (1) copper nitrate could be substituted for copper sulfate as the source for the copper catalyst, and (2) increasing the rate of peroxide addition resulted in enhanced reaction kinetics. Based on the data from these initial experiments the verification test (termed Demonstration \#1) was conducted using copper nitrate (in lieu of copper sulfate) but with a similar peroxide addition to the 2004 studies. Concurrently with, or subsequent to, Demonstration \#1 (henceforth termed DEMO 1) two principal processing variables were modified in an effort to improve the organic destruction efficiency and reaction kinetics; namely $\mathrm{pH}$ and temperature. Optimized processing $\mathrm{pH}$ and temperature were subsequently utilized in a second demonstration (DEMO 2). Following DEMO 2 additional testing sought to further optimize the CCPO process with respect to both copper loading and hydrogen peroxide addition rate. Details with respect to the experimental procedure, and the derived data, for all of the aforementioned experiments are provided in this section, and Section 3, respectively.

See Appendix C for an overview of the conditions from each test. 


\subsection{Simulant Preparation}

The Tank $48 \mathrm{H}$ simulant was prepared from reagent grade chemicals, doped with nonradioactive Cs, and catalysts known to be present in Tank $48 \mathrm{H}$. The actual material and recipe are outlined in a published document. ${ }^{10}$ Previously prepared simulant components from FBSR testing were used as a cost savings. From this recipe, SRNL prepared a number of slurries, ranging in size from 100 to $500 \mathrm{~mL}$. Table 1 provides the generic recipe.

"Metals A" is a solution of various metal salts of $\mathrm{Pd}, \mathrm{Cu}, \mathrm{Zn}, \mathrm{Pb}, \mathrm{Sn}, \mathrm{Ca}, \mathrm{Sr}, \mathrm{La}, \mathrm{Cd}, \mathrm{Ce}$, $\mathrm{Rh}$, and $\mathrm{Ru}$. "Metals B" is a solution of $\mathrm{Cr}$ and Mo salts. "PUREX sludge" is a caustic sludge that is a simulant for Plutonium Uranium Extraction (PUREX) real waste sludge. "Salt solution" is a typical caustic salt simulant containing enough potassium to precipitate the TPB as KTPB. The salt simulant also contains $335 \mathrm{mg} / \mathrm{L}$ of B-52 IIT antifoam. The benzene ( $44 \mu \mathrm{L}$ for a $500 \mathrm{~mL}$ slurry volume) is added to the simulant just before the commencement of testing to avoid benzene evaporative losses. The amount of added benzene was trivial and was ignored later analyses.

Upon mixing, the Tank $48 \mathrm{H}$ simulant slurry is slightly off white, and a large fraction of the KTPB floats to the surface. The slurry is capable of being well mixed, but this requires constant agitation. This is in contrast to the actual Tank $48 \mathrm{H}$ slurry, where the insoluble TPB salts have settled and no longer foam or entrain air easily. ${ }^{11}$

Simulant slurries were typically prepared a few days before use. To avoid heterogeneity issues with sampling and material balances, the slurries were prepared in individual bottles - one bottle of slurry per test. The benzene for the slurry was not added until after it was $\mathrm{pH}$ adjusted to avoid excessive evaporation.

Table 1. Simulant Slurry Recipe (nominal $500 \mathrm{~mL}$ slurry)

\begin{tabular}{|c|c|}
\hline Chemical & Amount required (g) \\
\hline NaTPB Solution & 85.2 \\
\hline Salt Solution & 513.6 \\
\hline Metals A & 4.35 \\
\hline Metals B & 0.55 \\
\hline PUREX Sludge & 2.15 \\
\hline MST Sludge & 5.75 \\
\hline sodium metasilicate & 0.465 \\
\hline phenol & 0.495 \\
\hline biphenyl & 0.32 \\
\hline diphenylmercury & 0.009 \\
\hline benzene & $44 \mu \mathrm{L}$ \\
\hline B-52 IIT antifoam & $335 \mathrm{mg} / \mathrm{L}$ \\
\hline
\end{tabular}




\subsection{Equipment}

For each test, care was taken to use materials that would not interfere with the CCPO process. Reaction vessels were fabricated of glass, stainless steel, or polypropylene. The nitric acid and hydrogen peroxide were metered into each reaction vessel using a gastight syringe, polyvinylchloride (PVC) flexible tubing, and stainless steel disposable needle. Agitation was provided either by a magnetic stirrer and Teflon coated sir-bar, or by a stainless steel agitator and stainless steel paddles. See Figure 10 for an example of one of the reaction vessels. The first three tests (two described in Section 3.1 and one described in Section 3.2) used $1 \mathrm{~L}$ polypropylene bottles and stir bars as the reaction vessels were not fabricated at the time.

\subsection{Experiment Procedure}

The general sequence of events for each experiment follows.

- The slurry for an experiment was dispensed into the reaction vessel.

- With constant agitation, the slurry was $\mathrm{pH}$ adjusted (at room temperature) to the desired $\mathrm{pH}$ using $10.4 \mathrm{M}$ nitric acid. The acid was added at a rate of $42 \mathrm{~mL} /$ hour using a syringe pump. For the first three tests (see Sections 3.1 and 3.2), the slurry was $\mathrm{pH}$ adjusted first and subsequently dispensed into the reaction vessel as the complete reaction vessels were not yet fabricated.

- At time $=0$ a sample of slurry was removed from the reaction vessel and archived for later analysis.

- The required amount of benzene per the simulant recipe (Table 1) was added at this time.

- The required amount of copper catalyst (typically, $500 \mathrm{mg}$ per $\mathrm{L}$ of slurry of $\mathrm{Cu}$, in the form of $\mathrm{Cu}\left(\mathrm{NO}_{3}\right)_{2} \bullet 2.5 \mathrm{H}_{2} \mathrm{O}$ ) was dissolved into $\sim 4 \mathrm{~mL}$ of deionized water and added drop-by-drop to the slurry with agitation.

- If the reaction required heating, the heater was turned on, and the heating bath was allowed to come to temperature (requiring typically 10 minutes or less).

- The $\mathrm{H}_{2} \mathrm{O}_{2}$ addition (using $50 \mathrm{wt} \% \mathrm{H}_{2} \mathrm{O}_{2}-17.5 \mathrm{M}$ ) was initiated (at time $=0$ ).

- Throughout the experiment, samples were removed from the vessel, filtered, and stored for later analysis. In a limited number of instances, a slurry sample (without filtration) was collected for analysis. 
At the end of the experiment, the $\mathrm{H}_{2} \mathrm{O}_{2}$ addition was stopped (temperature bath turned off, no further material additions, but allowed to stir) and the vessel was passively cooled to room temperature. The reactor bottoms were poured from the vessel into a tared 1L poly bottle. The weight of the recovered slurry was noted, and well-stirred sub-samples of the reactor bottoms were sent for analysis. The recovered slurry weight does not include a small and varying amount of material which was deposited on top of glass reactor head.

\subsection{Experiment Conditions}

Reaction conditions were varied between the tests to identify a set of optimal processing parameters. Experiments detailed in this report examined the effects of temperature, peroxide addition rates, form of copper catalyst, and starting $\mathrm{pH}$. Further experimental parameters or effects will be detailed in later documents or revisions. See Appendix C for an overview of test conditions.

\section{$2.5 \mathrm{pH}$ Adjustment With Nitric Acid}

For process economy, it is important to minimize the volumes of added chemicals to the experiment to match the limitations of the existing Building $241-96 \mathrm{H}$ equipment. This is not so much a limitation for the laboratory-scale experiments, but for the real waste

process. Since the reaction vessel capacity in $241-96 \mathrm{H}$ is 6200 gallons, large additions of chemicals will drastically reduce the quantity of real waste that can be processed in each batch and increase the waste volumes. For this reason, SRNL and the customer decided to use $50 \mathrm{wt} \%$ nitric acid. However, a disadvantage of using strong acids is related to the formation of tars and intractable solids upon contact with TPB solids, ${ }^{6}$ in addition to the potential for benzene formation via an acid hydrolysis reaction. ${ }^{12}$ Also, addition of concentrated nitric acid increases the risk of formation of nitrated compounds that may prove energetic.

\section{$2.6 \underline{\text { Addition of } \mathrm{H}_{2} \underline{\mathrm{O}}_{2}}$}

Hydrogen peroxide was added as a $50 \mathrm{wt} \%$ solution, and was added at a rate of $0.1 \mathrm{~mL} /$ hour for $250 \mathrm{~mL}$ of simulant slurry, and twice that rate for $500 \mathrm{~mL}$ of simulant slurry. This rate of addition is referred to as " $1 \times \mathrm{H}_{2} \mathrm{O}_{2}$ ". Reactions that have faster $\mathrm{H}_{2} \mathrm{O}_{2}$ delivery rates are integer multiples of the $1 \times \mathrm{H}_{2} \mathrm{O}_{2}$ rate. These rates approximately matched the rates used in the 2004 work, after scaling for volume differences.

Although the 2004 work used $30 \mathrm{wt} \% \mathrm{H}_{2} \mathrm{O}_{2}$, a decision was made to keep the addition rate the same despite the differences in $\mathrm{H}_{2} \mathrm{O}_{2}$ concentration. There were no anticipated negative processing effects in using a higher peroxide concentration, and $50 \mathrm{wt} \% \mathrm{H}_{2} \mathrm{O}_{2}$ should ultimately reduce the final waste volume. 


\subsection{Analysis of Samples}

Filtrate samples from the reactions were analyzed by any or all of Inductively Coupled Plasma Emission Spectroscopy (ICPES), IC-Anions, and wet chemistry techniques, all of which have a $10 \%$ analytical uncertainty. Samples of the slurry were removed from the reaction and analyzed by any or all of volatile organic analysis (VOA), semi-volatile organic analysis (SVOA), Total Inorganic Carbon/Total Organic Carbon (TIC/TOC), and high performance liquid chromatography (HPLC). VOA and SVOA methods have a $20 \%$ analytical uncertainty. TIC/TOC and HPLC have a 10\% analytical uncertainty.

Measurement (analytical) uncertainty is defined as a parameter associated with the result of a measurement that characterizes the dispersion of the values that could reasonably be attributed to the measured quantity. SRNL Analytical Development methods employ several techniques for estimating and calculating measurement uncertainty. These range from propagation of all sources of uncertainty within a method to monitoring of control charts. ${ }^{13}$ All estimated uncertainties are applied to customer sample results, available in LIMS.

ASTM Committee E-19 conducted a cooperative program on the study of the quantitation of HPLC which revealed that the technique is generally accurate and precise with relative standard deviations ranging from $3 \%$ to $8 \%$ for nearly all of the participating laboratories. ${ }^{14}$ For HPLC and IC, Initial Calibration Verification and Continuing Calibration Verification (ICV/CCV) standards are analyzed before and after each batch of samples and the results are maintained between $\pm 10 \%$ of the value of the standard. Graphing the ICV/CCV values on control charts shows most values are within 5\%, at $1 \sigma$ confidence level, of the standard average in keeping with the literature. Analytical Development sets the uncertainty of measurement at $10 \%$, at the $1 \sigma$ confidence level for IC and HPLC to capture the variety of matrices, bias, and the range of analyte concentrations in summited samples.

For ICP-ES, the uncertainty at the $1 \sigma$ confidence level is calculated using the equation $\sqrt{a^{2}+b^{2}}$ where $a$ is the variance allowed in the measurement of the CCV standards ( \pm $10 \%$ of the value of the standard) and $b$ is the deviation associated with the triplicate integrations for each sample at the instrument.

The uncertainty for the GCMS methods, general SVOA scan and VOA scan techniques is estimated from CCV values that are maintained between $\pm 20 \%$ of the value of the standard. An uncertainty value of $20 \%$ at the $1 \sigma$ confidence level is reported based on multiple CCV replicates.

The uncertainty for the TIC-TOC method is estimated from CCV values that are maintained between $\pm 10 \%$ of the value of the standard. An uncertainty value of $10 \%$ at the at $1 \sigma$ confidence level is reported based on multiple $\mathrm{CCV}$ replicates. 
While tables of data give error values, graphs of the data do not include error bars for reasons of clarity.

\subsection{Results and Discussion}

During the course of each reaction, the main method utilized for determining the progression of the reaction was ICPES analysis of filtrate samples. Prior to reaction, all of the boron in the simulant is associated with the solid KTPB. The total amount of boron in the simulant slurry is calculated to be on average approximately $548 \mathrm{mg} / \mathrm{L}$ though this value may vary slightly between slurries. As the KTPB, and its phenylborate decomposition compounds triphenyl borane (3PB), diphenylborinic acid (2PB) and phenyl boronic acid (1PB), are broken down during CCPO processing soluble boron species are derived. Soluble boron is derived from nitric acid attack (hydrolysis) of the TPB and phenylborate decomposition compounds during $\mathrm{pH}$ adjustment, and the later peroxide aided destruction of the same. As such changes in the boron concentration for filtrate samples retrieved at various reaction times are indicative of the time-dependent decomposition of TPB. It is, however, important to note that since it is not known whether all of the derived boron species formed during processing are soluble, the boron concentration in the filtrate may not provide an absolute measurement with respect to the degree of TPB destruction. A definitive value for the extent of TPB destruction rather is provided by the determining the post-reaction concentration of residual TPB via HPLC.

A sample is removed after $\mathrm{pH}$ adjustment (time $=0$ ), but prior to addition of the copper catalyst or $\mathrm{H}_{2} \mathrm{O}_{2}$; this sample serves as an indicator with respect to the proportion of TPB destruction associated with the $\mathrm{pH}$ adjustment alone. Due to the fact that multiple samples were removed from the reaction vessels for intermediate analyses, and added volume from the addition of the $\mathrm{H}_{2} \mathrm{O}_{2}$, each set of sample results is normalized to the time $=0$ sample results by using the sodium concentration as the normalization factor (i.e., comparing the sodium concentrations of the retrieved sample to that of the sample at time $=0)$.

At the end of each test, the extent of boron dissolution associated with the TPB destruction was calculated. The proportion of TPB destruction associated with acid addition is defined as:

$$
\left[B_{t=0}\right] /\left[B_{\text {total }}\right]
$$

The proportion of TPB destruction provided by the $\mathrm{H}_{2} \mathrm{O}_{2}$ /copper oxidation reaction is defined as: 


$$
\frac{\left[B_{\text {final }}\right]-\left[B_{t=0}\right]}{\left[B_{\text {total }}\right]}
$$

where variable $\left[\boldsymbol{B}_{t=0}\right]$ is defined as the analyzed boron concentration in the time $=0$ filtrate sample (after acid addition), variable $\left[\boldsymbol{B}_{\text {total }}\right]$ is defined as the concentration of boron if all the boron was in solution, and variable $\left[\boldsymbol{B}_{\text {final }}\right]$ is defined as the boron in the final filtrate sample.

The total TPB destruction is the sum of both contributions. This sum, as defined from the boron data can sometimes plateau at less than $100 \%$ destruction. It is possible that the boron-containing organic breakdown products are less than completely soluble; therefore the percent destruction values are possibly lower bounds. In this case, when the soluble boron indicates a leveling off, this can be assumed to imply total TPB destruction.

The presence of soluble potassium $(\mathrm{K})$ in the filtrate is also used as an indicator of the extent of destruction of the KTPB. The starting amount of potassium in the slurry simulant filtrate (i.e., not associated with solid KTPB) is calculated to be $\sim 278 \mathrm{mg} / \mathrm{L}$ though this value may vary slightly between slurries. The total amount of potassium in the simulant slurry is calculated to be $\sim 2260 \mathrm{mg} / \mathrm{L}$ which will also vary between slurries. Soluble potassium is derived from nitric acid attack on the KTPB during $\mathrm{pH}$ adjustment, and the later peroxide aided destruction of the same. As the time $=0$ sample is removed after $\mathrm{pH}$ adjustment, but before addition of the copper catalyst or $\mathrm{H}_{2} \mathrm{O}_{2}$, this sample serves as an indicator of the amount of destruction provided by the $\mathrm{pH}$ adjustment.

At the end of each test, the extent of potassium dissolution associated with the TPB destruction was calculated. In each case, the proportion of KTPB destruction from $\mathrm{pH}$ adjustment is defined as:

$$
\frac{\left[K_{t=0}\right]-\left[K_{\text {filtrate }}\right]}{\left[K_{\text {total }}\right]-\left[K_{\text {filtrate }}\right]}
$$

The proportion of KTPB destruction provided by the $\mathrm{H}_{2} \mathrm{O}_{2} /$ copper is defined as:

$$
\frac{\left[K_{\text {final }}\right]-\left[K_{t=0}\right]}{\left[K_{\text {total }}\right]-\left[K_{\text {filtrate }}\right]}
$$

where variable $\left[\boldsymbol{K}_{t=0}\right]$ is defined as the analyzed potassium concentration in the time $=0$ filtrate sample, variable $\left[\boldsymbol{K}_{\text {filtrate }}\right]$ is defined as the concentration of potassium in the filtrate before acidification, variable $\left[\boldsymbol{K}_{\text {total }}\right]$ is defined as the concentration of potassium 
if all the potassium was in solution, and variable $\left[\boldsymbol{K}_{\text {final }}\right]$ is defined as the potassium in the final filtrate sample.

The total KTPB destruction is the sum of both contributions.

The aforementioned formulas (1-4, above) are used to derive the $\%$ destruction. However, per a customer request, SRNL is incorporating the analytical uncertainty into these values. As a result, the \% TPB destruction results are given as ranges, based upon the 1-sigma analytical uncertainty. To calculate the range, the uncertainty in each calculation is applied to certain variables to derive a low and high value. For this purpose, the following variables have a $10 \%$ analytical uncertainty:

\section{$\boldsymbol{B}_{t=0}, \boldsymbol{B}_{\text {final }}, \boldsymbol{K}_{t=0}, \boldsymbol{K}_{\text {final }}$}

The other variables are derived from gravimetric data and are assumed to have an uncertainty small enough to ignore for this purposes of calculating the ranges.

Furthermore, as $\boldsymbol{B}_{\text {final }}$ and $\boldsymbol{K}_{\text {final }}$ are subject to normalization from sodium data this would normally trigger a new uncertainty propagation calculation, and consequently a third error propagation from the combination of the two original uncertainties. Rigorous error analysis to this degree is far outside the scope of this document, and SRNL is of the opinion that the level of error propagation presented here is reasonable.

In addition, the ICPES results also provide the soluble copper $(\mathrm{Cu})$ and titanium (Ti) concentrations. The concentration of soluble copper in the slurry is of interest since it indicates the proportion of the added copper catalyst that actually dissolves and potentially aids the destruction of TPB. It is assumed that undissolved copper plays no role in the CCPO reaction process. The starting amount of copper in the slurry simulant filtrate is calculated to be effectively zero. While there is $\sim 2 \mathrm{mg} / \mathrm{L}$ of $\mathrm{CuSO}_{4} \bullet 5 \mathrm{H}_{2} \mathrm{O}$ in the "Metals A" component of the waste simulant, the quantity is small relative to the $500 \mathrm{mg} / \mathrm{L}$ copper added as the catalyst.

The concentration of titanium in the filtrate is utilized as a measurement of the extent of solubility of the titanium cation. The only source of titanium in the slurry simulant is from the MST component, and therefore any significant ingrowth of titanium in solution is of concern since it indicates the decomposition of MST and potential release of sorbed fissionable materials ( $\mathrm{U}$ and $\mathrm{Pu}$ ).

HPLC results are also used to derive a \% TPB destruction value. A series of gravimetric measurements (density, weight, etc), as well as a pair of duplicate HPLC measurements are used as inputs. As with the \% TPB destruction values derived from boron and potassium data, the customer has requested that SRNL report the \% TPB destruction by HPLC as a range of values that incorporate the analytical uncertainty (10\%). As with the aforementioned calculations, SRNL assumes that the variables derived from gravimetric 
data are assumed to have an uncertainty small enough to ignore for this purposes of calculating the ranges. As the HPLC results are duplicate results, SRNL consulted with a statistician. From this discussion, SRNL has determined that presenting the average of the duplicate data points with the \%RSD already encompasses the analytical uncertainty, and therefore, presenting the data as a range of results is technically incorrect. Therefore, these analytes are reported as single values with a \% RSD. For calculated values derived directly from these analytes, value ranges are calculated by treating these analytical results as if they were single point results, where the range is derived from applying the $\% \mathrm{RSD}$ to the reported result. If the HPLC measurements provided a detection limit result (either $<4$ or $<10 \mathrm{mg} / \mathrm{L}$ ) it is assumed there is no uncertainty associated with the HPLC result and therefore, there is no range of values, only a single value reported.

The SVOA analysis is used to measure the quantity of residual organics (not counting TPB, 3PB, 2PB, 1PB, or phenol) in the reactor bottoms at the end of the experiment. Due to a customer request, the results are reported as a range of results when appropriate. For results that are single point results, the range is derived from the analytical uncertainty (20\%) applied to the reported result. Duplicate results are resolved as with the HPLC method, above. The residual organics do not include a small and varying amount of material deposited in the top of the reactor dome. This material was likely mostly biphenyl and was isolated for future analysis if necessary.

\subsection{Effect of the Form of the Copper Catalyst}

While the precise downstream destination of the CCPO-processed waste is not known, it is quite likely that some portion of the waste will ultimately be transferred to the Defense Waste Processing Facility (DWPF). The DWPF melter is sensitive to the amount of sulfate and therefore, there is a desire to minimize further additions of this anion.

In the 2004 work, ${ }^{2}$ SRNL used copper sulfate $\left(\mathrm{CuSO}_{4} \bullet 5 \mathrm{H}_{2} \mathrm{O}\right)$ as the source of the copper catalyst. The first set of tests SRNL performed in the current work scope was to examine the effect of changing the copper catalyst from $\mathrm{CuSO}_{4} \bullet 5 \mathrm{H}_{2} \mathrm{O}$ to $\mathrm{Cu}\left(\mathrm{NO}_{3}\right)_{2} \bullet 2.5 \mathrm{H}_{2} \mathrm{O}$. It was not anticipated that the change in chemical form would reduce the reactivity.

For this experiment, two $1 \mathrm{~L}$ poly bottles each with a magnetic stirrer and stir bar were set up. Two sets of slurries $(250 \mathrm{~mL}$ each) were generated according to the recipe in Table 1 . Each slurry was adjusted with $50 \mathrm{wt} \%(10.4 \mathrm{M})$ nitric acid to a final $\mathrm{pH}$ of 11 . The $\mathrm{pH}$ adjustment resulted in $\sim 300 \mathrm{~mL}$ of a brown slurry, with some heterogeneous solids present. See Figure 1. The slurry was used without further changes. To one bottle, copper catalyst was added in the form of $\mathrm{CuSO}_{4} \bullet 5 \mathrm{H}_{2} \mathrm{O}$, and in the other bottle, the copper was added in the form of $\mathrm{Cu}\left(\mathrm{NO}_{3}\right)_{2} \bullet 2.5 \mathrm{H}_{2} \mathrm{O}$. For each test $500 \mathrm{mg} / \mathrm{L}$ of copper was utilized. Tests were conducted at ambient laboratory temperature (typically $21^{\circ} \mathrm{C}$ ). Hydrogen peroxide was added at a rate of $0.1 \mathrm{~mL} /$ hour. 
The filtrate samples started with a dark orange and lightened over time. The slurry in the reaction vessel changed color from brown, to a slightly more green-brown.

Figure 1. Typical Appearance of Slurry after pH Adjustment

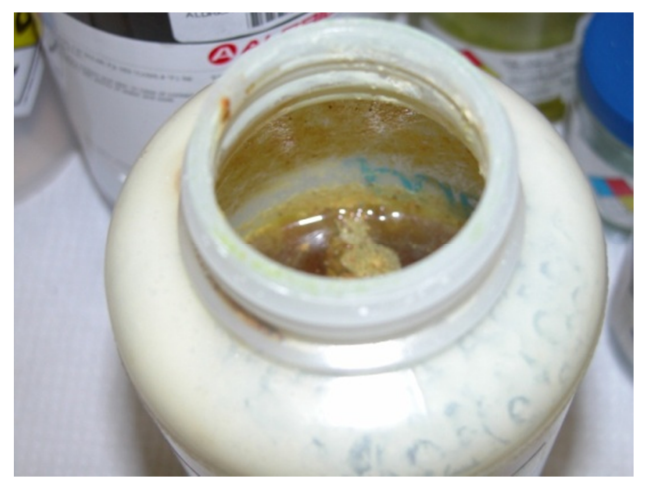

A total of 16 samples were removed (during the 3 week test period) for analysis by ICPES. From the ICPES results, the boron, potassium, copper, sodium, and titanium concentration results were examined. Results from each test were compared to establish potential differences in reactivity.

\subsubsection{Soluble Boron Results}

After the start of the $\mathrm{H}_{2} \mathrm{O}_{2}$ addition, the boron concentration in the filtrate samples slowly increased over time. See Figure 2.

The total TPB destruction is shown in Table 2.

\section{Table 2. Total TPB Destruction from Final Boron Results for Varying Copper Compounds}

\begin{tabular}{|cc|cc|cc|}
\hline \multicolumn{2}{|c|}{ Destruction by Acid } & \multicolumn{2}{c|}{ Destruction by $\mathrm{H}_{2} \mathrm{O}_{2}$} & \multicolumn{2}{c|}{ Total Destruction } \\
\hline Cu-nitrate & Cu-sulfate & Cu-nitrate & Cu-sulfate & Cu-nitrate & Cu-sulfate \\
\hline $23.8-29.1 \%$ & $24.1-29.4 \%$ & $31.9-46.0 \%$ & $28.9-42.4 \%$ & $58.9-72.0 \%$ & $56.1-68.6 \%$ \\
\hline
\end{tabular}

During the length of the experiment, both reactions provided virtually identical results, resulting in a total average TPB destruction of $62-65 \%$. 
Figure 2. Boron Results Comparison for Varying Copper Compounds

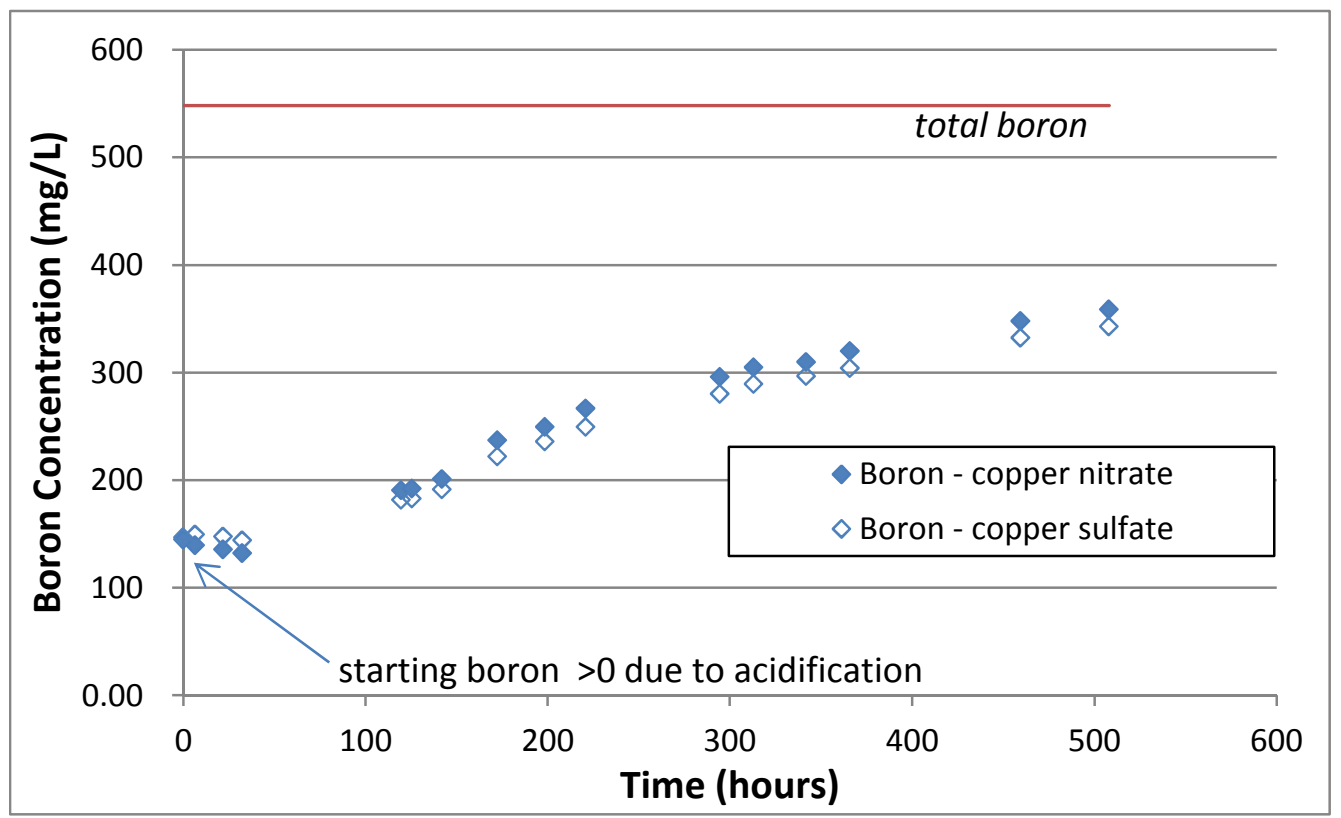

\subsubsection{Soluble Potassium Results}

Data for soluble potassium indicate the same time-dependent trends previously discussed for boron. See Figure 3.

The TPB destruction levels (based on the soluble potassium data) are shown in Table 3.

\section{Table 3. Total TPB Destruction from Final Potassium Results for Varying Copper Compounds}

\begin{tabular}{|c|c|cc|cc|}
\hline \multicolumn{2}{|c|}{ Destruction by Acid } & \multicolumn{2}{c|}{ Destruction by $\mathrm{H}_{2} \mathrm{O}_{2}$} & \multicolumn{2}{c|}{ Total Destruction } \\
\hline Cu-nitrate & Cu-sulfate & Cu-nitrate & Cu-sulfate & Cu-nitrate & Cu-sulfate \\
\hline $33.7-44.3 \%$ & $37.1-48.5 \%$ & $27.6-48.7 \%$ & $18.9-39.5 \%$ & $68.0-86.2 \%$ & $63.4-80.6 \%$ \\
\hline
\end{tabular}




\section{Figure 3. Potassium Results Comparison for Varying Copper Compounds}

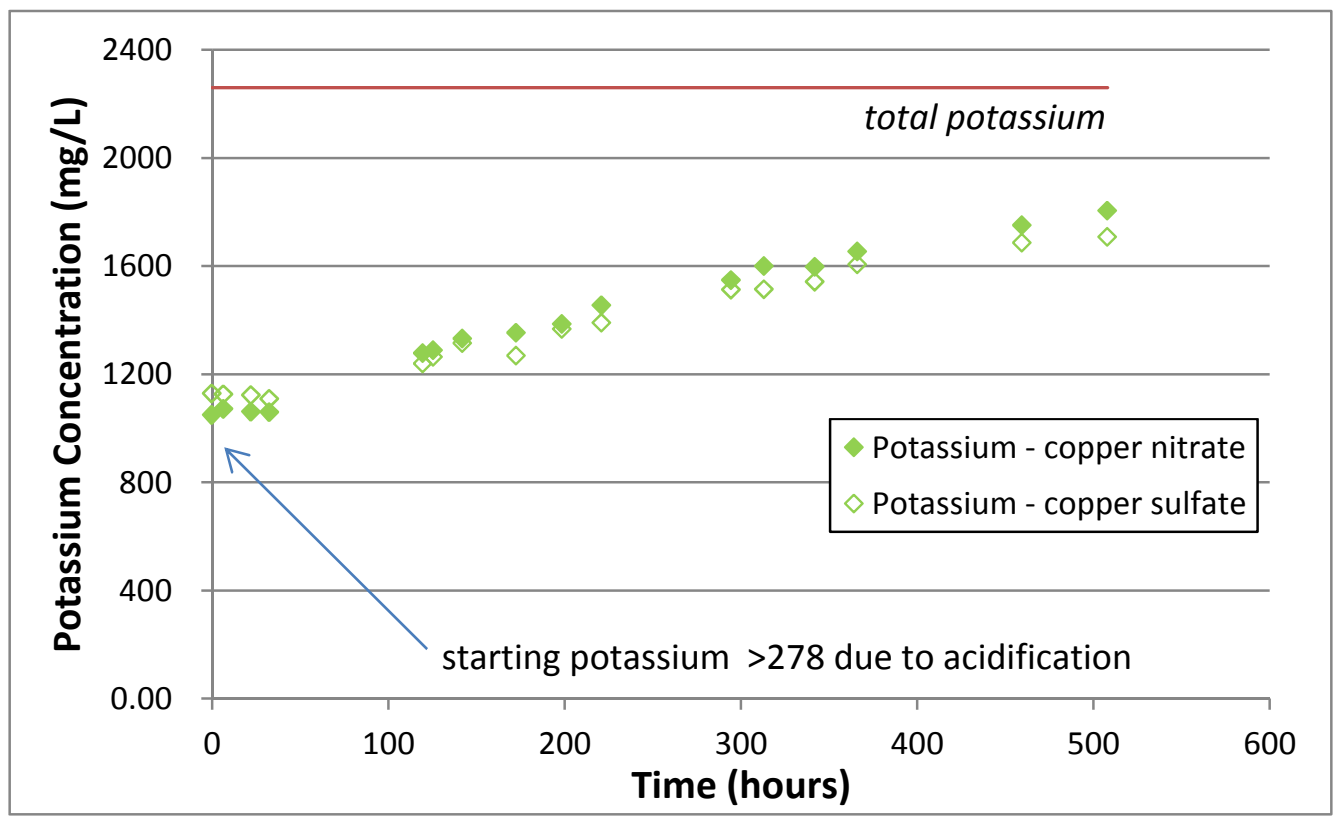

During the length of the experiment, both reactions provided virtually identical results, resulting in a final total average TPB destruction of $\sim 72-77 \%$. There is an offset in the boron and potassium derived TPB destruction values, possibly due to the fact that once KTPB is degraded, the potassium remains free in solution, whereas the organoboron degradation compounds may not be as soluble.

\subsubsection{Soluble Copper Results}

After the start of the $\mathrm{H}_{2} \mathrm{O}_{2}$ addition the copper in the filtrate samples slowly increased over time to a maximum of $\sim 100 \mathrm{mg} / \mathrm{L}$ (or $20 \%$ of the total added copper). See Figure 4 .

Both reactions provided virtually identical filtrate results for the copper. This finding is not surprising as both copper salts are highly water soluble and possess anions that are relatively non-coordinating (i.e. uninvolved in chemical reactions). The low percentage of dissolved copper suggests that both copper salts have a low initial solubility in the caustic salt slurry. Future work may be directed towards assessing alternative forms of copper catalyst addition to improve the copper solubility, as presumably, improved copper solubility may improve the catalytic function. 
Figure 4. Copper Concentration Comparison for Reactions with Varying Copper Compounds

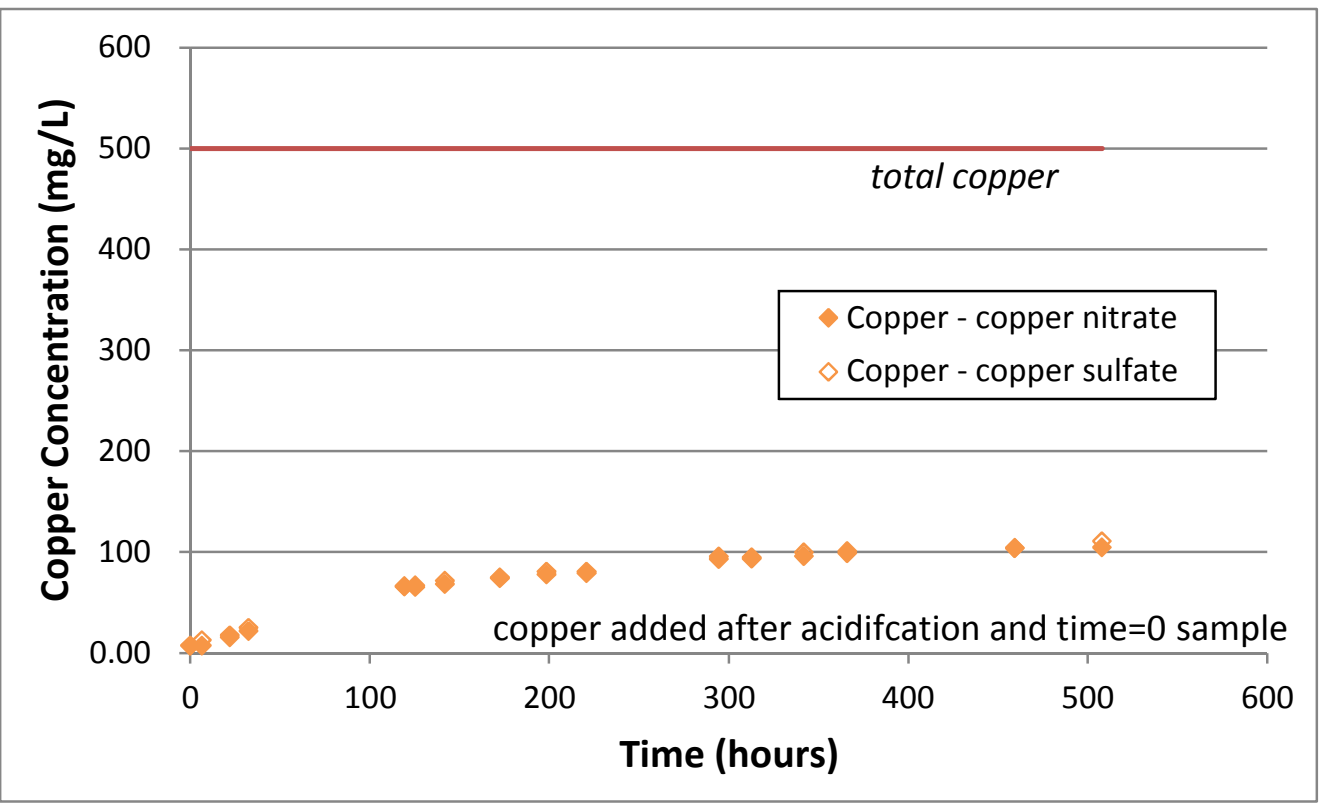

\subsubsection{Soluble Titanium Results}

Titanium is another element that requires monitoring as ingrowth of titanium in solution is indicative of leaching of titanium from MST. After the start of the $\mathrm{H}_{2} \mathrm{O}_{2}$ addition, the titanium concentration in the filtrate samples slowly increased to a maximum of $\sim 10 \mathrm{mg} / \mathrm{L}$ (see Figure 5). There was no significant difference between the proportion of soluble Ti for each of the tests. The slight ingrowth of titanium is probably due to the addition of the $\mathrm{H}_{2} \mathrm{O}_{2}$, and not the particular form of the copper. Previous work has shown that MST is known to react with $\mathrm{H}_{2} \mathrm{O}_{2} .{ }^{15}$

\subsubsection{Conclusion}

The cation dissolution data presented in previous sections indicates no significant differences in performance of the CCPO process when either copper sulfate, or copper nitrate, are utilized as the source of the copper catalyst. As such all subsequent experiments utilized $\mathrm{Cu}\left(\mathrm{NO}_{3}\right)_{2} \bullet 2.5 \mathrm{H}_{2} \mathrm{O}$ due the potential downstream impacts of sulfate for DWPF. While this material performs adequately, its low soluble concentration in the caustic environment indicates the need to investigate the optimal addition of copper nitrate, and in addition, to establish whether more soluble copper-based compounds are available. 
Figure 5. Titanium Concentration Comparison for Reactions with Varying Copper Compounds

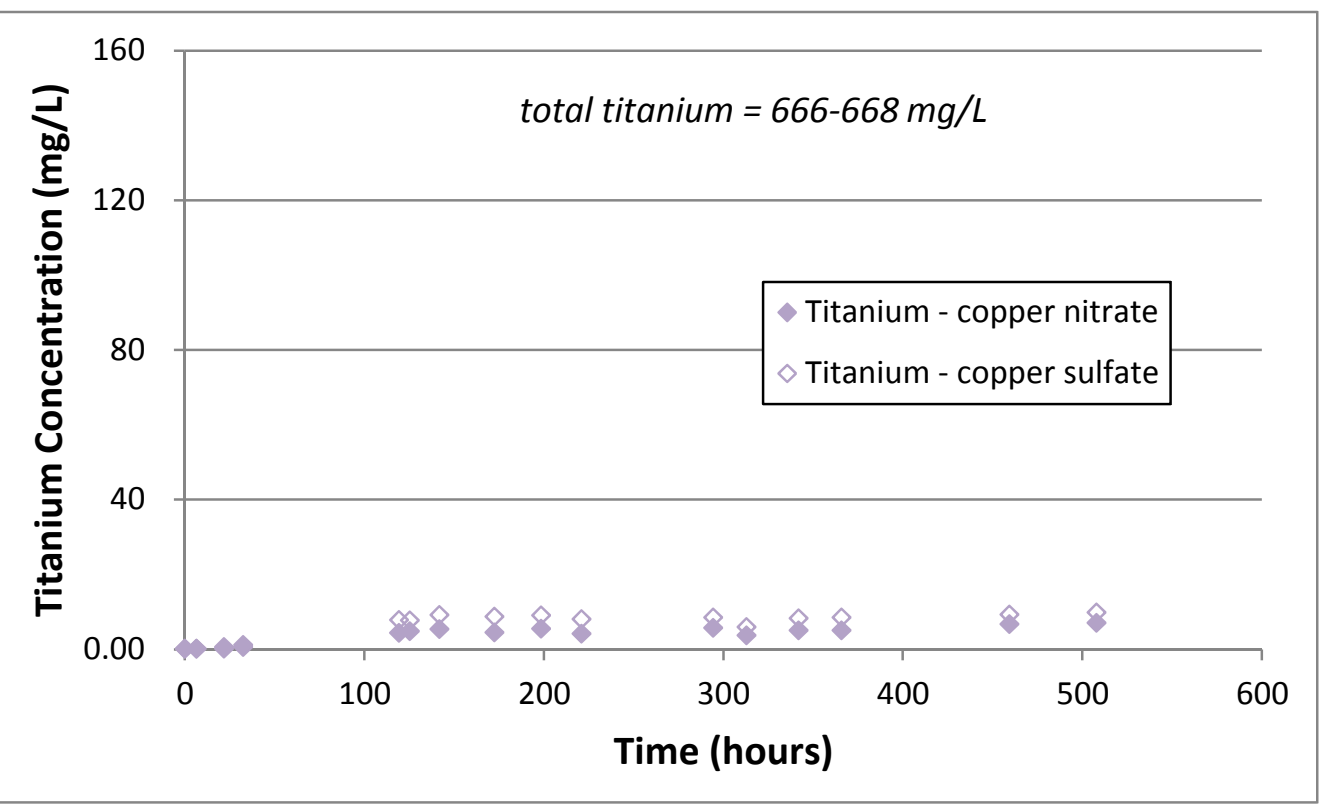

\subsection{Effect of Increased Hydrogen Peroxide Rates}

The baseline rate of $\mathrm{H}_{2} \mathrm{O}_{2}$ addition to the reaction vessels was chosen to match the delivery rates from the 2004 work. At this delivery rate, the estimated time to for process completion is approximately 3 weeks. It is desirable to reduce the process duration as much as possible to reduce the overall cycle time for each batch of waste.

For this experiment, a single 1L poly bottle with a magnetic stirrer and stir bar was set up. A single bottle of $250 \mathrm{~mL}$ of slurry was generated according to the simulant recipe (Table 1). The slurry was adjusted with $50 \mathrm{wt} \%(10.4 \mathrm{M})$ nitric acid to a final $\mathrm{pH}$ of 11 . The $\mathrm{pH}$ adjustment resulted in $\sim 300 \mathrm{~mL}$ of slurry. For each test $500 \mathrm{mg} / \mathrm{L}$ of copper was utilized. Tests were conducted at ambient laboratory temperature (typically $21^{\circ} \mathrm{C}$ ). Hydrogen peroxide was added at a rate of $1 \mathrm{~mL} /$ hour which is equivalent to $10 \times$ the nominal addition rate.

As the rate of $\mathrm{H}_{2} \mathrm{O}_{2}$ delivery was $10 \times$ the nominal rate, the test duration was reduced to approximately 12 days. A total of 13 filtrate samples were retrieved throughout the test period for determination of the soluble boron, potassium, copper, sodium, and titanium contents by ICPES. Results from this test were compared to the results from the previous test that used (see Section 3.1) $\mathrm{Cu}\left(\mathrm{NO}_{3}\right)_{2} \bullet 2.5 \mathrm{H}_{2} \mathrm{O}$ as the copper form. 
SRNL-STI-2012-00342

Revision 0

\subsubsection{Soluble Boron Results}

After the start of the $\mathrm{H}_{2} \mathrm{O}_{2}$ addition the boron in the filtrate samples slowly increased over time. See Figure 6.

\section{Figure 6. Boron Concentration Comparison at Varying Peroxide Addition Rates}

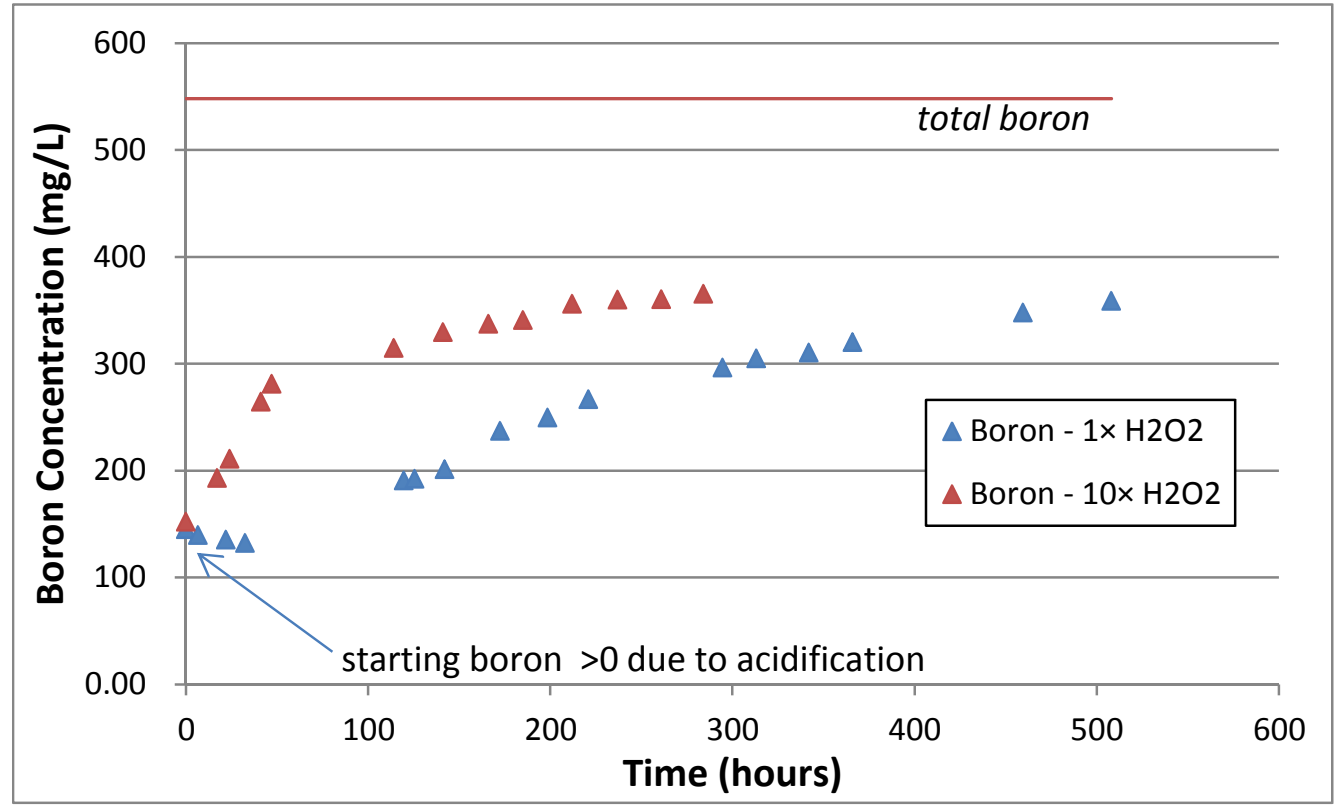

In Figure 6, the blue triangles represent data from the previous test using the nominal $1 \times$ peroxide addition rate (see Section 3.1.1). Note that the duration of this test was $>500$ hours in comparison to the shorter duration of 284 hours for the test utilizing a $10 \times$ peroxide addition rate.

The reaction was halted after 284 hours, and the extent of destruction for both reactions was calculated using the same methodology as in Section 3.1.1 (see Table 4).

Table 4. Total TPB Destruction from Final Boron Results at Varying Peroxide Addition Rates

\begin{tabular}{|c|c|c|c|c|c|}
\hline \multicolumn{2}{|c|}{ Destruction by Acid } & \multicolumn{2}{c|}{ Destruction by $\mathrm{H}_{2} \mathrm{O}_{2}$} & \multicolumn{2}{c|}{ Total Destruction } \\
\hline $1 \times \mathrm{H}_{2} \mathrm{O}_{2}$ & $10 \times \mathrm{H}_{2} \mathrm{O}_{2}$ & $1 \times \mathrm{H}_{2} \mathrm{O}_{2}$ & $10 \times \mathrm{H}_{2} \mathrm{O}_{2}$ & $1 \times \mathrm{H}_{2} \mathrm{O}_{2}$ & $10 \times \mathrm{H}_{2} \mathrm{O}_{2}$ \\
\hline $23.8-29.1 \%$ & $24.8-30.3 \%$ & $28.9-42.4 \%$ & $31.5-45.9 \%$ & $58.9-72.0 \%$ & $59.7-72.9 \%$ \\
\hline
\end{tabular}

Both the $1 \times$ and $10 \times \mathrm{H}_{2} \mathrm{O}_{2}$ peroxide reactions provided the same final level of average TPB destruction; $65-66 \%$. However, the $10 \times \mathrm{H}_{2} \mathrm{O}_{2}$ reaction proceeded at a much faster initial rate before tapering off. The $10 \times \mathrm{H}_{2} \mathrm{O}_{2}$ reaction also continued for a shorter time about half the time of the $1 \times \mathrm{H}_{2} \mathrm{O}_{2}$ reaction. As a rough comparison, at the termination of 
the $10 \times \mathrm{H}_{2} \mathrm{O}_{2}$ test (284 hours), the average total destruction was $66.3 \%$, compared to the $54.1 \%$ for the $1 \times \mathrm{H}_{2} \mathrm{O}_{2}$ test (295 hours). While the difference is not statistically significant by itself, it does suggest an improvement in destruction rates.

While the $10 \times$ peroxide addition rate clearly plays a role in the rate of TPB destruction during the initial stages of the reaction it does not appear to enhance the total TPB destruction. Therefore utilizing a $10 \times$ addition rate would effectively result in prohibitively increased waste volume with little overall enhancement in final destruction. As such additional experiments (see Section 3.7) to investigate the effects of peroxide addition rate were limited to $5 \times \mathrm{H}_{2} \mathrm{O}_{2}$ or less.

\subsubsection{Soluble Potassium Results}

After the start of the $\mathrm{H}_{2} \mathrm{O}_{2}$ addition the potassium concentration in the filtrate samples slowly increased over time. See Figure 7.

The reaction was halted after 284 hours and the extent of potassium dissolution associated with acid hydrolysis and peroxide oxidation calculated using the same methodology as in Section 3.1.1 (see Table 5).

\section{Figure 7. Potassium Concentration Comparison at Varying Peroxide Addition Rates}

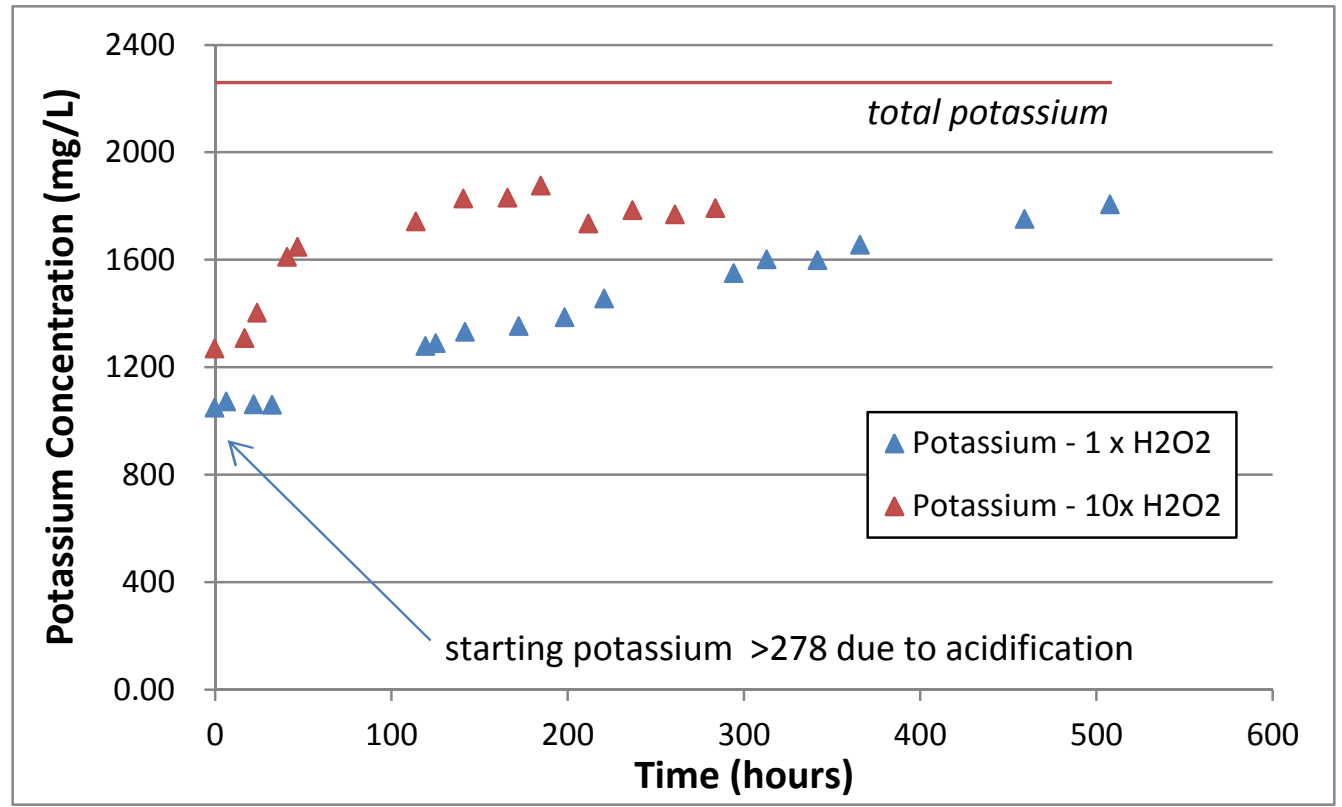


SRNL-STI-2012-00342

Revision 0

\section{Table 5. Total TPB Destruction from Final Potassium Results at Varying Peroxide Addition Rates}

\begin{tabular}{|c|c|c|c|c|c|}
\hline \multicolumn{2}{|c|}{ Destruction by Acid } & \multicolumn{2}{c|}{ Destruction by $\mathrm{H}_{2} \mathrm{O}_{2}$} & \multicolumn{2}{c|}{ Total Destruction } \\
\hline $1 \times \mathrm{H}_{2} \mathrm{O}_{2}$ & $10 \times \mathrm{H}_{2} \mathrm{O}_{2}$ & $1 \times \mathrm{H}_{2} \mathrm{O}_{2}$ & $10 \times \mathrm{H}_{2} \mathrm{O}_{2}$ & $1 \times \mathrm{H}_{2} \mathrm{O}_{2}$ & $10 \times \mathrm{H}_{2} \mathrm{O}_{2}$ \\
\hline $33.7-44.3 \%$ & $43.4-56.1 \%$ & $18.9-39.5 \%$ & $15.2-37.3 \%$ & $68.0-86.2 \%$ & $67.0-85.0 \%$ \\
\hline
\end{tabular}

Both the $1 \times$ and $10 \times \mathrm{H}_{2} \mathrm{O}_{2}$ peroxide rates provided approximately the same level of total TPB destruction, $\sim 76-77 \%$ destruction. All of the same trends and conclusions that are seen in the boron data also apply to the potassium data. The initial rate of destruction was more rapid, but then tapered off.

As a rough comparison, at the end of the $10 \times \mathrm{H}_{2} \mathrm{O}_{2}$ test (284 hours), the total destruction was $76.0 \%$, compared to $64.2 \%$ for the $1 \times \mathrm{H}_{2} \mathrm{O}_{2}$ test. While the difference is not statistically significant by itself, it does suggest an improvement in destruction rates.

\subsubsection{Soluble Copper Results}

After the start of the $\mathrm{H}_{2} \mathrm{O}_{2}$ addition the copper concentration in the filtrate samples slowly increased over time. See Figure 8.

Figure 8. Copper Concentration Comparison at Varying Peroxide Addition Rates

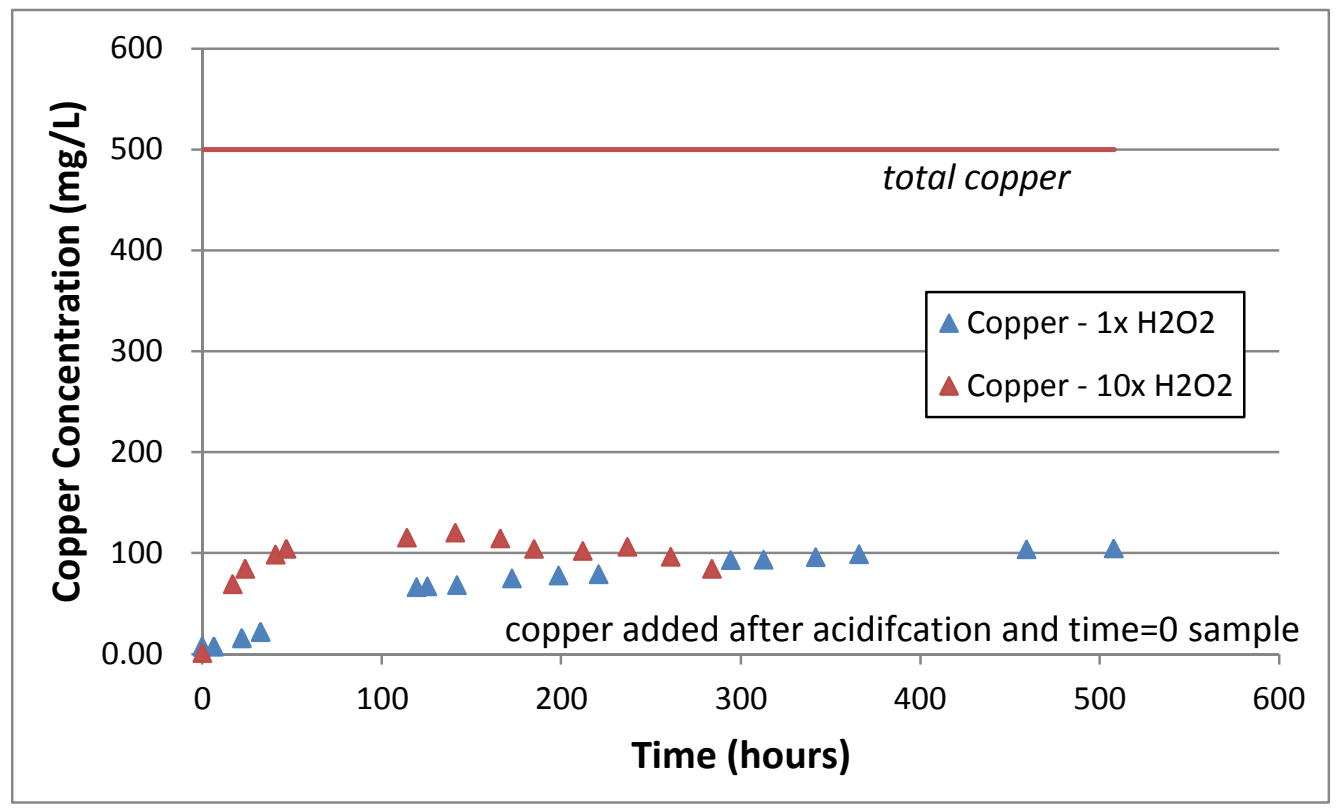

The trends seen in the boron and potassium results continue here. For both reactions the dissolution of copper initially increases with time. While both the $1 \times$ and $10 \times \mathrm{H}_{2} \mathrm{O}_{2}$ peroxide rates indicated a maximum copper soluble concentration of approximately $20 \%$, 
the $10 \times \mathrm{H}_{2} \mathrm{O}_{2}$ reaction provides a higher initial rate of copper dissolution which then tapered off.

In agreement with the data presented in Section 3.1 the majority of the added copper remains in an insoluble, and presumably, non-reactive form. Future work may consider modifying the form of the added copper to improve the solubility.

\subsubsection{Soluble Titanium Results}

The titanium concentrations in solution are monitored for the reasons outlined in Section 3.1.4 (see Figure 9).

Figure 9. Titanium Concentration Comparison at Varying Peroxide Addition Rates

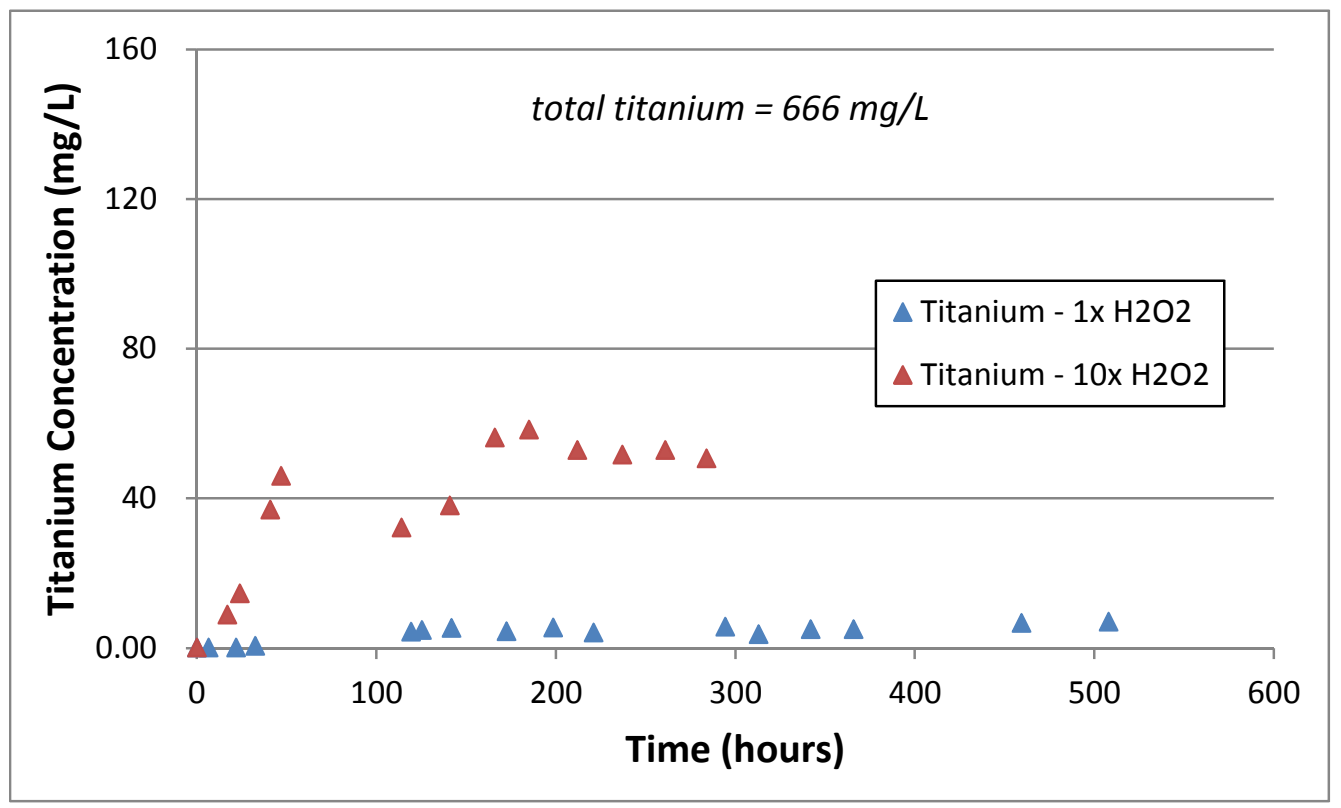

After the start of the $\mathrm{H}_{2} \mathrm{O}_{2}$ addition the titanium in the filtrate samples increased over time. However, unlike the other analytes, the titanium soluble concentration showed the largest differences between the two reactions. In the $1 \times \mathrm{H}_{2} \mathrm{O}_{2}$ reaction, the titanium in solution reached a maximum of $<10 \mathrm{mg} / \mathrm{L}$. In the $10 \times \mathrm{H}_{2} \mathrm{O}_{2}$ reaction, the titanium reached a maximum of $\sim 60 \mathrm{mg} / \mathrm{L}$. Furthermore, the rate of ingrowth of the titanium in the $10 \times \mathrm{H}_{2} \mathrm{O}_{2}$ reaction was more rapid and essentially complete in $\sim 2$ days. The excess $\mathrm{H}_{2} \mathrm{O}_{2}$ (at the $10 \times$ addition rate) likely results in enhanced reactivity between the $\mathrm{H}_{2} \mathrm{O}_{2}$ and the MST. This subsequently produces a soluble Ti-containing species which remains relatively stable for the duration of the experiment. 


\subsubsection{Conclusion}

Adding $\mathrm{H}_{2} \mathrm{O}_{2}$ at a ten-fold increased rate has several effects with respect to reaction characteristics. First, the rate of ingrowth of soluble boron, potassium and copper increased for the duration of the $10 \times \mathrm{H}_{2} \mathrm{O}_{2}$ reaction. Each analyte shows the same ingrowth trend. Second, while the initial ingrowth is noticeable, the end state remains approximately the same in comparison to the $1 \times \mathrm{H}_{2} \mathrm{O}_{2}$ reaction, although the duration of the two reactions was different. While there was no visible evidence of $\mathrm{H}_{2} \mathrm{O}_{2}$ autodecomposition (burping or foaming), the data suggests that in the $10 \times \mathrm{H}_{2} \mathrm{O}_{2}$ reaction, the $\mathrm{H}_{2} \mathrm{O}_{2}$ is not being used as efficiently as in the $1 \times \mathrm{H}_{2} \mathrm{O}_{2}$ reaction. Nevertheless, increasing the rate of $\mathrm{H}_{2} \mathrm{O}_{2}$ addition appears to be a valid method to increase the initial reaction rate.

The presence of the additional $\mathrm{H}_{2} \mathrm{O}_{2}$ also causes a higher initial and final concentration of titanium to come into solution, which must be from the MST solids. The amount of leaching titanium though is only a small fraction of the total MST inventory, $\sim 7.5 \%$ by mass.

\subsection{Effect of Reaction Temperatures}

In the 2004 work, processing temperatures were changed from $35^{\circ} \mathrm{C}$ to $75^{\circ} \mathrm{C}$ (with intermediate holds at $45^{\circ} \mathrm{C}$ and $55^{\circ} \mathrm{C}$ ) over the lifetime of the demonstration. For fullscale operation, however, it would be advantageous to process at a single reaction temperature in order to decrease the operational complexity. To this end, SRNL and the customer selected three processing temperatures to determine the effects of temperature on the reaction kinetics and TPB destruction efficiency. The temperatures utilized were $35^{\circ} \mathrm{C}, 50{ }^{\circ} \mathrm{C}$, and $65^{\circ} \mathrm{C}$. These temperatures were thought to be theoretically obtainable in the actual facility, and the $30^{\circ} \mathrm{C}$ range was considered broad enough to provide a reasonable indication of temperature effects.

For this experiment, three "new" reaction vessels were assembled. Each vessel consisted of a stainless steel bottom; 4.75 " diameter and 6 " tall with a $\sim 1 / 2$ " lip. Mated to the stainless steel bottom was a glass hemispherical dome with several penetrations. The penetrations were used for the stirring shaft, the chemical delivery, a pH probe, etc. (see Figure 10).

A set of baffles was incorporated in the stainless steel bottom. The baffles and the agitation paddles were designed to match the Froude number; a dimensionless number related to mixing. (see Appendix A). 


\section{Figure 10. Picture of One of the Designed Reactor Components}

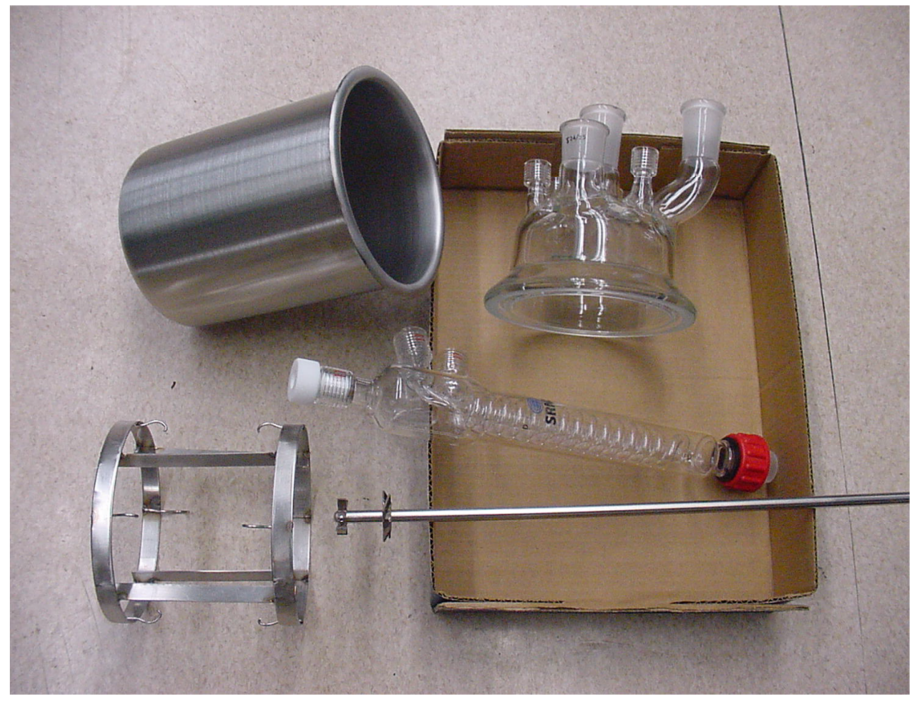

The vessel was designed to utilize $500 \mathrm{~mL}$ of Tank $48 \mathrm{H}$ slurry in each reaction, and contained enough volume to accommodate the additional $\mathrm{pH}$ adjustment acid and added $\mathrm{H}_{2} \mathrm{O}_{2}$. The vessel dimensions were also designed to fit inside a controlled temperature bath. For this work, a Thermo-Haake Model P1-B5 was used which is capable of sustaining temperatures beyond $75^{\circ} \mathrm{C}$.

Three bottles of $500 \mathrm{~mL}$ of slurry were generated according to the recipe (Table 1). The slurries were adjusted with $50 \mathrm{wt} \%(10.4 \mathrm{M})$ nitric acid to a final $\mathrm{pH}$ of 11 . The slurries were used without further changes. To each vessel, the copper catalyst in the form of $\mathrm{Cu}\left(\mathrm{NO}_{3}\right)_{2} \cdot 2.5 \mathrm{H}_{2} \mathrm{O}$ was added, with a targeted concentration of added copper $(\mathrm{Cu})$ as $500 \mathrm{mg} / \mathrm{L}$. Active temperature control was provided by the thermal baths. One reaction was conducted at a constant $35^{\circ} \mathrm{C}$, the second was conducted at a constant $50{ }^{\circ} \mathrm{C}$, and the third was conducted at a constant $65^{\circ} \mathrm{C}$. All three reactions were conducted at the same time to facilitate sample timing.

Hydrogen peroxide was added at the rates used in the 2004 work, after scaling for volume differences, $0.2 \mathrm{~mL} /$ hour.

Over time, the filtrate samples started with a dark orange and lightened over time. The slurry in the reaction vessel changed color from brown, to a slightly more green-brown.

Each test operated approximately 15 days. Filtrate samples were pulled initially at one per day, and towards the end of the test, once every 1-2 days. Samples were not pulled over the weekends. A total of $13\left(65^{\circ} \mathrm{C}\right.$ test) or 14 (35 or $50{ }^{\circ} \mathrm{C}$ tests) samples were removed for analysis by ICPES. From the ICPES results, the boron, potassium, copper, 
sodium, and titanium results were examined. Results from each test were compared to establish potential differences in reactivity.

\subsubsection{Soluble Boron Results}

As in previous experiments, the boron concentration in solution was measured as an indicator of TPB destruction. After the start of the $\mathrm{H}_{2} \mathrm{O}_{2}$ addition the boron in the filtrate samples increased over time. See Figure 11.

The reaction was halted after 372 hours, and the extent of boron dissolution associated with the acid hydrolysis and the peroxide oxidation reaction was calculated using the same methodology as in Section 3.1.1 (see Table 6).

Table 6. Total TPB Destruction from Final Boron Results at Varying Temperatures

\begin{tabular}{|c|c|c|c|c|c|c|c|c|}
\hline \multicolumn{3}{|c|}{ Destruction by Acid } & \multicolumn{3}{c|}{ Destruction by $\mathrm{H}_{2} \mathrm{O}_{2}$} & \multicolumn{3}{c|}{ Total Destruction } \\
\hline $35{ }^{\circ} \mathrm{C}$ & $50{ }^{\circ} \mathrm{C}$ & $65{ }^{\circ} \mathrm{C}$ & $35{ }^{\circ} \mathrm{C}$ & $50{ }^{\circ} \mathrm{C}$ & $65{ }^{\circ} \mathrm{C}$ & $35{ }^{\circ} \mathrm{C}$ & $50{ }^{\circ} \mathrm{C}$ & $65{ }^{\circ} \mathrm{C}$ \\
\hline $15.1-18.5 \%$ & $15.7-19.2 \%$ & $21.6-26.5 \%$ & $24.3-34.1 \%$ & $64.2-82.7 \%$ & $57.6-76.4 \%$ & $41.4-50.6 \%$ & $81.8-100 \%$ & $82.0-100 \%$ \\
\hline
\end{tabular}

Figure 11. Boron Concentration Comparison at Varying Temperatures

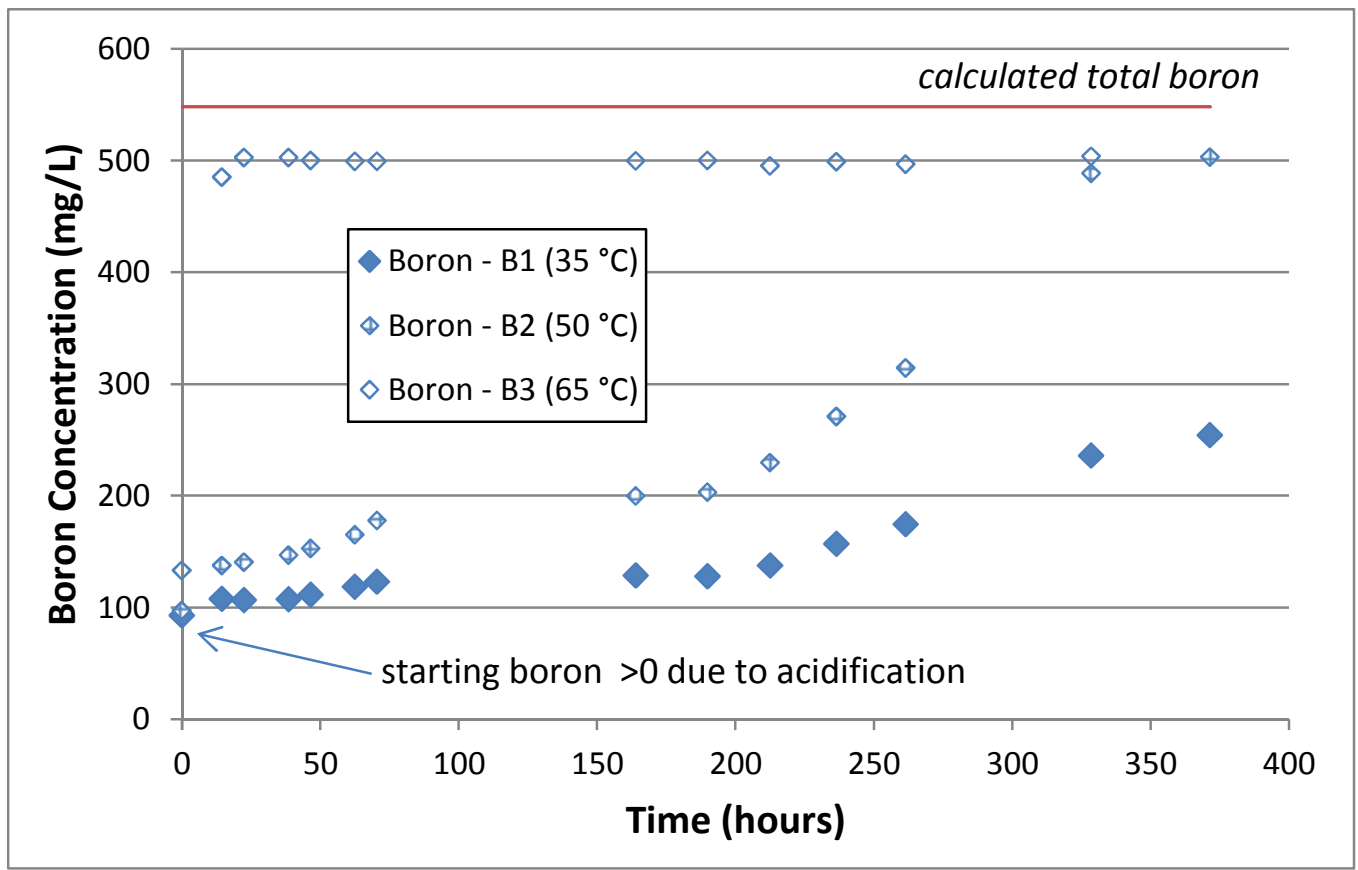


While all three reactions provided approximately the same TPB destruction from $\mathrm{pH}$ adjustment (which is to be expected as the $\mathrm{pH}$ adjustment occurred at room temperature), there were large differences in the level of TPB destruction resulting from the $\mathrm{H}_{2} \mathrm{O}_{2}$ aided reaction. By the end of the test period, the $35^{\circ} \mathrm{C}$ test indicated less than $50 \%$ TPB destruction. The $50{ }^{\circ} \mathrm{C}$ test reached total TPB destruction by the final sample, and the $65{ }^{\circ} \mathrm{C}$ test provided total TPB destruction in 1 day.

It is curious to note that the boron filtrate results plateau at $\sim 90 \%$ of the theoretical values. It is possible that the plateau is a function of incomplete dissolution (low solubility) of all the boron compounds liberated from the destruction of TPB.

\subsubsection{Soluble Potassium Results}

After the start of the $\mathrm{H}_{2} \mathrm{O}_{2}$ addition the potassium in the filtrate samples increased over time. See Figure 12.

\section{Figure 12. Potassium Concentration Comparison at Varying Temperatures}

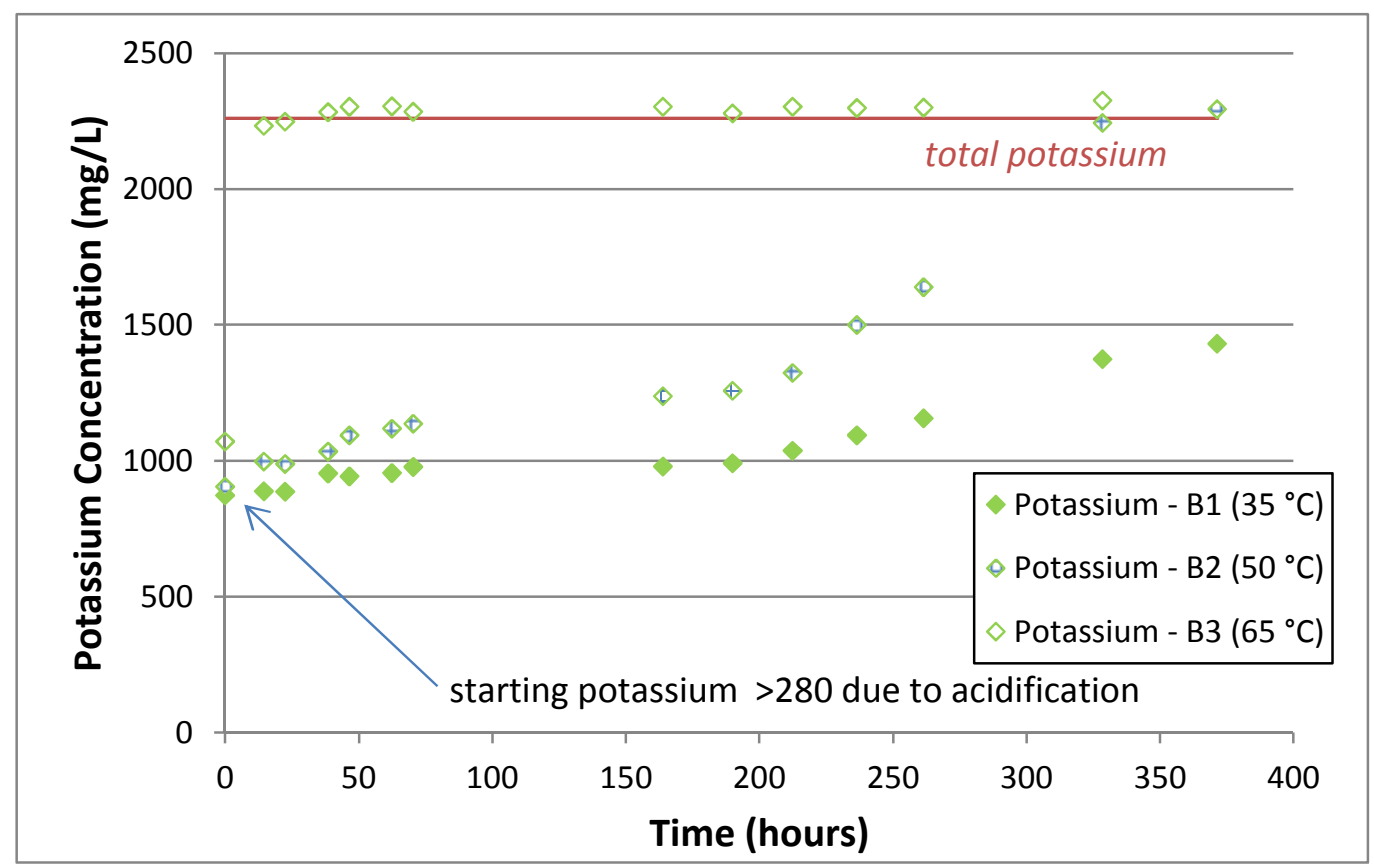

The reaction was halted after 372 hours, and the extent of potassium dissolution associated with the acid hydrolysis and peroxide oxidation reactions was calculated using the same methodology as in Section 3.1.1 (Table 7). 
SRNL-STI-2012-00342

Revision 0

\section{Table 7. Total TPB Destruction from Potassium Results at Varying Temperatures}

\begin{tabular}{|c|c|c|c|c|c|c|c|c|}
\hline \multicolumn{3}{|c|}{ Destruction by Acid } & \multicolumn{3}{c|}{ Destruction by $\mathrm{H}_{2} \mathrm{O}_{2}$} & \multicolumn{3}{c|}{ Total Destruction } \\
\hline $35{ }^{\circ} \mathrm{C}$ & $50^{\circ} \mathrm{C}$ & $65{ }^{\circ} \mathrm{C}$ & $35{ }^{\circ} \mathrm{C}$ & $50{ }^{\circ} \mathrm{C}$ & $65{ }^{\circ} \mathrm{C}$ & $35{ }^{\circ} \mathrm{C}$ & $50{ }^{\circ} \mathrm{C}$ & $65{ }^{\circ} \mathrm{C}$ \\
\hline $25.3-34.0 \%$ & $26.7-35.7 \%$ & $34.1-44.8 \%$ & $19.6-36.4 \%$ & $57.1-81.8 \%$ & $50.0-75.6 \%$ & $50.5-64.8 \%$ & $89.2-112 \%$ & $90.6-114 \%$ \\
\hline
\end{tabular}

The potassium results show the same temperature-related trends as the boron results and provide for the same conclusion.

\subsubsection{Soluble Copper Results}

After the start of the $\mathrm{H}_{2} \mathrm{O}_{2}$ addition the copper in the filtrate samples slowly increased over time. See Figure 13.

The data indicates that most of the copper remains in an insoluble form. The highest reaction temperature resulted in faster increase in soluble copper concentration but all reactions approached the same value of $\sim 100 \mathrm{mg} / \mathrm{L}$ which is also equivalent to the copper solubility observed in the earlier ambient temperature test (see Figure 4). This data suggests a similar reaction sequence.

\section{Figure 13. Copper Concentration Comparison at Varying Temperatures}

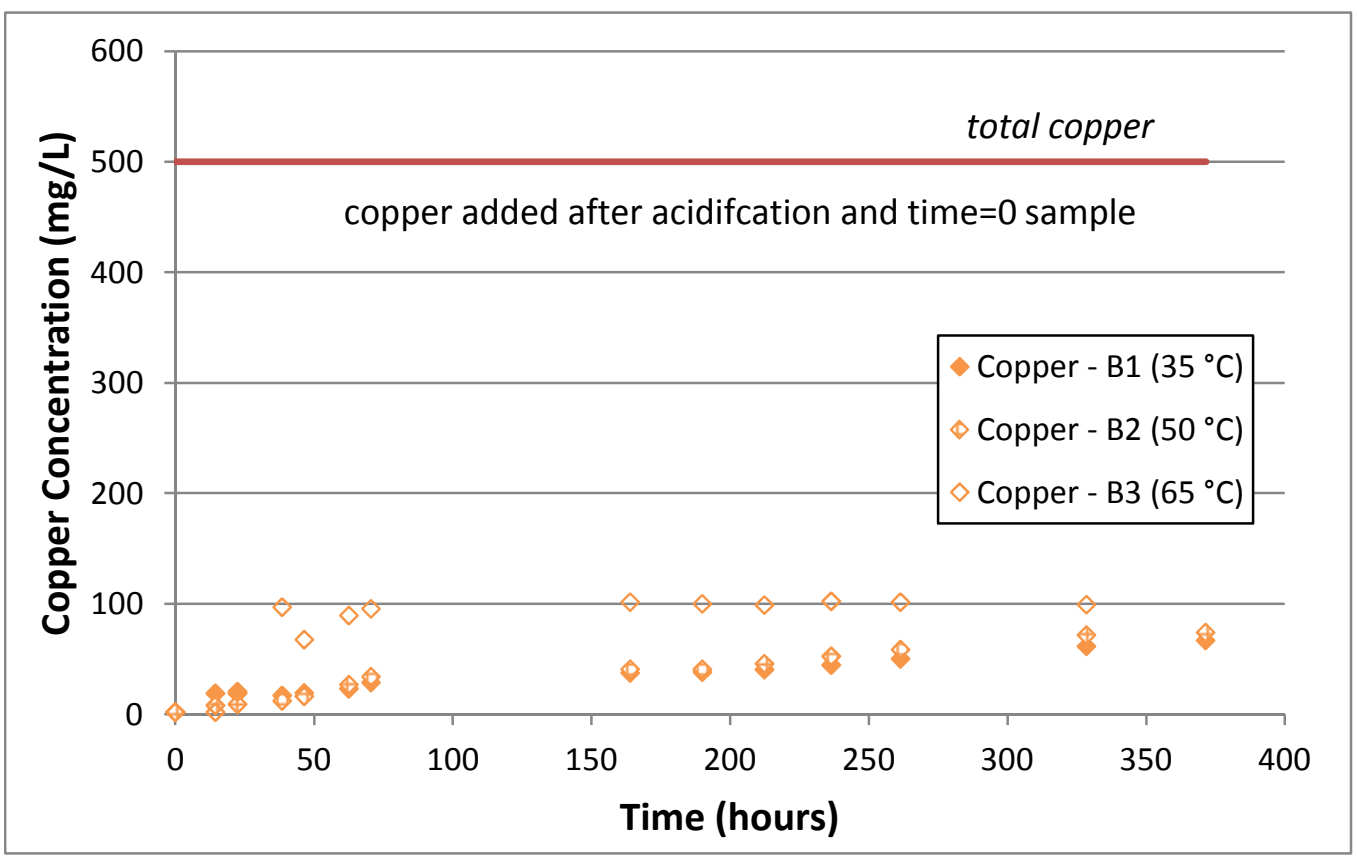




\subsubsection{Soluble Titanium Results}

The titanium in solution is monitored for the reasons outlined in Section 3.1.4. See Figure 14.

The titanium data indicates that the temperature range does have a moderate, but not immediate effect on the titanium leaching into solution. In each reaction, the titanium concentration towards the end of the experiment reached about double $(\sim 20 \mathrm{mg} / \mathrm{L})$ the concentration of the room temperature equivalent experiment. There is no effective difference between the $35 / 50 / 65^{\circ} \mathrm{C}$ temperatures at the end of the experiment.

\section{Figure 14. Titanium Concentration Comparison at Varying Temperatures}

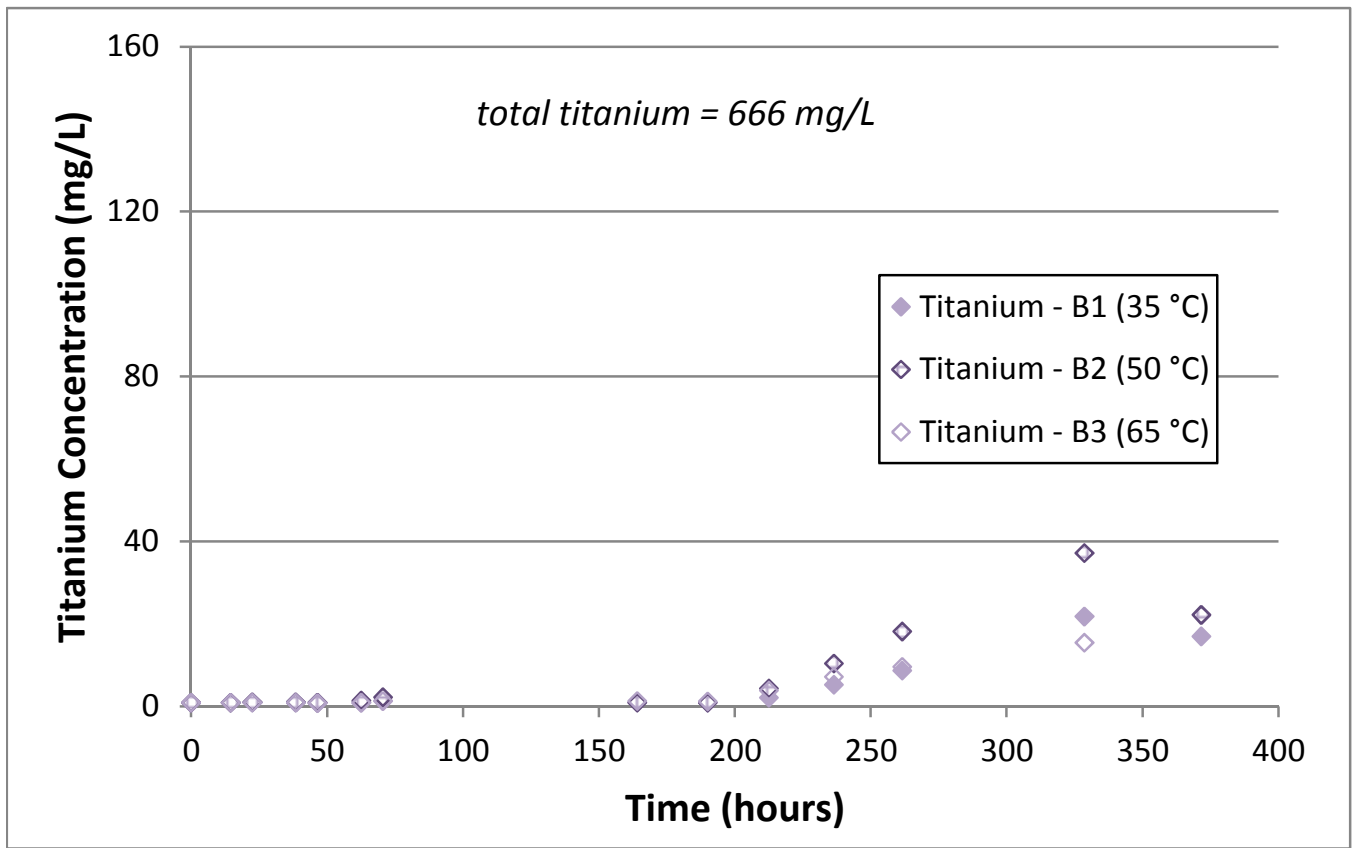

This data seems to suggest that the undesired reaction with MST is accelerating at a later point in the reaction, regardless of the reaction temperature in this range.

\subsubsection{Analysis of Reactor Bottoms}

After each reaction was complete, the residues were isolated from each of the reactor bottoms. The amount of recovered material is somewhat dependent on the efficiency of slurry removal (varying amounts of solids were caked on the upper parts of the reactor, or difficult to remove). 
From each bottle of bottoms, well-mixed (in an attempt to ensure homogeneity) duplicate samples were analyzed via HPLC, ${ }^{a}$ VOA and SVOA. However, due to the elapsed time from the end of the reaction $\left(\sim 1140\right.$ hours for the 35 and $50{ }^{\circ} \mathrm{C}$ reactions, and $\sim 1180$ hours for the $65{ }^{\circ} \mathrm{C}$ reaction), and the time of sampling, a filtered sample of the bottoms were also analyzed via ICPES as a check to see if the reaction had proceeded further. The results of the ICPES analyses are listed in Table 8. The results for the four important analytes $(\mathrm{B}, \mathrm{K}, \mathrm{Cu}, \mathrm{Ti})$ are given next to the chronologically previous sample results. These results are corrected for dilution using sodium concentration for normalization.

There are no statistically significant differences in the boron and potassium results between the two sample sets for any of the reactions. As boron and potassium are indicators of the extent of TPB destruction, this indicates us that the destruction reaction essentially did not proceed further in the time interval between the last sample and the check sample.

Table 8. ICPES Samples (mg/L) at Varying Temperatures

\begin{tabular}{|c|c|c|c|}
\hline Reaction & Analyte & $\begin{array}{c}\text { Final Filtrate } \\
\text { Result }\end{array}$ & $\begin{array}{c}\text { End of Reaction Period } \\
\text { Sample Result }\end{array}$ \\
\hline \multirow{3}{*}{$35{ }^{\circ} \mathrm{C}$} & $\mathrm{B}$ & 273 & 254 \\
\cline { 2 - 4 } & $\mathrm{K}$ & 1456 & 1429 \\
\cline { 2 - 4 } & $\mathrm{Cu}$ & 80.7 & 66.5 \\
\cline { 2 - 4 } & $\mathrm{Ti}$ & 8.37 & 17.0 \\
\hline \multirow{3}{*}{$50^{\circ} \mathrm{C}$} & $\mathrm{B}$ & 534 & 503 \\
\cline { 2 - 4 } & $\mathrm{K}$ & 2256 & 2292 \\
\cline { 2 - 4 } & $\mathrm{Cu}$ & 93.9 & 73.5 \\
\cline { 2 - 4 } & $\mathrm{Ti}$ & 22.5 & 22.2 \\
\hline \multirow{3}{*}{$65{ }^{\circ} \mathrm{C}$} & $\mathrm{B}$ & 573 & 504 \\
\cline { 2 - 4 } & $\mathrm{K}$ & 2283 & 2324 \\
\cline { 2 - 4 } & $\mathrm{Cu}$ & 108 & 98.7 \\
\cline { 2 - 4 } & $\mathrm{Ti}$ & 27.4 & 15.5 \\
\hline
\end{tabular}

The analytical uncertainty is $10 \%$ for each result.

As no additional destruction occurred, there is a valid comparison between the ICPES and HPLC results. Table 9 lists the HPLC results.

\footnotetext{
${ }^{a}$ SRNL modified the HPLC protocols as discussed in Appendix B in an attempt to lower the detection limits for the phenylboron compounds to $2-3 \mathrm{mg} / \mathrm{L}$. The lower detection limits were not generally achieved for the complex slurry composition.
} 
SRNL-STI-2012-00342

Revision 0

Table 9. HPLC Results from Reactor Bottoms Analyses (mg/L) at Varying Temperatures

\begin{tabular}{|c|c|c|c|c|c|c|}
\hline Reaction & TPB & 3PB & 2PB & 1PB & Phenol & \% Destruction \\
\hline $35^{\circ} \mathrm{C}$ & $7460(0.19 \%)$ & $<100$ & $<100$ & $<100$ & $<100$ & $50.7-50.9 \%$ \\
\hline $50^{\circ} \mathrm{C}$ & $16(0.00 \%)$ & $<10$ & $<10$ & $<10$ & $<10$ & $99.9-99.9 \%$ \\
\hline $65^{\circ} \mathrm{C}$ & $<10$ & $<10$ & $<10$ & $<10$ & $<10$ & $>99.9 \%$ \\
\hline
\end{tabular}

The value in parentheses is the \%relative standard deviation (\%RSD). The "\% Destruction" column is the calculated percent destruction. The value is based on the mass of TPB added to the simulant slurries and calculation of the mass of TPB in the reactor bottoms, after correcting for the mass of samples removed from the system during the reactions.

The reactor bottoms were also analyzed using VOA and SVOA. These two analytical methods are used to discern the presence of volatile or semi-volatile organic species. See Tables 10, 11, and 12. The values in parentheses are the \%RS.

In the results column, values that are shaded indicate only one real value with the other being a detection limit result. In this case, the values in parentheses are the analytical uncertainties. In the analyte column, shaded cells indicate the presence of that analyte is doubtful due to chemical conditions or interferences. The "total organic residuals" are the sum of all the mid-range values of the detected analytes, less benzene and the analytes that are declared to be from interferences. This term is intended to be an estimate of the propensity of the reaction conditions to generate these residual materials. These results are not normalized to the starting volumes.

Only the detection of benzene is anticipated from the VOA analysis. Due to the type of oxidation chemistry is unlikely that any other organic compound with a high enough volatility would be created in this type of reaction.

There is very little benzene left in solution by time of sampling. Benzene is highly volatile and the reactions were maintained at higher than room temperature for extended time periods (the duration of the experiments). 
Table 10. VOA and SVOA Results for $35^{\circ} \mathrm{C}$ Reaction

\begin{tabular}{|c|c|}
\hline Analyte & Result (mg/L) \\
\hline benzene & $0.765(2.77 \%)$ \\
\hline biphenyl & $1650(12.9 \%)$ \\
\hline nitrobenzene & $97.5(3.63 \%)$ \\
\hline p-terphenyl & $87.0(1.63 \%)$ \\
\hline triphenylboroxin & $46.0(6.15 \%)$ \\
\hline diisooctyl adipate & $34.4-51.6$ \\
\hline 4-nitro, 1,1-biphenyl & $16.5(30.0 \%)$ \\
\hline 7-nitro-6H-dibenzo [b d]pyran-6-one & $13.6-20.4$ \\
\hline ethanedioic acid dimethylester & $10.4-15.6$ \\
\hline o-phenylene benzeneboronate & $10.1(13.4 \%)$ \\
\hline o-terphenyl & $8.35(0.85 \%)$ \\
\hline m-terphenyl & $7.75(0.91 \%)$ \\
\hline 4-hydroxy-4-nitro-biphenyl & $3.04-4.56$ \\
\hline Total organic residuals & 1957 \\
\hline
\end{tabular}

Table 11. VOA and SVOA Results for $50^{\circ} \mathrm{C}$ Reaction

\begin{tabular}{|c|c|}
\hline Analyte & Result (mg/L) \\
\hline benzene & $0.12(11.8 \%)$ \\
\hline biphenyl & $940(6.02 \%)$ \\
\hline p-terphenyl & $38.5(5.51 \%)$ \\
\hline o-terphenyl & $11.5(6.15 \%)$ \\
\hline diisooctyl adipate & $10.5(60.6 \%)$ \\
\hline 2-phenoxy, 1,1-biphenyl & $4.5(6.29 \%)$ \\
\hline 2-phenyl-4H-1,3,2-benzodioxaborin-4-one & $2.75(33.5 \%)$ \\
\hline diphenylamine & $1.8(7.86 \%)$ \\
\hline 4-nitro-N-phenyl-benzenamine & $1.75(4.04 \%)$ \\
\hline 1,1,2,1,4,1-quaterphenyl & $1.6(8.84 \%)$ \\
\hline Total organic residuals & 1002 \\
\hline
\end{tabular}


Table 12. VOA and SVOA Results for $65^{\circ} \mathrm{C}$ Reaction

\begin{tabular}{|c|c|}
\hline Analyte & Result (mg/L) \\
\hline benzene & $<0.05$ \\
\hline biphenyl & $92(27.7 \%)$ \\
\hline [1,1-biphenyl]-3-amine & $91(1.55 \%)$ \\
\hline diphenyl ether & $64.5(1.10 \%)$ \\
\hline p-terphenyl & $31.5(33.7 \%)$ \\
\hline m-terphenyl & $14.4-21.6$ \\
\hline diisooctyl adipate & $16.5(21.4 \%)$ \\
\hline 2-phenoxy, 1,1-biphenyl & $13(0.00 \%)$ \\
\hline o-terphenyl & $9.25(2.29 \%)$ \\
\hline 2-nitro-N-(4-nitrophenyl)-benzenamine & $5.65(6.26 \%)$ \\
\hline 1,2-diphenoxybenzene & $5.45(3.89 \%)$ \\
\hline 1,1-oxybis(4-phenoxybenzene) & $5.50(36.0 \%)$ \\
\hline 1,1,4,1,4,1,4,1-quaterphenyl & $3.12-4.68$ \\
\hline 2,4-dinitro-N-phenylbenzenamine & $2.72-4.08$ \\
\hline diphenylamine & $2.15(3.29 \%)$ \\
\hline 2-nitro-N-(2-nitrophenyl)-benzenamine & $2.10(13.5 \%)$ \\
\hline azobenene & $2.16-3.24$ \\
\hline (4-nitrophenyl)diphenylamine & $1.30(32.6 \%)$ \\
\hline 4-phenyl-1,1,2,1-terphenyl & $1.04-1.56$ \\
\hline 1,1,2,1,2,1-quaterphenyl & $1.04-1.56$ \\
\hline Total organic residuals & 354 \\
\hline
\end{tabular}

The diisooctyl adipate is a known plasticizer and is likely a leachate from contact with a plastic surface.

Increased reaction temperatures resulted in greater proportions of organic compound destruction. Of the residual organics remaining in the reactor bottoms, biphenyl is the most concentrated. Given that this material has been noted as a reaction byproduct previously, ${ }^{2}$ the presence in these reactions is not surprising. While biphenyl readily sublimes under the reaction conditions (as evidenced by formation of biphenyl on the glass reactor head), there is no evidence that the biphenyl is exiting the system entirely since it is visibly apparent that the biphenyl is not depositing in the ambient temperature tubing lines leading to the GCs. For example, while all the reactions produced visible quantities of biphenyl on the glass reactor dome, the $65^{\circ} \mathrm{C}$ reaction provided the least quantity of biphenyl by the end of the reaction, with the $35^{\circ} \mathrm{C}$ reaction providing the most. It is assumed that the higher temperature reaction is destroying the biphenyl more effectively. Considering that biphenyl fouling may be an issue in the real facility, efficient destruction of biphenyl is an important consideration. However, the biphenyl is 
refluxing into the slurry during the laboratory work due to the liquid condensation on the hemispherical vessel lids exposed to ambient air flow in the hood. The relative amount of biphenyl reflux in these experiments may differ appreciably from that experienced by the demister equipment in the actual process facility.

With respect to the other analytes remaining in the reactor bottoms, they are almost all partially degraded or functionalized aryl compounds. It is very difficult to locate any trend in these analytes.

\subsubsection{Conclusion}

Not surprisingly increasing the process temperature significantly enhances the CCPO reaction kinetics. At $35^{\circ} \mathrm{C}$ complete TPB destruction was not achieved in the time-frame of the test (approximately 350 hours), whereas the $50{ }^{\circ} \mathrm{C}$ reaction achieved total TPB destruction by the end of the test, and the $65{ }^{\circ} \mathrm{C}$ test achieved complete destruction in $\sim 1$ day. Furthermore, higher temperatures generate smaller quantities of residual organics, and in particular, biphenyl and amines.

Compared to the room temperature tests (Section 3.1), the lower destruction efficiency of the $35^{\circ} \mathrm{C}$ test is due to the shortened time frame of the experiment. The room temperature tests have similar destruction efficiencies as the $35^{\circ} \mathrm{C}$ test, at the similar times.

Not only do the ICPES boron and potassium data indicate excellent agreement in regards to predicting the level of TPB destruction, the HPLC results are also internally consistent. As such, there is confidence that using all three methods to determine the TPB destruction levels result in a "real" destruction efficiency. However, the reader should recall that the destruction efficiency, as defined for this investigation, equates to the destruction of TPB. At this time it has not been possible to close the carbon balance due to the lack of off-gas data and other data (carbonate, IC-anions). It is considered possible that the majority of the organic carbon is leaving the system as carbon dioxide and benzene. It has not currently been determined if the concentration of benzene in the offgas will be acceptable in terms of environmental emissions and vapor space flammability in the reaction vessel.

The higher temperatures do not affect the copper concentrations in the filtrate. Presumably this is because the copper solubility is not primarily a function of temperature, but the form of the copper species being relatively insoluble in the alkaline simulant

Higher temperature does have a moderate, but not immediate effect on the extent of titanium leaching from the MST. The unexplained increase in titanium occurred in all three tests. 
SRNL-STI-2012-00342

Revision 0

\subsection{Demonstration\#1}

Part of the documented work scope involves duplicating the 2004 work. DEMO 1 is the initial attempt to duplicate those results.

This experiment used the same reaction vessel and temperature control as described in Section 3.3. Other experimental details were as described in previous Sections, except for those changes subsequently listed.

(1) The vessel was attached to a gas chromatograph (GC), which enabled the concentration of the following gaseous species to be tracked: $\mathrm{CO}_{2}, \mathrm{~N}_{2} \mathrm{O}, \mathrm{O}_{2}, \mathrm{~N}_{2}$, light organics (benzene). The GC actively analyzed the contents of the reactor headspace during the entire reaction every 15 minutes, including during $\mathrm{pH}$ adjustment.

(2) $\mathrm{A} \mathrm{pH}$ probe was inserted into the reaction solution to facilitate $\mathrm{pH}$ adjustment in the reactor. The probe was calibrated prior to its use.

A bottle of $500 \mathrm{~mL}$ of slurry was generated according to the recipe (see Table 1). The $\mathrm{pH}$ of the slurry was adjusted (in the reaction vessel) with $50 \mathrm{wt} \%(10.4 \mathrm{M})$ nitric acid to a final $\mathrm{pH}$ of 11 . The $\mathrm{pH}$ adjustment resulted in $\sim 600 \mathrm{~mL}$ of slurry. During the acid addition it was observed that the stainless steel needles used for acid addition suffered from excessive corrosion. No evidence of ingrowth of steel leachates into the solution was detected, but nonetheless the acid delivery method was modified to avoid the use of stainless steel delivery needles.

It was noted that the "prototypical mixing" is in fact very poor compared to the reactions performed in poly bottles with a magnetic stirrer. The agitation was insufficient to prevent a semi-stable floating solids mass. This poor agitation may affect the overall reaction efficiency. Also, since the rheology of real waste is known to differ from the simulated slurries, this behavior may lead to experimental offsets in similar tests.

Copper catalyst in the form of $\mathrm{Cu}\left(\mathrm{NO}_{3}\right)_{2} \bullet 2.5 \mathrm{H}_{2} \mathrm{O}$ (to the targeted amount of $500 \mathrm{mg} / \mathrm{L}$ copper) was added to the reaction vessel. Active temperature control was provided by the thermal bath. The initial temperature was set to $35^{\circ} \mathrm{C}$. At approximately 144, 264, and 336 hours into the test, the operating temperature was raised to 45,55 , and $75^{\circ} \mathrm{C}$, respectively. The total duration of the test was 497 hours. This temperature profile matches that of the 2004 work, with the exception that the initial room temperature phase of $\sim 2$ weeks was omitted. Given the lack of reactivity at $35^{\circ} \mathrm{C}$ in the 2004 work, it was anticipated that removing the room temperature step would have little impact on overall reactivity. (Note, in the 2004 experiment, the copper concentration was increased after one week at $35^{\circ} \mathrm{C}$ to a value of $467 \mathrm{mg} / \mathrm{L}$ with relatively slow reaction occurring as noted by one filtrate sample analysis and then the temperature was increased to $45^{\circ} \mathrm{C}$.) 
Hydrogen peroxide was added at the rates used in the 2004 work, after scaling for volume differences; $0.2 \mathrm{~mL} /$ hour.

The test ran for approximately 21 days. Filtrate samples were removed once per day. A total of 23 samples were removed for analysis by ICPES. From the ICPES results, the boron, potassium, copper, sodium, and titanium soluble concentrations were examined. Results from each test were compared to establish potential differences in reactivity.

\subsubsection{Soluble Boron Results}

As in previous experiments, the concentration of soluble boron was used as an indicator of the extent of TPB destruction. After the start of the $\mathrm{H}_{2} \mathrm{O}_{2}$ addition the boron in the filtrate samples increased over time. See Figure 15.

The reaction was halted after 497 hours, and the extent of boron dissolution associated with the acid hydrolysis and peroxide oxidation reactions was calculated using the same methodology as in Section 3.1.1 (see Table 13). The final data point at $\mathrm{t}=708$ hours is from the confirmation sample from the reactor bottoms (see Section 3.4.5) and is not used in the percent destruction calculation.

Figure 15. Boron Concentration Results for Demonstration 1

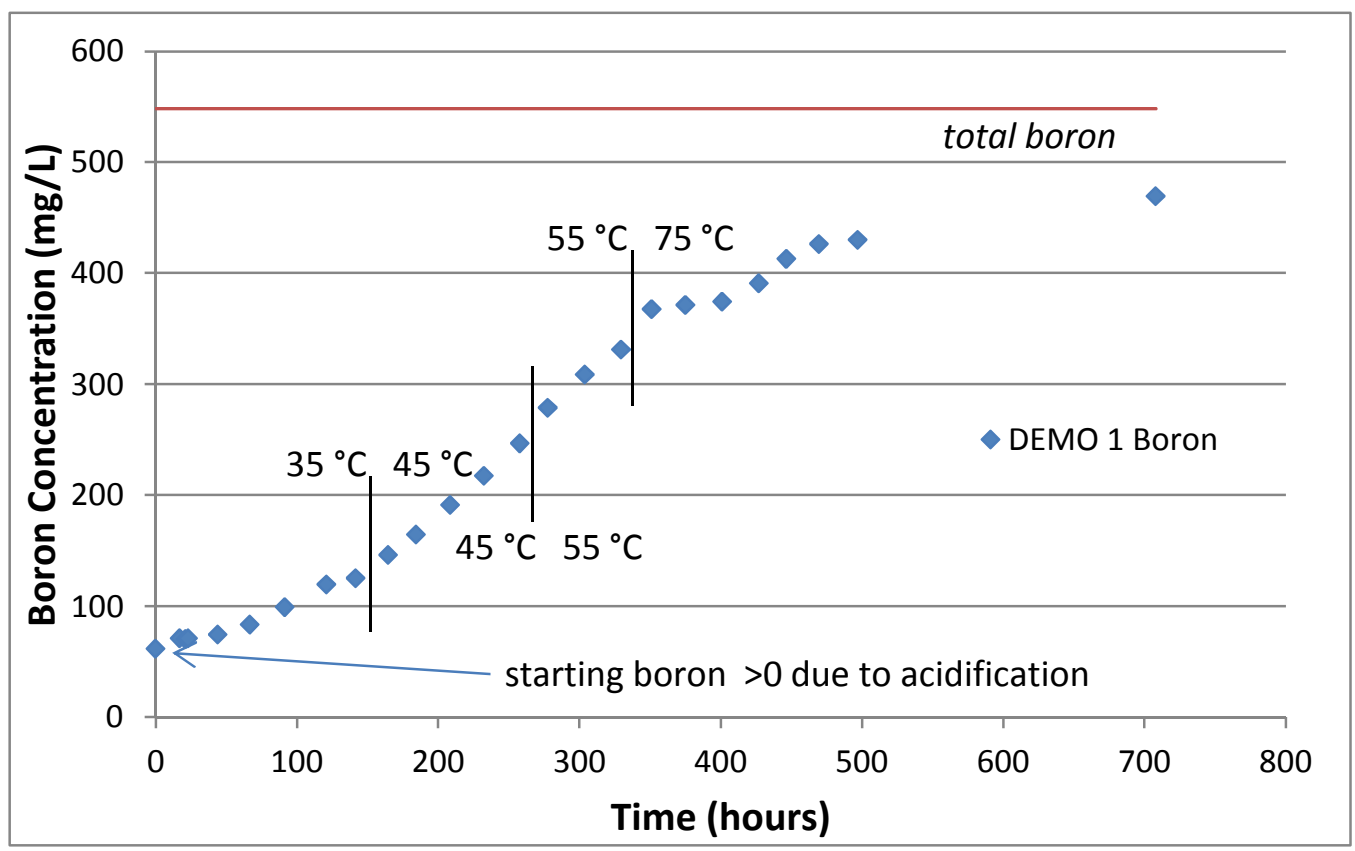


SRNL-STI-2012-00342

Revision 0

Table 13. Total TPB Destruction from Final Boron Results for Demonstration 1

\begin{tabular}{|c|c|c|}
\hline Destruction by Acid & Destruction by $\mathrm{H}_{2} \mathrm{O}_{2}$ & Total Destruction \\
\hline $10.1-12.4 \%$ & $59.0-74.8 \%$ & $70.3-85.9 \%$ \\
\hline
\end{tabular}

The drop off in reactivity in DEMO 1 is counter to expectations from previous data sets. At this time causes for the lack of reactivity at 55 and $75^{\circ} \mathrm{C}$ have not been established, though there is no reason to think that temperatures above $45^{\circ} \mathrm{C}$ are detrimental.

\subsubsection{Soluble Potassium Results}

As in previous experiments, the concentration of soluble potassium was used as an indicator of TPB destruction. After the start of the $\mathrm{H}_{2} \mathrm{O}_{2}$ addition the potassium in the filtrate samples increased over time. See Figure 16.

From the potassium data, the same trends found in the boron data are observed, including the temperature dependencies. The extent of destruction is closer to complete from the potassium data (as usual, the potassium data shows a higher extent of destruction than the boron data), and within the analytical uncertainty of showing $100 \%$ destruction.

The reaction was halted after 497 hours, and the extent of potassium dissolution associated with the acid hydrolysis and the peroxide oxidation reaction was calculated using the same methodology as in Section 3.1.1 (see Table 14). The final data point at $\mathrm{t}=708$ hours is from the confirmation sample from the reactor bottoms (see Section 3.4.5) and is not used in the percent destruction calculation.

Table 14. Total TPB Destruction from Potassium Results for Demonstration 1

\begin{tabular}{|c|c|c|}
\hline Destruction by Acid & Destruction by $\mathrm{H}_{2} \mathrm{O}_{2}$ & Total Destruction \\
\hline $19.5-26.9 \%$ & $60.3-83.4 \%$ & $85.7-108 \%$ \\
\hline
\end{tabular}


Figure 16. Potassium Concentration Results for Demonstration 1

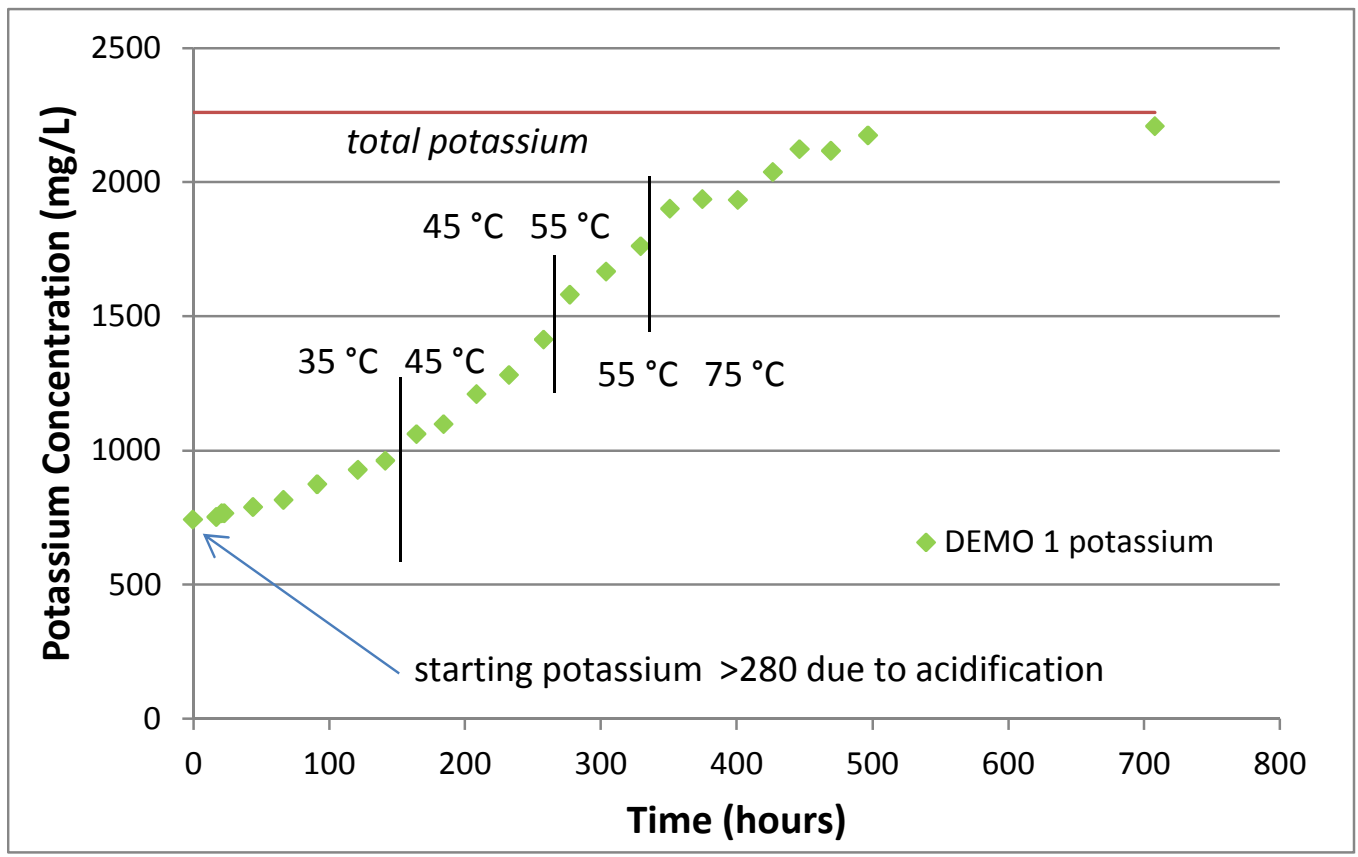

\subsubsection{Soluble Copper Results}

Copper concentrations are tracked in the filtrate for the reasons outlined in Section 3.1.3. After the start of the $\mathrm{H}_{2} \mathrm{O}_{2}$ addition the copper in the filtrate samples slowly increased over time. See Figure 17.

DEMO 1 shows unique time-dependent copper soluble concentrations in comparison to the aforementioned tests. Previous tests all exhibited a relatively slow increase in copper soluble concentrations, reaching a maximum of $\sim 100 \mathrm{mg} / \mathrm{L}$. DEMO 1, however, indicates a more rapid rate of copper dissolution and higher maximum copper concentration. The maximum concentration is subsequently followed by a decline in soluble concentrations after the slurry is heated to $75^{\circ} \mathrm{C}$ eventually reaching $\sim 60 \%$ of the peak concentration, but still leveling off at $\sim$ twice as high as other reactions. Even the confirmation sample, which had long since cooled to room temperature, showed a higher filtrate concentration than the other reactions. Even more significant is that the boron and copper behavior both show a distinct change in behavior at the time the temperature was increased from $55^{\circ} \mathrm{C}$ to $75^{\circ} \mathrm{C}$ (see Figure 18). 
Figure 17. Copper Concentration Results for DEMO 1

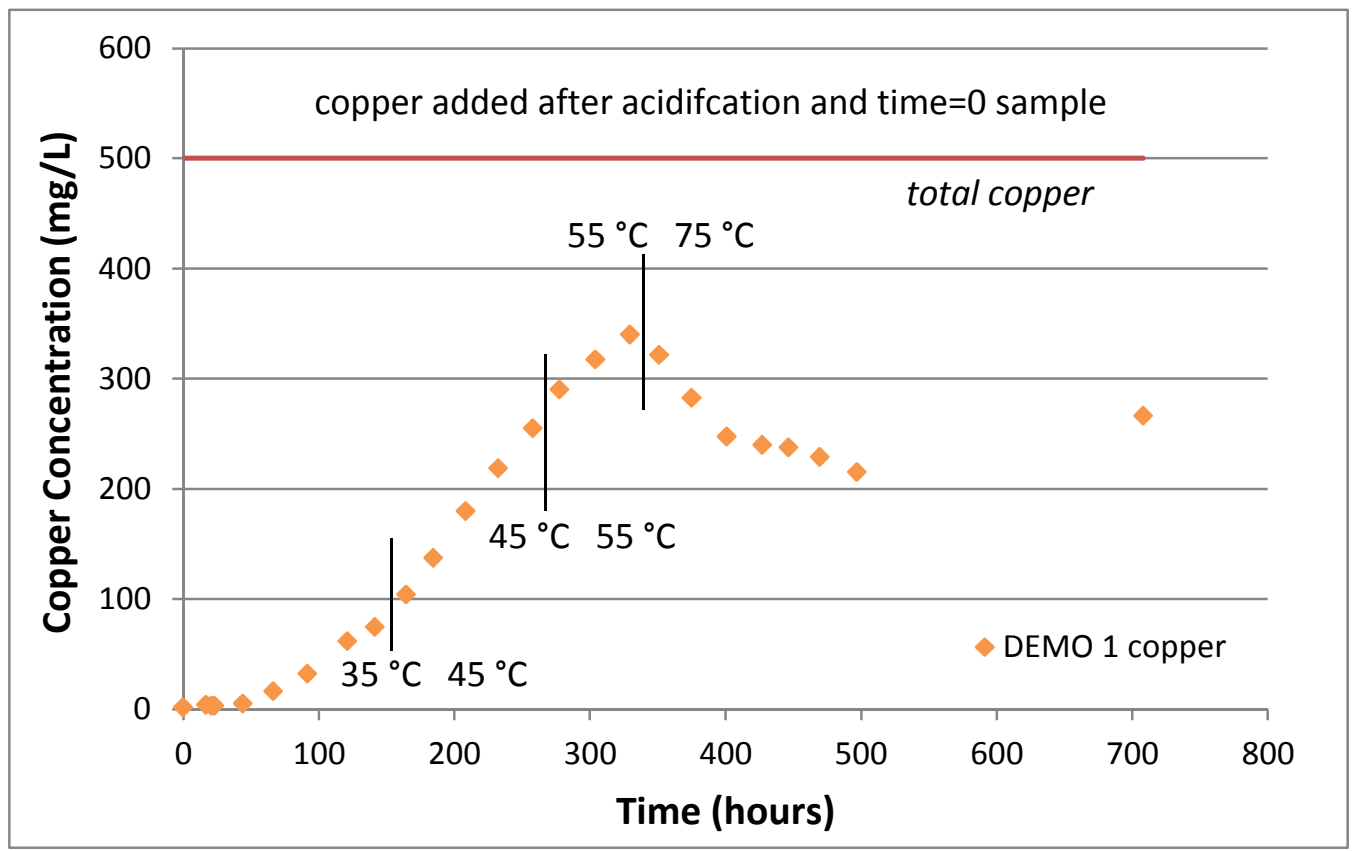

At the point of temperature change from 55 to $75{ }^{\circ} \mathrm{C}$, the rate of destruction (slope of the line) from the boron data shows a distinct negative impact, as opposed to the intuitive positive impact that was anticipated. At the same time, the copper sharply declines to $\sim 60 \%$ of its peak concentration. Both of these behaviors are unique in the tests to date. 


\section{Figure 18. Boron and Copper Concentration Behavior Correlation for DEMO 1}

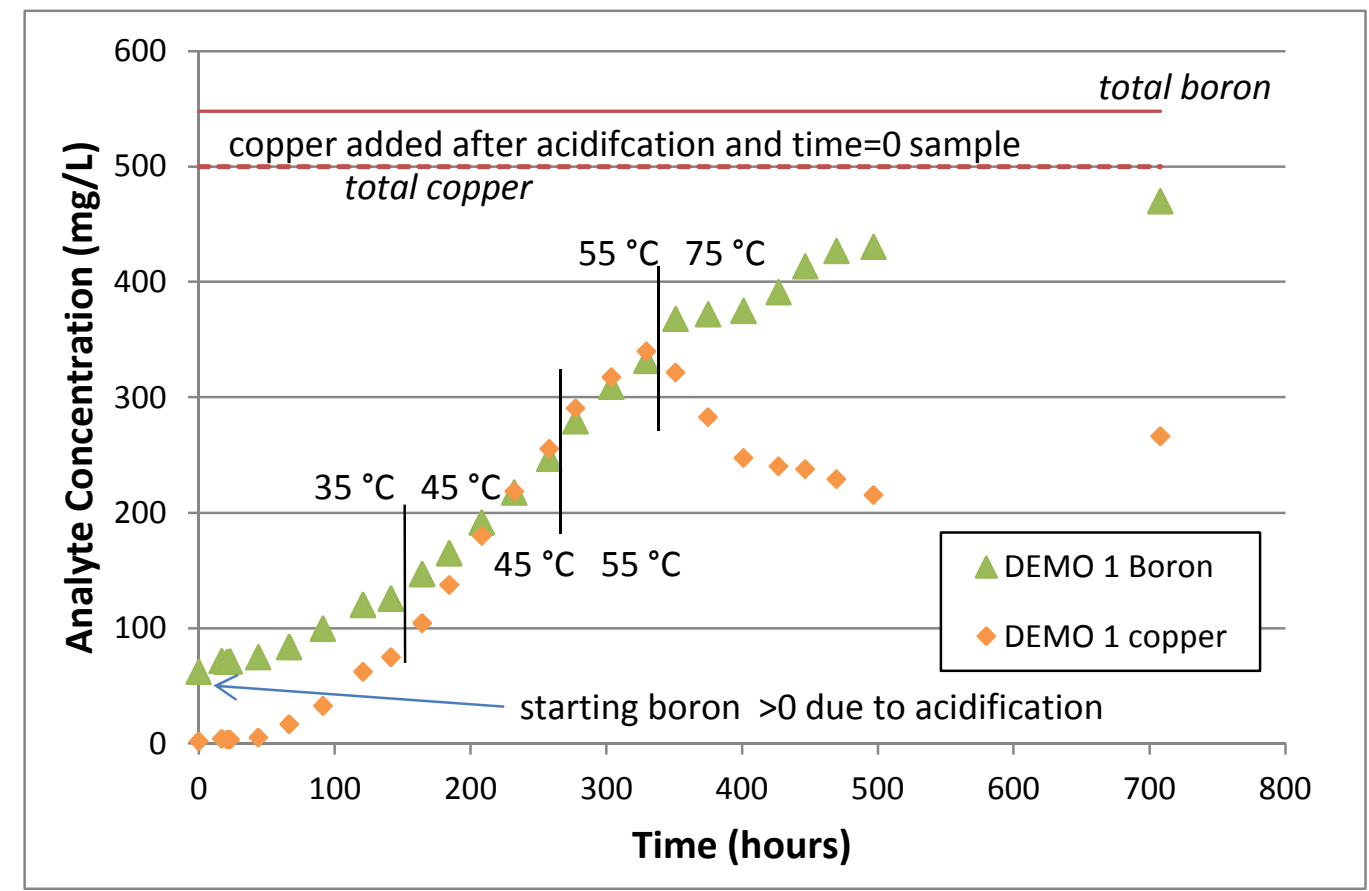

\subsubsection{Soluble Titanium Results}

The titanium concentration in solution is monitored for the reasons outlined in Section 3.1.4. See Figure 19.

The titanium data indicates no significant thermally induced changes in the soluble concentration of titanium. At all four reaction temperatures, the titanium concentrations were below $5 \mathrm{mg} / \mathrm{L}$. In addition, although it cannot be discerned on Figure 19, the titanium levels drop to below detection limits $(1.2 \mathrm{mg} / \mathrm{L})$ at the same time the boron and copper concentrations decrease (i.e., at the time the temperature was increased from 55 to $\left.75^{\circ} \mathrm{C}\right)$. 
Figure 19. Titanium Concentration Results for Demonstration 1

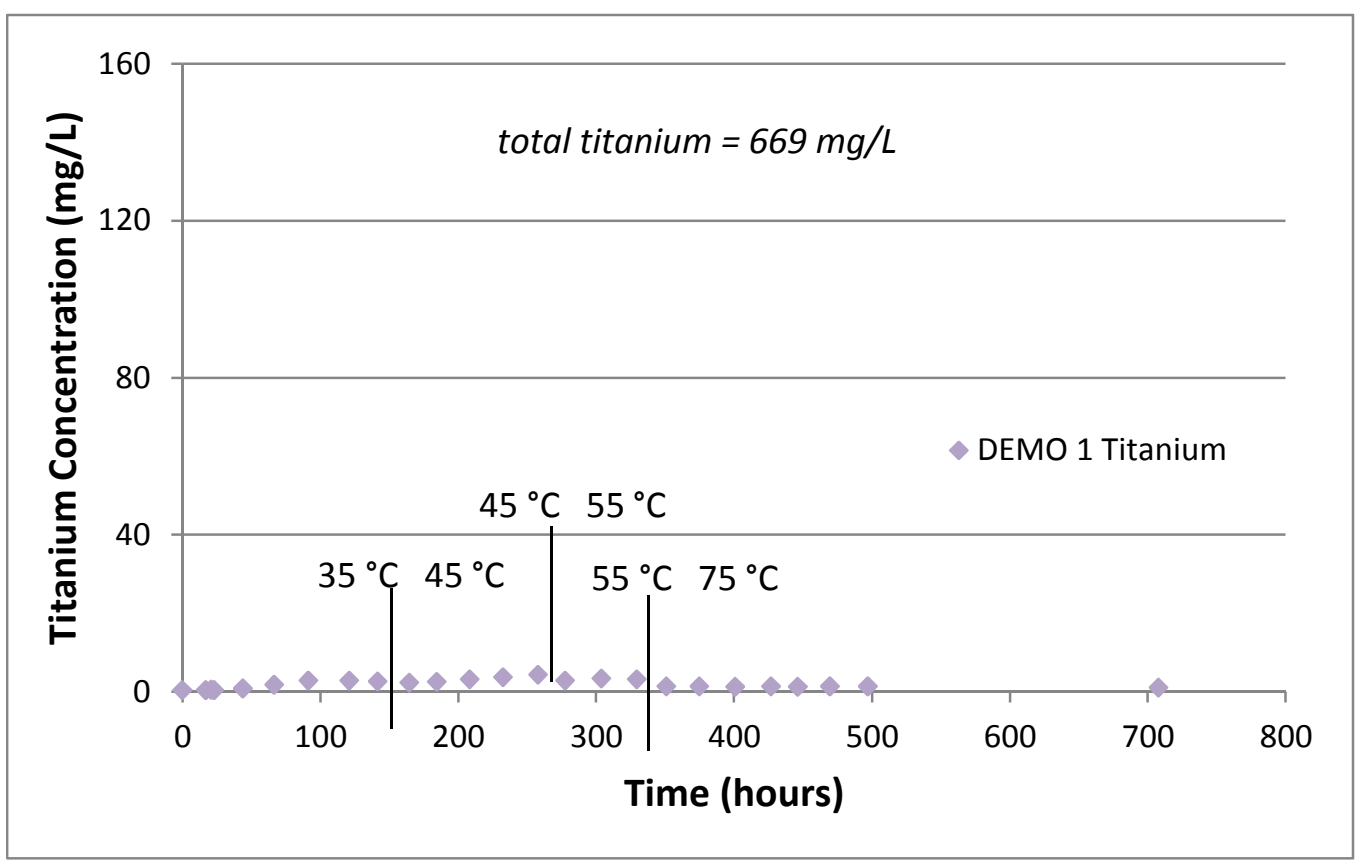

\subsubsection{Analysis of Reactor Bottoms}

After DEMO 1 was complete, the remaining reactor bottom was removed. The amount of recovered material is somewhat dependent on the efficiency of slurry removal (some solids were caked on the upper parts of the reactor or difficult to remove).

Well-mixed duplicate samples of the reactor bottom were analyzed via HPLC, VOA and SVOA. However, due to the elapsed time from the end of the reaction ( 211 hours), and the time of sampling, a filtered sample of the bottom was analyzed via ICPES as a check to see if the reaction had proceeded further. The results of the ICPES analyses are listed in Table 15. These results are corrected for dilution as normal.

There are no statistically significant differences in the boron and potassium results between the two sample sets for any of the reactions. This is indicative of no further TPB destruction occurring in the time interval between the last sample and the check sample. 
SRNL-STI-2012-00342

Revision 0

Table 15. ICPES Check Samples for Demonstration $1(\mathrm{mg} / \mathrm{L})$

\begin{tabular}{|c|c|c|}
\hline Analyte & $\begin{array}{c}\text { Final Filtrate } \\
\text { Result }\end{array}$ & $\begin{array}{c}\text { End of Reaction Period } \\
\text { Sample Result }\end{array}$ \\
\hline $\mathrm{B}$ & 469.8 & 430.4 \\
\hline $\mathrm{K}$ & 2207 & 2173 \\
\hline $\mathrm{Cu}$ & 266.2 & 215.2 \\
\hline $\mathrm{Ti}$ & 0.936 & 1.248 \\
\hline
\end{tabular}

The analytical uncertainty is $10 \%$ for each result.

As no additional destruction occurred, a valid comparison between the ICPES and HPLC results exists. Table 16 lists the HPLC results.

\section{Table 16. HPLC Results from Reactor Bottoms Analysis (mg/L) for Demonstration 1}

\begin{tabular}{|c|c|c|c|c|c|}
\hline TPB & 3PB & 2PB & 1PB & Phenol & \% Destruction \\
\hline $2420(1.17 \%)$ & $<10$ & $<10$ & $<10$ & $<10$ & $84.0-84.4 \%$ \\
\hline
\end{tabular}

The value in parentheses is the \%RSD. The "\% Destruction" column is the calculated percent destruction. The value is based on the mass of TPB added to the simulant slurries and calculation of the mass of TPB in the reactor bottoms, after correcting for the mass of samples removed from the system during the reactions.

Finally, samples of the reactor bottoms were analyzed using VOA and SVOA. See Table 17. The values in parentheses are the \%RSD. In the results column, values that are shaded indicate only one real value with the other being a detection limit result. In this case, the values in parentheses are the analytical uncertainties. The "total organic residuals" are the sum of all the mid-range values of the detected analytes, less benzene. This term is intended to be an estimate of the propensity of the reaction conditions to generate these residual materials. These results are not normalized to the beginning volumes.

Of the residual organics remaining in the reactor bottoms, biphenyl is the most concentrated. Given that this material has been noted as a reaction byproduct before, the presence in these reactions is not surprising.

With respect to the other analytes left in the reactor bottoms, they are almost all partially degraded or functionalized aryl compounds. 
Table 17. VOA and SVOA Results for Demonstration 1

\begin{tabular}{|c|c|}
\hline Analyte & Result (mg/L) \\
\hline benzene & $0.20(0.00 \%)$ \\
\hline biphenyl & $760(81.9 \%)$ \\
\hline p-terphenyl & $40.0(28.3 \%)$ \\
\hline 2-nitrophenol & $30.5(67.2 \%)$ \\
\hline nitrobenzene & $32.8-49.2$ \\
\hline phenol & $6.72-10.1$ \\
\hline 4-nitrobiphenyl & $5.92-8.88$ \\
\hline o-phenylene benzeneboronate & $3.2-4.8$ \\
\hline o-terphenyl & $2.72-4.08$ \\
\hline m-terphenyl & $2.8(0.00 \%)$ \\
\hline Total organic residuals & 898 \\
\hline
\end{tabular}

\subsubsection{Gas Chromatography Results}

During the entire life of DEMO 1, including the $\mathrm{pH}$ adjustment, the off-gas composition was monitored using GC. This enables tracking of important off-gas species such as benzene and $\mathrm{CO}_{2}$ which can potentially provide information on reaction rates. During the $\mathrm{pH}$ adjustment, benzene is produced from hydrolysis of the TPB, while $\mathrm{CO}_{2}$ is from the acid attack on the carbonate in the slurry. During CCPO activity, benzene is less likely to be formed, and $\mathrm{CO}_{2}$ production is from the total degradation of organic compounds.

The major off-gas components are benzene and $\mathrm{CO}_{2}$. The presence of benzene and $\mathrm{CO}_{2}$ are associated with $\mathrm{pH}$ adjustment of the slurry and chemical oxidation of the organic compounds (both gases are evolved throughout the reaction). See Figure 20. 
Figure 20. Gas Release Rates for DEMO 1

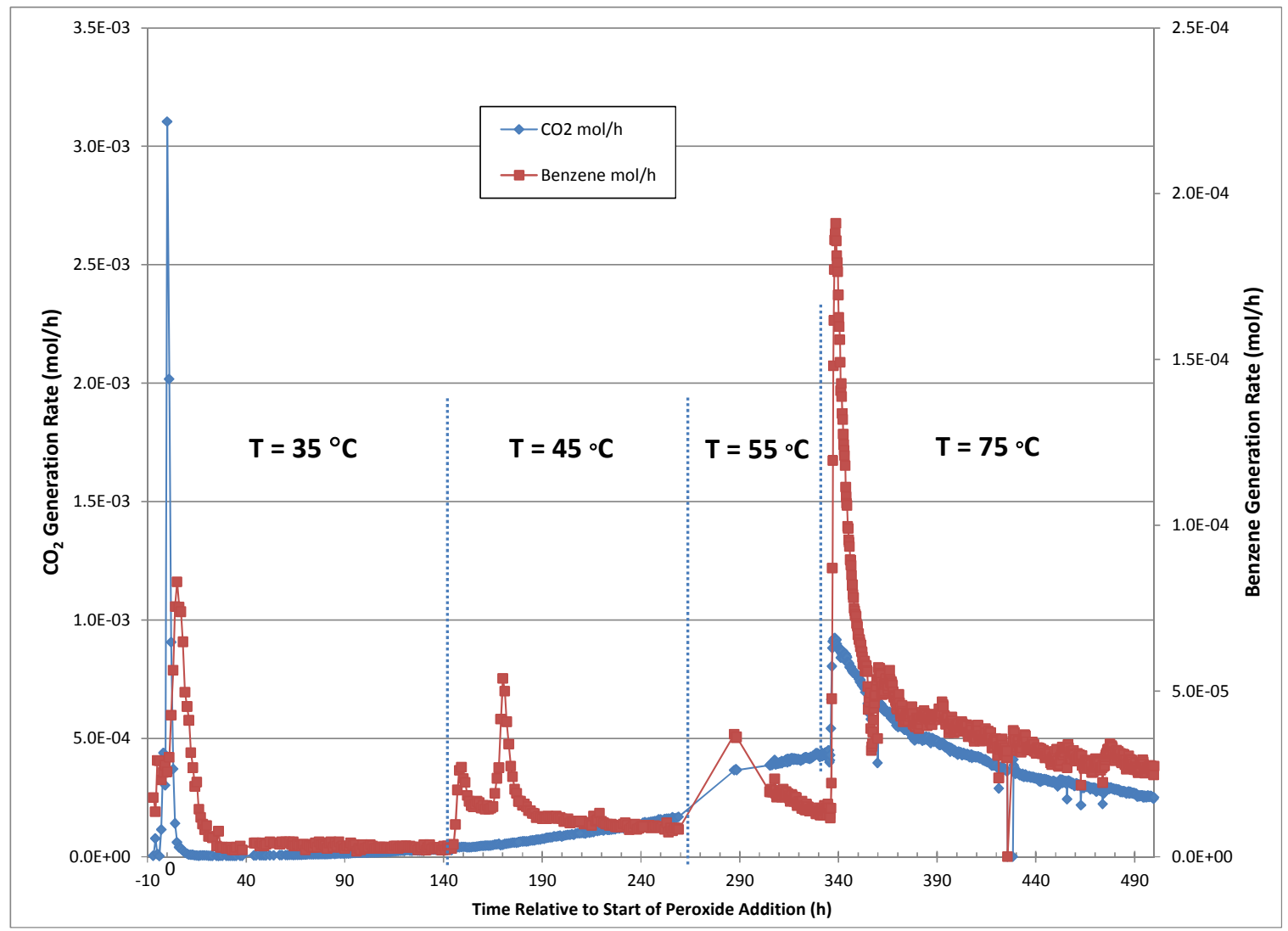

The generation rates of benzene and carbon dioxide are clearly affected by the changes in temperature. At each temperature increase, a corresponding increase in benzene and carbon dioxide gas is observed. The $\mathrm{CO}_{2}$ gas release can be due to two factors decreased solubility as the temperature increases, and increases in generation from the decomposition reactions. The initial spikes in $\mathrm{CO}_{2}$ concentration must be due to the $\mathrm{pH}$ adjustment process, and are more clearly shown in Figure 21.

Figure 21 shows the gas generation from the initiation of GC monitoring to 13 hours into the reaction. The $\mathrm{H}_{2} \mathrm{O}_{2}$ addition and temperature increase to $35^{\circ} \mathrm{C}$ started at time $=0$. The $\mathrm{pH}$ adjustment occurred before time $=0$, and is indicated by the shaded area in Figure 21. 
Figure 21. Gas Release near Time $=0$

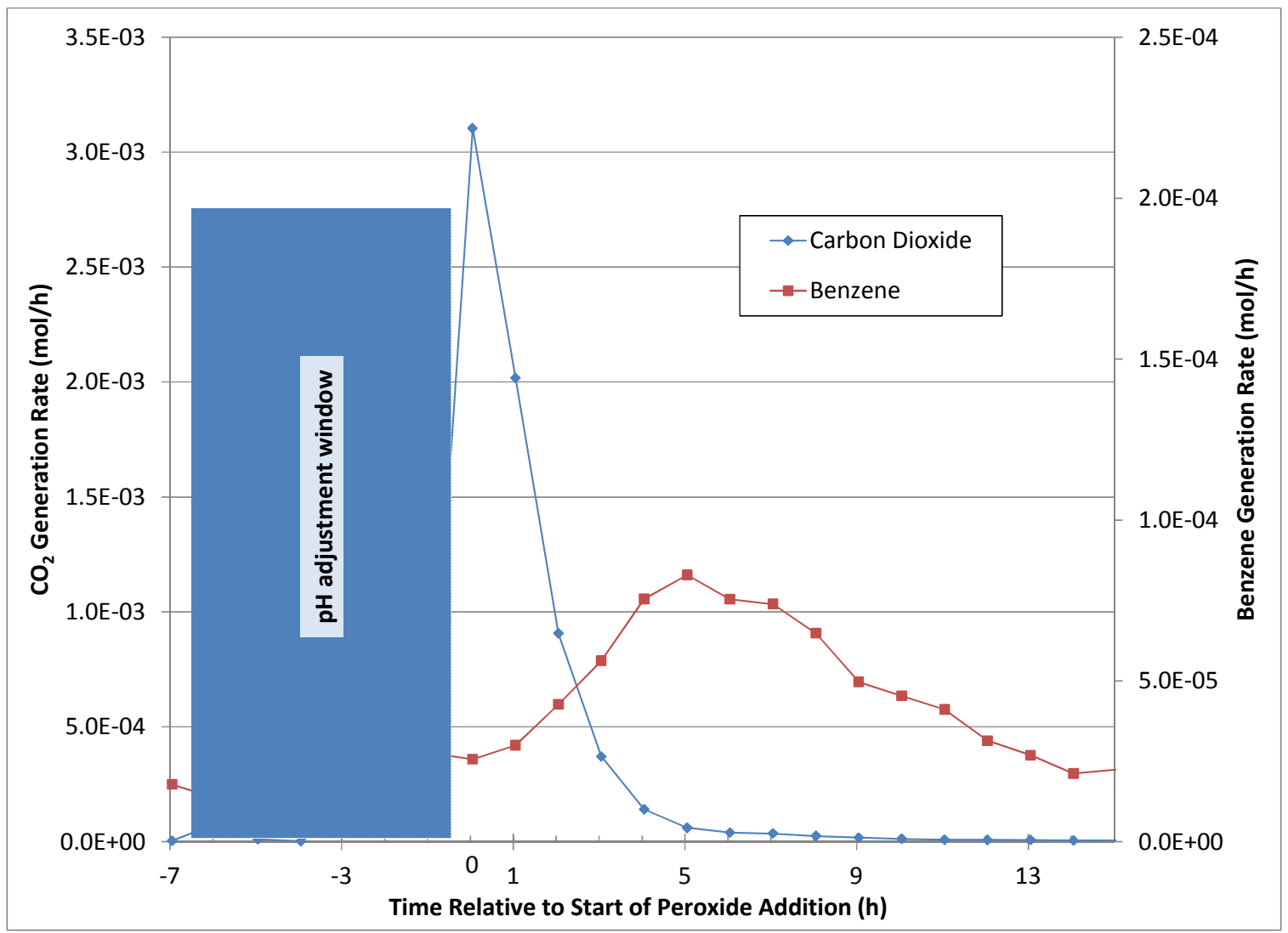

Several important points can be drawn from this graph:

- $\mathrm{CO}_{2}$ evolution occurs slowly about 4 hours after acid addition is commenced (presumed due to acid-carbonate reaction) and then rapidly increases as the $\mathrm{pH}$ adjustment continues. The acid-carbonate reaction continues after the acid is no longer added.

- Even though the benzene is assumed to be produced during acid hydrolysis it is not released until after the almost concurrent increase to reaction temperature and addition of peroxide. Previous work indicates a correlation between temperature increases and increased release of benzene. ${ }^{18}$

- Since such a small amount of peroxide is added in the first hours $(0.2 \mathrm{~mL} /$ hour $)$ it is more likely that the benzene release is associated with increase in temperature. 
- Increased temperature can have two potential effects; increased benzene volatility or decreased gas solubility.

There are complications in further analyzing the off-gas concentrations. Firstly, because acidification occurs in the reactor (as opposed to the 2004 work), it is impossible to deconvolute $\mathrm{CO}_{2}$ generated from acidification of carbonate in the simulant, and $\mathrm{CO}_{2}$ generated from organic oxidation. This is because degassing of the $\mathrm{CO}_{2}$ is not immediate and takes place over time.

In the case of benzene, it is not possible to deconvolute benzene generated during acidification or during the $\mathrm{H}_{2} \mathrm{O}_{2}$ aided destruction. Furthermore, any generated benzene may be degassed from solution, or oxidized as part of a chemical reaction. Finally, as part of the simulant recipe, for each reaction, $44 \mu \mathrm{L}$ of benzene $(0.000495$ moles $)$ is added to the simulant after the acidification, but before the addition of the $\mathrm{H}_{2} \mathrm{O}_{2}$.

In the case of $\mathrm{CO}_{2}$, it is difficult to determine from the graph if this was generated during acidification versus $\mathrm{H}_{2} \mathrm{O}_{2}$ aided destruction, other than to assume that as time progresses the $\mathrm{CO}_{2}$ produced is more likely to be from organic destruction than the acidification. Furthermore, any generated $\mathrm{CO}_{2}$ may be degassed from solution, or oxidized as part of a chemical reaction.

It is possible to use the $\mathrm{GC}$ data in attempt to determine a mass balance for DEMO 1. To do this, it is necessary to determine the moles of benzene and $\mathrm{CO}_{2}$ available in the simulant slurry before $\mathrm{pH}$ addition, and compare this against the moles of benzene and $\mathrm{CO}_{2}$ remaining in the bottoms at the end of the reaction.

Figure 22 shows the cumulative amount of benzene and $\mathrm{CO}_{2}$ detected over the life of the experiment. The graph is also broken into the four different temperature blocks.

From this graph several key points can be determined.

- There is a noticeable temperature effect. Increased temperatures generate more $\mathrm{CO}_{2}$ and benzene. Whether this is from degassing or from generation is impossible to say.

- The amount of benzene produced by the end of the reaction is 0.0117 moles $(0.914$ grams).

- The amount of $\mathrm{CO}_{2}$ produced by the end of the reaction is 0.119 moles. 
SRNL-STI-2012-00342

Revision 0

Figure 22. Cumulative Off-gas Release in Demonstration 1

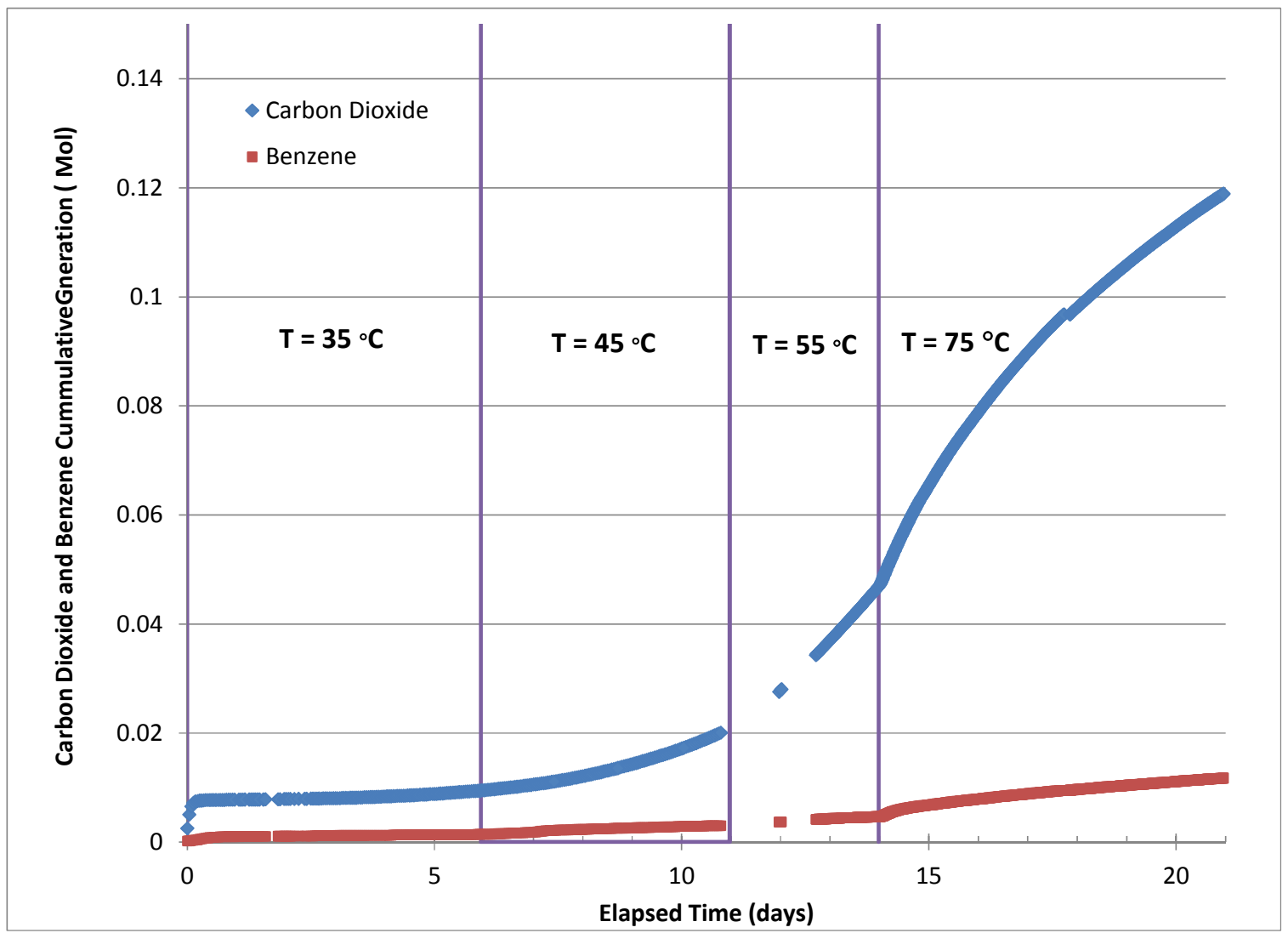

With respect to benzene, from the HPLC and VOA measurements, 0.00474 moles of TPB remains in the reactor bottoms as TPB (as well as a trivial amount of benzene detected from VOA). Each mole of TPB can convert to 4 moles of benzene, for a maximum possible remaining inventory of 0.114 moles of $\mathrm{CO}_{2}{ }^{\mathrm{b}}$

With respect to $\mathrm{CO}_{2}$, a sample of the DEMO 1 bottoms was analyzed by TIC/TOC. The TIC (total inorganic carbon - assumed to be carbonate ${ }^{16,17}$ ) result indicated that 0.098 moles of carbonate remained in the reactor bottoms.

From the reactor bottoms, SVOA analysis provided a result of $898 \mathrm{mg} / \mathrm{L}$ of residual organics, the bulk of which is in the form of biphenyl. For the sake of simplicity, if it is

${ }^{\mathrm{b}}$ For the moment, the initial added quantities of biphenyl and phenol will be ignored for the sake of clarity. At a later point a more complete carbon balance will be performed when the IC-anions results have been received. 
assumed that all of this is biphenyl, this converts to a maximum possible remaining inventory of 0.0438 moles of $\mathrm{CO}_{2}$.

Against these observations, the initial inventory of benzene was calculated. Each $500 \mathrm{~mL}$ of simulant slurry has a maximum benzene inventory of 0.12 moles (this includes the 44 $\mu \mathrm{L}$ of benzene added just before time $=0$ ). The GC measured only 0.0117 moles of benzene over the life of the reaction and so it can be concluded that $\sim 9.7 \%$ of the potential benzene inventory left the system as benzene. Ideally, no benzene should leave the system.

The inventory of carbonate was calculated. Each slurry starts with 0.290 moles of carbonate. This serves as a possible inventory for an equimolar amount of $\mathrm{CO}_{2}$, as any decrease in the carbonate concentration in the slurry must be due to the $\mathrm{pH}$ adjustment (carbonate $\rightarrow \mathrm{CO}_{2}$ ).

For DEMO 1 the starting carbonate amount is 0.290 moles, and by the end of the reaction, the amount left over is 0.098 moles. Therefore, the difference, 0.192 moles, was lost from $\mathrm{pH}$ adjustment. This carbonate was converted to $\mathrm{CO}_{2}$ and left the system.

The slurry used in DEMO 1, as generated, also contained 0.0300 moles of TPB. Under ideal conditions, if all of the phenyl groups in the TPB were converted into $\mathrm{CO}_{2}$, this would allow for a maximum $\mathrm{CO}_{2}$ generation of 0.72 moles of $\mathrm{CO}_{2}$.

Now it is possible to calculate the amount of $\mathrm{CO}_{2}$ that was actually created during DEMO 1. The maximum possible amount is 0.72 moles. To this value must be added the $\mathrm{CO}_{2}$ that was produced from the conversion of carbonate to $\mathrm{CO}_{2}$ which occurred during the $\mathrm{pH}$ adjustment, or 0.192 moles, for a total of 0.912 moles. From this total, the known remains in the bottoms must be subtracted:

- 0.114 moles from the residual TPB (HPLC)

- 0.0438 moles from the residual other organics (SVOA)

- 0.069 moles from the benzene that the GC measured

This gives a calculated amount of created $\mathrm{CO}_{2}$ of 0.658 moles. ${ }^{\mathrm{c}}$ The remaining carbonate is not subtracted since this material should not be further converted to $\mathrm{CO}_{2}$ through the action of the CCPO.

The GC only detected 0.119 moles, or $\sim 18 \%$ of the calculated $\mathrm{CO}_{2}$ produced.

\footnotetext{
${ }^{c}$ Again, this is intended as a rough measurement. The production of oxalate and formate results would affect this value.
} 
Potential losses from the system due to leaks are being investigated to account for the differential.

\subsection{7 pH Monitoring}

$\mathrm{pH}$ was monitored during the reaction (see Figure 23).

The chemical reactions appear to drive towards a final $\mathrm{pH}$ of about 9. SRNL is currently considering the possible reasons for this result.

Figure 23. pH Readings for Demonstration 1

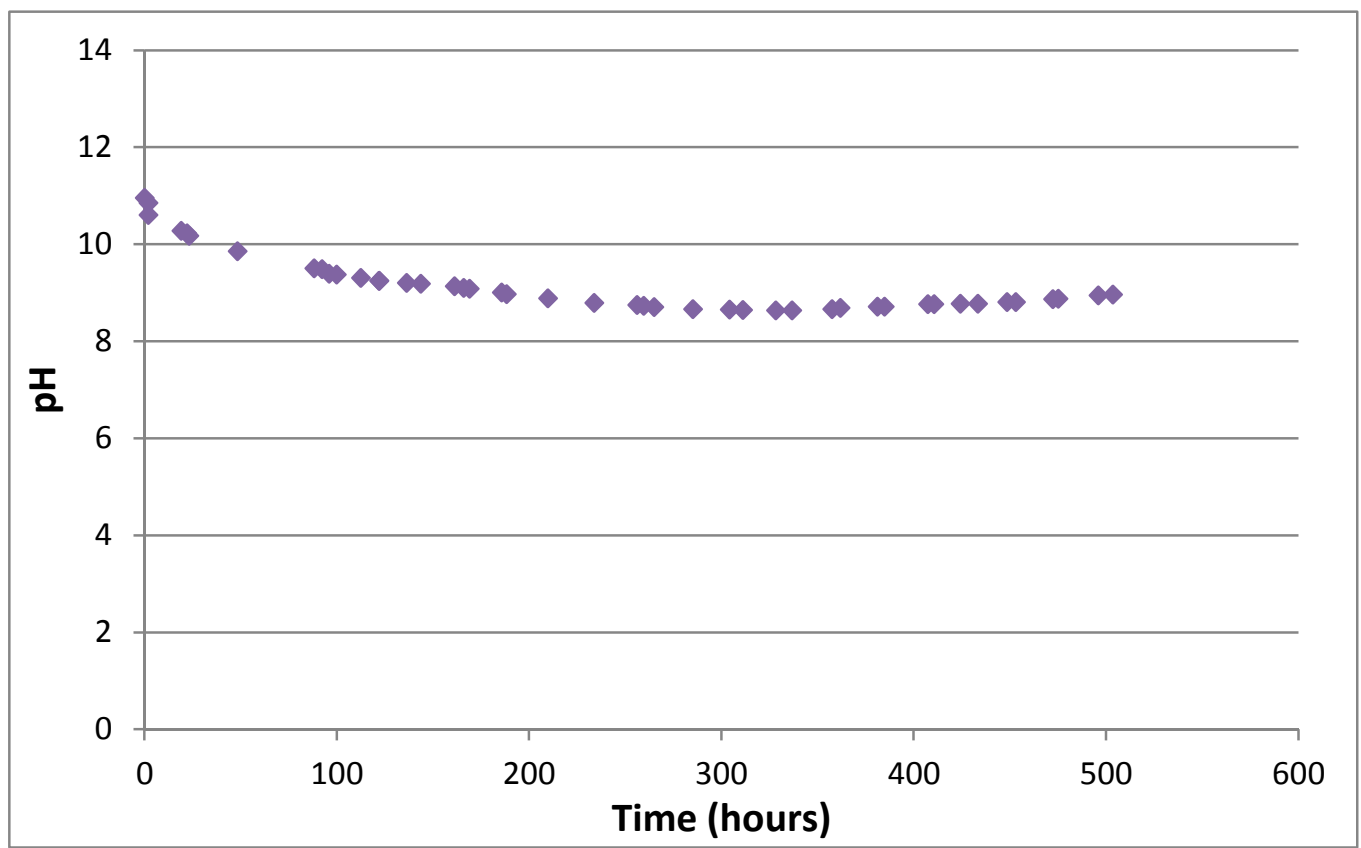

\subsubsection{Conclusion}

DEMO 1 did not lead to complete destruction. However, the ICPES data indicates some unique behavior. Boron and potassium indicate a decline in the rate of TPB destruction at the point of the temperature increase to $75^{\circ} \mathrm{C}$, and copper and titanium show a decline in concentration during the same temperature transition. It seems unlikely that these observations are coincidental. SRNL believes that at $75^{\circ} \mathrm{C}$, the rate of autodecomposition of the $\mathrm{H}_{2} \mathrm{O}_{2}$ may become severe enough that it is essentially depleted from the reaction. In the absence of the $\mathrm{H}_{2} \mathrm{O}_{2}$ (and subsequent chemical oxidation of TPB) the rate of ingrowth of soluble boron and potassium would decrease. 
With respect to the copper, this test resulted in copper filtrate concentrations much higher than previous tests. The method of addition was the same in all cases, and potential causes of the higher copper concentration for this particular reaction have not been determined.

There was no significant effect on the titanium. Concentrations started low, and stayed low during the entire lifetime of the test.

\subsection{Effect of Lower $\mathrm{pH}$ Conditions}

Up to this time, all the tests have been conducted at $\mathrm{pH} 11$. This is due to a legacy restriction of operating in-situ in Tank $48 \mathrm{H}$, where corrosion of the carbon steel tanks would have been a concern. The strike tanks in Building 241-96H are made of stainless steel and the $\mathrm{pH}$ requirements are less restrictive. Thus, as part of the process optimization strategy the effects of utilizing $\mathrm{pH} 7$ and 9 were investigated.

A pair of new tests (also referred to as "Test 1b" and "Test 1c") were assembled using the same general conditions as previous tests except SRNL and the customer selected two new $\mathrm{pH}$ parameters ( $\mathrm{pH} 7$ for Test $1 \mathrm{c}$ and $\mathrm{pH} 9$ for Test $1 \mathrm{~b}$ ) to use in an experiment to determine the effects of starting $\mathrm{pH}$ on the extent of reaction. The same reaction vessels as detailed previously were used (see Sections 3.3 and 3.4).

Two bottles of $500 \mathrm{~mL}$ of slurry were generated according to the recipe, and poured into separate vessels. One slurry was adjusted with $50 \mathrm{wt} \%(10.4 \mathrm{M})$ nitric acid to a final $\mathrm{pH}$ of 9 . The second slurry was adjusted to a $\mathrm{pH}$ of 7 . To the bottle, the copper catalyst was added in the form of $\mathrm{Cu}\left(\mathrm{NO}_{3}\right)_{2} \bullet 2.5 \mathrm{H}_{2} \mathrm{O}$, with a target copper concentration of $500 \mathrm{mg} / \mathrm{L}$. Active temperature control was provided by the thermal baths. Both reactions were conducted at a constant $50{ }^{\circ} \mathrm{C}$. Both reactions were conducted at the same time to facilitate sample timing. Due to a procedural error, the addition of the $44 \mu \mathrm{L}$ of benzene was omitted in these two experiments.

Hydrogen peroxide was added at the rates used in the 2004 work, after scaling for volume differences, $0.2 \mathrm{~mL} / \mathrm{hour}$.

Each test ran approximately 20 days. Filtrate samples were removed once per day. A total of 19 samples were removed for analysis by ICPES.

\subsubsection{Soluble Boron Results}

After the start of the $\mathrm{H}_{2} \mathrm{O}_{2}$ addition the boron in the filtrate samples increased over time. See Figure 24. 
Figure 24. Boron Concentration Comparison Between pH 7 and 9 Reactions

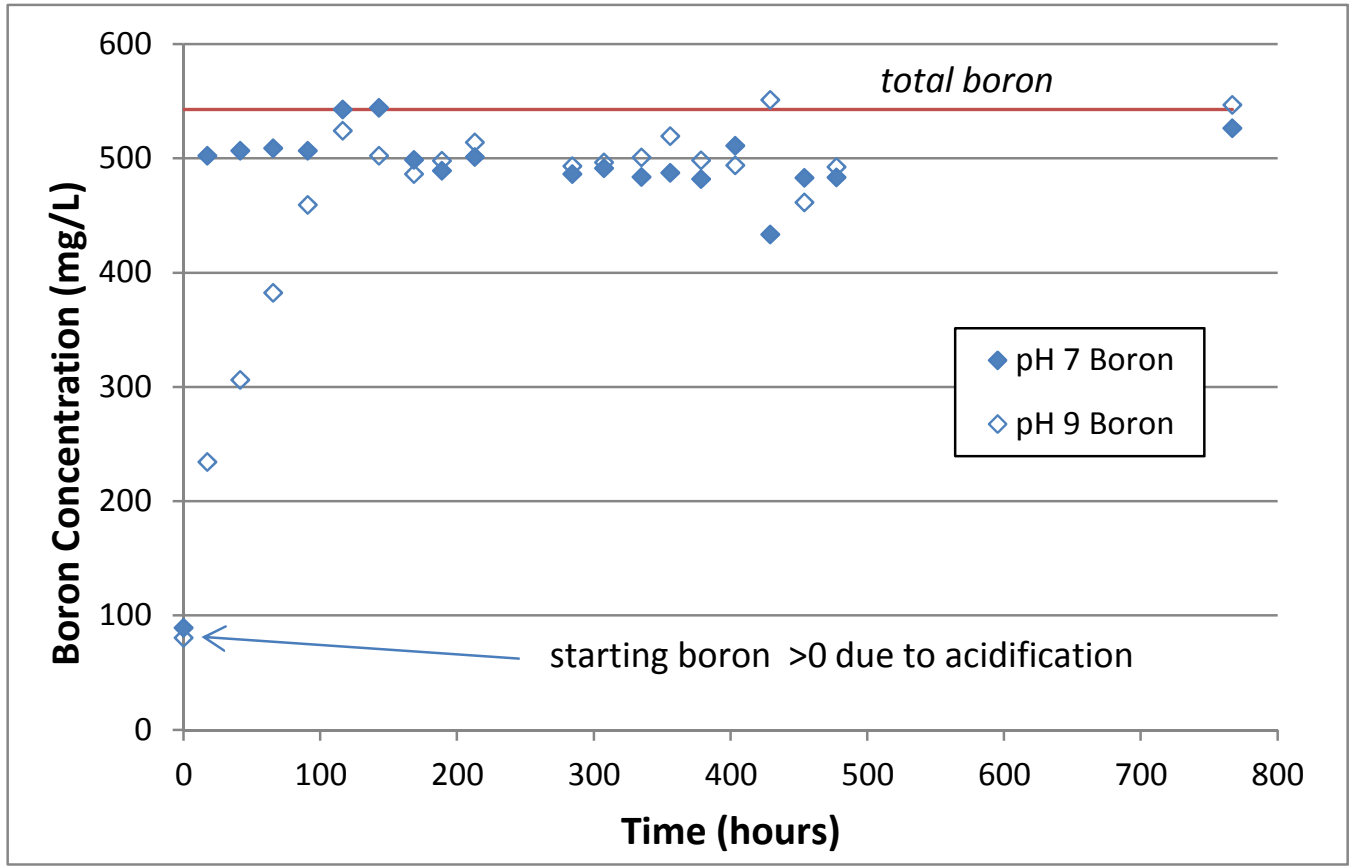

The reaction was halted after 478 hours, and the extent of boron dissolution associated with the acid hydrolysis and peroxide oxidation reactions was calculated using the same methodology as in Section 3.1.1 (see Table 18). The final data point at $\mathrm{t}=767$ hours is from the confirmation sample from the reactor bottoms (see Section 3.5.5) and is not used in the percent destruction calculation.

Table 18. Total TPB Destruction from Final Boron Results for Initial pH of 7 and 9

\begin{tabular}{|c|c|cc|cc|}
\hline \multicolumn{2}{|c|}{ Destruction by Acid } & \multicolumn{2}{c|}{ Destruction by $\mathrm{H}_{2} \mathrm{O}_{2}$} & \multicolumn{2}{c|}{ Total Destruction } \\
\hline $\mathrm{pH} 7$ & $\mathrm{pH} 9$ & $\mathrm{pH} \mathrm{7}$ & $\mathrm{pH} 9$ & $\mathrm{pH} \mathrm{7}$ & $\mathrm{pH} \mathrm{9}$ \\
\hline $14.9-18.2 \%$ & $13.3-16.2 \%$ & $64.4-82.7 \%$ & $66.8-85.1 \%$ & $81.1-99.2 \%$ & $81.6-100 \%$ \\
\hline
\end{tabular}

At $\mathrm{pH} 7$ and $\mathrm{pH} 9$ complete TPB destruction (per boron soluble concentrations) was achieved after approximately 1 and 5 days, respectively. The increased destruction kinetics at $\mathrm{pH} 7$ cannot be directly attributed to the $\mathrm{pH}$ adjustment since both reactions produced a typical amount of destruction for that step. Rather, the addition of the copper and increased temperature initiated a rapid chemical degradation. Even though the reactions have not technically liberated $100 \%$ of the boron into solution, the fact that both reactions plateau at the same point (average of $91-95 \%$ destruction) yields confidence that all of the TPB has been degraded. 


\subsubsection{Soluble Potassium Results}

As in previous experiments, the potassium in solution was measured as an indicator of organic destruction. After the start of the $\mathrm{H}_{2} \mathrm{O}_{2}$ addition the potassium in the filtrate samples increased over time. See Figure 25.

From the potassium data, the same trends are found in the boron data, including the evidence of a much faster reaction at $\mathrm{pH} 7$.

The reaction was halted after 478 hours, and the extent of potassium dissolution associated with the acid hydrolysis and peroxide oxidation reactions was calculated using the same methodology as in Section 3.1.1 (see Table 19). The final data point at $t=767$ hours is from the confirmation sample from the reactor bottoms (see Section 3.4.5) and is not used in the percent destruction calculation.

Table 19. Total TPB Destruction from Potassium Results for Initial pH of 7 and 9

\begin{tabular}{|cc|cc|cc|}
\hline \multicolumn{2}{|c|}{ Destruction by Acid } & \multicolumn{2}{|c|}{ Destruction by $\mathrm{H}_{2} \mathrm{O}_{2}$} & \multicolumn{2}{c|}{ Total Destruction } \\
\hline $\mathrm{pH} \mathrm{7}$ & $\mathrm{pH} \mathrm{9}$ & $\mathrm{pH} \mathrm{7}$ & $\mathrm{pH} \mathrm{9}$ & $\mathrm{pH} \mathrm{7}$ & $\mathrm{pH} \mathrm{9}$ \\
\hline $39.4-51.3 \%$ & $31.8-42.0 \%$ & $64.3-94.5 \%$ & $56.1-82.2 \%$ & $111-139 \%$ & $94.1-118 \%$ \\
\hline
\end{tabular}

Figure 25. Potassium Concentrations for the $\mathrm{pH} 7$ and 9 Reactions

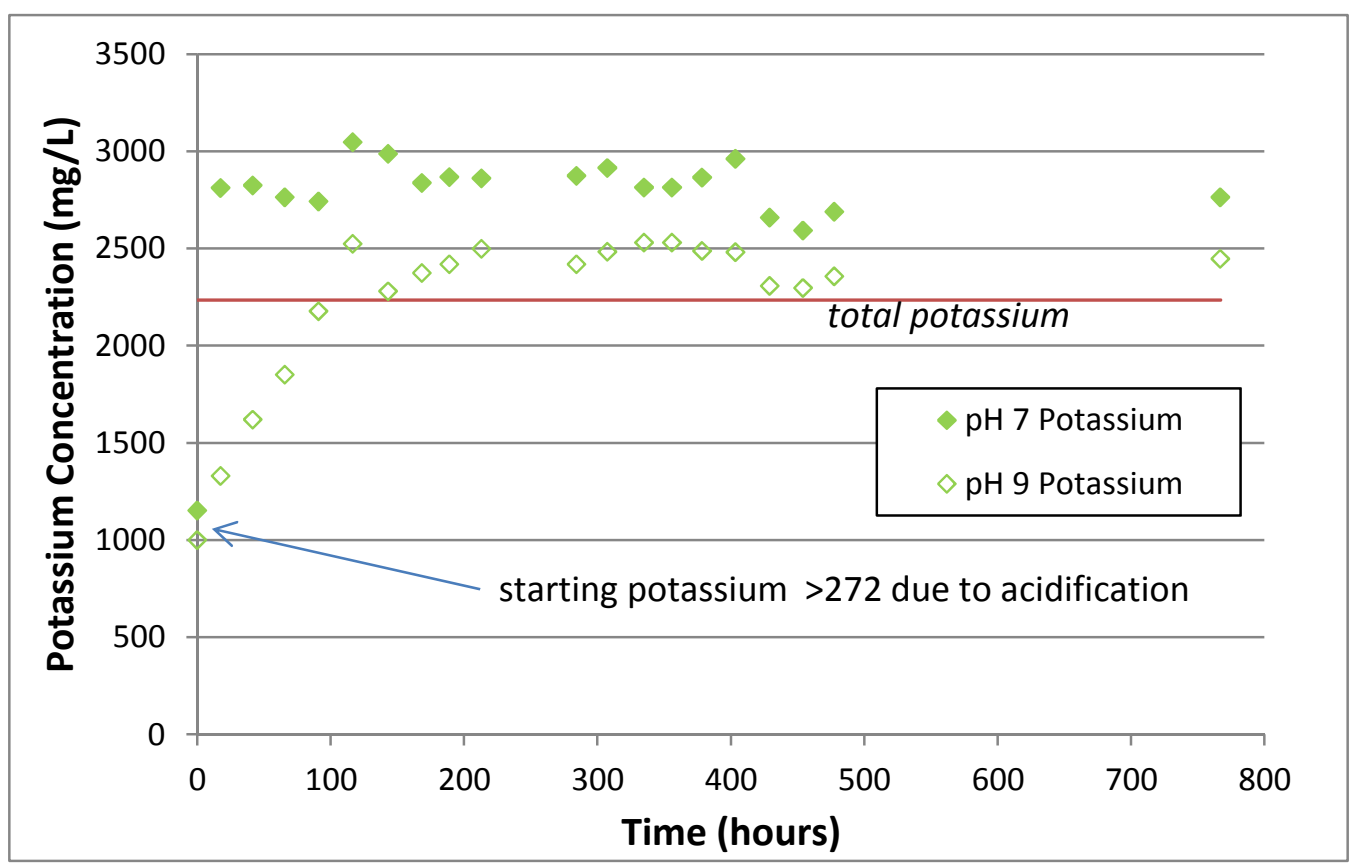


While the $\mathrm{pH} 9$ reaction potassium concentration is slightly high by the end $(112 \%$ destruction), it is within the sum of the analytical uncertainties of the two ICPES results required to derive the final percentage destruction. The $\mathrm{pH} 7$ reaction is outside the analytical uncertainty sums. Initially, the reason for the high potassium values in the $\mathrm{pH}$ 7 reaction could not be determined. After further examination of the log sheets, and the $\mathrm{pH}$ data (see Section 3.5.6 below) it was determined that 19 hours into the reaction the $\mathrm{pH}$ probe began giving readings that were anomalously high. The probe was removed at $\sim 94$ hours into the reaction and it was determined that the probe was physically damaged by excessive contact with the agitator shaft, which resulted in a hole being abraded into the inner shaft of the $\mathrm{pH}$ probe. $\mathrm{pH}$ probes typically contain a solution of $\mathrm{KCl}$. Once a hole was made in the probe, the $\mathrm{KCl}$ would be free to leak into the reaction vessel. Assuming the anomalously high $\mathrm{pH}$ readings indicate the time of damage and leaking, then this happened at some point between 3 and 19 hours into the reaction (overnight). This early leak of potassium would then be reflected in all further samples, which was the observation made in the reaction sample results.

Therefore, SRNL believes that the $\mathrm{pH} 7$ high potassium reaction results are a reflection of the $\mathrm{pH}$ probe failure, but still indicate complete TPB destruction.

\subsubsection{Soluble Copper Results}

The copper concentrations in the filtrate were monitored for the reasons outlined in Section 3.1.3. After the start of the $\mathrm{H}_{2} \mathrm{O}_{2}$ addition the copper in the filtrate samples slowly increased over time. See Figure 26.

These two reactions provide the same approximate results as for the previous reactions (other than DEMO 1). Copper solubility averages $\sim 100 \mathrm{mg} / \mathrm{L}$ over the duration of the experiment, after a gradual ramp up to those concentrations. Processing at $\mathrm{pH} 9$ appears to provide slightly higher copper concentrations throughout the tests. 
SRNL-STI-2012-00342

Revision 0

Figure 26. Copper Concentration Results for $\mathrm{pH} 7$ and 9 Reactions

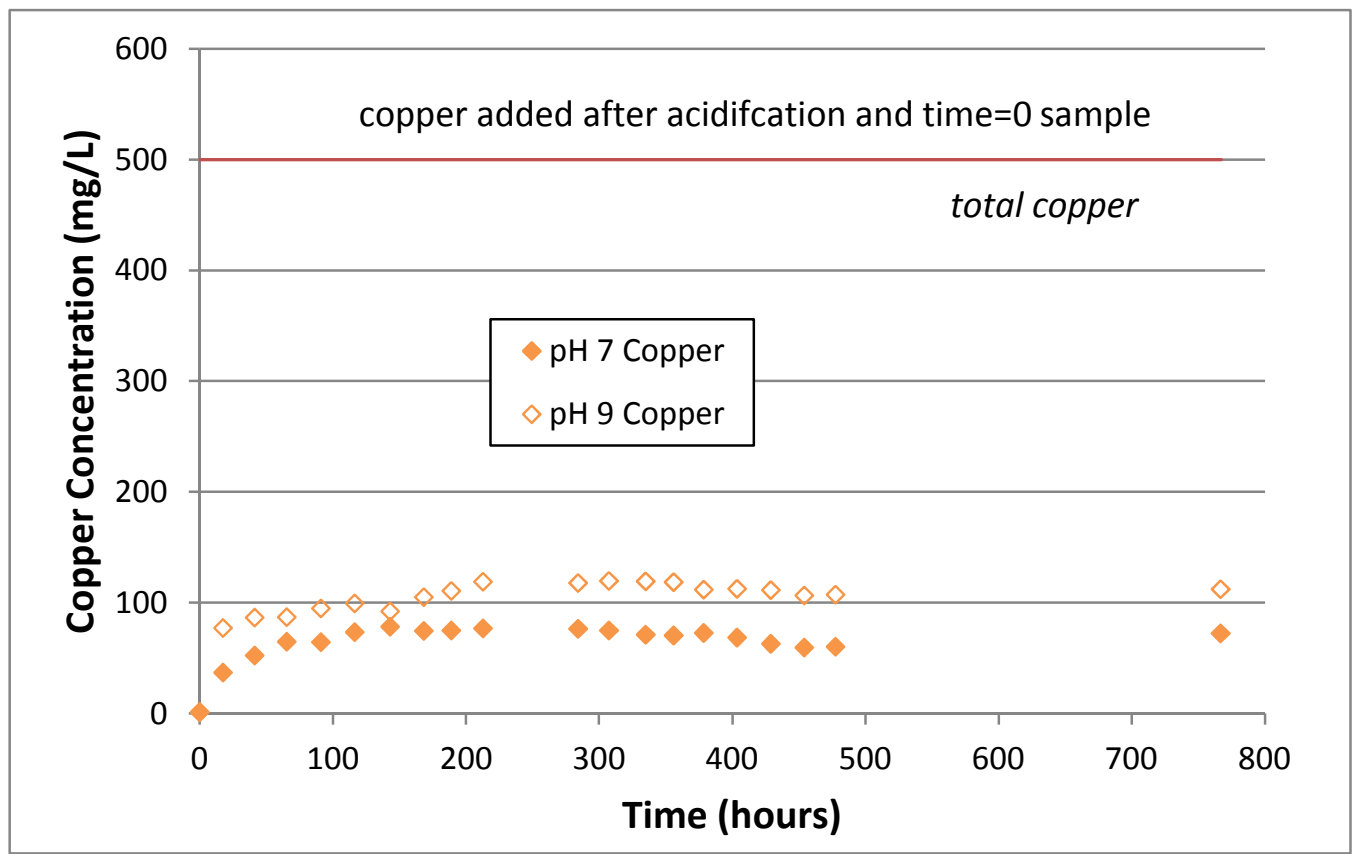

\subsubsection{Soluble Titanium Results}

The titanium concentration in solution is monitored for the reasons outlined in Section 3.1.4. See Figure 27.

The titanium data indicates that the $\mathrm{pH}$ difference has a virtually negligible effect on the titanium concentration. In all cases, the titanium concentrations were below $10 \mathrm{mg} / \mathrm{L}$. 
Figure 27. Titanium Concentration Results for pH 7 and 9 Experiments

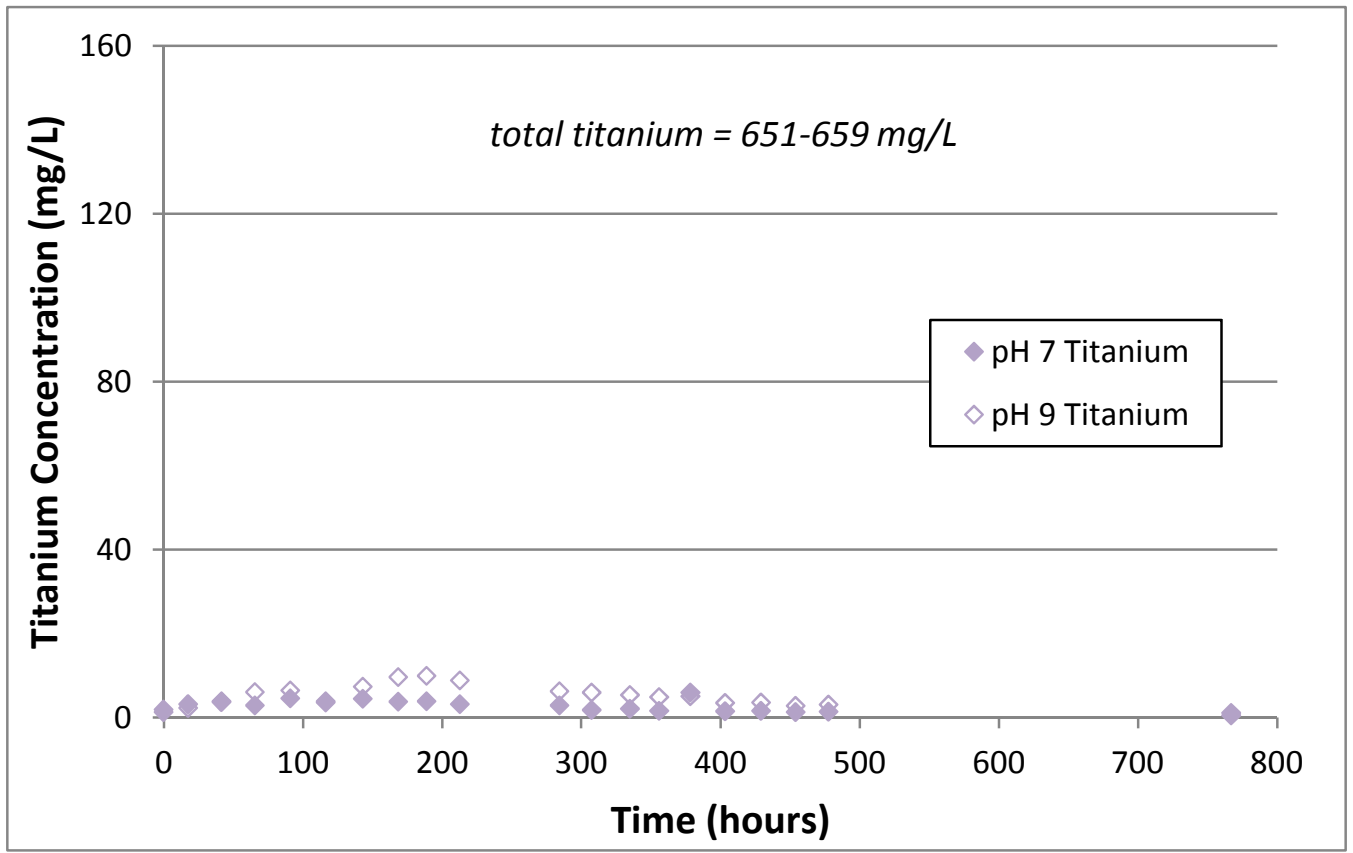

\subsubsection{Analysis of Reactor Bottoms}

After the $\mathrm{pH} 7$ and 9 reactions were complete, the reactor bottoms were removed. The amount of recovered material is somewhat dependent on the efficiency of slurry removal (some solids were caked on the upper parts of the reactor or difficult to remove).

From the bottle of bottoms, well-mixed (in an attempt to ensure homogeneity) duplicate samples were analyzed via HPLC, VOA and SVOA. However, due to the elapsed time from the end of the reaction ( 290 hours), and the time of sampling, a filtered sample of the bottoms was also analyzed via ICPES as a check to see if the reaction had proceeded further. The results of the ICPES analyses are listed in Table 20. The results for the four important analytes $(\mathrm{B}, \mathrm{K}, \mathrm{Cu}, \mathrm{Ti})$ are given next to the chronologically previous sample results. These results are corrected for dilution as normal.

There are no statistically significant differences in the boron and potassium results between the two sample sets for any of the reactions. 
Table 20. ICPES Check Samples (mg/L) for Varying Initial pH Reactions

\begin{tabular}{|c|c|c|c|}
\hline Reaction & Analyte & $\begin{array}{c}\text { Final Filtrate } \\
\text { Result }\end{array}$ & $\begin{array}{c}\text { End of Reaction Period } \\
\text { Sample Result }\end{array}$ \\
\hline \multirow{3}{*}{ pH 7 } & $\mathrm{B}$ & 526.2 & 483.3 \\
\cline { 2 - 4 } & $\mathrm{K}$ & 2762 & 2688 \\
\cline { 2 - 4 } & $\mathrm{Cu}$ & 71.95 & 60.20 \\
\cline { 2 - 4 } & $\mathrm{Ti}$ & $<0.49$ & 1.33 \\
\hline \multirow{3}{*}{$\mathrm{pH} \mathrm{9}$} & $\mathrm{B}$ & 546.7 & 492.5 \\
\cline { 2 - 4 } & $\mathrm{K}$ & 2446 & 2355 \\
\cline { 2 - 4 } & $\mathrm{Cu}$ & 111.8 & 106.8 \\
\cline { 2 - 4 } & $\mathrm{Ti}$ & 1.06 & 2.99 \\
\hline
\end{tabular}

The analytical uncertainty is $10 \%$ for each result.

As there is no detectable additional destruction occurring, a valid comparison existed between the ICPES and HPLC results. Table 21 lists the HPLC results.

Table 21. HPLC Results from Reactor Bottoms Analyses (mg/L)

\begin{tabular}{|c|c|c|c|c|c|c|}
\hline Reaction & TPB & 3PB & 2PB & 1PB & Phenol & \% Destruction \\
\hline pH 7 & $<10$ & $<10$ & $<10$ & $<10$ & $<10$ & $>99.9 \%$ \\
\hline pH 9 & $<10$ & $<10$ & $<10$ & $<10$ & $<10$ & $>99.9 \%$ \\
\hline
\end{tabular}

The "\% Destruction" column is the calculated percent destruction. The value is based on the mass of TPB added to the simulant slurries and calculation of the mass of TPB in the reactor bottoms, after correcting for the mass of samples removed from the system during the reactions.

Given the very rapid destruction indicated by the boron and potassium data, less than detectable levels of all the HPLC analytes were anticipated.

Samples of the reactor bottoms were analyzed using VOA and SVOA (see Tables 22 and 23). The values in parentheses are the \%RSD. In the results column, values that are shaded indicate only one real value with the other being a detection limit result. In this case, the values in parentheses are the analytical uncertainties. In the analyte column, shaded cells indicate the presence of that analyte is doubtful due to chemical conditions or interferences. The "total organic residuals" are the sum of all the mid-range values of the detected analytes, less benzene and the analytes that are declared to be from interferences. The "total organic residuals" are the sum of all the detected analytes, less benzene and the analytes that are declared to be from interferences. This term is intended to be a rough indicator of the propensity of the reaction conditions to generate these residual materials. These results are not normalized to the beginning volumes. 
Table 22. VOA and SVOA Results for pH 7 Reaction

\begin{tabular}{|c|c|}
\hline Analyte & Result (mg/L) \\
\hline benzene & $<0.05$ \\
\hline biphenyl & $195(39.9 \%)$ \\
\hline 2,4-dinitro-N-phenylbenzeneamine & $45.5(82.4 \%)$ \\
\hline 2-nitro-N-4-nitrophenylbenzeneamine & $42.4-63.6$ \\
\hline 2-methyl-4,6-diphenylpyridine & $29.6-44.4$ \\
\hline 1,2-ditrobenzene & $34(0.00 \%)$ \\
\hline 1,2-dinitrobenzene & $27.2-40.8$ \\
\hline $\mathrm{N}, \mathrm{N}$-diphenylbenzeneamine & $29.7(126 \%)$ \\
\hline diisooctyladipate & $19.2-28.8$ \\
\hline diphenylamine & $20.00(7.07 \%)$ \\
\hline p-terphenyl & $19.0(22.3 \%)$ \\
\hline o-terphenyl & $17(0.00 \%)$ \\
\hline 2,3,4-trinitrodiphenylamine & $10.2(66.6 \%)$ \\
\hline 4-nitro-N-phenylbenzeneamine & $5.25(25.6 \%)$ \\
\hline Diphenyl(2-pyridyl)methanol & $5.05(4.20 \%)$ \\
\hline diphenyl ether & $4.90(11.5 \%)$ \\
\hline 2-nitro-N-phenylbenzenamine & $3.15(2.25 \%)$ \\
\hline azobenzene & $1.92-2.88$ \\
\hline $1,1,2,1,4,1$-quaterphenyl & $2.00(28.3 \%)$ \\
\hline Total organic residuals & 518 \\
\hline
\end{tabular}

Of the residual organics left in the reactor bottoms, biphenyl is the most concentrated and the presence of a fair concentration of various amines is noted. Considering that biphenyl fouling, or amine deposition may be an issue in the real facility, efficient destruction of these compounds are an important consideration.

It would appear that driving the starting $\mathrm{pH}$ to below 11 provides superior biphenyl destruction. In the thermal reactions (Section 3.3.3), the $50{ }^{\circ} \mathrm{C}$ test $(\mathrm{pH} 11)$ gave a final biphenyl concentration of $940 \mathrm{mg} / \mathrm{L}$. The equivalent $\mathrm{pH} 9$ reaction gave $29 \mathrm{mg} / \mathrm{L}$ and the equivalent $\mathrm{pH} 7$ reaction gave $195 \mathrm{mg} / \mathrm{L}$. It may be that a starting $\mathrm{pH}$ of 9 is the ideal starting point to minimize residual biphenyl though this result will require verification.

As for the other analytes left in the reactor bottoms, they are almost all partially degraded or functionalized aryl compounds. It is very difficult to define any trend in these analytes, other than to note that the $\mathrm{pH} 7$ reaction gave about $2.5 \times$ the amount of residuals compared to the $\mathrm{pH}$ reaction. 
Table 23. VOA and SVOA Results for pH 9 Reaction

\begin{tabular}{|c|c|}
\hline Analyte & Result (mg/L) \\
\hline benzene & $<0.05$ \\
\hline 4-methyl-3-hexanol & $35.2-52.8$ \\
\hline 3-aminobiphenyl & $30.4-45.6$ \\
\hline [1,1]biphenyl-3-amine & $25.6-38.4$ \\
\hline biphenyl & $29.0(19.5 \%)$ \\
\hline p-terphenyl & $26(27.2 \%)$ \\
\hline m-terphenyl & $13.6-20.4$ \\
\hline o-terphenyl & $10.1(12.6 \%)$ \\
\hline diphenyl ether & $8.25(19.7 \%)$ \\
\hline 2,4-dinitro-N-phenylbenzeneamine & $8.20(5.17 \%)$ \\
\hline 2-nitro-N-(2-nitrophenylbenzeneamine) & $5.95(3.57 \%)$ \\
\hline diphenylamine & $4.4-6.6$ \\
\hline 2-phenoxybiphenyl & $4.08-6.12$ \\
\hline N, N-diphenylbenzeneamine & $3.52-5.28$ \\
\hline 2-phenoxy, 1,1-biphenyl & $3.52-5.28$ \\
\hline 4-methyl-1-heptanol & $3.12-4.68$ \\
\hline 2,3,4-trinitrodiphenylamine & $2.32-3.48$ \\
\hline 4-nitro-N-(4-nitrophenyl)bezeneamine & $2.16-3.24$ \\
\hline 4-nitrophenyl)diphenylamine & $1.92-2.88$ \\
\hline 4-nitro-N-phenylbenzeneamine & $1.12-1.68$ \\
\hline 1,1,2,1,4,1-quaterphenyl & $0.68-1.02$ \\
\hline Total organic residuals & 199 \\
\hline
\end{tabular}

\subsection{6 pH Monitoring}

$\mathrm{pH}$ was monitored during the reaction (see Figure 28).

As with DEMO 1, the $\mathrm{pH}$ in both reactions trended towards a final $\mathrm{pH}$ of 9 - from both high and lower initial $\mathrm{pH}$ values.

As late as 19 hours into the $\mathrm{pH} 7$ reaction, the $\mathrm{pH}$ probe readings increased suddenly to 10 and higher. This was unanticipated behavior given previous results, and upon replacing the probe at 94 hours, it was observed that the $\mathrm{pH}$ probe had been physically damaged by contact with the agitator (see Section 3.5.2). After replacing the $\mathrm{pH}$ probe, the readings returned to what was considered typical. 
Figure 28. pH Readings for Lower pH Reactions

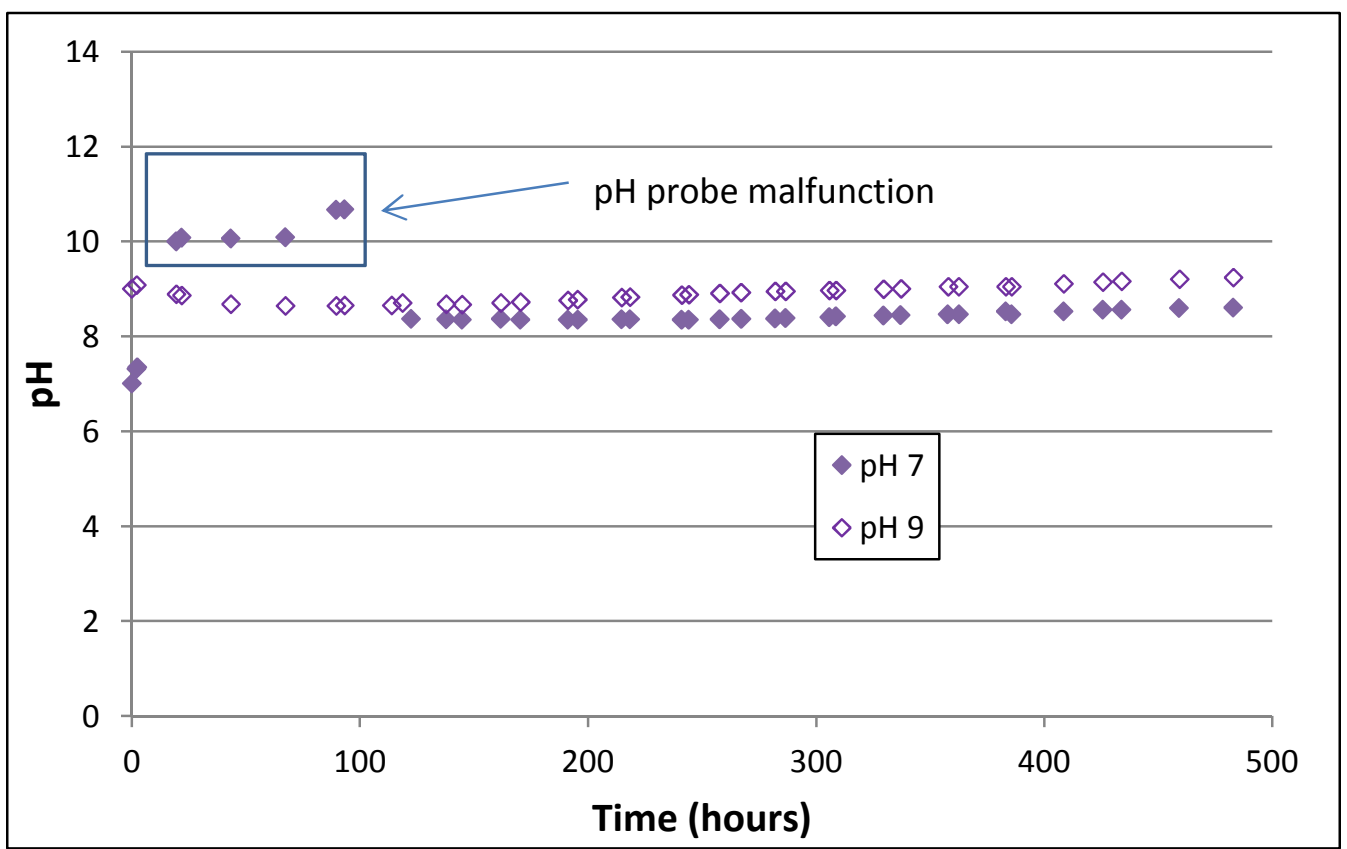

\subsubsection{Conclusion}

The $\mathrm{pH} 7$ and 9 experiments both gave rapid and complete destruction of the KTPB slurries. By the end of the reactions, there were no traces of organic materials by HPLC, and SVOA analysis indicated only small quantities of the partially degraded or functionalized aryl compounds, which are more than likely due to the $\mathrm{pH}$ adjustment process. The $\mathrm{pH} 7$ reaction resulted in larger quantities of residuals so from this perspective, the $\mathrm{pH} 9$ starting $\mathrm{pH}$ is preferential.

For both reactions, the destruction was complete in a significantly shorter time-frame than would be required to add a stoichiometric amount of $\mathrm{H}_{2} \mathrm{O}_{2}$ at the $0.2 \mathrm{~mL} / \mathrm{h}$ addition rate. For the $\mathrm{pH} 7$ reaction, $<5 \mathrm{~mL}$ of $\mathrm{H}_{2} \mathrm{O}_{2}$ had been added by the time of complete destruction, and for the $\mathrm{pH}$ experiment, $<24 \mathrm{~mL}$. This makes it quite likely that hydrolysis (TPB to benzene) is the dominant initial reaction mechanism.

With respect to the copper, once again only $20 \%$ of the added copper was present in a soluble form. There was no significant effect on the titanium. Concentrations started low, and stayed low during the entire lifetime. 


\subsection{DEMONSTRATION 2}

The TTQAP for this work calls for formal demonstrations after DEMO 1, although by this point, all the reactions use the same equipment and methodology for each test. Therefore, the title "DEMONSTRATION" implies no further differences from a "test".

This experiment used the same reaction vessel and temperature control (at $50^{\circ} \mathrm{C}$ ) as described in Section 3.4. Other experimental details were as described in previous Sections. It was noted that the "prototypical mixing" is in fact, very poor compared to reactions performed in poly bottles with a magnetic stirrer. The agitation was insufficient to prevent a semi-stable floating solids mass. This may affect the overall reaction efficiency.

Hydrogen peroxide was added at $0.4 \mathrm{~mL} /$ hour $(2 \times)$.

The test continued for approximately 20 days. Filtrate samples were pulled one per day. A total of 22 samples were removed for analysis by ICPES. From the ICPES results, boron, potassium, copper, sodium, and titanium concentrations were examined.

Results from each test were compared to establish potential differences in reactivity.

\subsubsection{Soluble Boron Results}

After the start of the $\mathrm{H}_{2} \mathrm{O}_{2}$ addition the boron in the filtrate samples increased over time. See Figure 29.

Figure 29. Boron Concentration Results for Demonstration 2

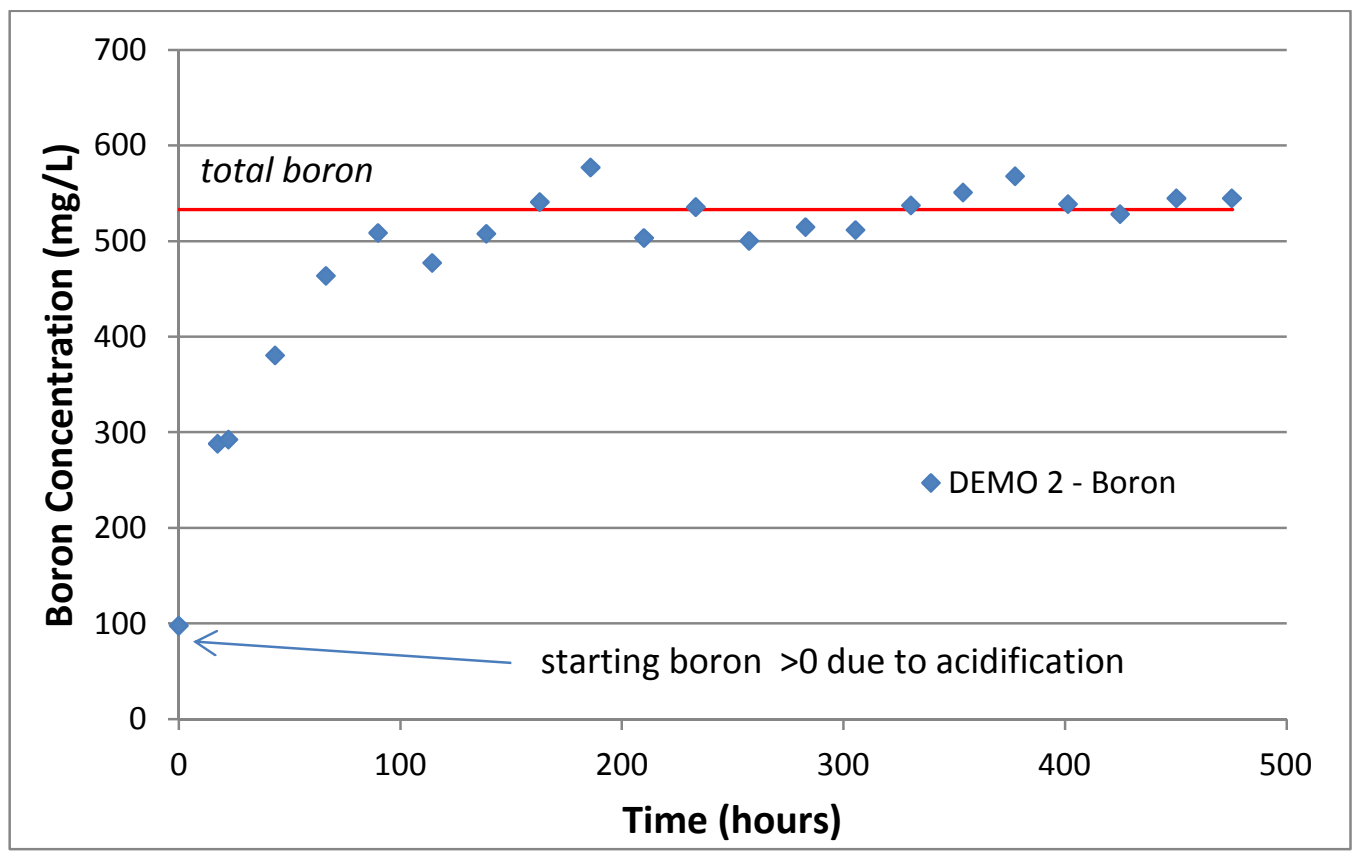


The reaction was halted after 476 hours, and the extent of boron dissolution associated with the acid hydrolysis and the peroxide oxidation reaction was calculated using the same methodology as in Section 3.1.1 (see Table 24). A final data point at $t=937$ hours from the confirmation sample from the reactor bottoms (see Section 3.6.5) is not shown for clarity and is not used in the percent destruction calculation.

Table 24. Total TPB Destruction from Final Boron Results: Demonstration 2

\begin{tabular}{|c|c|c|}
\hline Destruction by Acid & Destruction by $\mathrm{H}_{2} \mathrm{O}_{2}$ & Total Destruction \\
\hline $16.4-20.1 \%$ & $73.5-94.3 \%$ & $91.9-112 \%$ \\
\hline
\end{tabular}

By 90 hours the TPB destruction was complete. This is comparable, though slightly faster, than the most equivalent previous reaction (see Section 3.5.1, $\mathrm{pH} 9$ reaction).

\subsubsection{Soluble Potassium Results}

After the start of the $\mathrm{H}_{2} \mathrm{O}_{2}$ addition the potassium in the filtrate samples increased over time. See Figure 30.

Figure 30. Potassium Concentration Results for Demonstration 2

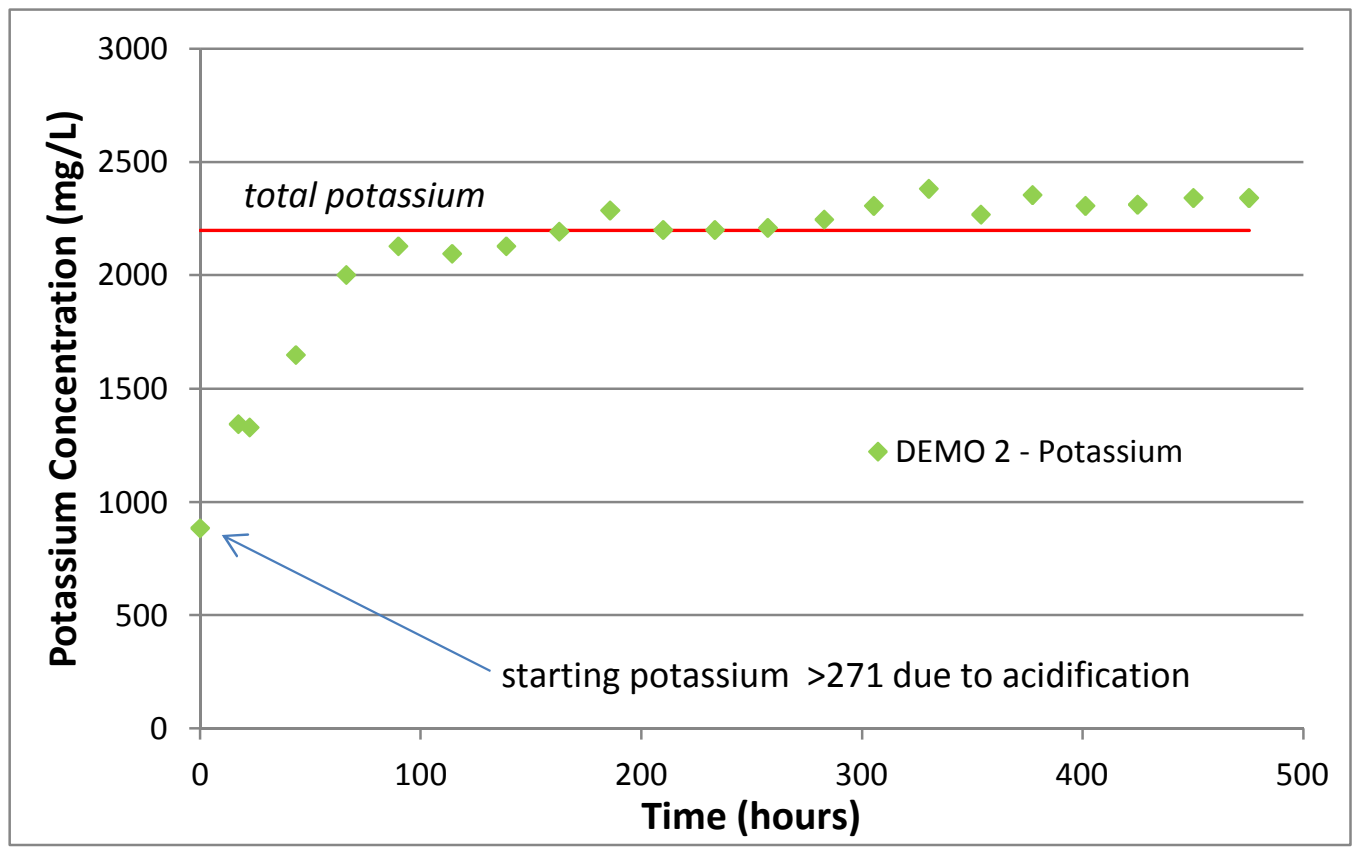


The reaction was halted after 476 hours, and the extent of boron dissolution associated with the acid hydrolysis and the peroxide oxidation reaction was calculated using the same methodology as in Section 3.1.1 (see Table 25). The final data point at $t=937$ hours is from the confirmation sample from the reactor bottoms (see Section 3.6.5) and is not used in the \%destruction calculation.

\section{Table 25. Total TPB Destruction from Potassium Results: Demonstration 2}

\begin{tabular}{|c|c|c|}
\hline Destruction by Acid & Destruction by $\mathrm{H}_{2} \mathrm{O}_{2}$ & Total Destruction \\
\hline $27.2-36.4 \%$ & $63.7-88.7 \%$ & $95.3-120 \%$ \\
\hline
\end{tabular}

As with the boron data, the destruction appeared complete after $\sim 90$ hours.

\subsubsection{Soluble Copper Results}

After the start of the $\mathrm{H}_{2} \mathrm{O}_{2}$ addition the copper in the filtrate samples quickly increased near the reaction start, then remained stable. See Figure 31.

Figure 31. Copper Concentration Results for Demonstration 2

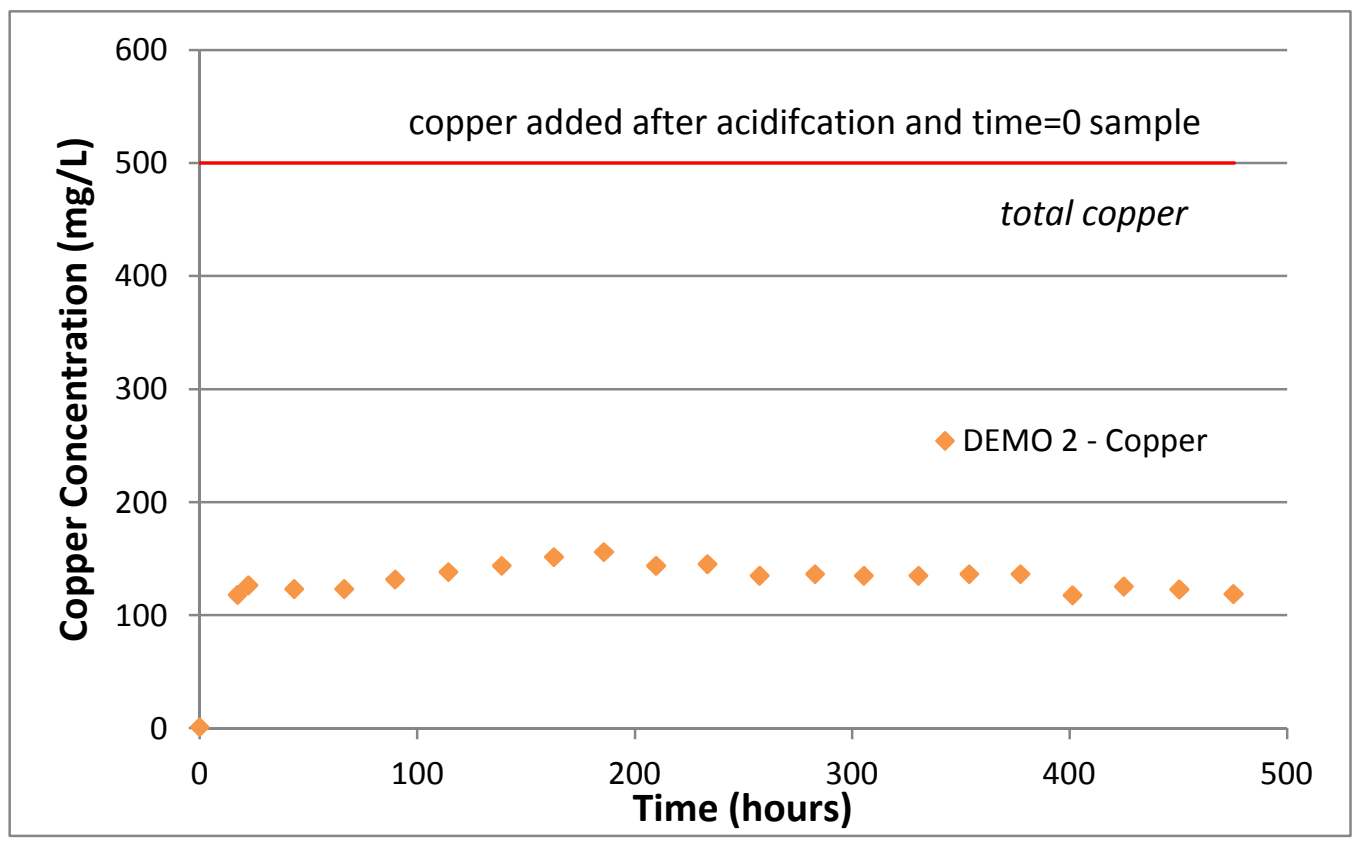

The copper results show a fairly similar pattern to most of the previous tests, although slightly higher in magnitude. 
SRNL-STI-2012-00342

Revision 0

\subsubsection{Soluble Titanium Results}

The titanium in solution is monitored for the reasons outlined in Section 3.1.4 (see Figure 32).

The titanium results are very typical, with a maximum of $\sim 20 \mathrm{mg} / \mathrm{L}$. The data shows a slow decline from the peak value.

Figure 32. Titanium Concentration Results for Demonstration 2

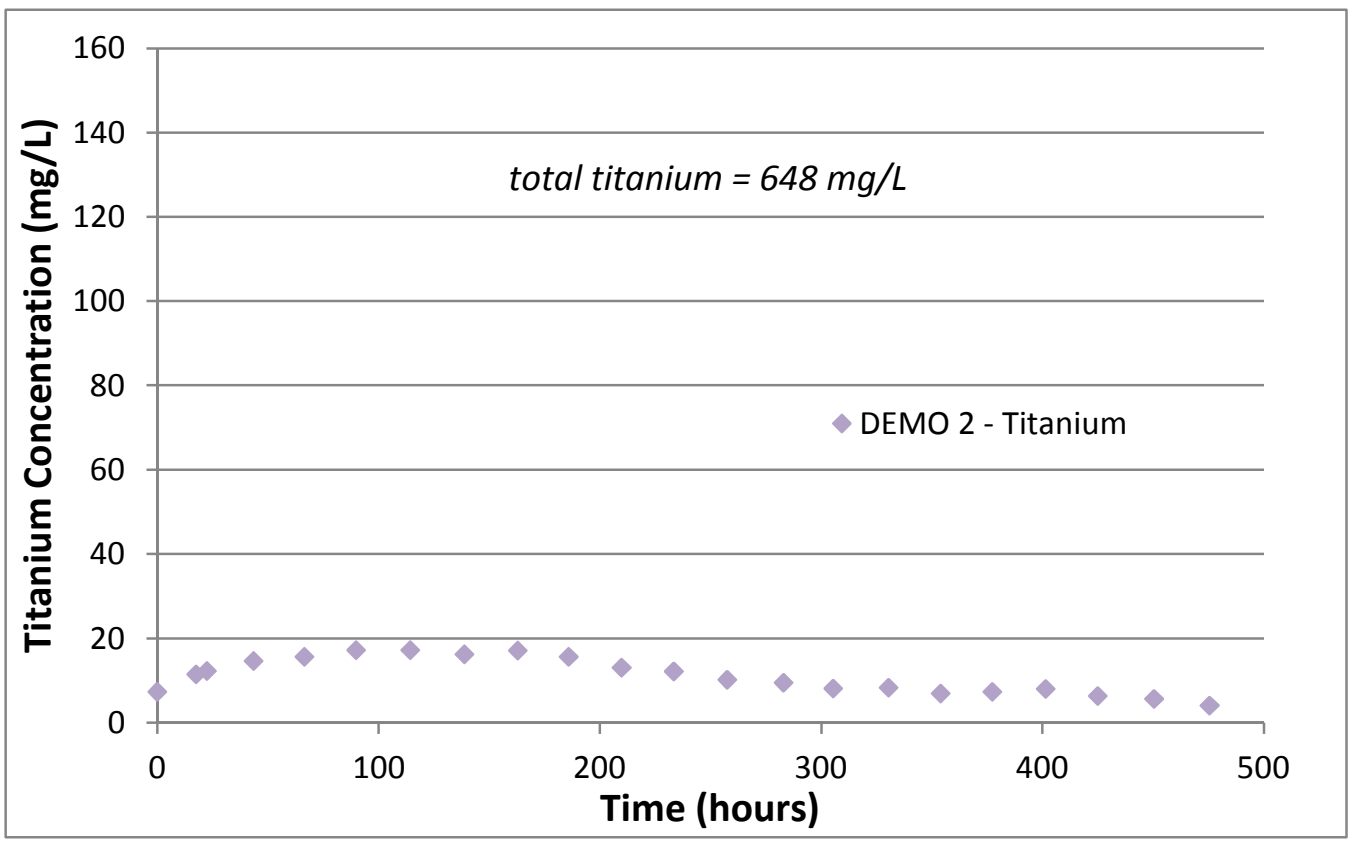

\subsubsection{Analysis of Reactor Bottoms}

After the reaction was complete, the reactor bottoms were removed. The amount of recovered material is somewhat dependent on the efficiency of slurry removal (some solids were caked on the upper parts of the reactor or difficult to remove).

From the bottle of bottoms, well-mixed (in an attempt to ensure homogeneity) duplicate samples were analyzed via HPLC, VOA and SVOA. However, due to the elapsed time from the end of the reaction ( $\sim 462$ hours), and the time of sampling, a filtered sample of the bottoms was also analyzed via ICPES as a check to see if the reaction had proceeded 
further. The results of the ICPES analyses are listed in Table 26. The results for the four important analytes $(\mathrm{B}, \mathrm{K}, \mathrm{Cu}, \mathrm{Ti})$ are given next to the chronologically previous sample results. These results are corrected for dilution as normal.

There are no statistically significant differences in the boron and potassium results between the two sample sets for any of the reactions. The titanium results showed a drop in titanium soluble concentrations, which is consistent with the trend displayed in previous titanium data.

Table 26. ICPES Check Samples (mg/L) for Demonstration 2

\begin{tabular}{|c|c|c|}
\hline Analyte & $\begin{array}{c}\text { Final Filtrate } \\
\text { Result }\end{array}$ & $\begin{array}{c}\text { End of Reaction Period } \\
\text { Sample Result }\end{array}$ \\
\hline $\mathrm{B}$ & 513.9 & 544.5 \\
\hline $\mathrm{K}$ & 2294 & 2341 \\
\hline $\mathrm{Cu}$ & 102.8 & 118.4 \\
\hline $\mathrm{Ti}$ & $<1.54$ & 4.02 \\
\hline
\end{tabular}

The analytical uncertainty is $10 \%$ for each result.

As there is no evidence for additional destruction, a valid comparison between the ICPES and HPLC results exists. Table 27 lists the HPLC results.

Table 27. HPLC Results from Reactor Bottoms Analyses (mg/L) for Demonstration 2

\begin{tabular}{|c|c|c|c|c|c|}
\hline TPB & 3PB & 2PB & 1PB & Phenol & \% Destruction \\
\hline$<4$ & $<4$ & $<4$ & $<4$ & $<4$ & $>99.9 \%$ \\
\hline
\end{tabular}

The "\% Destruction" column is the calculated percent destruction. The value is based on the mass of TPB added to the simulant slurries and calculation of the mass of TPB in the reactor bottoms, after correcting for the mass of samples removed from the system during the reactions.

While previous results have a HPLC detection limit of $10 \mathrm{mg} / \mathrm{L}$, the analyst had been investigating methods to further improve the detection limit. This work resulted in a decrease of the detection limit to $4 \mathrm{mg} / \mathrm{L}$ (see Appendix B).

Given the very rapid destruction indicated by the boron and potassium data, less than detectable concentrations of all the HPLC analytes were anticipated after almost 500 hours of CCPO processing. 
Samples of the reactor bottoms were analyzed using VOA and SVOA. See Table 28. The values in parentheses are the \%RSD. In the results column, values that are shaded indicate only one real value with the other being a detection limit result. In this case, the values in parentheses are the analytical uncertainties. In the analyte column, shaded cells indicate the presence of that analyte is doubtful due to chemical conditions or interferences. The "total organic residuals" are the sum of all the mid-range values of the detected analytes, less benzene and the analytes that are declared to be from interferences. This term is intended to be a rough indicator of the propensity of the reaction conditions to generate these residual materials. These results are not normalized to the beginning volumes.

Table 28. VOA and SVOA Results for Demonstration 2

\begin{tabular}{|c|c|}
\hline Analyte & Result (mg/L) \\
\hline benzene & $<0.05$ \\
\hline biphenyl & $16.0(35.4 \%)$ \\
\hline [1,1-biphenyl]-3-amine & $30.4-45.6$ \\
\hline diisooctyl adipate & $35.5(41.8 \%)$ \\
\hline p-terphenyl & $8.85(7.19 \%)$ \\
\hline m-terphenyl & $4.96-7.44$ \\
\hline diphenyl amine & $4.05(40.2 \%)$ \\
\hline o-terphenyl & $3.35(52.8 \%)$ \\
\hline diphenyl ether & $2.55(41.6 \%)$ \\
\hline 2-phenoxy-1,1-biphenyl & $1.44-2.16$ \\
\hline 2-nitro-N-(2-nitrophenyl)benzeneamine & $1.2-1.8$ \\
\hline N, N diphenylbenzeneamine & $0.8-1.2$ \\
\hline Total organic residuals & 83.3 \\
\hline
\end{tabular}

The diisooctyl adipate is a known plasticizer and is more than likely leachate from contact with a plastic surface.

As for the other analytes left in the reactor bottoms, they are almost all partially degraded or functionalized aryl compounds. It is very difficult to locate any trend in these analytes. It is interesting to note that the number and total amounts of these materials are less than seen in previous tests.

\subsubsection{Gas Chromatography Results}

For the duration of the experiment, including the $\mathrm{pH}$ adjustment, the off-gas composition was monitored using GC. This enabled the important off-gas species such as benzene 
and $\mathrm{CO}_{2}$ to be tracked which can help determine how the organics are being broken down. See Figure 33.

All the concerns listed in regards to the GC data in Section 3.4.6 also pertain here. First, because of in-reactor acidification (as opposed to the 2004 work), it is impossible to deconvolute $\mathrm{CO}_{2}$ generated from acidification of carbonate in the simulant, and $\mathrm{CO}_{2}$ generated from organic oxidation. This is because degassing of the $\mathrm{CO}_{2}$ is not immediate and takes place over time. Second, the reactor vessel cannot be made gastight (the physical design has penetrations that cannot be completely sealed) and leaks are probable.

Figure 33. Gas Release Rates for Demonstration 2

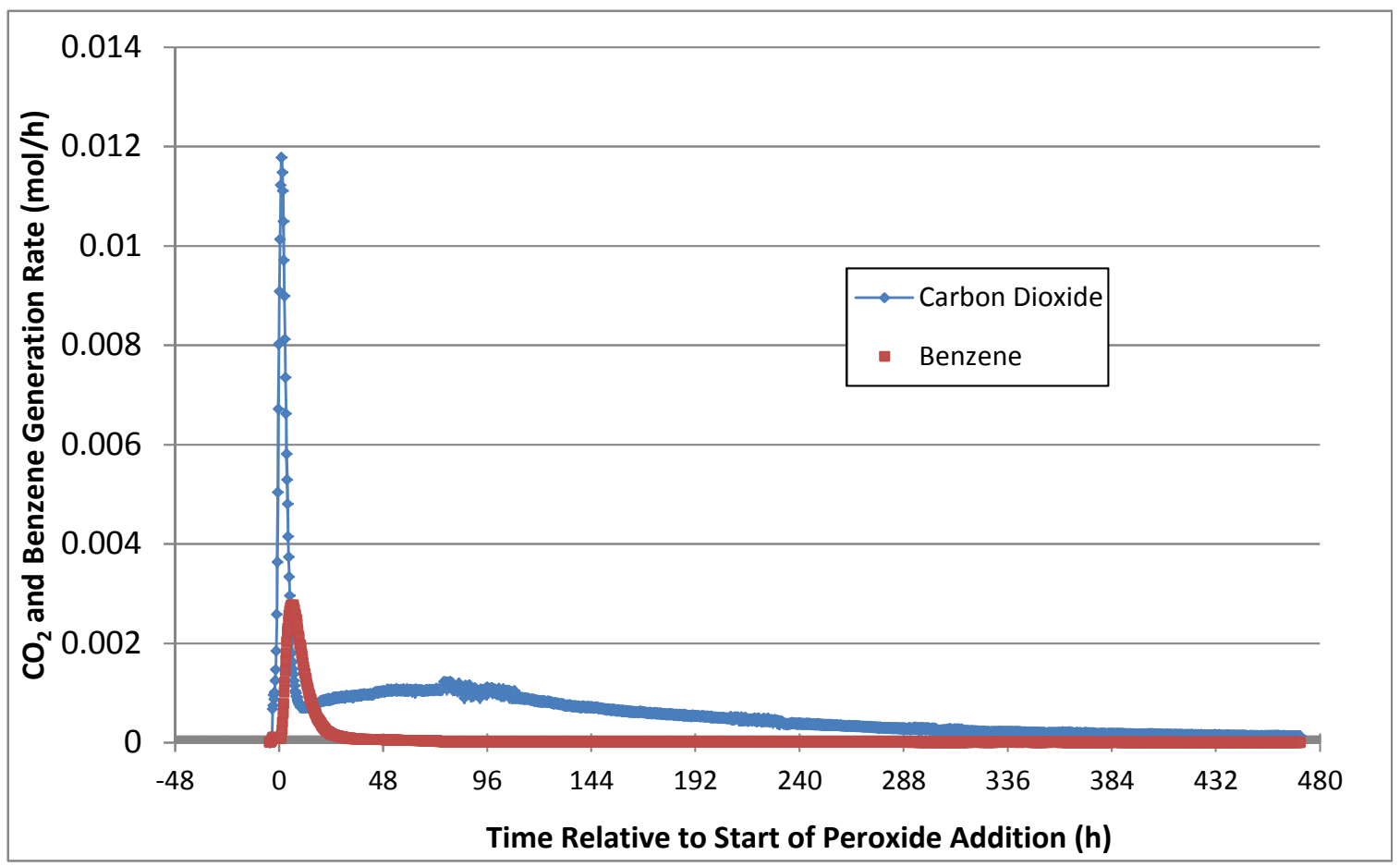

The major off-gas components are benzene and $\mathrm{CO}_{2}$. The benzene and $\mathrm{CO}_{2}$ are from the $\mathrm{pH}$ adjustment of the slurry, as well as degradation of organics (the presence of these two gases was observed throughout the reaction).

The initial spikes in gas generation must be due to the $\mathrm{pH}$ adjustment process, and a closer inspection of the data set shows the same general behavior as observed for DEMO 1 - the benzene and $\mathrm{CO}_{2}$ generation spikes closely follow the $\mathrm{pH}$ adjustment and then taper off quickly (Figure 34). 
In the case of benzene, again, it is not possible to deconvolute benzene generated during acidification or during the $\mathrm{H}_{2} \mathrm{O}_{2}$ addition. However, it is possible to confidently state that the initial benzene spike is from $\mathrm{pH}$ adjustment, and the decline in generation rate from the GC data indicates that any benzene, if generated, is being consumed in the reactor.

Figure 34. Close In View of Gas Release Data for Demonstration 2

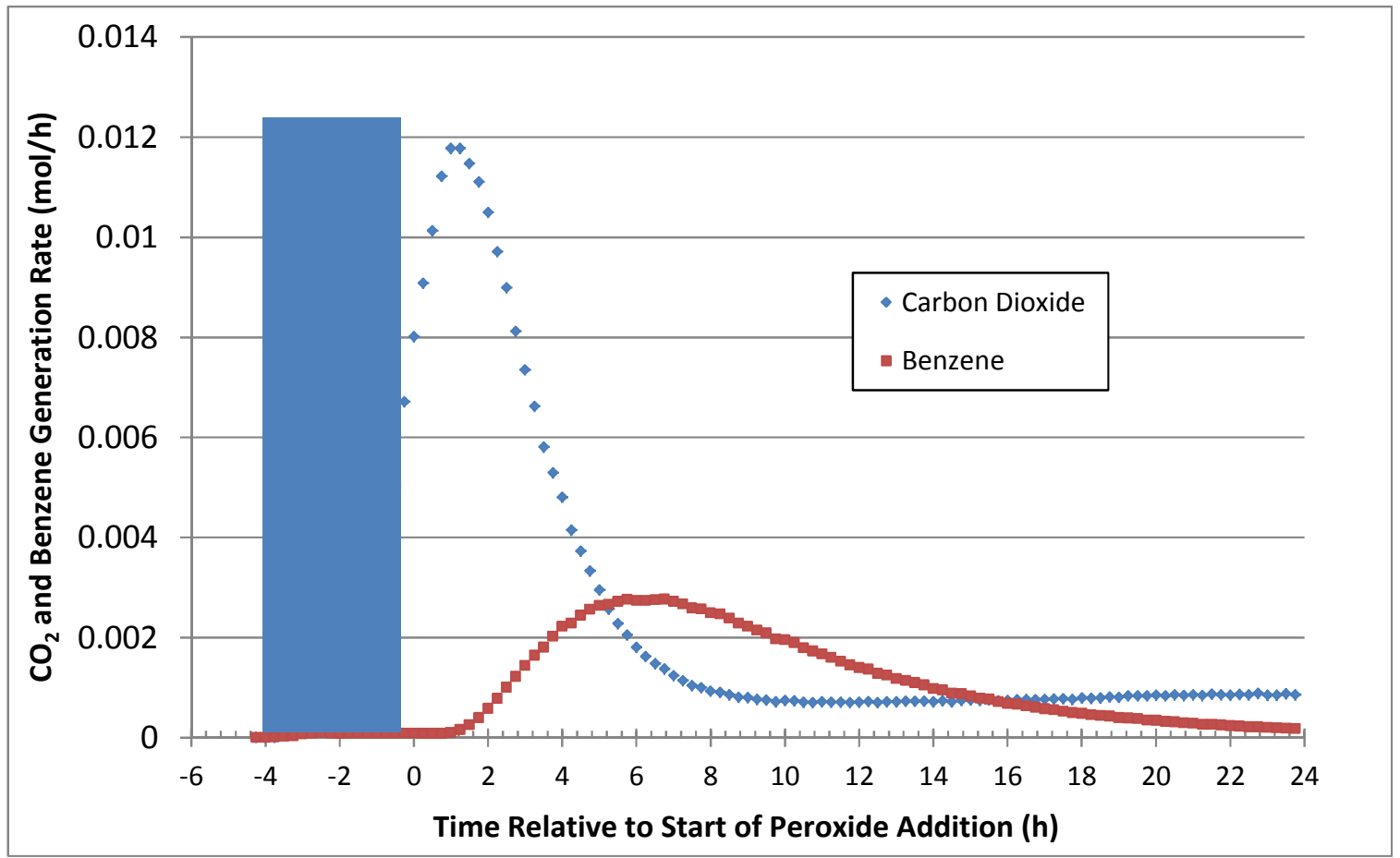

Several important points can be drawn from this graph:

- $\mathrm{CO}_{2}$ evolution occurs slowly about 1 hour after acid addition is commenced (presumed due to acid-carbonate reaction) and then rapidly increases as the $\mathrm{pH}$ adjustment continues. The acid-carbonate reaction continues after the acid is no longer added.

- Even though the benzene is assumed to be produced during acid hydrolysis it is not released until after the almost concurrent increase to reaction temperature and addition of peroxide. Previous work indicates a correlation between temperature increases and increased release of benzene. ${ }^{18}$

- Since such a small amount of peroxide is added in the first hours $(0.4 \mathrm{~mL} /$ hour $)$ it is more likely that the benzene release is associated with increase in temperature. 
- Increased temperature can have two potential effects; increased benzene volatility or decreased gas solubility.

The GC data can be used in attempt to determine a mass balance for DEMO 2. To do this, the moles of benzene and $\mathrm{CO}_{2}$ available in the simulant slurry before $\mathrm{pH}$ addition must be determined, and compared against the moles of benzene and $\mathrm{CO}_{2}$ remaining in the bottoms at the end of the reaction.

Figure 35 shows the cumulative amount of benzene and $\mathrm{CO}_{2}$ detected over the life of the experiment.

Figure 35. Cumulative Off-gas Release in Demonstration 2

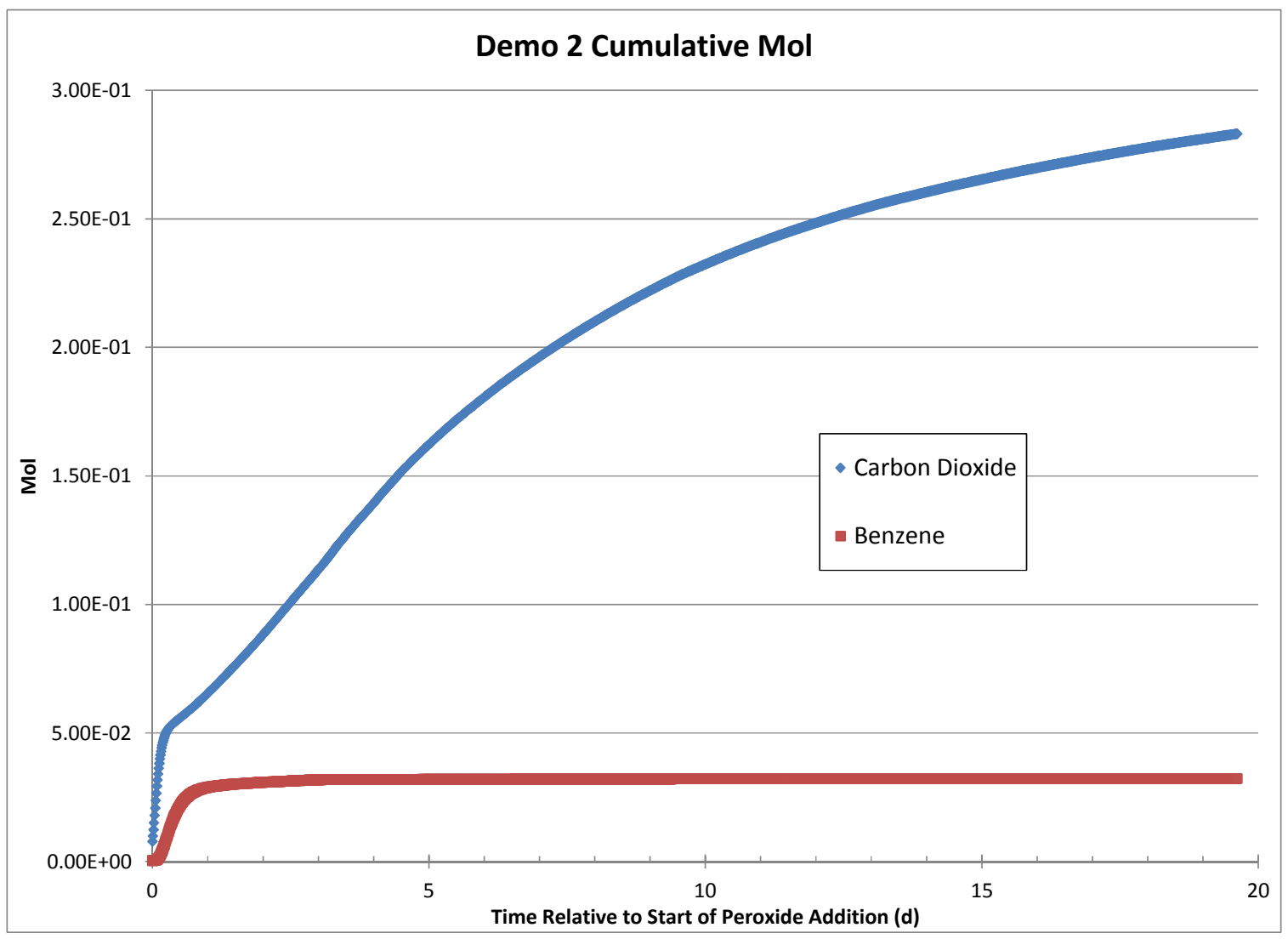

From this graph several key points can be determined.

- The amount of benzene produced by the end of the reaction is 0.032 moles. 
- The amount of $\mathrm{CO}_{2}$ produced by the end of the reaction is 0.283 moles with no apparent precipitous drop off in production.

- The majority of the observed benzene is generated in the first 5 hours of testing.

With respect to benzene, from the HPLC and VOA measurements, $\sim 0$ moles of TPB remain in the reactor bottoms as TPB which means there is no reservoir of benzene (and therefore $\mathrm{CO}_{2}$ ) from there. ${ }^{\mathrm{d}}$

With respect to $\mathrm{CO}_{2}$, a sample of the DEMO 2 bottoms was analyzed by TIC/TOC. The TIC (total inorganic carbon - assumed to be carbonate ${ }^{16,17}$ ) result indicated that 0.172 moles of carbonate remained in the reactor bottoms.

From the reactor bottoms, SVOA analysis provided a result of $83 \mathrm{mg} / \mathrm{L}$ of residual organics, the bulk of which is in the form of biphenyl. For the sake of simplicity, if it is assumed all of this is biphenyl, this converts to a maximum possible remaining inventory of 0.00473 moles of $\mathrm{CO}_{2}$.

Against these observations, the initial inventory of benzene was calculated. Each $500 \mathrm{~mL}$ of simulant slurry has maximum benzene inventory of 0.12 moles (this includes the 44 $\mu \mathrm{L}$ of benzene added just before time $=0$ ). The $\mathrm{GC}$ measured only 0.032 moles of benzene over the life of the reaction and as such it can be concluded that only $\sim 26.7 \%$ of the potential benzene inventory left the system as benzene. Ideally, no benzene should leave the system.

The inventory of carbonate was calculated. Each slurry starts with 0.290 moles of carbonate. This serves as a possible inventory for an equimolar amount of $\mathrm{CO}_{2}$, as any decrease in the carbonate concentration in the slurry must be due to the $\mathrm{pH}$ adjustment (carbonate $\rightarrow \mathrm{CO}_{2}$ ).

For DEMO 2 the starting carbonate amount is 0.290 moles, and by the end of the reaction, the amount remaining is 0.172 moles. Therefore, the difference, 0.118 moles, was lost from $\mathrm{pH}$ adjustment. This carbonate was converted to $\mathrm{CO}_{2}$ and left the system.

The slurry used in DEMO 2, as generated, also contained 0.0300 moles of TPB. Under ideal conditions, if all of the phenyl groups in the TPB were converted into $\mathrm{CO}_{2}$, this would allow for a maximum $\mathrm{CO}_{2}$ generation of 0.72 moles of $\mathrm{CO}_{2}$.

Now it is possible to calculate the amount of $\mathrm{CO}_{2}$ that was actually created during DEMO 2. The maximum possible amount is 0.72 moles. To this value is added the $\mathrm{CO}_{2}$ that was

\footnotetext{
${ }^{\mathrm{d}}$ For the moment, the initial added quantities of biphenyl and phenol will be ignored for the sake of clarity. At a later point a more complete carbon balance will be performed when the IC-anions results have been received.
} 
produced from the conversion of carbonate to $\mathrm{CO}_{2}$ which occurred during the $\mathrm{pH}$ adjustment, or 0.118 moles, for a total of 0.838 moles. From this total the known remains in the bottoms are subtracted:

- 0 moles from the residual TPB (HPLC)

-0.00478 moles from the residual other organics (SVOA)

- 0.192 moles from the benzene that the GC measured

- 0.0216 moles remaining as oxalate (see Section 3.6.7, below)

This gives a calculated amount of created $\mathrm{CO}_{2}$ of 0.620 moles. ${ }^{\mathrm{e}}$ The remaining carbonate is not subtracted as this material should not be further converted to $\mathrm{CO}_{2}$ through the action of the CCPO.

The GC only detected 0.283 moles, or $\sim 46 \%$ of the calculated $\mathrm{CO}_{2}$ produced.

Potential losses from the system due to leaks are being investigated to account for the differential.

\subsubsection{IC-Anions Data}

The fate of the various anions in the simulant was also evaluated. While most anions in the simulant slurry are likely unaffected by the reaction chemistry, it is known that the concentrations of certain anions, such as nitrite, oxalate or formate, may change during processing, In previous work, ${ }^{6}$ a number of reaction samples were examined to establish the effects on these types of anions.

As part of DEMO 2, the slurry was sampled at $0,17.5,22.5,43.5$ and 475.5 hours into the reaction. These samples were subjected to IC-Anions analysis. The results are in Table 29 and have been dilution corrected in the same manner as the ICPES data.

There was no formate or oxalate added to the salt simulant, so the appearance of those species is significant. It appears that the formate is initially generated though finally consumed whereas the concentration of oxalate increases throughout the test.

\footnotetext{
${ }^{\mathrm{e}}$ Again, this is intended as a rough measurement. The production of oxalate and formate results would affect this value.
} 
Table 29. IC-Anions Concentration Results for DEMO 2 Samples (mg/L)

\begin{tabular}{|c|c|c|c|c|c|}
\hline & \multicolumn{5}{|c|}{ Time (hours) } \\
\hline analyte & $\mathbf{0}$ & $\mathbf{1 7 . 5}$ & $\mathbf{2 2 . 5}$ & $\mathbf{4 3 . 5}$ & $\mathbf{4 7 5 . 5}$ \\
\hline fluoride & $<100$ & $<98.9$ & $<97.8$ & $<91.6$ & $<136$ \\
\hline formate & $<100$ & 101.8 & 144.7 & 255.7 & $<136$ \\
\hline chloride & 167 & 164 & 163 & 157 & 242 \\
\hline nitrite & 14000 & 13545 & 13199 & 12371 & 10522 \\
\hline bromide & $<500$ & $<494$ & $<489$ & $<458$ & $<681$ \\
\hline nitrate & 121000 & 119635 & 118300 & 112710 & 137478 \\
\hline phosphate & 174 & 199 & $<207$ & $<236$ & $<362$ \\
\hline sulfate & 183 & 175 & 174 & 165 & 221 \\
\hline oxalate & $<100$ & 229 & 310 & 539 & 1742 \\
\hline
\end{tabular}

The analytical uncertainty for each IC-Anions sample is $10 \%$.

Using the highest measured values for both anions, the amount of carbon sequestered in those materials that came from benzene can be estimated. $255.7 \mathrm{mg} / \mathrm{L}$ of formate translates to 0.00385 moles of benzene. $1742 \mathrm{mg} / \mathrm{L}$ of oxalate translates to 0.013 moles of benzene. Together, these two anions account for $\sim 14.4 \%$ of the potential benzene inventory.

There is a moderately statistically significant decline in nitrite, which is not surprising as nitrite can be oxidized to nitrate.

There are also statistically significant increases in chloride and sulfate which is not anticipated. In principle, these anion concentrations should remain constant since no chemicals are added during the tests that incorporate these species.

\subsection{8 pH Monitoring}

$\mathrm{pH}$ was monitored during the reaction. See Figure 36.

The chemical reactions appear to drive towards a final $\mathrm{pH}$ of about 9 , which is not surprising given previous reaction results. 
Figure 36. pH Readings for Demonstration 2

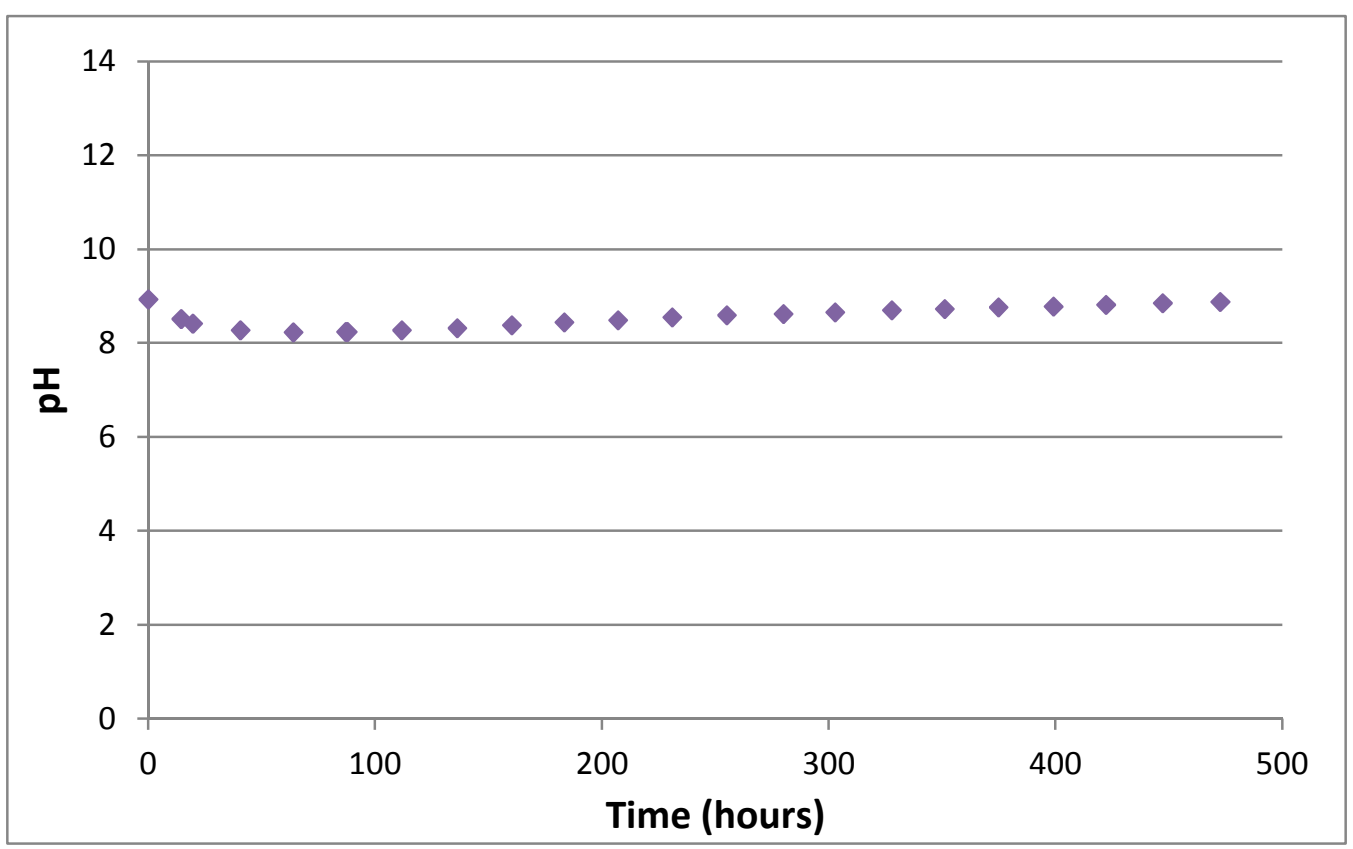

\subsubsection{Conclusion}

DEMO 2 showed complete destruction within 4 days, which is comparable, if not slightly faster than the closest comparable reaction (see Section 3.5.5, the $\mathrm{pH} 9$ reaction). Furthermore, there is only a small fraction of measurable $(<1 \%)$ residual organic material left in the reactor at the end. This is less than half the amount residual material left in the reactor for the closest comparable reaction. The difference between these two reactions is the rate of $\mathrm{H}_{2} \mathrm{O}_{2}$ addition. This indicates that the increased $\mathrm{H}_{2} \mathrm{O}_{2}$ addition in DEMO 2 is beneficial. Furthermore, the increased $\mathrm{H}_{2} \mathrm{O}_{2}$ delivery does not appear to effect the copper concentrations, although it does provide for slightly elevated titanium concentrations.

\subsection{Further Examination of $\mathrm{H}_{2} \underline{\mathrm{O}}_{2}$ Addition Rates}

While previous tests examined the effects of a ten-fold increase in the $\mathrm{H}_{2} \mathrm{O}_{2}$ addition rate conducted at room temperature (see Section 3.2), SRNL also performed a further test at five-fold $(5 \times)$ the nominal peroxide addition rate. This test is also identified as "Test $2 \mathrm{a}$ ".

This experiment used the same reaction vessel and temperature control $\left(50^{\circ} \mathrm{C}\right)$ as described in Section 3.5. Other experimental details were as described in previous Sections, except where as noted below. It was noted that the "prototypical mixing" is in fact, very poor compared to reactions performed in poly bottles with a magnetic stirrer. The agitation was insufficient to prevent a semi-stable floating solids mass. This may have effects in the overall reaction efficiency. 
Hydrogen peroxide was added at $1 \mathrm{~mL} /$ hour $(5 \times)$.

The test ran approximately 20 days. Filtrate samples were taken once per day. A total of 22 samples were removed for analysis by ICPES.

\subsubsection{Soluble Boron Results}

After the start of the $\mathrm{H}_{2} \mathrm{O}_{2}$ addition the boron in the filtrate samples increased over time. See Figure 37. In the figure the data from related tests are also included to show the effect of varying rates of $\mathrm{H}_{2} \mathrm{O}_{2}$ addition.

The reaction was halted after 472 hours, and the extent of boron dissolution associated with the acid hydrolysis and the peroxide oxidation reaction was calculated using the same methodology as in Section 3.1.1 (see Table 30). A final data point at $t=957$ hours from the confirmation sample from the reactor bottoms (see Section 3.6.5) is not shown for clarity, and is not used in the percent destruction calculation.

\section{Table 30. Total TPB Destruction from Final Boron Results: $5 \times$ Peroxide Addition Rate}

\begin{tabular}{|c|c|c|c|c|c|c|c|c|}
\hline \multicolumn{3}{|c|}{ Destruction by Acid } & \multicolumn{3}{c|}{ Destruction by $\mathrm{H}_{2} \mathrm{O}_{2}$} & \multicolumn{3}{c|}{ Total Destruction } \\
\hline $1 \mathrm{xH}_{2} \mathrm{O}_{2}$ & $2 \mathrm{xH}_{2} \mathrm{O}_{2}$ & $5 \mathrm{xH}_{2} \mathrm{O}_{2}$ & $1 \mathrm{xH}_{2} \mathrm{O}_{2}$ & $2 \mathrm{xH}_{2} \mathrm{O}_{2}$ & $5 \mathrm{xH}_{2} \mathrm{O}_{2}$ & $1 \mathrm{xH}_{2} \mathrm{O}_{2}$ & $2 \mathrm{xH}_{2} \mathrm{O}_{2}$ & $5 \mathrm{xH}_{2} \mathrm{O}_{2}$ \\
\hline $13.3-16.2 \%$ & $16.4-20.1 \%$ & $12.5-15.3 \%$ & $66.8-85.1 \%$ & $73.5-94.3 \%$ & $69.4-88.1 \%$ & $81.6-100 \%$ & $91.9-112 \%$ & $83.4-102 \%$ \\
\hline
\end{tabular}

By $\sim 100$ hours the TPB destruction is complete. This is comparable to the most equivalent previous reactions (see Section 3.5.1, $\mathrm{pH} 9$ reaction and Section 3.6.1). As this test and the previously mentioned two tests form a series with only one variation $\left(\mathrm{H}_{2} \mathrm{O}_{2}\right.$ addition rate), it is possible to plot them against each other (see Figure 38$)$ to determine the effect of $\mathrm{H}_{2} \mathrm{O}_{2}$ addition rates.

The " $5 \times \mathrm{H}_{2} \mathrm{O}_{2}$ " reaction is the one described in this section. The " $2 \times \mathrm{H}_{2} \mathrm{O}_{2}$ " is DEMO 2, and the " $1 \times \mathrm{H}_{2} \mathrm{O}_{2}$ " is the $\mathrm{pH} 9$ experiment from Section 3.5.1. All three reactions were conducted at $50{ }^{\circ} \mathrm{C}$, starting at $\mathrm{pH} 9$, with $500 \mathrm{mg} / \mathrm{L}$ of copper.

The differences in the boron data are fairly small. All three reactions appear to go to completion by $\sim 100$ hours. The " $5 \times$ " appears to be slightly faster than the " $2 \times$ ", which is slightly faster than the " $1 \times$ " reaction, but the differences are small and sometimes statistically insignificant. 
Figure 37. Boron Concentration Results Comparison at Varying Peroxide Addition Rates

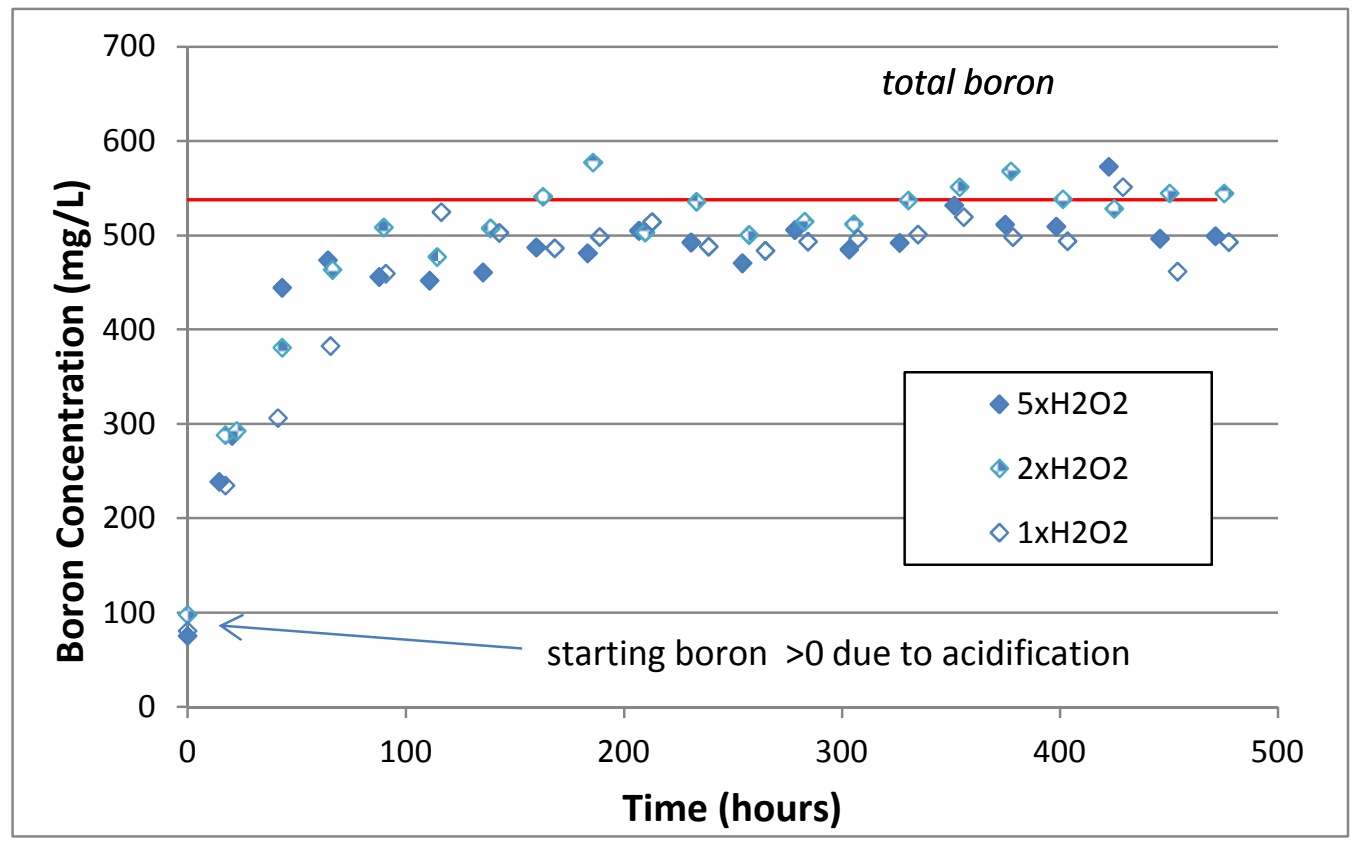

\subsubsection{Soluble Potassium Results}

After the start of the $\mathrm{H}_{2} \mathrm{O}_{2}$ addition the potassium in the filtrate samples increased over time (see Figure 38). In the figure data from related tests is also included to show the effect of varying rates of $\mathrm{H}_{2} \mathrm{O}_{2}$ addition.

The reaction was halted after 472 hours, and the extent of potassium dissolution associated with the acid hydrolysis and the peroxide oxidation reaction was calculated using the same methodology as in Section 3.1.1 (see Table 31). The final data point at $\mathrm{t}=957$ hours is from the confirmation sample from the reactor bottoms (see Section 3.7.5) and is not used in the percent destruction calculation. 


\section{Figure 38. Potassium Concentration Results Comparison at Varying Peroxide} Addition Rates

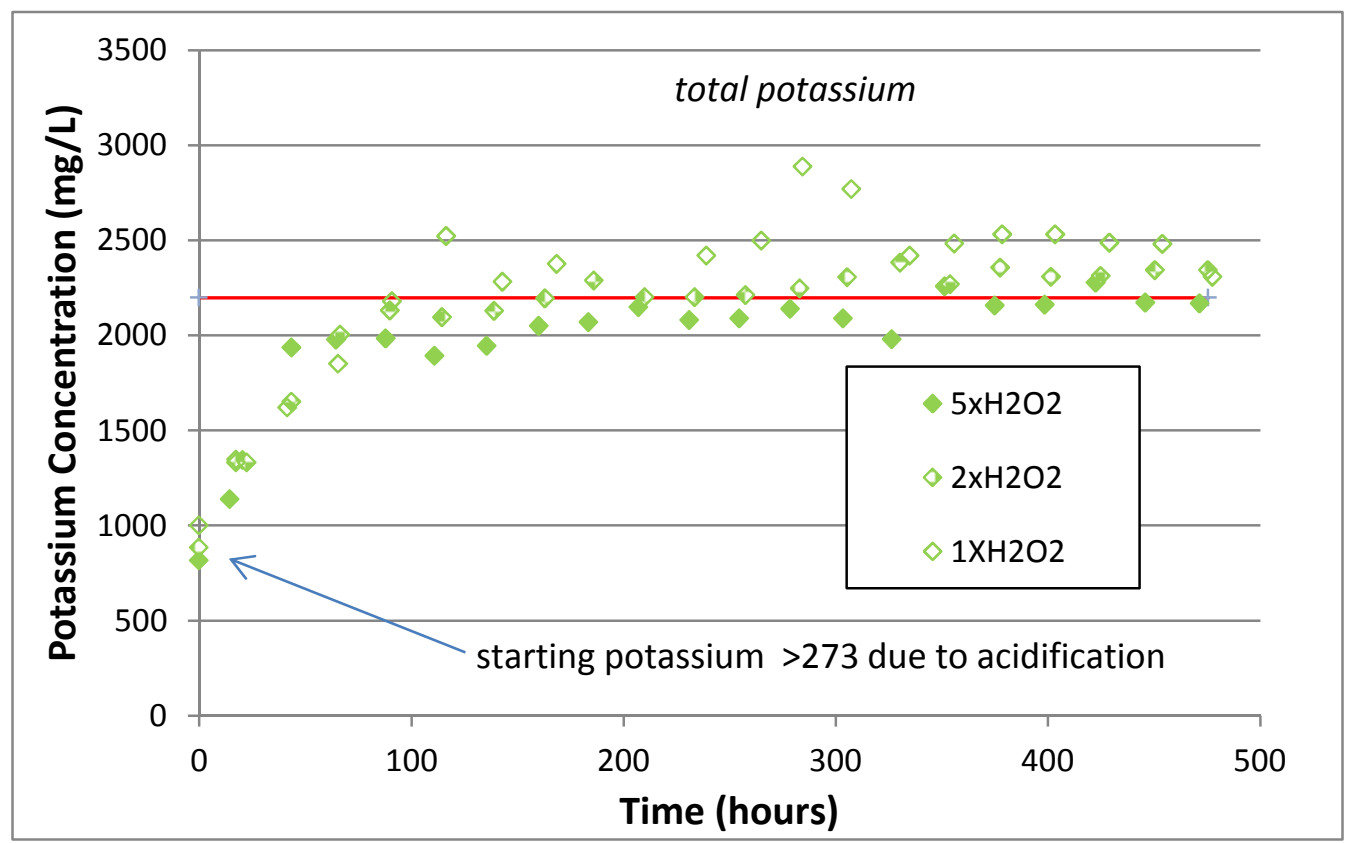

\section{Table 31. Total TPB Destruction from Potassium Results at $5 \times$ Peroxide Addition Rate}

\begin{tabular}{|c|c|c|c|c|c|c|c|c|}
\hline \multicolumn{3}{|c|}{ Destruction by Acid } & \multicolumn{3}{c|}{ Destruction by $\mathrm{H}_{2} \mathrm{O}_{2}$} & \multicolumn{3}{c|}{ Total Destruction } \\
\hline $1 \mathrm{xH}_{2} \mathrm{O}_{2}$ & $2 \mathrm{xH}_{2} \mathrm{O}_{2}$ & $5 \mathrm{xH}_{2} \mathrm{O}_{2}$ & $1 \mathrm{xH}_{2} \mathrm{O}_{2}$ & $2 \mathrm{xH}_{2} \mathrm{O}_{2}$ & $5 \mathrm{xH}_{2} \mathrm{O}_{2}$ & $1 \mathrm{xH}_{2} \mathrm{O}_{2}$ & $2 \mathrm{xH}_{2} \mathrm{O}_{2}$ & $5 \mathrm{xH}_{2} \mathrm{O}_{2}$ \\
\hline $31.8-42.0 \%$ & $27.2-36.4 \%$ & $23.7-32.1 \%$ & $56.1-82.2 \%$ & $63.7-88.7 \%$ & $57.6-81.5 \%$ & $94.1-118 \%$ & $95.3-120 \%$ & $86.3-109 \%$ \\
\hline
\end{tabular}

As with the boron data, the TPB destruction is complete by $\sim 100$ hours.

It is also possible to compare the potassium data for the series of three comparable reactions, as described in Section 3.7.1 (see Figure 38).

The differences in the potassium data are very small. All three reactions appear to go to completion by $\sim 100$ hours. The differences in the three reactions are probably statistically insignificant.

\subsubsection{Soluble Copper Results}

After the start of the $\mathrm{H}_{2} \mathrm{O}_{2}$ addition the copper in the filtrate samples quickly increased near the start of the reaction, then slowly decreased. See Figure 39. 
Figure 39. Copper Concentration Results for Test 2a

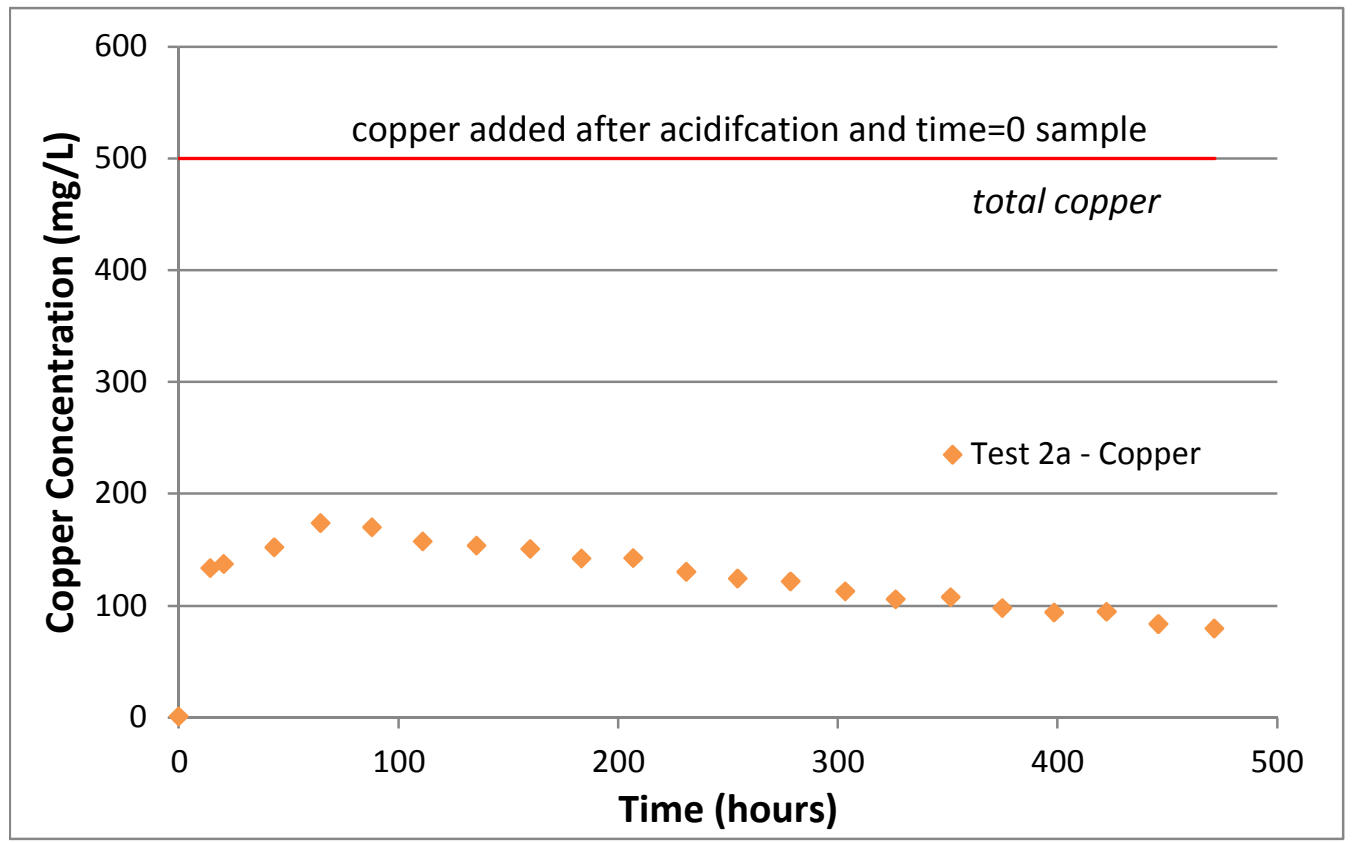

The copper results show a fairly similar pattern to the previous tests (DEMO 2), although slightly higher in magnitude. It is interesting to note that despite increased dilution for this experiment the copper concentration at the end of the experiment is equivalent to that observed for DEMO 2.

\subsubsection{Soluble Titanium Results}

The titanium concentration in solution is monitored for the reasons outlined in Section 3.1.4. See Figure 40.

The titanium results differ notably from those of the $10 \times \mathrm{H}_{2} \mathrm{O}_{2}$ reaction (see Section 3.2). The peak occurs with a maximum concentration of $\sim 60 \mathrm{mg} / \mathrm{L}$, similar to the $10 \times$ peroxide addition rate. However, unlike that previous test, the titanium declines to levels more typical by the end of the test; $10 \mathrm{mg} / \mathrm{L}$. 
Figure 40. Titanium Concentration Results for Test 2a

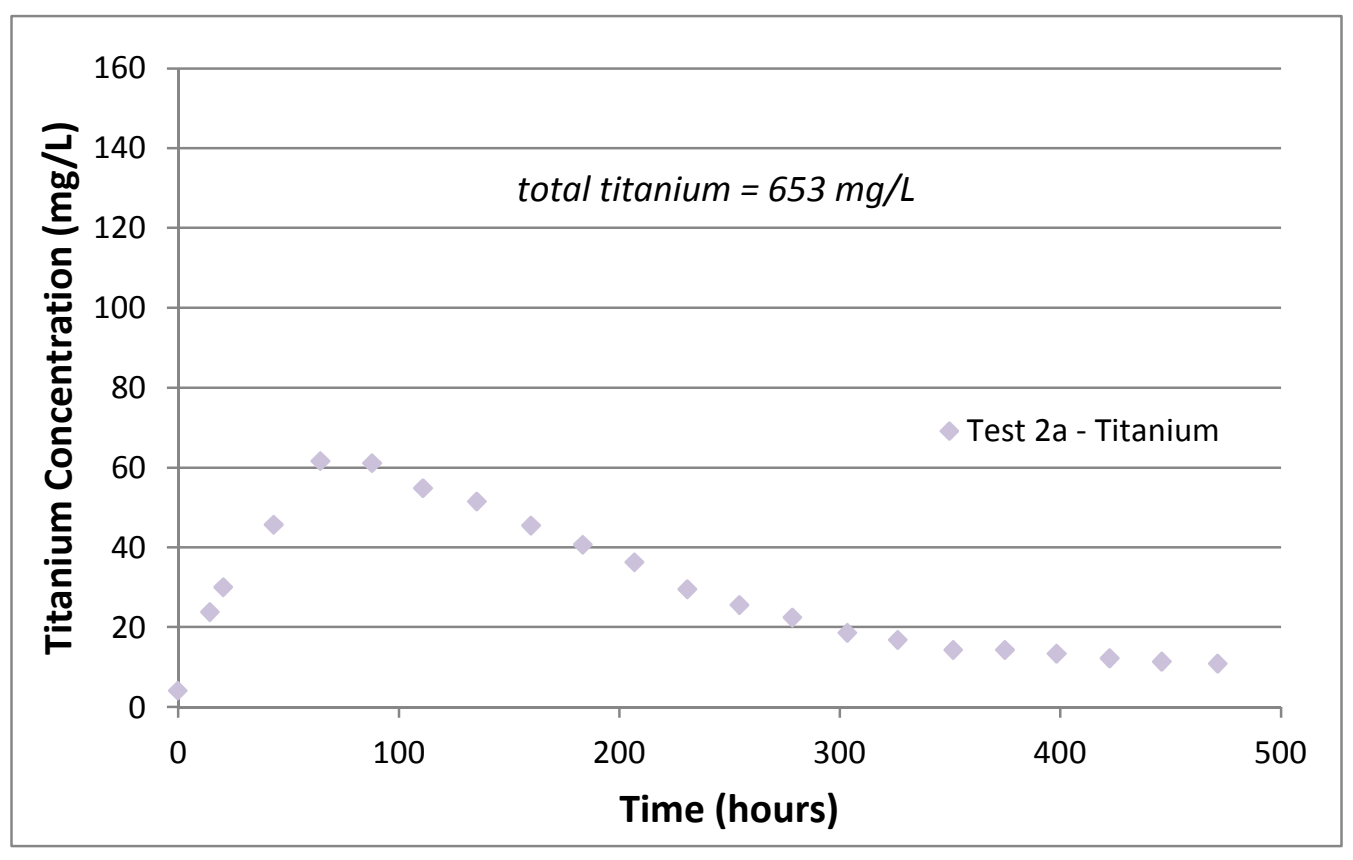

\subsubsection{Analysis of Reactor Bottoms}

After the reaction was complete, the reactor bottoms were removed. The amount of recovered material is somewhat dependent on the efficiency of slurry removal (some solids were caked on the upper parts of the reactor or difficult to remove).

From the bottle of bottoms, well-mixed (in an attempt to ensure homogeneity) duplicate samples were analyzed via HPLC, VOA and SVOA. However, due to the elapsed time from the end of the reaction ( $\sim 486$ hours), and the time of sampling, a filtered sample of the bottoms was also analyzed via ICPES to determine if the reaction had proceeded further. The results of the ICPES analyses are listed in Table 32. The results for the four important analytes $(\mathrm{B}, \mathrm{K}, \mathrm{Cu}, \mathrm{Ti})$ are given next to the chronologically previous sample results. These results are corrected for dilution as normal.

Table 32. ICPES Check Samples for Test 2a (mg/L)

\begin{tabular}{|c|c|c|}
\hline Analyte & $\begin{array}{c}\text { Final Filtrate } \\
\text { Result }\end{array}$ & $\begin{array}{c}\text { End of Reaction Period } \\
\text { Sample Result }\end{array}$ \\
\hline $\mathrm{B}$ & 469.1 & 498.6 \\
\hline $\mathrm{K}$ & 2079 & 2166 \\
\hline $\mathrm{Cu}$ & 66.90 & 79.24 \\
\hline $\mathrm{Ti}$ & $<1.93$ & 10.83 \\
\hline
\end{tabular}

The analytical uncertainty is $10 \%$ for each result. 
There are no statistically significant differences in the boron and potassium results between the two sample sets for any of the reactions. The titanium results showed a drop, which is consistent with the trend displayed in previous titanium data.

As there is no detectable additional destruction occurring, a valid comparison existed between the ICPES and HPLC results. Table 33 lists the HPLC results.

Table 33. HPLC Results from Reactor Bottoms Analyses for Test 2a (mg/L)

\begin{tabular}{|c|c|c|c|c|c|}
\hline TPB & 3PB & 2PB & 1PB & Phenol & \% Destruction \\
\hline$<4$ & $<4$ & $<4$ & $<10$ & $<4$ & $>99.9 \%$ \\
\hline
\end{tabular}

The "\% Destruction" column is the calculated percent destruction. The value is based on the mass of TPB added to the simulant slurries and calculation of the mass of TPB in the reactor bottoms, after correcting for the mass of samples removed from the system during the reactions.

Given the very rapid destruction indicated by the boron and potassium data, less than detectable concentrations of all the HPLC analytes were anticipated.

In addition to the reactor bottoms samples, two slurry samples were also removed at 207 and 304 hours. These two samples were analyzed by HPLC and the results are listed in Table 34.

Table 34. HPLC Results from Time $=207,304$ Hour Slurry Samples for Test 2 a (mg/L)

\begin{tabular}{|c|c|c|c|c|c|c|}
\hline Sample & TPB & 3PB & 2PB & 1PB & Phenol & \% Destruction \\
\hline 207 hour & $<10$ & $<10$ & $<10$ & $<10$ & $<10$ & $>99.9 \%$ \\
\hline 304 hour & $<10$ & $<10$ & $<10$ & $<10$ & $<10$ & $>99.9 \%$ \\
\hline
\end{tabular}

The $\%$ Destruction values in Table 34 were calculated in a manner differently than other examples of this type. In this case, as the mass of the entire slurry (the reaction is ongoing) cannot be determined, it is necessary to use the starting TPB concentration and the TPB concentration at the sample time to determine the \% Destruction.

These two HPLC measurements also corroborate the boron and potassium data indicating complete destruction as early as 189 hours. 
Samples of the reactor bottoms were analyzed using VOA and SVOA (see Table 35). The values in parentheses are the $\%$ RSD. In the analyte column, shaded cells indicate the presence of that analyte is doubtful due to chemical conditions or interferences. The "total organic residuals" are the sum of all the mid-range values of the detected analytes, less benzene and the analytes that are declared to be from interferences. This term is intended to be a rough indicator of the propensity of the reaction conditions to generate these residual materials. These results are not normalized to the beginning volumes.

Table 35. VOA and SVOA Results for Test 2 a

\begin{tabular}{|c|c|}
\hline Analyte & Result (mg/L) \\
\hline benzene & $<0.05$ \\
\hline diisooctyl adipate & $35.5(41.8 \%)$ \\
\hline p-terphenyl & $2.20(32.1 \%)$ \\
\hline m-terphenyl & $2.60(81.6 \%)$ \\
\hline biphenyl & $1.65(4.29 \%)$ \\
\hline o-terphenyl & $1.30(32.6 \%)$ \\
\hline Total organic residuals & 7.75 \\
\hline
\end{tabular}

Unlike all previous reactions, there are very few compounds left in the reactor bottoms. The diisooctyl adipate is a known plasticizer and is more than likely leachate from contact with a plastic surface such as the bottle than contained the slurry prior to the experiment or from the analytical method equipment. The other analytes are in very small concentrations and the low levels may be due to the larger influx of $\mathrm{H}_{2} \mathrm{O}_{2}$ causing more extensive degradation.

\subsection{6 pH Monitoring}

$\mathrm{pH}$ was monitored during the reaction. See Figure 41.

Again, the $\mathrm{pH}$ values remain at $\sim \mathrm{pH} 9$ for the duration of the reaction. 
Figure 41. pH Readings for Test 2 a

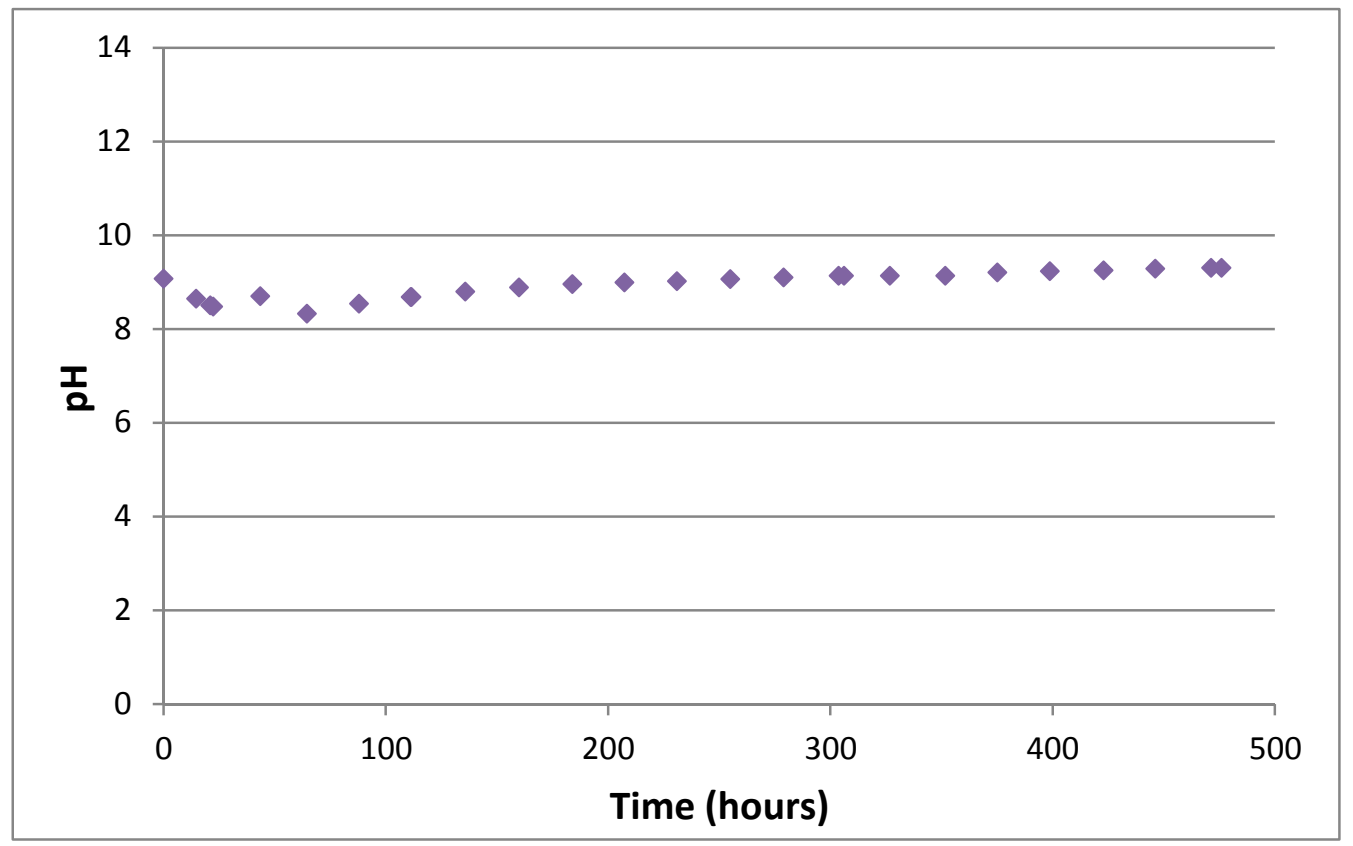

\subsubsection{Conclusion}

Test $2 \mathrm{a}$ showed complete destruction within 4 days. It appears that the increased $\mathrm{H}_{2} \mathrm{O}_{2}$ delivery $(5 \times$ nominal rates) did not provide a further decrease in time required to reach complete TPB destruction. However it is clear that the increased $\mathrm{H}_{2} \mathrm{O}_{2}$ did provide a reduction in the residual organic materials in the reactor bottoms though this may be offset by the potential volume increase associated with higher $\mathrm{H}_{2} \mathrm{O}_{2}$ addition rates.

The additional $\mathrm{H}_{2} \mathrm{O}_{2}$ did not increase the final copper soluble concentrations.

The titanium data suggests that while increased rates of $\mathrm{H}_{2} \mathrm{O}_{2}$ addition can lead to elevated MST leaching, the titanium does not remain soluble. This reaction provided the highest titanium values in solution, but this maximum was not sustained, and the titanium values declined to $\sim 11 \mathrm{mg} / \mathrm{L}$ by the end of the reaction, indicating precipitation to a less soluble titanium compound.

\subsection{Effect of Lower Copper Concentrations}

Up to this time, all the reactions have been conducted using $500 \mathrm{mg} / \mathrm{L}$ of copper. Given that previous results in this document reveal that the $500 \mathrm{mg} / \mathrm{L}$ of copper is not completely dissolved into the caustic slurry, there is the potential to reduce the amount of 
added copper while still retaining rapid and complete destruction. Lower copper additions are desired for processing at DWPF.

For this set of experiments 0 and $100 \mathrm{mg} / \mathrm{L}$ of copper were investigated. These are referred to as "Test $2 \mathrm{c}$ " and "Test $2 \mathrm{~b}$ " respectively. The former was considered to confirm the beneficial role of copper as a catalyst, and the latter concentration was used since a maximum of $100 \mathrm{mg} / \mathrm{L}$ dissolution had previously been observed for previous tests despite the addition of $500 \mathrm{mg} / \mathrm{L}$.

These experiments used the same reaction vessels and temperature controls $\left(50{ }^{\circ} \mathrm{C}\right)$ as described in Section 3.5. Other experimental details were as described in previous sections, except where noted below. It was noted that the "prototypical mixing" is in fact, very poor compared to reactions performed in poly bottles with a magnetic stirrer. The agitation was not sufficient enough to prevent a semi-stable floating solids mass. This may have effects in the overall reaction efficiency.

Hydrogen peroxide was added at $0.2 \mathrm{~mL} /$ hour.

Each test continued for approximately 20 days. Filtrate samples were pulled one per day. From both reactions, a total of 21 samples were removed for analysis by ICPES.

\subsubsection{Soluble Boron Results}

After the start of the $\mathrm{H}_{2} \mathrm{O}_{2}$ addition the boron in the filtrate samples increased over time (see Figure 42). The two reactions of this sequence displayed on the same graph, but the results from the comparable $500 \mathrm{mg} / \mathrm{L}$ copper test (Section 3.5.1, $\mathrm{pH} 9$ reaction) are also shown. 
Figure 42. Boron Concentration Comparison From Low Copper Reactions

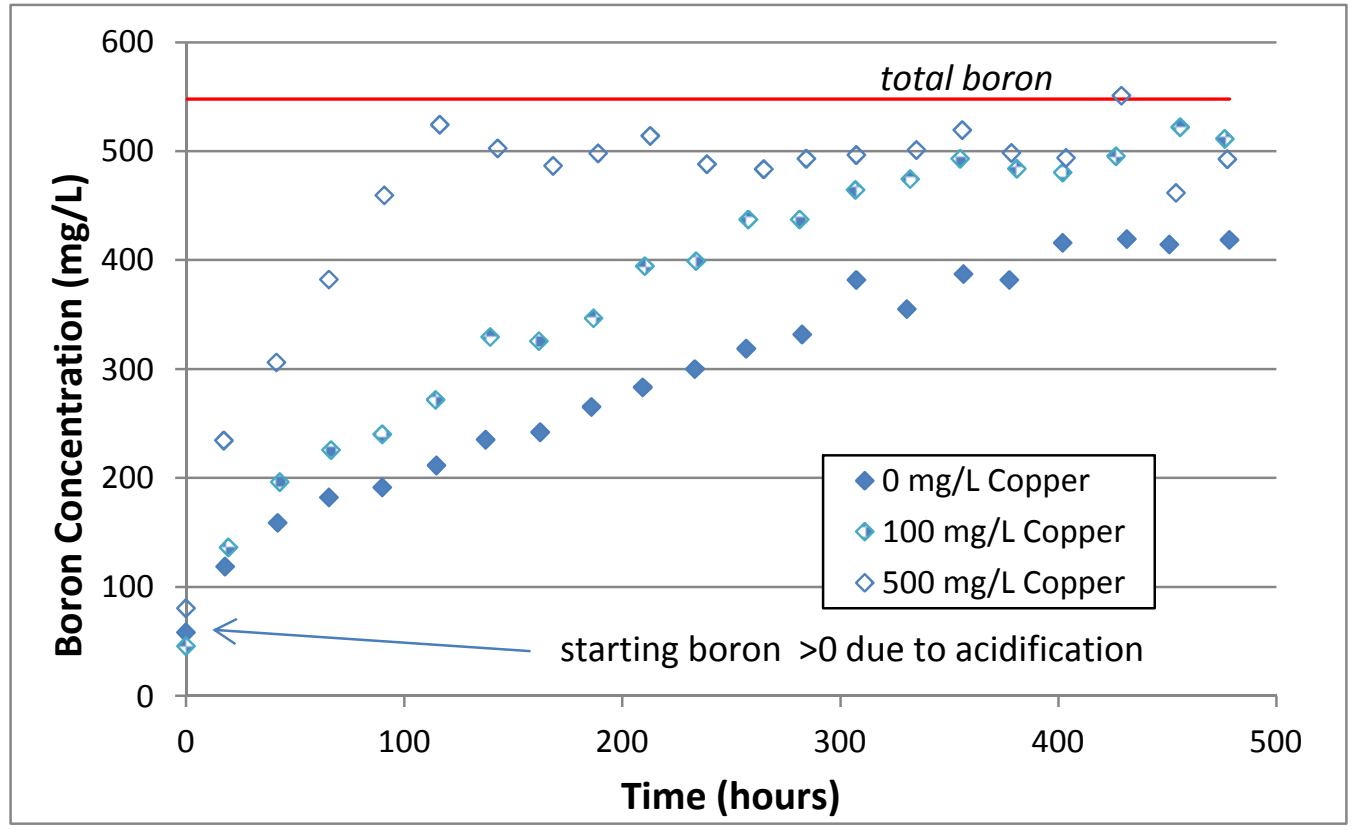

The correlation is very clear; higher copper concentrations provide faster reactivity. It is interesting to note, however, that the destruction of TPB proceeds (though not to completion in the 480 hour test time-frame) without any addition of copper catalyst.

The reaction was halted after 480 hours, and the extent of boron dissolution associated with the acid hydrolysis and the peroxide oxidation reaction was calculated using the same methodology as in Section 3.1.1 (see Table 36). A final data point at $t=793$ hours from the confirmation sample from the reactor bottoms (see Section 3.8.5) is not shown for clarity and is not used in the percent destruction calculation (Table 36).

\section{Table 36. Total TPB Destruction from Final Boron Results}

\begin{tabular}{|c|c|c|c|c|c|c|c|c|}
\hline \multicolumn{3}{|c|}{ Destruction by Acid } & \multicolumn{3}{|c|}{ Destruction by $\mathrm{H}_{2} \mathrm{O}_{2}$} & \multicolumn{3}{|c|}{ Total Destruction } \\
\hline & $\mathrm{LCu}$ & 500 & $\mathrm{Cu}$ & $100 \mathrm{mg} / \mathrm{L} \mathrm{Cu}$ & 500 & & $100 \mathrm{mg} / \mathrm{L} \mathrm{Cu}$ & \\
\hline $9.8-11.9 \%$ & $7.6-9.3 \%$ & \begin{tabular}{|l|}
$13.3-16.2 \%$ \\
\end{tabular} & $59.5-75.3 \%$ & $77.1-96.2 \%$ & $66.8-85.1 \%$ & $70.4-86.0 \%$ & $85.6-105 \%$ & $81.6-100 \%$ \\
\hline
\end{tabular}

Both data sets showed slower, and in one case $(0 \mathrm{mg} / \mathrm{L} \mathrm{Cu})$ incomplete destruction. Clearly, $100 \mathrm{mg} / \mathrm{L}$ of copper (or less) is insufficient to achieve a rapid cycle time.

\subsubsection{Soluble Potassium Results}

After the start of the $\mathrm{H}_{2} \mathrm{O}_{2}$ addition the potassium in the filtrate samples increased over time. See Figure 43. 
From the potassium data, the same trends found in the boron data are observed, including the evidence of a much faster reaction at higher copper concentrations.

Figure 43. Potassium Concentration Comparison from Low Copper Reactions

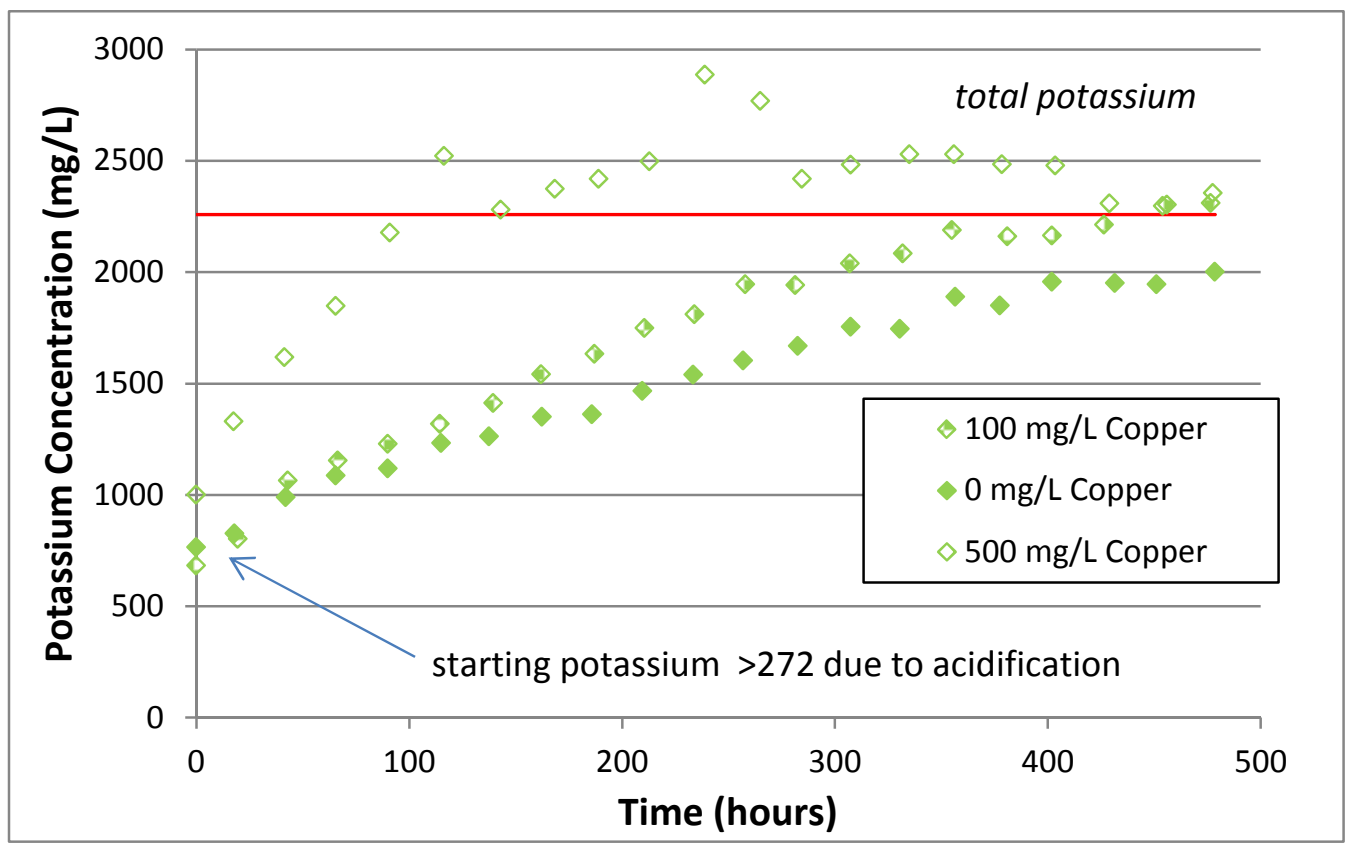

The reaction was halted after 480 hours, and the extent of boron dissolution associated with the acid hydrolysis and peroxide oxidation reactions was calculated using the same methodology as in Section 3.1.1. See Table 37. A final data point at $t=793$ hours from the confirmation sample from the reactor bottoms (see Section 3.8.5) is not shown for clarity and is not used in the percent destruction calculation.

Table 37. Total TPB Destruction from Potassium Results

\begin{tabular}{|r|c|c|c|c|c|c|c|c|}
\hline \multicolumn{3}{|c|}{ Destruction by Acid } & \multicolumn{3}{c|}{ Destruction by $\mathrm{H}_{2} \mathrm{O}_{2}$} & \multicolumn{3}{c|}{ Total Destruction } \\
\hline $0 \mathrm{mg} / \mathrm{L} \mathrm{Cu}$ & $100 \mathrm{mg} / \mathrm{L} \mathrm{Cu}$ & $500 \mathrm{mg} / \mathrm{L} \mathrm{Cu}$ & $0 \mathrm{mg} / \mathrm{L} \mathrm{Cu}$ & $100 \mathrm{mg} / \mathrm{L} \mathrm{Cu}$ & $500 \mathrm{mg} / \mathrm{L} \mathrm{Cu}$ & $0 \mathrm{mg} / \mathrm{L} \mathrm{Cu}$ & $100 \mathrm{mg} / \mathrm{L} \mathrm{Cu}$ & $500 \mathrm{mg} / \mathrm{L} \mathrm{Cu}$ \\
\hline $21.6-29.5 \%$ & $17.6-24.7 \%$ & $31.8-42.0 \%$ & $52.9-75.1 \%$ & $71.5-96.4 \%$ & $56.1-82.2 \%$ & $79.2-100 \%$ & $93.2-117 \%$ & $94.1-118 \%$ \\
\hline
\end{tabular}

The trends in the potassium data match the trends in the boron data. 


\subsubsection{Soluble Copper Results}

After the start of the $\mathrm{H}_{2} \mathrm{O}_{2}$ addition the copper in the filtrate samples slowly increased over time (see Figure 44). The figure only shows the copper data from the $100 \mathrm{mg} / \mathrm{L}$ reaction, as there were less than detectable concentrations of copper in the $0 \mathrm{mg} / \mathrm{L}$ reaction.

Figure 44. Copper Concentration Results for Low Copper Reactions

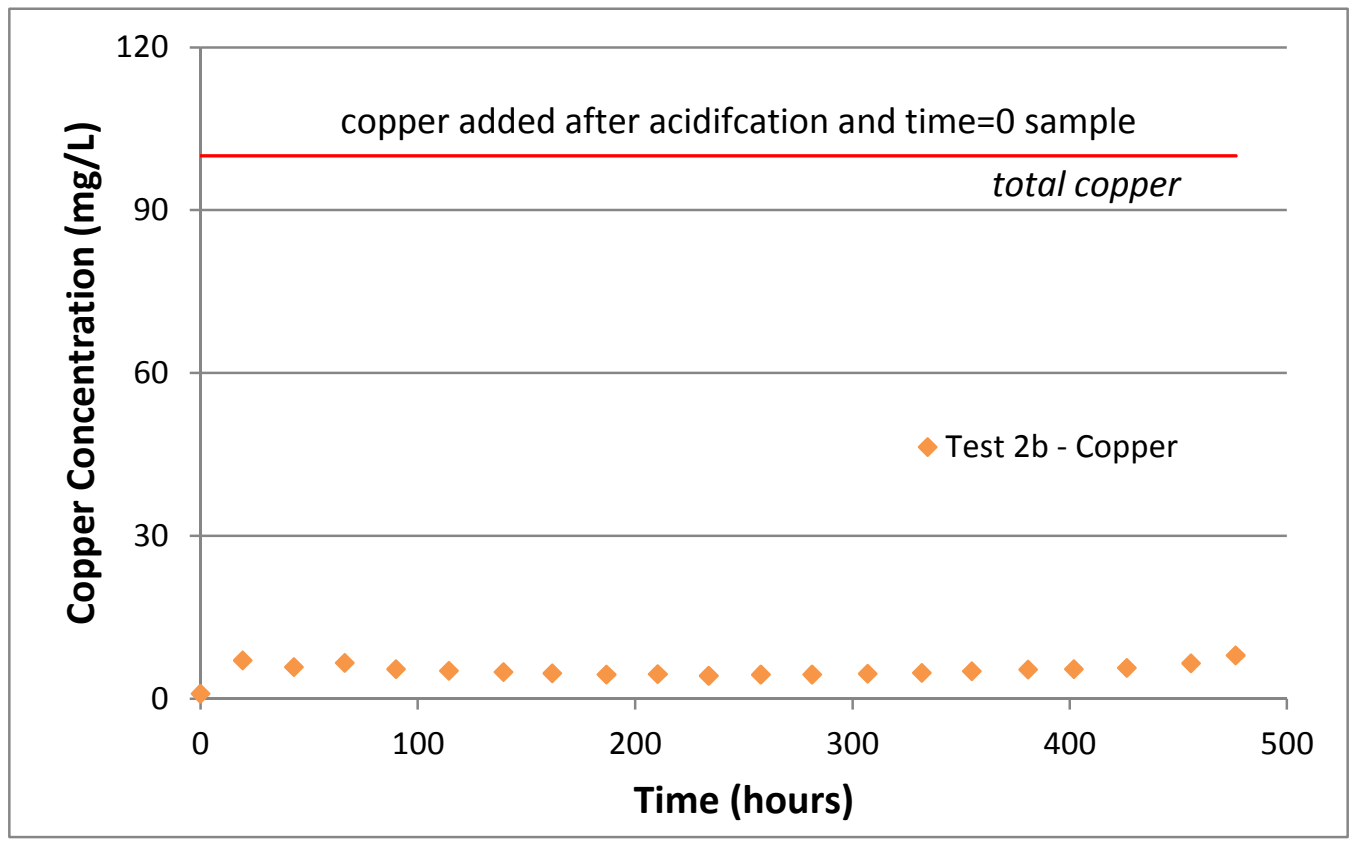

In previous reactions which added copper to $500 \mathrm{mg} / \mathrm{L}$, the filtrates typically contained $\sim 100 \mathrm{mg} / \mathrm{L}$ by the end of the test (about $20 \%$ of the added copper). With copper added to only $100 \mathrm{mg} / \mathrm{L}$, an even smaller fraction $(<10 \%)$ of the copper dissolved. SRNL is unsure for the reason for this at this time.

\subsubsection{Soluble Titanium Results}

Soluble titanium is monitored for the reasons outlined in Section 3.1.4 (see Figure 45). In all cases, the titanium levels were below $30 \mathrm{mg} / \mathrm{L}$. Perhaps of some significance is that there appears to be a trend that lower copper concentrations lead to higher titanium concentrations. There is, however, no intuitively obvious connection between the presence of copper and the titanium concentration. In the presence of less catalyst, the competing reaction of peroxide with other species - such as MST - becomes more favored. 


\section{Figure 45. Titanium Concentration Results for Low Copper Experiments}

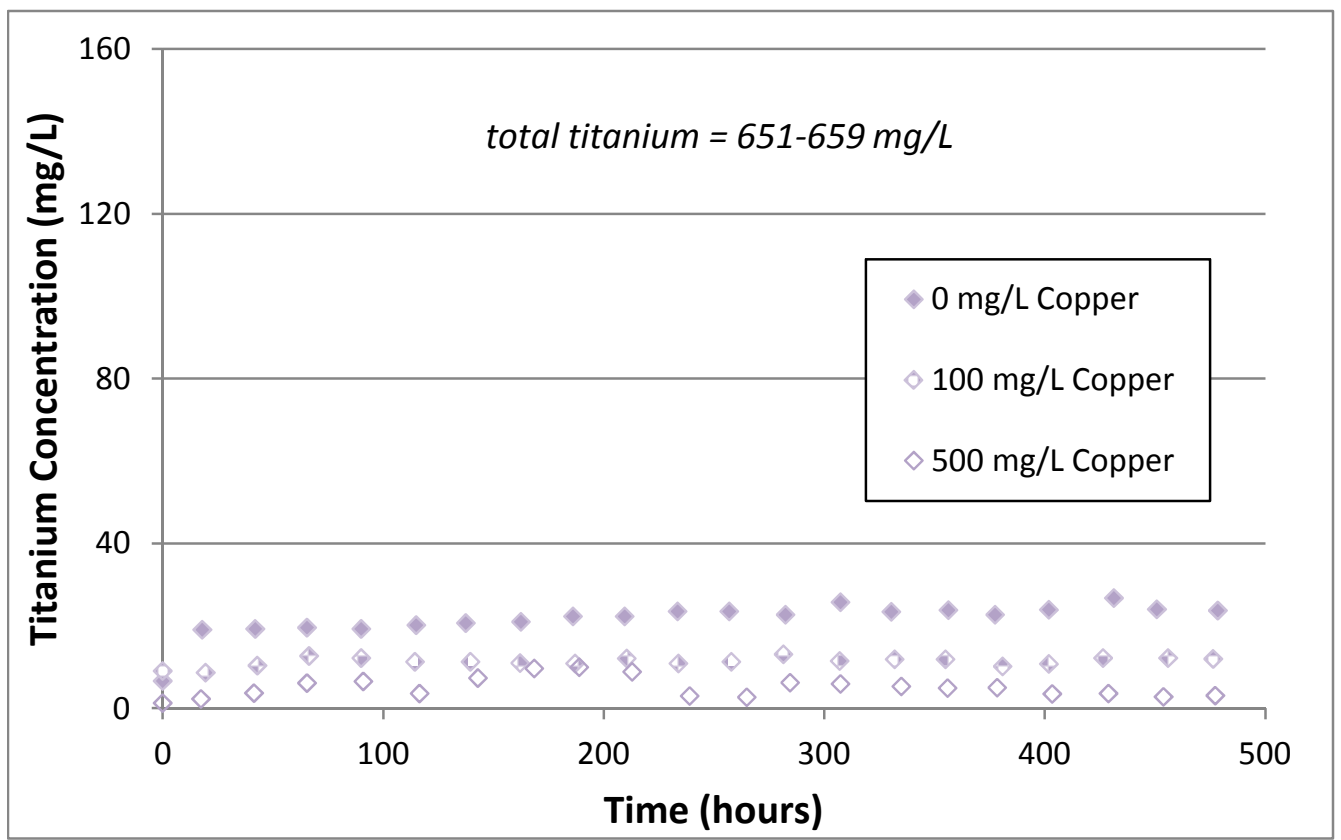

\subsubsection{Analysis of Reactor Bottoms}

After the low copper reactions were complete, the reactor bottoms were removed. The amount of recovered material is somewhat dependent on the efficiency of slurry removal (some solids were caked on the upper parts of the reactor or difficult to remove).

From the bottle of bottoms, well-mixed (in an attempt to ensure homogeneity) duplicate samples were analyzed via HPLC, VOA and SVOA. However, due to the elapsed time from the end of the reaction ( $\sim 315$ hours), and the time of sampling, a filtered sample of the bottoms was also analyzed via ICPES as a check to see if the reaction had proceeded further. The results of the ICPES analyses are listed in Table 38. The results for the four important analytes $(\mathrm{B}, \mathrm{K}, \mathrm{Cu}, \mathrm{Ti})$ are given next to the chronologically previous sample results. These results are corrected for dilution.

There are no statistically significant differences in the boron and potassium results between the two sample sets for any of the reactions. 
Table 38. ICPES Check Samples (mg/L) for Varying Amounts of Added Copper

\begin{tabular}{|c|c|c|c|}
\hline Reaction & Analyte & $\begin{array}{c}\text { Final Filtrate } \\
\text { Result }\end{array}$ & $\begin{array}{c}\text { End of Reaction Period } \\
\text { Sample Result }\end{array}$ \\
\hline \multirow{3}{*}{$0 \mathrm{mg} / \mathrm{L} \mathrm{Cu}$} & $\mathrm{B}$ & 422.8 & 418.4 \\
\cline { 2 - 4 } & $\mathrm{K}$ & 2076 & 2002 \\
\cline { 2 - 4 } & $\mathrm{Cu}$ & $<0.86$ & $<0.86$ \\
\cline { 2 - 4 } & $\mathrm{Ti}$ & 18.56 & 23.62 \\
\hline \multirow{3}{*}{$100 \mathrm{mg} / \mathrm{L} \mathrm{Cu}$} & $\mathrm{B}$ & 497.0 & 511.0 \\
\cline { 2 - 4 } & $\mathrm{K}$ & 2193 & 2311 \\
\cline { 2 - 4 } & $\mathrm{Cu}$ & 6.51 & 7.95 \\
\cline { 2 - 4 } & $\mathrm{Ti}$ & 4.06 & 11.87 \\
\hline
\end{tabular}

The analytical uncertainty is $10 \%$ for each result.

As there is no detectable additional destruction occurring, a valid comparison existed between the ICPES and HPLC results. Table 39 lists the HPLC results.

Table 39. HPLC Results from Reactor Bottoms Analyses (mg/L) for Lesser Amounts of Added Copper

\begin{tabular}{|c|c|c|c|c|c|c|}
\hline Reaction & TPB & 3PB & 2PB & 1PB & Phenol & \% Destruction \\
\hline $0 \mathrm{mg} / \mathrm{L} \mathrm{Cu}$ & $2585(0.82 \%)$ & 12 & $<10$ & $<10$ & 33 & $84.6-84.8 \%$ \\
\hline $100 \mathrm{mg} / \mathrm{L} \mathrm{Cu}$ & $245(2.89 \%)$ & $<10$ & $<10$ & $<10$ & $<10$ & $98.4-98.5 \%$ \\
\hline $500 \mathrm{mg} / \mathrm{L} \mathrm{Cu}$ & $<10$ & $<10$ & $<10$ & $<10$ & $<10$ & $>99.9 \%$ \\
\hline
\end{tabular}

The value in parentheses is the \%RSD. The "\% Destruction" column is the calculated percent destruction. The value is based on the mass of TPB added to the simulant slurries and calculation of the mass of TPB in the reactor bottoms, after correcting for the mass of samples removed from the system during the reactions.

The HPLC results corroborate the boron and potassium data. While the $100 \mathrm{mg} / \mathrm{L} \mathrm{Cu}$ reaction is virtually complete after 480 hours of processing, the $0 \mathrm{mg} / \mathrm{L}$ copper test indicates the need for additional reaction time.

Samples of the reactor bottoms were analyzed using VOA and SVOA. See Tables 40 and 41. The values in parentheses are the $\% \mathrm{RSD}$. In the results column, values that are shaded indicate only one real value with the other being a detection limit result. In this case, the values in parentheses are the analytical uncertainties. In the analyte column, shaded cells indicate the presence of that analyte is doubtful due to chemical conditions or interferences. The "total organic residuals" are the sum of all the mid-range values of 
the detected analytes, less benzene and the analytes that are declared to be from interferences.

Table 40. VOA and SVOA Results for $0 \mathrm{mg} / \mathrm{L} \mathrm{Cu}$ Reactions

\begin{tabular}{|c|c|}
\hline Analyte & Result (mg/L) \\
\hline benzene & $0.20(0.00 \%)$ \\
\hline biphenyl & $301(9.87 \%)$ \\
\hline benzophenone & $47.4(136 \%)$ \\
\hline p-terphenyl & $21.5(23.0 \%)$ \\
\hline diisooctyl adipate & $18.5(3.82 \%)$ \\
\hline o-terphenyl & $3.70(7.64 \%)$ \\
\hline m-terphenyl & $3.15(6.73 \%)$ \\
\hline 4-nitro-1,1-biphenyl & $1.28-1.92$ \\
\hline 3-nitrophenol & $0.88-1.32$ \\
\hline Total organic residuals & 380 \\
\hline
\end{tabular}

Table 41. VOA and SVOA Results for $100 \mathrm{mg} / \mathrm{L} \mathrm{Cu}$ Reaction

\begin{tabular}{|c|c|}
\hline Analyte & Result (mg/L) \\
\hline benzene & $0.0975(3.63 \%)$ \\
\hline biphenyl & $51.0(80.4 \%)$ \\
\hline p-terphenyl & $24.4(60.1 \%)$ \\
\hline diisooctyl adipate & $17.0(49.9 \%)$ \\
\hline o-terphenyl & $3.85(38.6 \%)$ \\
\hline m-terphenyl & $1.84-2.76$ \\
\hline diphenyl ether & $1.04-1.56$ \\
\hline Total organic residuals & 82.9 \\
\hline
\end{tabular}

Of the residual organics left in the reactor bottoms, biphenyl is the most concentrated. The most interesting result is that there are relatively few species present in these two bottoms compared to previous reactions. While the $100 \mathrm{mg} / \mathrm{L}$ copper may be optimized for minimization of organic residuals, $500 \mathrm{mg} / \mathrm{L}$ of copper gives a faster rate. 


\subsection{6 pH Monitoring}

$\mathrm{pH}$ was monitored during the reaction. See Figure 46. In addition to the two experiments described in this Section, the $500 \mathrm{mg} / \mathrm{L}$ copper test (see Section 3.5.1, $\mathrm{pH} 9$ reaction) is also shown in Figure 46.

Again, the $\mathrm{pH}$ values remain at $\sim \mathrm{pH} 9$ throughout the life of the reaction. The varying concentrations of copper do not affect the change in $\mathrm{pH}$ of the reactions.

Figure 46. pH Readings for Tests $2 b$ and $2 c$

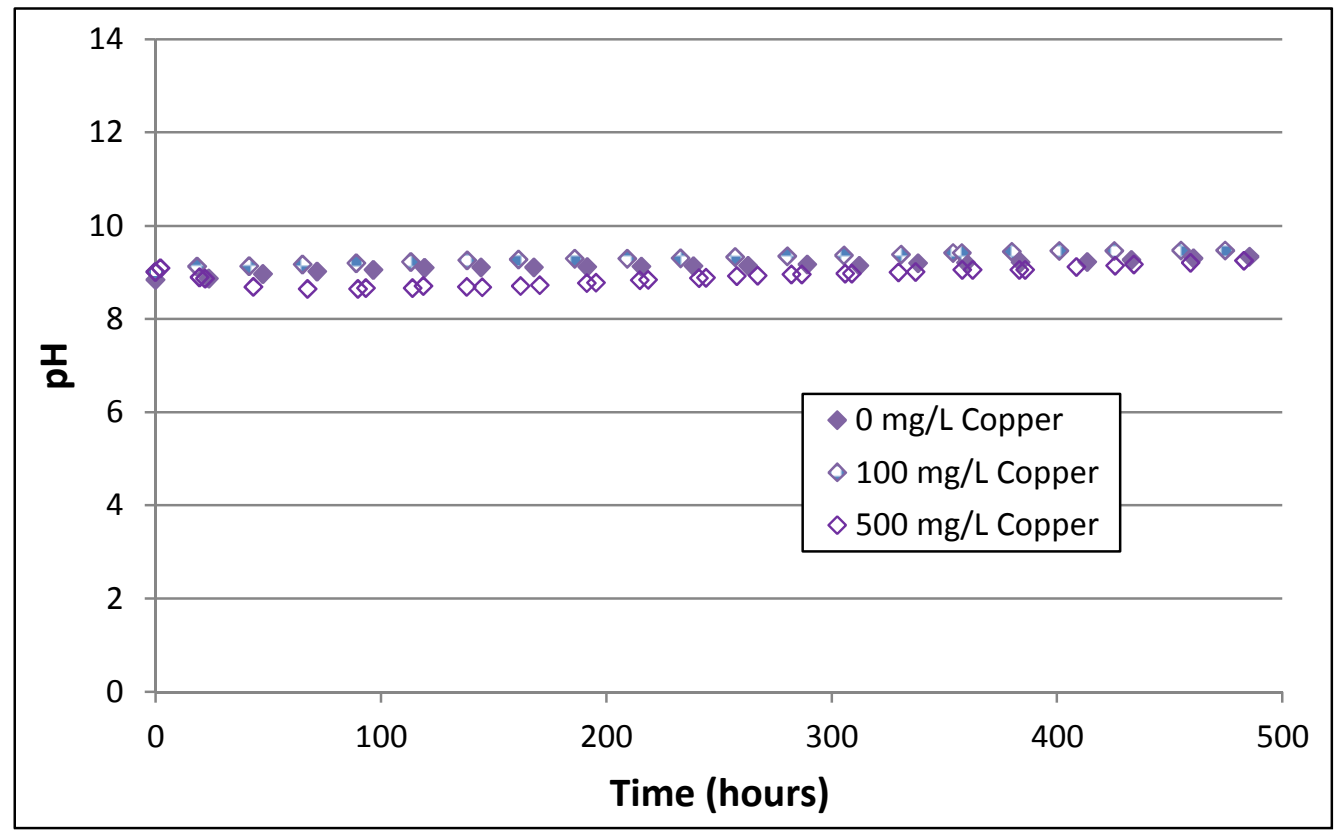

\subsubsection{Conclusion}

While lower concentrations of copper are desirable to reduce impacts at DWPF, lowering the copper to $100 \mathrm{mg} / \mathrm{L}$ or lower detrimentally affects the rate of TPB destruction.

Future experiments designed to study the effects of copper should chose an intermediate concentration, such as $250 \mathrm{mg} / \mathrm{L}$. However given the consistent lack of total dissolution of the added copper, it is possible that intermediate concentrations will bring intermediate extents of organic destruction.

The extent of copper loading appears to affect the proportion of soluble titanium. The data sets tentatively suggest that excess amounts of $\mathrm{H}_{2} \mathrm{O}_{2}$ will leach titanium into solution. The excess $\mathrm{H}_{2} \mathrm{O}_{2}$ may either occur as a function of increasing the $\mathrm{H}_{2} \mathrm{O}_{2}$ addition rate (see Section 3.7.3) or by reducing the amount of added copper. For the latter, reduced copper 
catalyst is assumed to decrease the formation of hydroxyl radicals that would be utilized in the oxidation of organic compounds thus making more $\mathrm{H}_{2} \mathrm{O}_{2}$ available for interaction with MST.

\subsection{Comparison of Demonstration 1 and the 2004 Final Test}

In the 2004 report, ${ }^{2}$ SRNL provided the results from two tests designed to prove the efficacy of $\mathrm{H}_{2} \mathrm{O}_{2}$ aided organic destruction. In that report, the reaction which was conducted at $\mathrm{pH} 11$ is the most relevant to the current work. The current work for DEMO 1 was conducted very similarly to the 2004 work as an attempt to repeat it. However, there were three differences.

- The simulant slurry was not $\mathrm{pH}$ adjusted in the same manner. The 2004 test used samples from earlier tests with a composite slurry initial $\mathrm{pH}$ of 11 . Hence, the initial slurry processing history differed.

- The current work used $50 \mathrm{wt} \% \mathrm{H}_{2} \mathrm{O}_{2}$ instead of $30 \mathrm{wt} \%$. Volume additions were not corrected for the difference There were no anticipated negative processing effects in using a higher peroxide concentration, and $50 \mathrm{wt} \% \mathrm{H}_{2} \mathrm{O}_{2}$ should ultimately reduce the final waste volume.

- $\quad$ The current test simulated the 2004 test procedure that followed addition of 467 $\mathrm{mg} / \mathrm{L}$ copper catalyst since prior to this point no significant reactivity was observed. As such a one week reaction period at room temperature, and four days at $35{ }^{\circ} \mathrm{C}$ (both with a lesser $24 \mathrm{mg} / \mathrm{L}$ added copper catalyst) were omitted from the current test procedure.

At the end of the 2004 reaction, the report ${ }^{2}$ claimed $95 \%$ of the TPB had decomposed as determined by boron in solution. By the potassium result, $100 \%$ (111\% as reported) of the TPB had decomposed.

Table 42 shows the comparison of the final slurry analyses. The residual TPB and other organics in the bottoms corroborate the lower extent of reaction for the current test (DEMO 1). Potential factors associated with the reduced destruction efficiencies for the verification test have not yet been identified. 
Table 42. Comparison of 2004 and Demonstration 1

\begin{tabular}{|c|c|c|}
\hline Analyte & 2004 Result & Current Result \\
\hline TPB destruction - B & $95 \%$ & $78.1 \%$ \\
\hline TPB destruction - K & $111 \%$ & $95.1 \%$ \\
\hline TPB & $<10$ & $2420 \mathrm{mg} / \mathrm{L}$ \\
\hline 3PB & $<10$ & $<10$ \\
\hline 2PB & $<10$ & $<10$ \\
\hline 1PB & $<10$ & $<10$ \\
\hline Phenol & $<10$ & $<10$ \\
\hline TIC & $2760 \mathrm{mg} / \mathrm{L}$ & $1870 \mathrm{mg} / \mathrm{L}$ \\
\hline TOC & $1160 \mathrm{mg} / \mathrm{L}$ & $1150 \mathrm{mg} / \mathrm{L}$ \\
\hline $\begin{array}{c}\text { Total residual SVOA } \\
\text { organics }\end{array}$ & $16 \mathrm{mg} / \mathrm{L}$ & $898 \mathrm{mg} / \mathrm{L}$ \\
\hline Final $\mathrm{pH}$ & 9.6 & 8.96 \\
\hline
\end{tabular}

The off-gas measurements from the two reactions can also be compared (Figure 47). Note that $\mathrm{CO}_{2}$ was not measured in the 2004 test.

The benzene in both reactions shows the same general trends - a spike in gas released to the $\mathrm{GC}$ at each temperature increase, although in the 2004 test the increase at $45{ }^{\circ} \mathrm{C}$ is rather small. In DEMO 1, the initial release of benzene occurs after the $\mathrm{pH}$ adjustment; $\mathrm{pH}$ adjustment was not required in the 2004 work since the simulant was already $\mathrm{pH}$ adjusted. 
Figure 47. Comparison of 2004 pH11 Test and Demonstration 1

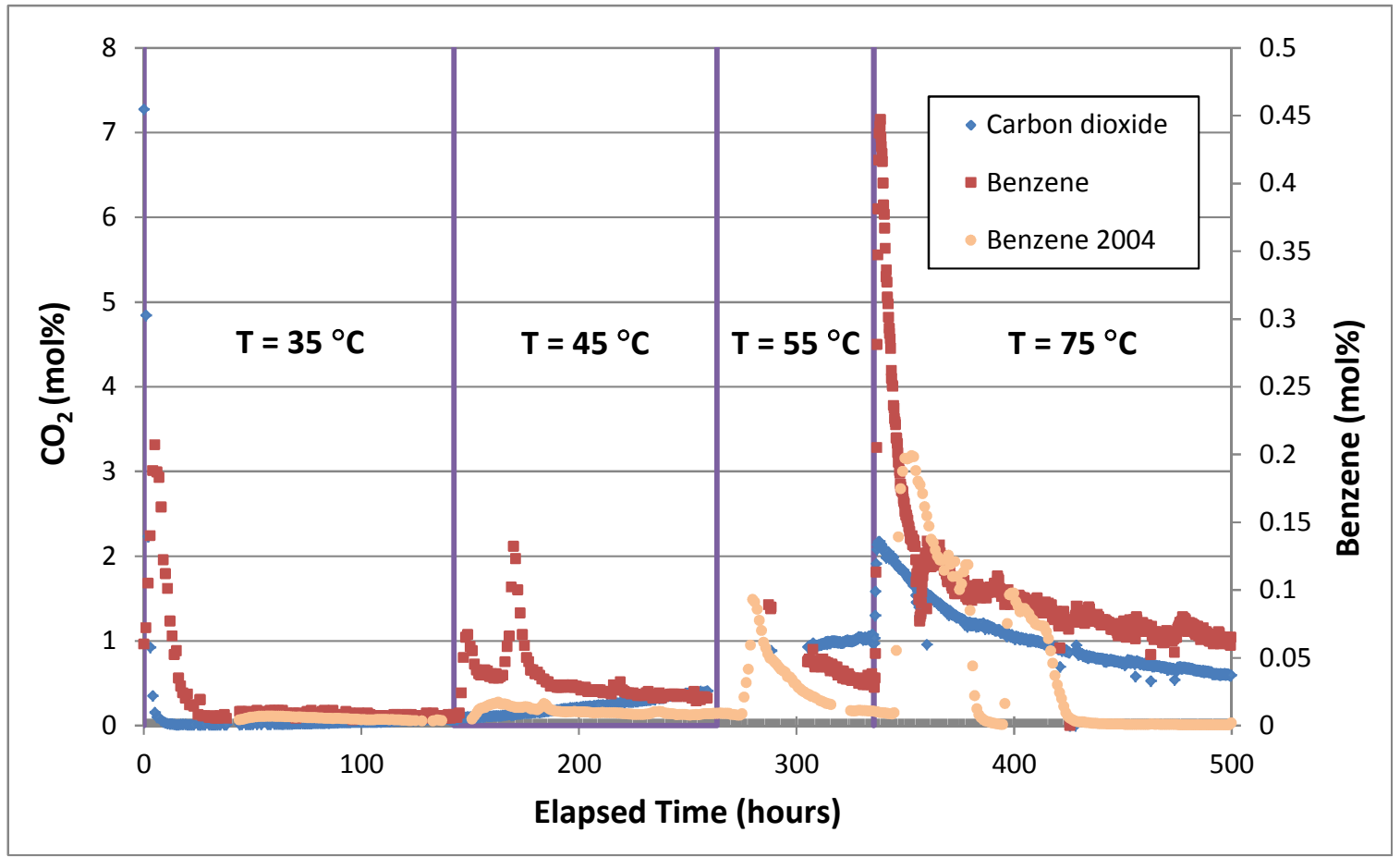

It is also possible to compare the 2004 and current work with respect to boron and potassium results though the 2004 work has a sparse data set in comparison to the current data. Figure 48 shows the boron results from the current work, converted into \%Destruction values on the y-axis. The two relevant data points from 2004 are also in the figure. The 2004 data is not volume normalized due to the lack of sodium data in those analyses. Furthermore, the method of calculating the \%Destruction varies slightly between the 2004 and the current work. Thus the 2004 data points should be considered to have uncertainties larger than just their analytical uncertainty (10\%).

The same exercise can be performed with the potassium data. See Figure 49. 
Figure 48. Comparison of the \%Destruction by Boron Results in the 2004 and Current Work

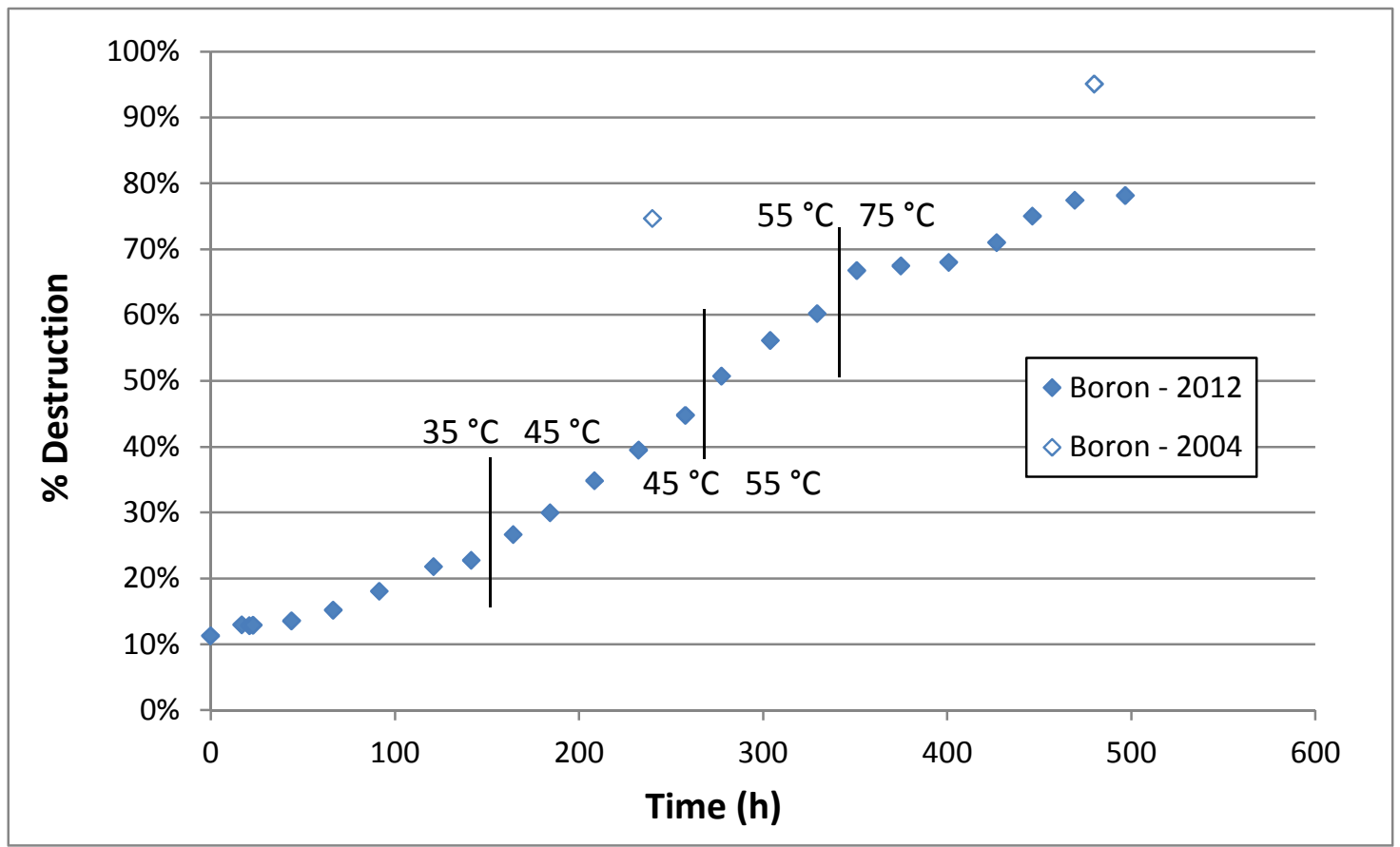

Figure 49. Comparison of the \%Destruction by Potassium Results in the 2004 and Current Work

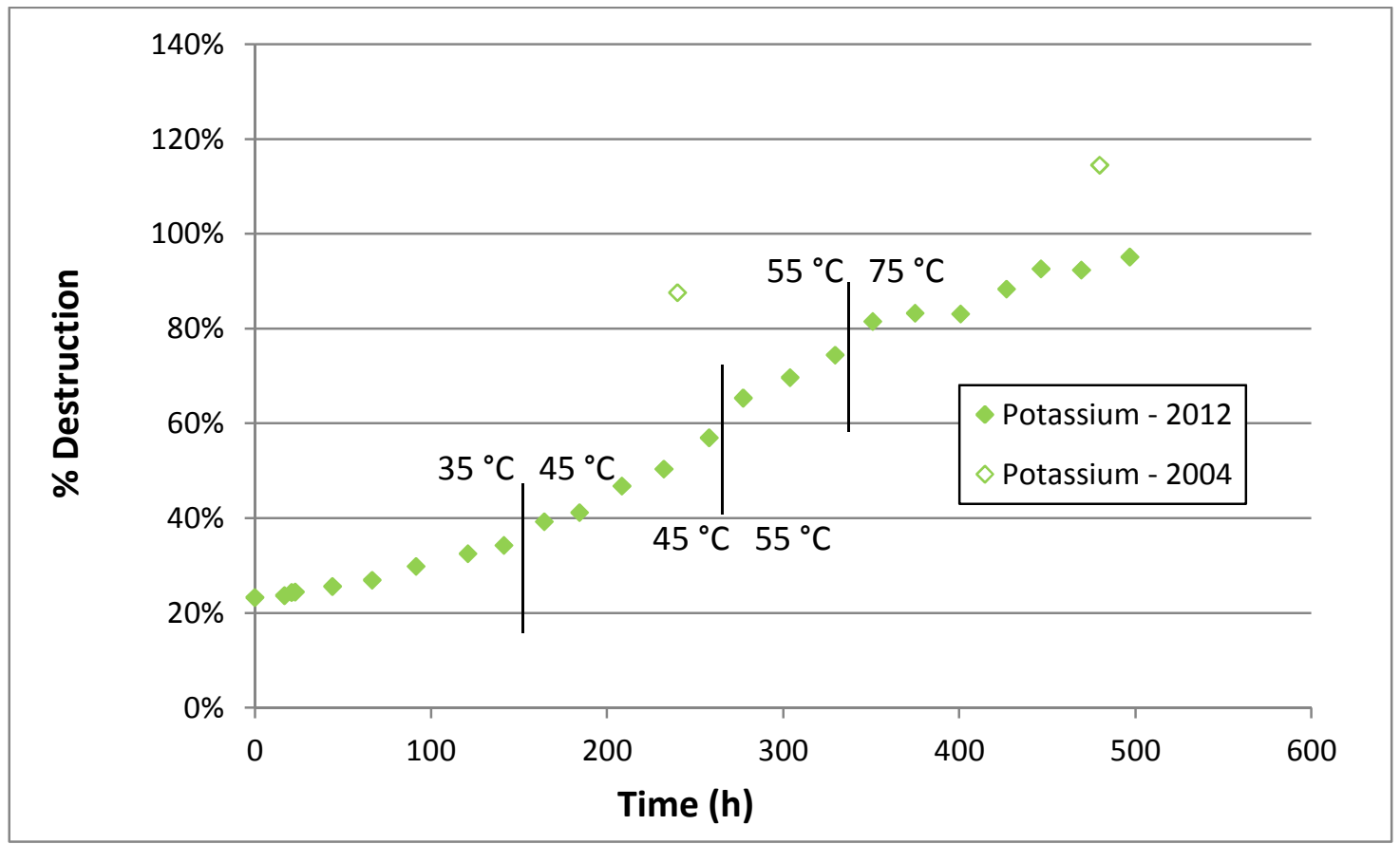


Both sets of data show an offset between the 2004 and the current work. The offset between the appropriate comparison points averages $\sim 28 \%$ (flat percent, not a percentage of the values), with the 2004 data being uniformly higher. From an inspection of 2004 data points that fall outside the time window of the current work (room temperature data), it appears that the 2004 work started at a higher \%Destruction than the current work. In other words, the 2004 work had a "head start" in the total destruction. ${ }^{\mathrm{f}}$

\subsection{Conclusions}

SRNL has performed a series of reactions to define an ideal set of reaction conditions to destroy KTPB, its decomposition products, and other organic materials present in Tank $48 \mathrm{H}$. The following CCPO process observations have been made.

Form of the added copper: There was no difference in the reactivity between hydrated copper nitrate and hydrated copper sulfate. It is most likely that copper salts with similar weakly coordinating anions will display the same levels of reactivity and solubility.

However, at no point did all of the added copper dissolve into the simulant solution. This may indicate that an alternate copper catalyst may give superior performance.

Effect of reaction temperature: There is a clear increase in reactivity with an increase in reaction temperature. Reactions conducted at $35^{\circ} \mathrm{C}$ did not reach completion in 3 weeks, while reactions conducted at $65^{\circ} \mathrm{C}$ were complete within $\sim 1$ day. Furthermore, the $65^{\circ} \mathrm{C}$ reaction provided the least amount of residual organics by the end. Each $15{ }^{\circ} \mathrm{C}$ increase in reaction temperature provided a $2-3 \times$ decrease in the residual organics. Increased temperatures also provided for higher concentrations of soluble copper, but not titanium.

Effect of decreasing initial $\mathrm{pH}$ : Initial tests adjusted the slurry $\mathrm{pH}$ to 11 . Starting at $\mathrm{pH} 9$ provides for a faster reaction, and starting at $\mathrm{pH} 7$ is even faster, reducing the destruction time to $\sim 1$ day. For each reaction in which $\mathrm{pH}$ was monitored over time, the $\mathrm{pH}$ values trended towards a final $\mathrm{pH}$ of $\sim 9$, regardless of the initial $\mathrm{pH}$. While a starting $\mathrm{pH}$ of 7 provided faster TPB destruction, a starting $\mathrm{pH}$ of 9 provided a lesser quantity $(\sim 40 \%$ of the $\mathrm{pH} 7$ reaction) of residual organics by the end of the reaction. The reaction at $\mathrm{pH} 9$ gave slightly higher copper and titanium concentrations.

Effect of increasing $\mathrm{H}_{2} \underline{\mathrm{O}}_{2} \underline{\text { rate: }}$ Faster additions of $\mathrm{H}_{2} \mathrm{O}_{2}$ provided a slight benefit in the rate of TPB destruction, although it is difficult to say if the benefit was statistically significant. This benefit may be outweighed by the additional generated volume.

\footnotetext{
${ }^{\mathrm{f}}$ The 2004 work actually ran at $75^{\circ} \mathrm{C}$ for a longer time period (453 hours) than the current work (161 hours). However, the 2004 work removed the "final" sample after only 168 hours. No further chemical samples were removed for the 2004 work even though the temperature was maintained.
} 
However, it can be stated that increased amounts of $\mathrm{H}_{2} \mathrm{O}_{2}$ provided for less amounts of

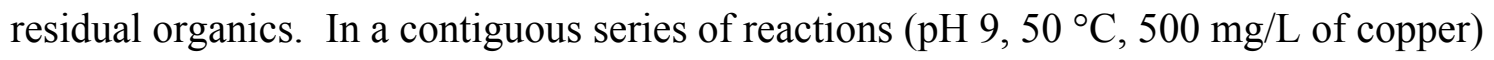
that varied only in the $\mathrm{H}_{2} \mathrm{O}_{2}$ delivery rates $(1 \times, 2 \times, 5 \times), 192.2,81.6$, and $7.75 \mathrm{mg} / \mathrm{L}$ of residual organics were generated, respectively. Increased $\mathrm{H}_{2} \mathrm{O}_{2}$ delivery clearly plays an important role in removing the residual organics.

Effect of copper loading: Increasing the concentration of copper catalyst provided faster organic destruction. Reactions involving copper added to $500 \mathrm{mg} / \mathrm{L}$ provided destruction times as short as $\sim 1$ day, while lowering or eliminating the added copper entirely increases the destruction time considerably. Curiously, despite changing the amounts of added copper, at no point did all of the added copper completely dissolve into the simulant solution. While increased copper gave higher reaction rates, the highest concentration of copper did not give the lowest concentrations of residual organics. This suggests that from the viewpoint of residual organic destruction, intermediate concentrations (between 100 and $500 \mathrm{mg} / \mathrm{L}$ ) of copper may be more ideal.

Residual organic compounds: In each set of reactor bottoms analyzed, the presence of a variety of residual organic compounds, in varying concentrations was noted. SRNL suspects that much of this residual material is caused by the method of $\mathrm{pH}$ adjustment $50 \mathrm{wt} \%$ nitric acid. In the simulant reactions, the slurry maintains a mat of floating material that comes into contact with the added nitric acid. This direct contact is probably conducive to the formation of many of the aryl compounds noted in the SVOA analyses. Adjusting the $\mathrm{pH}$ by less harsh methods may provide for a small final concentration of residual organics. Furthermore, it is possible that real waste operations may provide for comparatively smaller amounts of residual organics as the TPB solids do not form a floating matt of material.

Formate and Oxalate production: Although limited to one data set, it appears that both formate and oxalate anions are produced as part of the $\mathrm{H}_{2} \mathrm{O}_{2}$ aided destruction. While the formate was ultimately reduced to below detection limits, the oxalate continued to increase in concentration over the life of the reaction. The potential production of formate and oxalate should be considered for downstream impacts and may lead to the desire for longer reaction times and/or higher $\mathrm{H}_{2} \mathrm{O}_{2}$ delivery rates.

\subsection{Future Work}

Based upon the conclusions, SRNL proposes the following future work

- A real waste test should be conducted to ensure that the simulant and real waste perform in a similar manner.

- Future reactions should be centered around the proven conditions of $\mathrm{pH} 9$ and 
$50{ }^{\circ} \mathrm{C}$. While temperatures $>50{ }^{\circ} \mathrm{C}$ attain faster destruction rates, it may be problematic to achieve the elevated processing temperatures in the actual facility. Reactions below $\mathrm{pH} 9$ also appear to generate large quantities of biphenyl, which could potentially plate out in the Building $241-96 \mathrm{H}$ process vessel vent system.

- $\mathrm{H}_{2} \mathrm{O}_{2}$ delivery rates should probably stay bounded in the current matrix $(1 \times$ to $5 \times)$. Higher addition rates reduce the residual organics, but generate a higher final volume.

- Consideration needs to be given to the exit pathway for the treated material. The ultimate endpoint for the treated waste may influence the success criteria.

- Consideration should be given to trying to $\mathrm{pH}$ adjust the slurries with alternative acids so as to avoid production of residual organics and to reduce the production of benzene associated with $\mathrm{pH}$ adjustment. It is also hoped that this may provide additional benefits in deconvoluting the gas release data, if the hydrolysis reactions and decomposition of the carbonate salts in the simulant solutions can be avoided. (Deconvolution of the gas release data is also possible by inserting a delay between the end of $\mathrm{pH}$ adjustment and the start of the peroxide addition.)

- Further tests are required to more accurately close the carbon mass balance. Additional analysis of formate and oxalate will help close the material balance but some carbon species may not be tractable given the current analytical and sampling techniques. Use of mass flow controllers may improve the certainty of $\mathrm{GC}$ data. Continuing gas analyses of the stirred slurry for an extended period after reaction completion may also help close the material balance gap. Similarly, refrigeration of samples may also reduce any uncertainty from evolved benzene or from continuing reaction.

- Samples of all the remaining reactor bottoms will be analyzed by IC-Anions and TIC/TOC to help provide a superior carbon balance.

- SRNL will refine the reactor apparatus to reduce leakage of gas from the vessels. 


\section{Appendix A. Design of a Mixing Vessel for TPB/Peroxide Reactions}

Goal: Design and construct a mixing vessel with similarities to that of WSRC-TR-2005$00114,{ }^{2}$ using scaling laws where possible, to mimic Tank $48 \mathrm{H}$ slurry oxidation processing in the Building 241-96H reaction tank. This work is to provide equipment that will handle both simulant and actual Tank $48 \mathrm{H}$ sample slurries. The lab scale batch volume is to be approximately the same as the "Lab Scale Integrated Demonstrations" from the 2004 work. ${ }^{2}$ The process is now planned for the stainless steel tank in Building $241-96 \mathrm{H}$ rather than the carbon steel Tank $48 \mathrm{H}$, so the current work will also use a stainless steel vessel. The laboratory agitator will be scaled considering the agitator in the Building 241-96H reaction tank.

\section{A. General Direction}

1. Scaling shall consider the geometry of the Building 241-96H tank. The tank is made of stainless steel with a vertical mixer impeller with an upper and lower mixing turbine ( 4 blades each). The upper turbine has $45^{\circ}$ slanted blades designed for downflow and the lower turbine has vertical paddle blades that induce radial outward flow. The tank is a vertical cylinder of 12 foot diameter and has four vertical baffles at the side wall. The lab rig is to be built mostly of stainless steel to maintain similarity with the facility vessel. The chemistry uses hydrogen peroxide, so materials of construction may provide catalytically active surfaces that may produce bubbles or affect the process to some extent.

2. The dimensions of the facility tank and mixer are given in Table 43, with prior data $^{19,20}$.

3. Operating experience ${ }^{6}$ showed that the vessel temperature needs improved control over just a hot plate and stirrer. Prior work applied this lesson by using a water bath with the temperature being controlled to values in a range of $35^{\circ}$ to $75^{\circ} \mathrm{C} .^{2}$

4. Operating experience ${ }^{6}$ showed no benefit if chemical additions to the vessel used a downcomer (below liquid level). The facility design does not currently include downcomers.

5. Earlier work $^{6}$ recommended an agitator and baffled vessel vs. the magnetic stir bar that was used. It suggested that the improvement in mixing should improve the results. One negative aspect of observed foaming was that tetraphenylborate solids were not in contact with the reaction liquid.

\section{B. Scaling of Mixing}

The current work is to use a 0.5 to 1 liter volume of reacting liquid, while the facility vessel processes 20,000 liter batches. Tatterson lists the general method to scale mixing using dimensional analysis. ${ }^{21}$ The variables for mixing equipment include fluid properties, geometric features including tank and impeller dimensions, and dimensionless numbers, the most common being the Impeller Reynolds Number (Re), Froude Number 
(Fr), and Power Number (Po). The current work is constrained in that fluid (simulant, hydrogen peroxide, and any acid) properties (density, viscosity, etc.), reaction rates, temperature, and pressure must be scaled $1: 1$ with the facility process.

Linear geometric scaling is recommended for mixing processes. ${ }^{22,23}$ It is recommended that the linear factor be no greater than 10:1, but the sample size in the current work dictates a greater scale factor (30:1). The current effort examined linear geometric scaling and found that Fr or mixing time are practical scaling strategies. Fr scaling is recommended because agitation is at good practical rates and the faster mixing time of the lab unit vs. facility tank can be easily addressed. However, slurry foaming may be an issue that influences agitator speed selection. ${ }^{24}$

The dimensionless numbers are defined as follows:

Reynolds number, $\mathrm{Re}=\mathrm{D}^{2} * \mathrm{~N} * \rho / \mu \quad$ [ratio of inertial to viscous force] Froude Number, $\mathrm{Fr}=\mathrm{D} * \mathrm{~N}^{2} / \mathrm{g} \quad$ [ratio of inertial to gravitational force] Power Number, Po $=\mathrm{P} * \mathrm{~g}_{\mathrm{c}} /\left(\rho * \mathrm{~N}^{3} * \mathrm{D}^{5}\right) \quad$ [ratio of drag force to inertial force]

A summary of data are provided in Table 43, with the lab scale rig being 1/30 linear scale of the Building 241-96H tank. Both the lower and upper impellers have the same diameter D. Density is $\rho$ and $\mathrm{N}$ is impeller speed.

Table 43. Dimensional Data for Mixing Vessels

\begin{tabular}{|l|c|c|}
\hline \multicolumn{1}{|c|}{ Quantity } & Building 241-96H Tank & Lab Scale Vessel \\
\hline Tank Diameter, T & $12.00 \mathrm{ft}$ & $12.20 \mathrm{~cm}$ \\
\hline Liquid Height, H & $6.28 \mathrm{ft}$ & $6.38 \mathrm{~cm}$ \\
\hline Flat Turbine Diameter, D & $2.83 \mathrm{ft}$ & $2.88 \mathrm{~cm}$ \\
\hline Slanted turbine Diameter, D & $2.83 \mathrm{ft}$ & $6.88 \mathrm{~cm}$ \\
\hline Baffle height & $6.03 \mathrm{ft}$ & $1.00 \mathrm{~cm}$ \\
\hline Baffle width & $1.00 \mathrm{ft}$ & $4.76 \mathrm{~cm}$ \\
\hline $\begin{array}{l}\text { Slanted Turbine height off } \\
\text { bottom }\end{array}$ & $4.69 \mathrm{ft}$ & $0.71 \mathrm{~cm}$ \\
\hline $\begin{array}{l}\text { Flat Turbine height off } \\
\text { bottom }\end{array}$ & $0.70 \mathrm{ft}$ & 0.75 liters \\
\hline Tank Volume & $710.63 \mathrm{cubic}$ feet $(5300$ gal $)$ & \\
\hline
\end{tabular}

B.1 Reynolds Number Scaling

Tables 43 and 44 list the geometric data and fluid properties along with results from further calculations. At equal lab and facility Fr the lab rig would have Re of $2.77 \mathrm{E}+03$ while the facility vessel would see a Re of $4.5 \mathrm{E}+05$. This difference in Re is actually not that significant given that Po is a weak function of Re when Re exceeds $1 \mathrm{E}+04$ (in the turbulent mixing regime). ${ }^{25}$ An attempt to match Re by increasing the lab scale agitator 
speed would not be practical and would eject the vessel contents from the beaker. The lab scale agitator would lose contact with the liquid and would be spinning at approximately 48,000 rpm.

\section{B.2 Froude Number Scaling}

Fr between plant and lab scale can be matched if the lab scale agitator is spinning at 462 $\mathrm{rpm}$. This is practical operation for lab work.

\section{B.3 Mixing Time Scaling}

Literature provides other means of scaling, including mixing time. This value would be the time, for example, to mix an injected miscible liquid into the agitated vessel and see high uniformity, such as $90 \%$. After the linear scaling and impeller speed was obtained, several different correlations for mixing time were applied to the geometry.

The Fr scaling method (462 rpm) is recommended as long as reagent additions to the lab unit are slow and steady, vs. pulsed. The estimated mixing time is of the order of magnitude 5 seconds.

Table 44 below is a summary of scaling results for $1 / 30$ length scaling and a lab impeller speed of $462 \mathrm{rpm}$. Froude number matching is exact, and mixing times given by several different correlations are in reasonable agreement with each other, showing that the lab unit mixing time is about 3 to 5 times faster than the facility tank on an absolute basis. This is not considered to be a problem since the chemical reaction characteristic time is much longer than the mixing time, so both facility and lab vessels are well mixed relative to other parts of the process. The facility tank contents sees higher power dissipation per volume, and this is typical of mixed tanks. The work here predicts that the facility agitator delivers $16 \mathrm{Hp}$ of shaft work to the liquid in that tank.

Norwood and Metzner ${ }^{26}$ expressed mixing time with turbines in a baffled tank using a dimensionless parameter " $\mathrm{f}_{\mathrm{t}}$ ":

$$
\mathrm{f}_{\mathrm{t}}=\mathrm{t}^{*}\left(\mathrm{ND}^{2}\right)^{2 / 3} * \mathrm{~g}^{1 / 6} *(\mathrm{D} / \mathrm{H})^{0.5} /\left(\mathrm{T}^{1.5}\right)
$$

where $\mathrm{t}$ is mixing time, $\mathrm{g}$ is gravitational acceleration, $\mathrm{N}$ is impeller speed, $\mathrm{D}$ is impeller diameter, $\mathrm{H}$ is fluid depth, and $\mathrm{T}$ is tank diameter. A graph in that paper allows determination of $f_{t}$ as a function of Reynolds number, and the values are shown in Table 44. The mixing time provided by the application of Norwood and Metzner's empirical work is shown in the line that follows in the table.

In a separate analysis Rushton presents an empirical graph, in this case providing Power Number (Po) as a function of Reynolds Number. ${ }^{27}$ The values of Po from the graph are shown in Table 44. An estimate of mixing time was calculated from a correlation by Grenville: ${ }^{28}$ 


$$
\text { Mixing time }=5.2 *(\mathrm{~T} / \mathrm{D})^{2} *\left(\mathrm{Po}^{(1 / 3)}\right) / \mathrm{N}
$$

Moo-Young presents a correlation using Reynolds number $(\mathrm{Re})$ directly for turbine mixers and baffled tanks: ${ }^{29}$

$$
\text { Mixing time }=\mathrm{A} *\left((\mathrm{Re})^{\mathrm{b}}\right) / \mathrm{N}
$$

where $\mathrm{A}$ and $\mathrm{b}$ are parameters that Moo-Young provides given ranges of Re. From MooYoung's work $\mathrm{A}$ is 36 and $\mathrm{b}$ is zero in the range of $\mathrm{Re}$ of $1.0 \mathrm{E}+03$ to $1.0 \mathrm{E}+05$.

The Van de Vusse Parameter in Table 44 determines if the tank geometry is adverse in the sense that there may be dead corners that affect the vessel mixing time. ${ }^{30}$ The parameter is defined below, and is to be between 0.001 and 0.04 for acceptable prediction of mixing time. The geometry and liquid fill height of the vessels considered here are within the acceptable range.

$$
\text { Van de Vusse Parameter (dimensionless) }=\mathrm{D}^{3} /\left(\mathrm{T}^{2.5} * \mathrm{H}^{0.5}\right)
$$

In all cases the mixing time for the facility and also lab vessels are predicted to be less than half a minute. Given that the chemical reactions take hours, the mixing keeps well ahead of chemical reaction rates and the liquid batches are well mixed.

Table 44. Mixing Time Predictions and Mixing Power

\begin{tabular}{|l|r|r|}
\hline \multicolumn{1}{|c|}{ Quantity } & $\begin{array}{c}\text { Building 241-96H } \\
\text { Tank }\end{array}$ & Lab Scale Vessel \\
\hline Impeller speed, rotations/s, N & 1.40 & 7.7 \\
\hline Reynolds Number, dimensionless & $4.52 \mathrm{E}+05$ & $2.77 \mathrm{E}+03$ \\
\hline Froude Number, dimensionless & 0.173 & 0.174 \\
\hline Impeller Tip speed, cm/s & 1180 & 219 \\
\hline Norwood \& Metzner Parameter ft, dimensionless & 4 & 7 \\
\hline Norwood \& Metzner Mix Time, s & 27.7 & 8.8 \\
\hline $\begin{array}{l}\text { Power number for Grenville Mix Time, } \\
\text { dimensionless }\end{array}$ & 7 & 5 \\
\hline Grenville Mix Time, s & 25.2 & 5.1 \\
\hline Moo-Young Mix Time, s & 25.7 & 4.7 \\
\hline N times Grenville mix time & 35.3 & 39.5 \\
\hline Van de Vusse Dimensionless Parameter & 0.02 & 0.02 \\
\hline cgs power from Po, erg/s & $1.20 \mathrm{E}+11$ & $5.87 \mathrm{E}+05$ \\
\hline cgs power per volume, erg/s/cm & $5.96 \mathrm{E}+03$ & $7.87 \mathrm{E}+02$ \\
\hline convert power to total Hp for the vessel & 16.1 & $7.87 \mathrm{E}-05$ \\
\hline Hp/gal & $3.03 \mathrm{E}-03$ & $3.99 \mathrm{E}-04$ \\
\hline
\end{tabular}


C. Services to the Reactor Vessel

Earlier work ${ }^{2}$ showed many of the services needed to the vessel, and a list for the current work shall include:

1. central rotary mixing shaft, larger port,

2 . thermocouple, probably $1 / 8$ " diameter,

3. small diameter tube for adding reagents (connected to a syringe pump source),

4. small diameter tube for sampling (withdraw using a syringe),

5. gas in (combination of oxygen and nitrogen, maybe air), using a small port and,

6. gas out through a glass condenser (on a larger port).

This describes the experimental program to demonstrate and optimize the laboratoryscale catalyzed peroxide oxidation process for the destruction of TPB in both simulated and real Tank $48 \mathrm{H}$ waste. This work builds off of previous work performed during the period of 2001-2005.

Experiments will initially be directed towards optimizing the peroxide oxidation of TPB utilizing a waste simulant and, once established, the process will be confirmed for real waste. This program may use various peroxide-based oxidants (hydrogen peroxide, sodium percarbonate, sodium perborate), catalysts and acids to decompose the TBP salts, as well as their decomposition products (such as triphenylborane, diphenylboronic acid, and phenylborinic acid). Copper will be the primary catalyst studied and hydrogen peroxide will be the primary oxidant, other catalysts and oxidants may be explored during this study. Where possible, optimization guidelines outlined in Perry's Chemical Handbook will be used ${ }^{31}$.

Although the precise scope of the experiments will be determined during testing, they fall into two categories. The first category is small scale experiments, in the $250-500 \mathrm{~mL}$ range. These experiments will typically involve only simulants. These smaller tests are designed to determine the effects of various operating parameters, such as temperature, agitation, amount of peroxide, etc.

Larger scale (1-2L) tests may be performed after to corroborate earlier results. These larger tests will involve either simulants or real waste. These larger tests will also typically utilize off-gas monitoring through the use of a gas chromatograph.

Nomenclature

D Impeller diameter

$\rho \quad$ Liquid Density

$\mathrm{Fr} \quad$ Froude Number

$\mathrm{g} \quad$ Value of gravitational acceleration

$\mathrm{g}_{\mathrm{c}} \quad$ Conversion factor for force and accelerated mass

$\mathrm{H} \quad$ Liquid depth in the tank 


$\begin{array}{ll}\mathrm{N} & \text { Impeller rotational speed } \\ \mathrm{P} & \text { Power } \\ \mathrm{Po} & \text { Power Number } \\ \mathrm{Re} & \text { Reynolds Number (for impeller) } \\ \mathrm{T} & \text { Tank diameter } \\ \mu & \text { Viscosity }\end{array}$


SRNL-STI-2012-00342

Revision 0

Appendix B

\section{Analysis for Tetraphenylborate and Decomposition Products}

\section{Sample Preparation}

\section{Chemicals}

Potassium phosphate monobasic $\left(\mathrm{KH}_{2} \mathrm{PO}_{4}\right)$

Deionized water

Acetonitrile

\section{Protocol}

In a $10 \mathrm{~mL}$ volumetric flask, add $1.0 \mathrm{~mL}$ of sample, $2.5 \mathrm{~mL}$ of saturated potassium phosphate solution, and mix. Determine the $\mathrm{pH}$ falls within the range of $6-7$. Fill the flask to the line with acetonitrile and mix. Allow to stand for 5 minutes and remove the top layer for analysis.

\section{Analyses}

\section{Chemicals}

Tetraphenylborate - Can use either the potassium or sodium salt.

Triphenylborane (3PB) - Flammable compound so you need to purchase the triphenylborane-sodium hydroxide adduct and precipitate the 3PB-ammonia adduct with ammonium hydroxide.

Diphenylborinic acid (2PB) - Sold as diphenylborinic acid, ethanolamine ester Phenylboric acid (1PB)

Phenol

Acetonitrile

Acetonitrile 33\% vol/Methanol 27\% vol/Buffer 40\% volume (La-Mar-Ka, Inc., Order \# 0980, MP320)

\section{Standards}

The instrument standards are prepared in acetonitrile. 
Table 45. Summary of Reversed-phase HPLC Methods for TPB and Degradation Products

\begin{tabular}{|l|c|}
\hline \multicolumn{1}{|c|}{ Method } & Conditions \\
\hline \hline \multicolumn{2}{|c|}{ Isocratic for tetraphenylborate (TPB), triphenylborane (3PB), diphenylborinic acid (2PB) } \\
\hline $\begin{array}{l}\text { Mobile Phase } \\
\text { Column }\end{array}$ & $\begin{array}{c}\text { Acetonitrile (27\% vol)-ammonium phosphate buffer (33\% vol)- } \\
\text { methanol (40\% vol) }\end{array}$ \\
\hline Oven Temperature & Dychrom Chemcosorb 5-ODS-UH, 3.2 mm x 250 mm \\
\hline Flow-rate & $0.5 \mathrm{~mL} / \mathrm{min}$ \\
\hline Stop Time & $20 \mathrm{minutes}$ \\
\hline $\begin{array}{l}\text { Diode } \\
\text { Detector }\end{array}$ & $219 \mathrm{~nm}, 240 \mathrm{~nm}$ \\
\hline Injection Volume & $5 \mu \mathrm{L}$ \\
\hline TPB Retention Time & $11 \mathrm{~min}(219 \mathrm{~nm}), \mathrm{r}^{2}=0.999,1$ to $200 \mathrm{mg} / \mathrm{L}$ \\
\hline 3PB Retention Time & $16 \min (219 \mathrm{~nm}), \mathrm{r}^{2}=0.999,1$ to $200 \mathrm{mg} / \mathrm{L}$ \\
\hline 2PB Retention Time & $9 \min (240 \mathrm{~nm}), \mathrm{r}^{2}=0.999,1$ to $200 \mathrm{mg} / \mathrm{L}$ \\
\hline
\end{tabular}

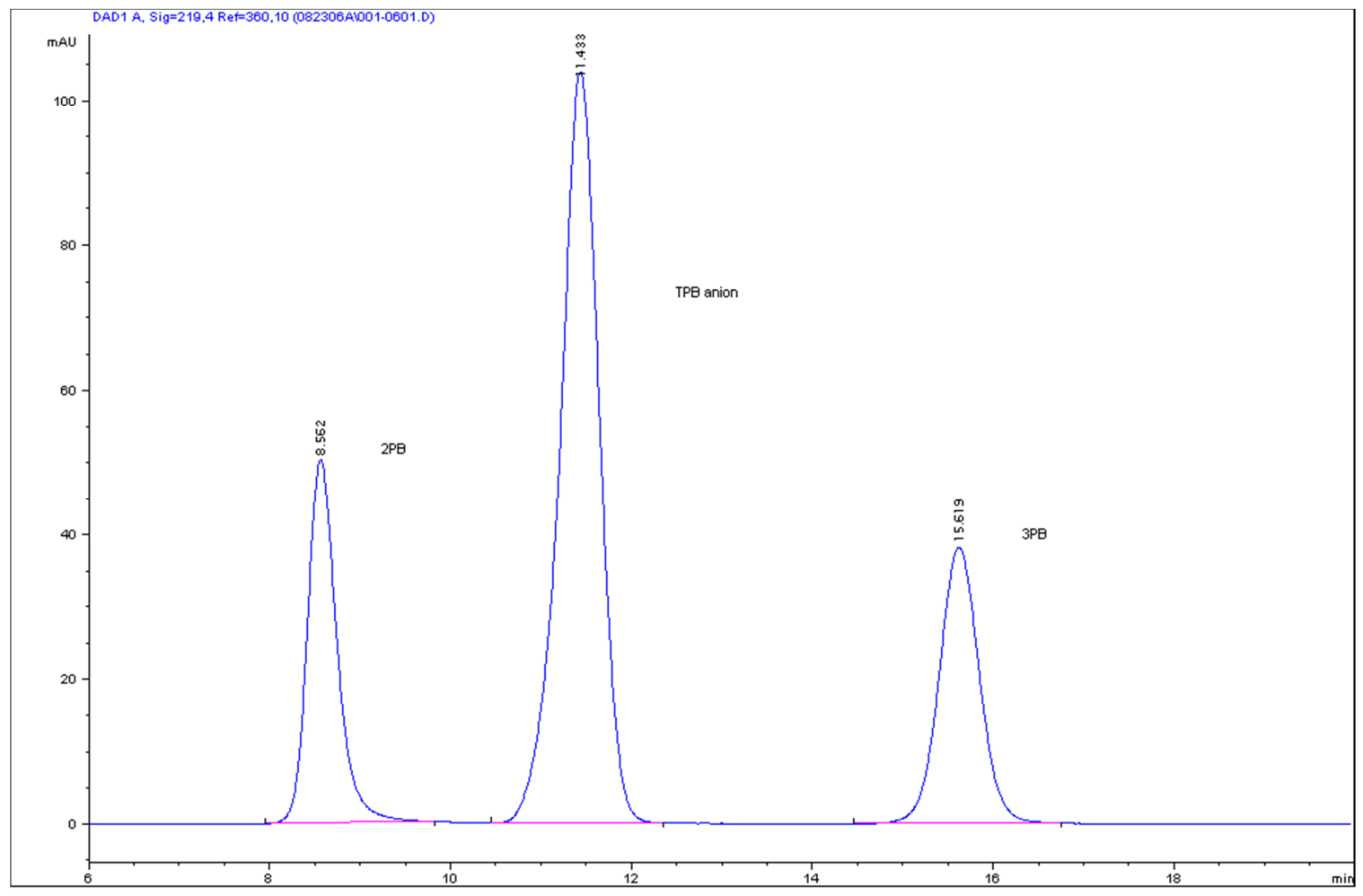

Figure 50. Chromatogram of TPB (11 min), 3PB (16 min) and 2PB (9 min) 50 min Gradient Method for PBA, Phenol and other Decomposition Products 
Table 46. Summary of Reversed-phase Gradient HPLC Method for Degradation Products

\begin{tabular}{|c|c|}
\hline Method & Conditions \\
\hline Mobile Phase & "Acetonitrile $(25 \%$ vol $)$ - Water $(75 \%$ vol $)$ \\
\hline Column & Dychrom Chemcosorb 5-ODS-UH, $3.2 \mathrm{~mm} \times 250 \mathrm{~mm}$ \\
\hline Oven Temperature & N/A \\
\hline Flow-rate & $0.5 \mathrm{~mL} / \mathrm{min}$ \\
\hline $\mathrm{t}_{0}$ to $\mathrm{t}_{1}=14 \mathrm{~min}$ & $25: 75$ \\
\hline $\mathrm{t}_{2}=20 \mathrm{mn}$ & $50: 50$ \\
\hline $\mathrm{t}_{3}=29 \mathrm{~min}$ & $60: 40$ \\
\hline $\mathrm{t}_{4}=38 \mathrm{~min}$ & 100:0 \\
\hline$t_{5}=45 \mathrm{~min}$ & 100:0 \\
\hline $\begin{array}{l}\text { Post time }=5(50 \mathrm{~min} \text { total } \\
\text { time })\end{array}$ & $25: 75$ \\
\hline Diode Array Detector & $217,222,262,281 \mathrm{~nm}$ \\
\hline Injection Volume & $10 \mu \mathrm{L}$ \\
\hline PBA Retention Time & $8.6 \mathrm{~min}$, \\
\hline Phenol Retention Time & $14.0 \mathrm{~min}$, \\
\hline Nitrobenzene Retention Time & $28.0 \mathrm{~min}$ \\
\hline $\begin{array}{l}\text { Nitrosobenzene Retention } \\
\text { Time }\end{array}$ & $29.6 \mathrm{~min}$ \\
\hline $\begin{array}{l}\text { 4-Phenylphenol Retention } \\
\text { Time }\end{array}$ & $31.0 \mathrm{~min}$ \\
\hline $\begin{array}{l}\text { 2-Phenylphenol Retention } \\
\text { Time }\end{array}$ & $32.8 \mathrm{~min}$ \\
\hline $\begin{array}{l}\text { Diphenylamine Retention } \\
\text { Time }\end{array}$ & $36.9 \mathrm{~min}$ \\
\hline Biphenyl Retention Time & $39.6 \mathrm{~min}$ \\
\hline$o$-Terphenyl Retention Time & $42.6 \mathrm{~min}$ \\
\hline$m$-Terphenyl Retention Time & $43.2 \mathrm{~min}$ \\
\hline$p$-Terphenyl Retention Time & $43.6 \mathrm{~min}$ \\
\hline
\end{tabular}




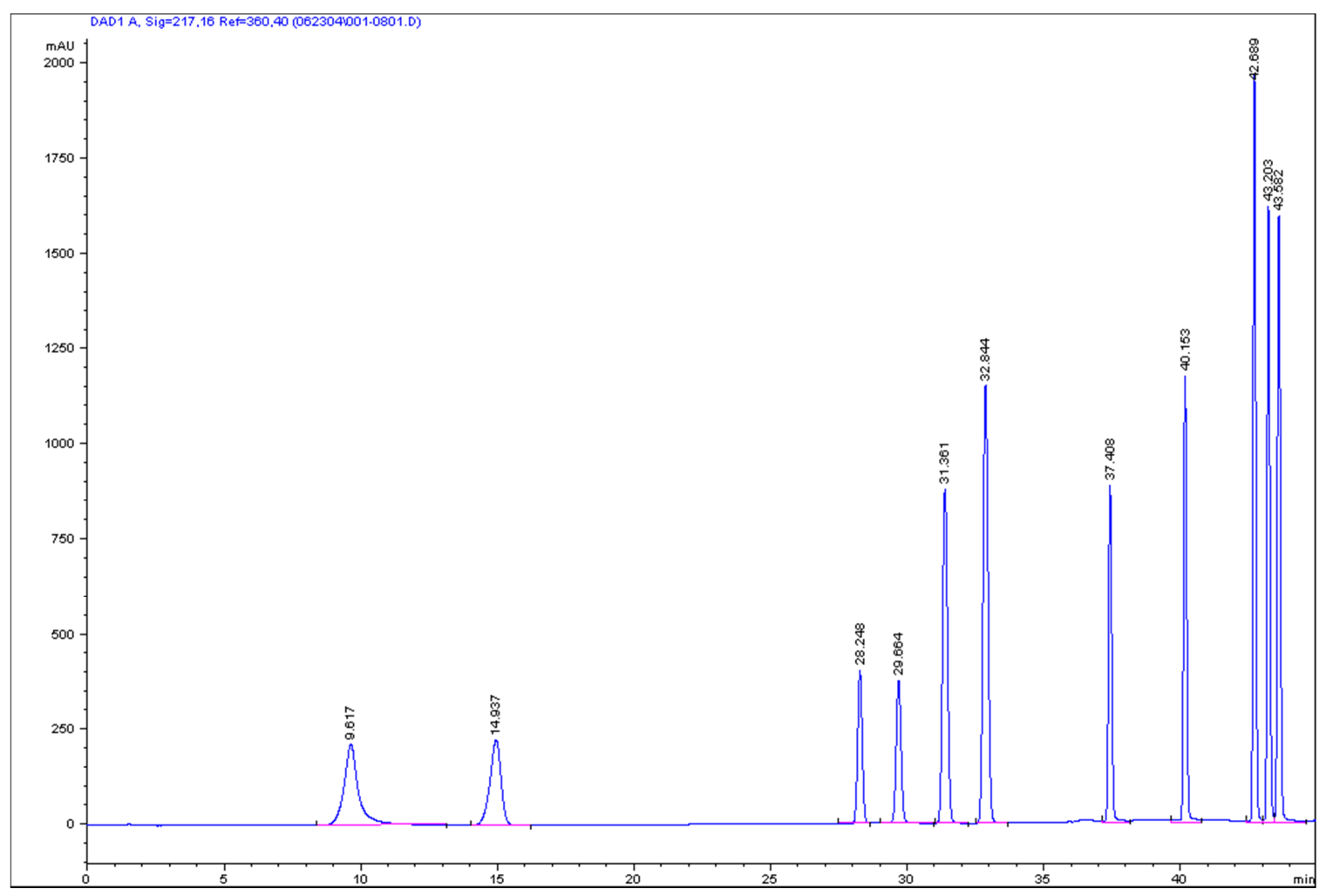

Figure 51. Chromatogram $100 \mathrm{mg} / \mathrm{L}$ Standard in Acentonitrile of PBA (10 min), Phenol (15 min), Nitrobenzene (28 min), Nitrosobenzene (30 min), 4-Phenylphenol (31 min), 2-Phenylphenol (33 min), Diphenylamine (37 min), Biphenyl (40 min), oTerphenyl (43 min), $m$-Terphenyl (43a min), and $p$-Terphenyl (44 min). 
Appendix C

List of Experiments and Conditions

\begin{tabular}{|c|c|c|c|c|c|c|c|c|c|c|c|c|c|c|}
\hline Test & $\begin{array}{l}\text { Simulant } \\
\text { Vol. }(\mathrm{mL})\end{array}$ & $\mathrm{pH}$ & $\begin{array}{l}\text { Temp. } \\
\left({ }^{\circ} \mathrm{C}\right)\end{array}$ & $\begin{array}{c}\mathrm{Cu} \\
(\mathrm{mg} / \mathrm{L})\end{array}$ & $\begin{array}{c}\mathrm{H}_{2} \mathrm{O}_{2} \text { Add. } \\
\text { Rate } \\
(\mathrm{mL} / \mathrm{h})\end{array}$ & $\begin{array}{c}\text { Test } \\
\text { Time (h) }\end{array}$ & $\begin{array}{c}\text { Total } \\
\mathrm{H}_{2} \mathrm{O}_{2}(\mathrm{~mL})\end{array}$ & HPLC & $\begin{array}{c}\text { \% TPB } \\
\text { Decomp. } \\
\text { HPLC }\end{array}$ & $\begin{array}{l}\text { SVOA resdiual } \\
\text { organics (mg/L) }\end{array}$ & $\begin{array}{c}\text { Time for } \\
100 \% \text { B in } \\
\text { Soln. (h) }\end{array}$ & $\begin{array}{c}\text { Time for } \\
100 \% \mathrm{~K} \text { in } \\
\text { Soln. (h) }\end{array}$ & $\begin{array}{c}\text { Max. Cu } \\
\text { Conc. } \\
\text { (mg/L) }\end{array}$ & $\begin{array}{r}\text { Max. } \mathrm{Ti} \\
\text { Conc. } \\
\text { (mg/L) }\end{array}$ \\
\hline Cu-nitrate & 250 & 11 & 21 & 500 & 0.1 & 508 & 50.8 & NA & NA & NA & NA & NA & 104 & 9 \\
\hline Cu-sulfate & 250 & 11 & 21 & 500 & 0.1 & 508 & 50.8 & NA & NA & NA & NA & NA & 104 & 10 \\
\hline $10 \times \mathrm{H} 2 \mathrm{O} 2$ & 250 & 11 & 21 & 500 & 1 & 284 & 284 & NA & NA & NA & NA & NA & 120 & 58 \\
\hline Thermal $35^{\circ} \mathrm{C}$ & 500 & 11 & 35 & 500 & 0.2 & 372 & 74.4 & \begin{tabular}{||c|} 
TPB: 7460 \\
3PB: $<100$ \\
2PB: $<100$ \\
1PB: $<100$ \\
Phenol: \\
$<100$ \\
\end{tabular} & |50.7-50.9 & 1957 & NA & NA & 75 & 25 \\
\hline Thermal $50^{\circ} \mathrm{C}$ & 500 & 11 & 50 & 500 & 0.2 & 372 & 74.4 & \begin{tabular}{||c|} 
TPB: 16 \\
3PB: $<10$ \\
2PB: $<10$ \\
1PB: $<10$ \\
Phenol: $<10$
\end{tabular} & |99.9-99.9 & 1002 & $\sim 370$ & $\sim 370$ & 80 & 40 \\
\hline Thermal $65^{\circ} \mathrm{C}$ & 500 & 11 & 65 & 500 & 0.2 & 372 & 74.4 & \begin{tabular}{||c|} 
TPB: $<10$ \\
3PB: $<10$ \\
2PB: $<10$ \\
1PB: $<10$ \\
Phenol: $<10$
\end{tabular} & $>99.9$ & 354 & $<24$ & $<24$ & 100 & 25 \\
\hline DEMO 1 & 500 & 11 & $35-75$ & 500 & 0.2 & 497 & 99.4 & \begin{tabular}{||c|} 
TPB: 2420 \\
3PB: $<10$ \\
2PB: $<10$ \\
1PB: $<10$ \\
Phenol: $<10$
\end{tabular} & $84.0-84.4$ & 898 & NA & NA & 340 & 5 \\
\hline Test 1b & 500 & 9 & 50 & 500 & 0.2 & 404 & 80.8 & \begin{tabular}{||c|} 
TPB: $<10$ \\
3PB: $<10$ \\
2PB: $<10$ \\
1PB: $<10$ \\
Phenol: $<10$
\end{tabular} & $>99.9$ & 199 & $\sim 120$ & $\sim 120$ & 110 & 10 \\
\hline Test 1c & 500 & 7 & 50 & 500 & 0.2 & 404 & 80.8 & \begin{tabular}{||c|} 
TPB: $<10$ \\
3PB: $<10$ \\
2PB: $<10$ \\
1PB: $<10$ \\
Pheno: $<10$
\end{tabular} & $>99.9$ & 518 & $<24$ & $<24$ & 78 & 10 \\
\hline DEMO 2 & 500 & 9 & 50 & 500 & 0.4 & 476 & 190.4 & \begin{tabular}{||c|c|} 
TPB $:<4$ \\
3PB: $<4$ \\
2PB: $<4$ \\
1PB: $<4$ \\
Phenol: $<4$
\end{tabular} & $>99.9$ & 83.3 & $\sim 160$ & $\sim 180$ & 160 & 20 \\
\hline Test 2a & 500 & 9 & 50 & 500 & 1 & 472 & 472 & \begin{tabular}{||c|} 
TPB: $:<4$ \\
3PB: $<4$ \\
2PB: $<4$ \\
1PB: $<10$ \\
Phenol: $<4$ \\
\end{tabular} & $>99.9$ & 7.75 & $\sim 100$ & $\sim 100$ & 180 & 60 \\
\hline Test $\mathbf{2 b}$ & 500 & 9 & 50 & 100 & 0.2 & 477 & 95.4 & \begin{tabular}{||c|} 
TPB: 245 \\
3PB: $<10$ \\
2PB: $<10$ \\
1PB: $<10$ \\
Phenol: $<10$
\end{tabular} & 98.4-98.5 & 82.9 & $\sim 400$ & $\sim 400$ & $<10$ & 15 \\
\hline Test 2c & 500 & 9 & 50 & 0 & 0.2 & 479 & 95.8 & \begin{tabular}{||c|} 
TPB: 2585 \\
3PB: 12 \\
2PB: $<10$ \\
1PB: $<10$ \\
Phenol: 33
\end{tabular} & $84.6-84.8$ & 380 & NA & NA & NA & 30 \\
\hline
\end{tabular}




\section{Appendix D Nitric Acid Titration of Tank 48H Simulant Slurries}

Acid demand of the Tank 48H simulant was determined by titrating $100 \mathrm{~mL}$ of simulant with nitric acid. Nitric acid was added using a syringe pump at rates of 0.071 and 0.71 $\mathrm{mL} / \mathrm{min}$. Acid concentrations were 15,35 , and $70 \mathrm{wt} \%$ for each addition rate. $\mathrm{pH}$ data were logged using a laptop computer, and graphs were generated providing the molar amount of acid needed to reach a simulant $\mathrm{pH}$ of 5. Samples were collected at each $\mathrm{pH}$ interval and stored for future analysis.

Figure 52. Titration of Tank 48H Simulant Slurries

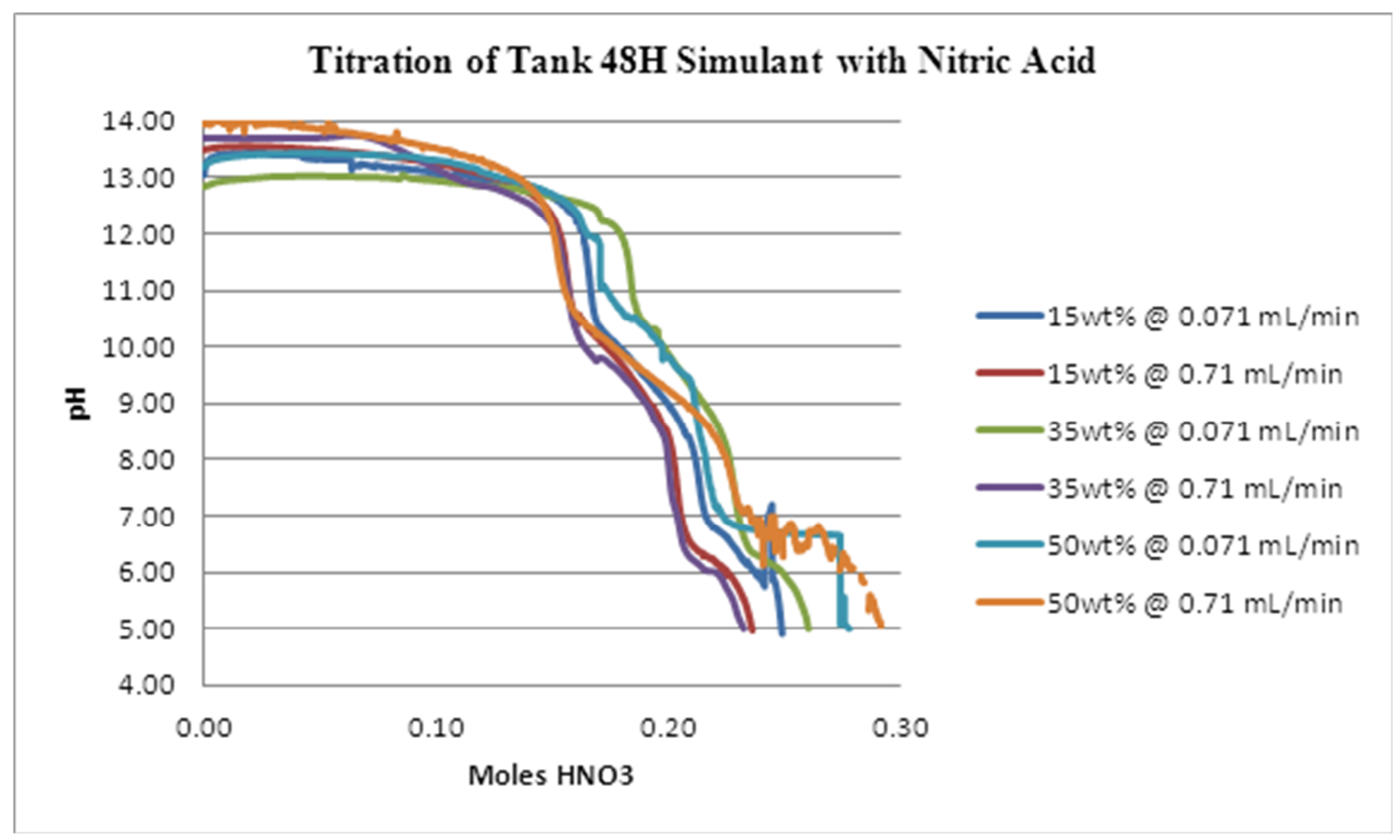

Vigorous foaming was noted when titrating with $50 \mathrm{wt} \%$ acid for both rates. Less intense foaming was seen when using $35 \mathrm{wt} \%$ and hardly any foaming was observed with $15 \mathrm{wt} \%$ nitric. Foaming began when the $\mathrm{pH}$ ranged between 7-6 in all cases. When excessive occurred, acid addition was stopped and the foam was allowed to settle. Tapping the mixing vessel sometimes helped disperse the foam but resulted in $\mathrm{pH}$ oscillation, as seen during the $50 \mathrm{wt} \%$ titration at the $0.71 \mathrm{~mL} / \mathrm{min}$ rate. The quick drop off in $\mathrm{pH}$ seen in the $50 \mathrm{wt} \%$ titration at the $0.071 \mathrm{~mL} / \mathrm{min}$ rate was due to a loss of mixing. Tabulated results of the acid demand are presented below (see Table 46). 
Table 47. Acid Demand for Tank 48H Simulant Slurries

\begin{tabular}{|c|c|c|}
\hline $\begin{array}{c}\text { HNO }_{3} \text { conc. } \\
(\mathbf{w t} \%)\end{array}$ & $\begin{array}{c}\text { addition rate } \\
(\mathbf{m L} / \mathbf{m i n})\end{array}$ & $\begin{array}{c}\text { acid demand } \\
(\mathbf{m o l})\end{array}$ \\
\hline 15 & 0.071 & 0.25 \\
\hline 15 & 0.710 & 0.24 \\
\hline 35 & 0.071 & 0.26 \\
\hline 35 & 0.710 & 0.23 \\
\hline 50 & 0.071 & 0.28 \\
\hline 50 & 0.710 & 0.29 \\
\hline
\end{tabular}


SRNL-STI-2012-00342

Revision 0

\subsection{References}

${ }^{1}$ K. B. Burnau, “Tank 48 Treatment Execution Strategy”, WDPD-11-69, June 9, 2011.

${ }^{2}$ D. P. Lambert, T. B. Peters, S. D. Fink, "In-Tank Peroxide Oxidation Process for the Decomposition of Tetraphenylborate in Tank 48H”, WSRC-TR-2005-00114, April 2005.

${ }^{3}$ S. P. Simner, "Process Optimization for Cu-Catalyzed Peroxide Oxidation of Tank 48H

Tetraphenylborate", G-TTR-H-00005, 2012.

${ }^{4}$ S. P. Simner, Tank 48 Chemical Destruction - Flow-Sheet Options Report, SRR-CES-2012-00018, Rev. 0 (2012).

${ }^{5}$ D. P. Chew, and B. A. Hamm, Liquid Waste System Plan Revision 17, SRR-LWP-2009-00001, Rev. 17 (2012)

${ }^{6}$ D. P. Lambert, T. B. Peters, M. E. Stallings, S. D. Fink, "Process Development for Oxidative Destruction of Tetraphenylborate in Savannah River Site Tank 48H”, WSRC-TR-2003-00404, REV. 0, April 13, 2004.

${ }^{7}$ W. R. Wilmarth, R. E. Eibling, D. D. Walker, C. L. Crawford, "Peer Review of Tank 48H Testing”, WSRC-TR-2004-00437, June 4, 2004.

${ }^{8}$ D. P. Lambert, M. J. Barnes, S. D. Fink, “Task Technical and Quality Assurance Plan for Benzene Generation Testing Matrix: Pd Catalyzed Decomposition”, WSRC-RP-2004-00471, Rev. 0, June 18, 2004.

${ }^{9}$ T. B. Peters, C. A. Nash, F. F. Fondeur, K. M. Taylor-Pashow, T. L. White, D. J. Newell, S. D. Fink, "Task Technical and Quality Assurance Plan for Process Optimization for CU-Catalyzed Peroxide Oxidation of Tank 48H”, SRNL-RP-2011-01525, Rev. 1, March 2012.

${ }^{10}$ M. R. Williams, “Tank 48 Treatment Project - Preparing/Procuring Tank 48 Simulant”, SRNL-PSE2007-00248, Rev.0, November 14, 2007.

${ }^{11}$ D. P. Lambert, T. B. Peters, M. E. Stallings, S. D. Fink, “Analysis of Tank 48H Samples HTF-E-03-73 (June 03, 2003) and HTF-E-03-127 (September 17, 2003)”, WSRC-TR-2003-00720, Rev. 0, January 20, 2004.

${ }^{12}$ H. E. Shook and R. E. Eibling, "Proposed Reaction Mechanisms in Precipitate Hydrolysis: Trip Report", DPST-88-1026, December 8, 1988.

${ }^{13}$ J. K. Taylor, "Quality Assurance of Chemical Measurements"; Lewis Publishers, Inc.: Chelsa, Michigan, 1987; p. 131.

${ }^{14}$ B. A. Bidlingmeyer, Practical HPLC Methodology and Applications; John Wiley \& Sons, Inc.: New York, 1992; p. 237.

${ }^{15}$ M. Nyman, and D. T. Hobbs, (2006) "A Family of Peroxo-titanate Materials Tailored for Optimal Strontium and Actinide Sorption.” Chem. Mater. 18 (26): 6425.

${ }^{16}$ Physical and Engineering Data, January 1978 ed. The Hague: Shell Internationale Petroleum Maatschappij BV, 1978

${ }^{17}$ P. M. Jarrell, C. E. Fox, M. H. Stein, S. L. Webb, 2002, Practical Aspects of CO2 Flooding, SPE Monograph 22, 220p 
${ }^{18}$ M. R. Poirier, P. R. Monson, "Laboratory-Scale Study of Parameters Influencing Benzene Retention and Release in Potassium Tetraphenylborate Slurries”, WSRC-TR-97-00375, September 5, 1997.

19 SRS Drawings P-PM-H-08228 (rev. 0) and W752790 (Rev. 2)

${ }^{20}$ G. A. Taylor, “ARP Mixing Tank”, SRNL-ITB-2004-00026, October 6, 2004.

${ }^{21}$ G. B. Tatterson, Fluid Mixing and Gas Dispersion in Agitated Tanks, McGraw-Hill, New York, NY, 1991.

${ }^{22}$ C. M. Garrison, "How to Design and Scale Mixing Pilot-Plants", Chemical Engineering, pp. 63-70, February 7, 1983.

${ }^{23}$ R. R Rautzen, R. R. Corpstein, and D. S. Dickey, "How to Use Scale-Up Methods for Turbine Agitators", Chemical Engineering, pp. 119-126, October 25, 1976.

${ }^{24}$ WSRC-NB-2004-00148

${ }^{25}$ J. H. Rushton, E. W. Costich, and H. J. Everett, "Power Characteristics of Mixing Impellers, Part I", Chemical Engineering Progress, Vol. 46, no. 8, pp. 395-404, 1950.

${ }^{26}$ K. W. Norwood, , and A. B. Metzner, "Flow Patterns and Mixing Rates in Agitated Vessels", A. I. Ch. E. Journal, vol. 6, no. 3, pp. 432-437, September 1960.

${ }^{27}$ J. H. Rushton, E. W. Costich, and H. J. Everett, "Power Characteristics of mixing Impellers, Part II", Chemical Engineering Progress, vol. 46, no. 9, pp. 467 - 476, September 1950.

28 "Handbook of Industrial Mixing", Edited by E. L. Paul, V. A. Atiemo-Obeng, and S. M. Kresta, Wiley Interscience, p. 511, 2004.

${ }^{29}$ M. Moo-Young, K. Tichar, and F. Dullien, "The Blending Efficiencies of Some Impellers in Batch Mixing”, A. I. Ch. E. Journal, vol. 18, no. 1, pp. 178-182, January 1972.

30 J. G. Van de Vusse, "Mixing by Agitation of Miscible Liquids", Chemical Engineering Science, vol. 4 pp. 178-200, August 1955.

${ }^{31}$ Chemical Engineer's Handbook, $5^{\text {th }}$ Edition, R. H. Perry, , and C. H. Chilton, , editors, McGraw Hill Book Company, Ney York, NY, 1973. 


\section{Distribution:}

K. M. Fox, 999-W

S. D. Fink, 773-A

B. J. Giddings, 786-5A

C. C. Herman, 999-W

S. L. Marra, 773-A

F. M. Pennebaker, 773-42A

W. R. Wilmarth, 773-A

Records Administration (EDWS)

C. Wilson, 773-A

D. P. Lambert, 999-W

J. Pareizs, 773-A

C. Martino, 773-42A

C. A. Nash, 773-42A

T. B. Peters, 773-42A

D. Newell, 999-W

T. L. White, 773-A

E. J. Freed, 704-56H

D. J. Martin, 241-152H

P. R. Jackson, DOE-SR, 703-46A

K. H. Subramanian, 766-H

J. S. Contardi, 766-H

C. J. Winkler, 766-H

E. A. Brass, 249-8H

S. P. Simner, $249-8 \mathrm{H}$

C. Aponte, $249-8 \mathrm{H}$ 